\title{
ELECTRICAL AND BIOLOGICAL EFFECTS OF TRANSMISSION LINES: \\ A REVIEW
}

Prepared by the Biological Studies

Task Team

\author{
Jack M. Lee, Jr. (Chair) \\ Vernon L. Chartier \\ David P. Hartmann \\ Gerald E. Lee \\ Katherine S. Pierce \\ Fay L. Shon \\ Rick D. Stearns \\ Michael T. Zeckmeister
}

\section{U.S. Department of Energy}

Bonneville Power Administration

Portland, Oregon

1989 


\section{DISCLAIMER}

This report was prepared as an account of work sponsored by an agency of the United States Government. Neither the United States Government nor any agency Thereof, nor any of their employees, makes any warranty, express or implied, or assumes any legal liability or responsibility for the accuracy, completeness, or usefulness of any information, apparatus, product, or process disclosed, or represents that its use would not infringe privately owned rights. Reference herein to any specific commercial product, process, or service by trade name, trademark, manufacturer, or otherwise does not necessarily constitute or imply its endorsement, recommendation, or favoring by the United States Government or any agency thereof. The views and opinions of authors expressed herein do not necessarily state or reflect those of the United States Government or any agency thereof. 


\section{DISCLAIMER}

Portions of this document may be illegible in electronic image products. Images are produced from the best available original document. 


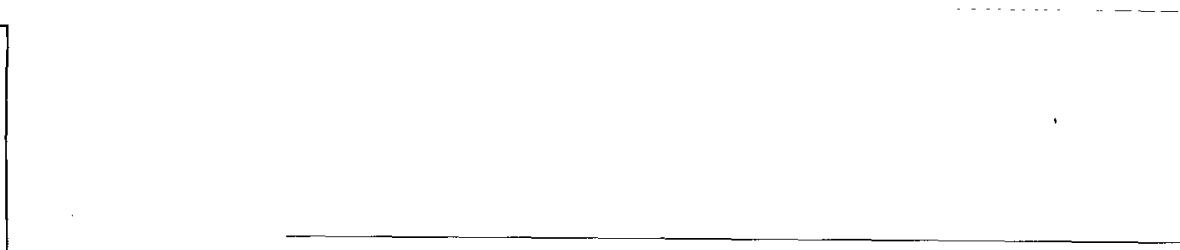

DO NOT MíñofILM THIS PAEE 


\section{TABLE OF CONTENTS}

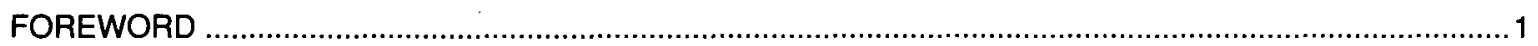

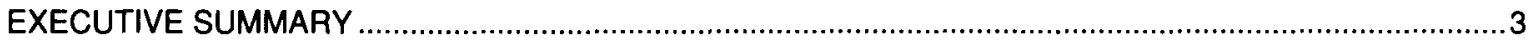

INTRODUCTION

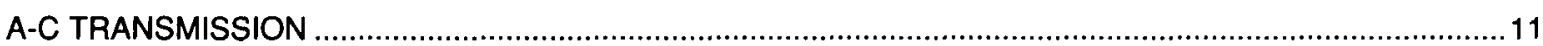

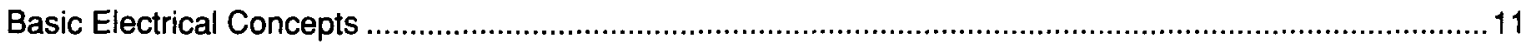

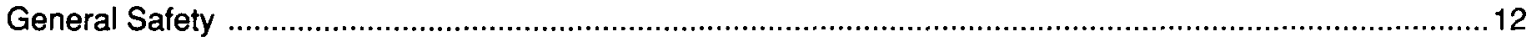

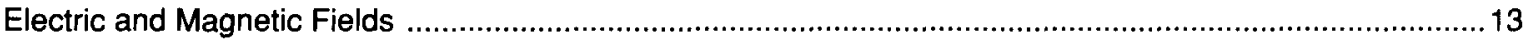

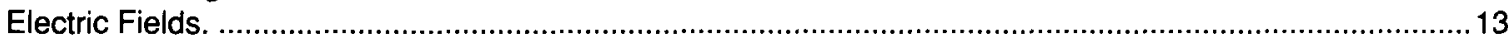

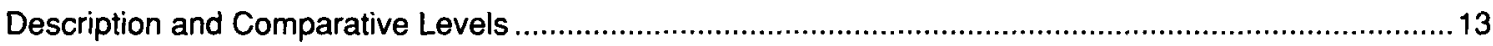

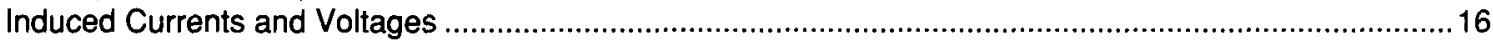

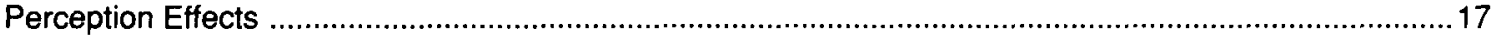

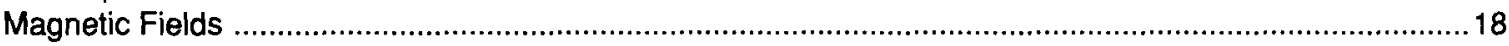

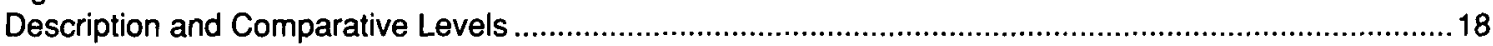

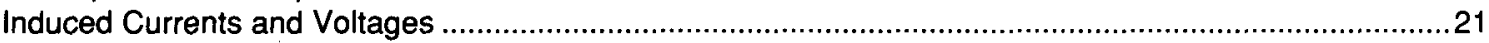

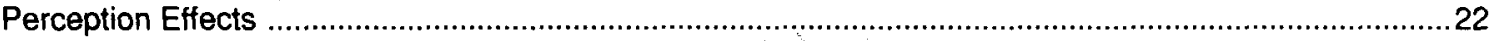

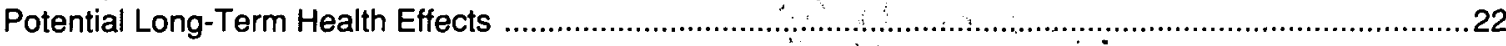

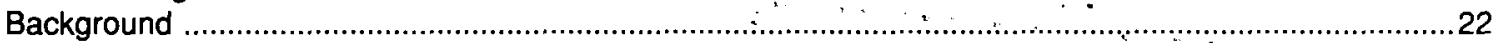

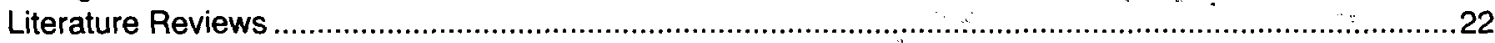

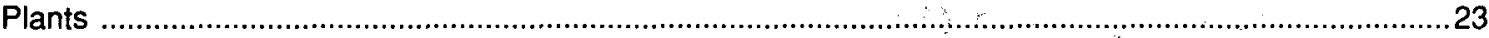

Insects

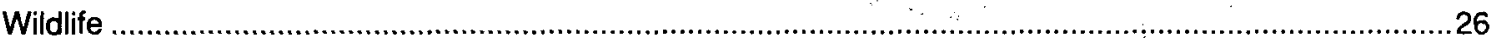

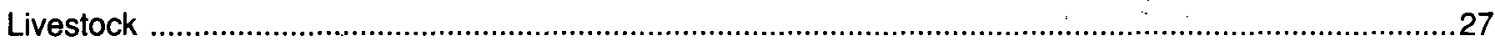

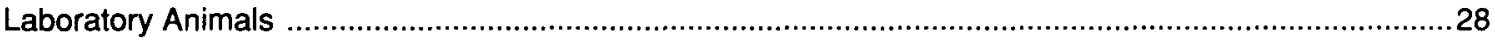

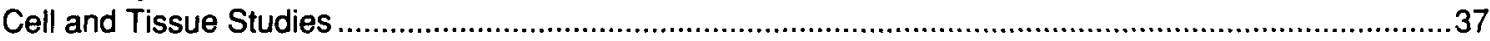

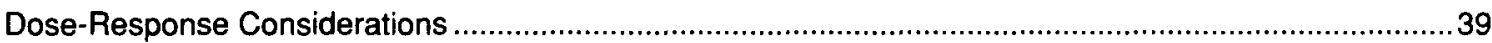

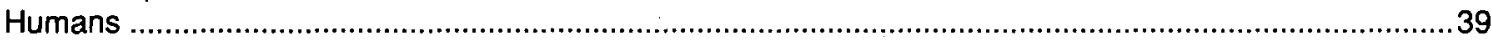

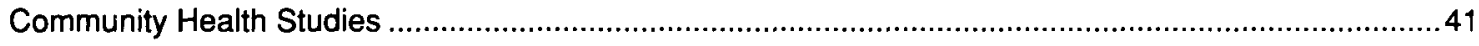

Community Cancer Studies ........................................................................................................... 41

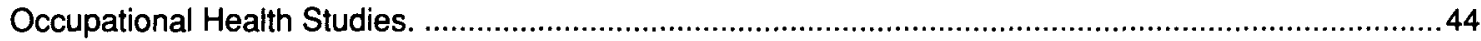

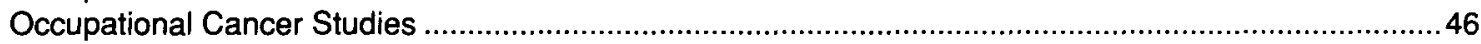

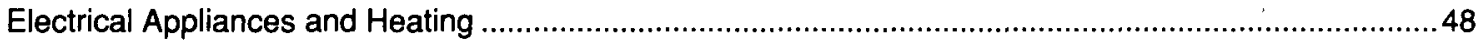

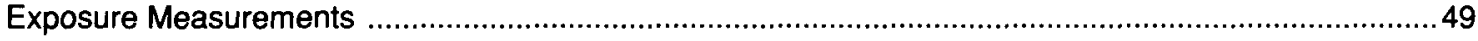

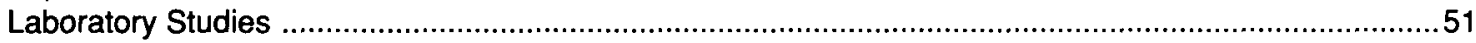

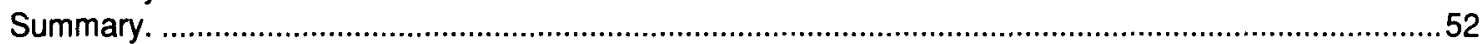

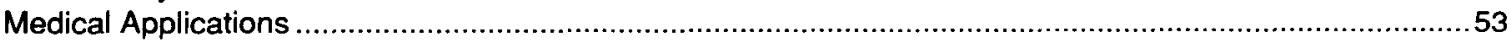

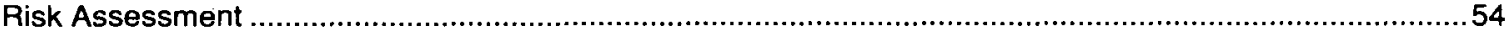

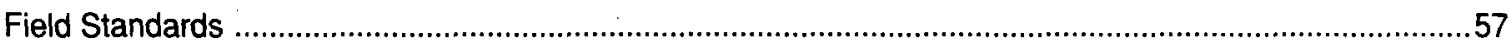

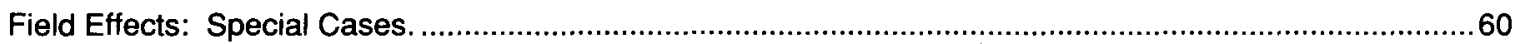

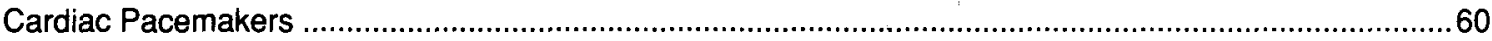

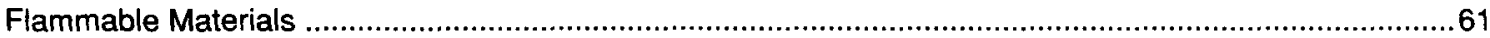

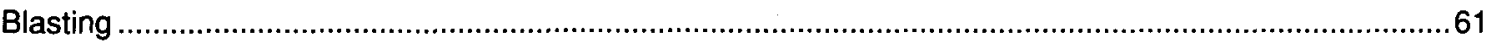

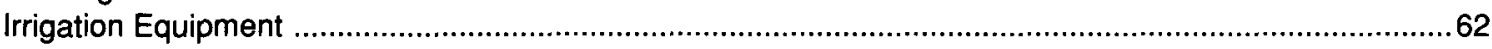

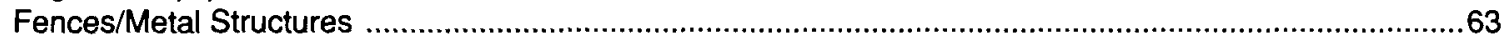

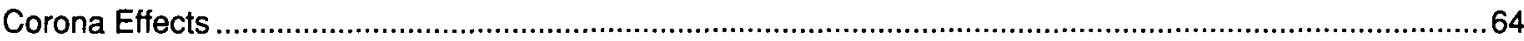

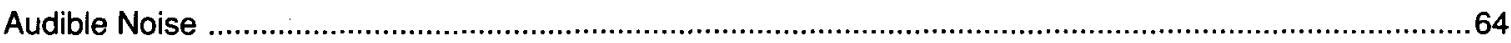

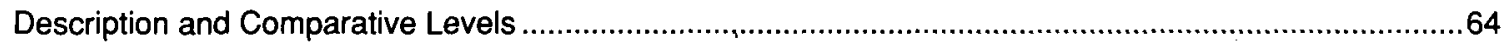

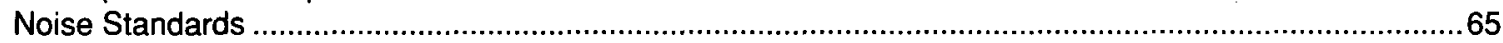

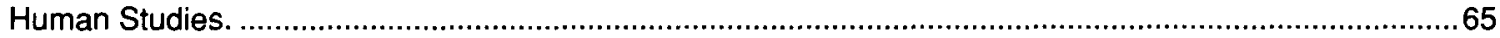

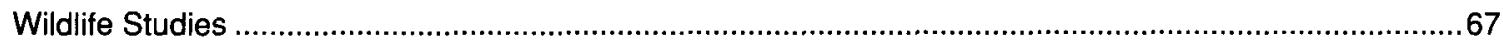

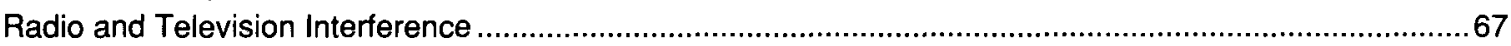

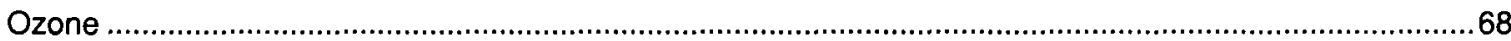




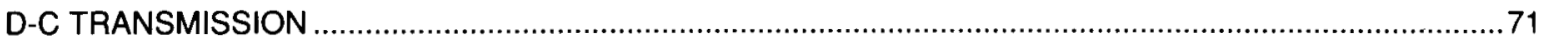

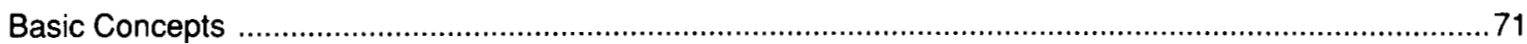

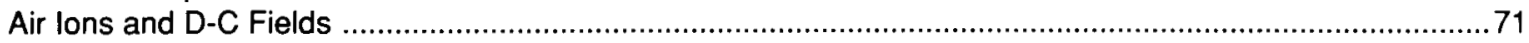

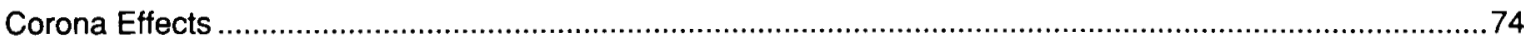

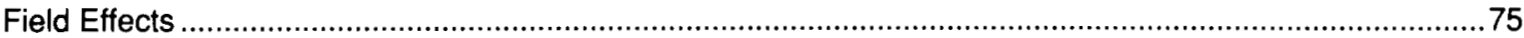

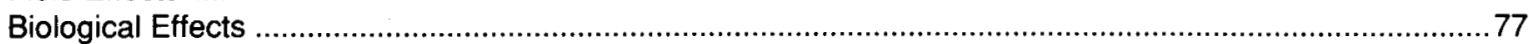

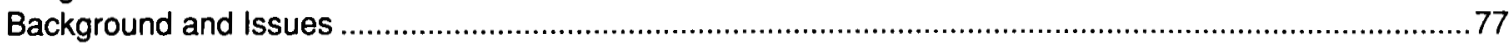

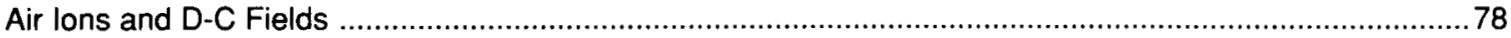

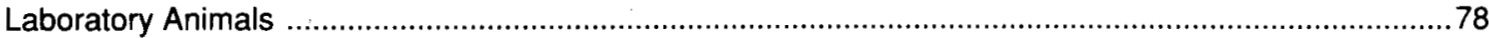

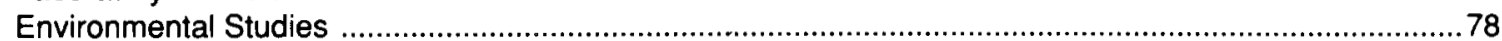

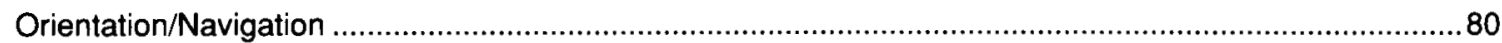

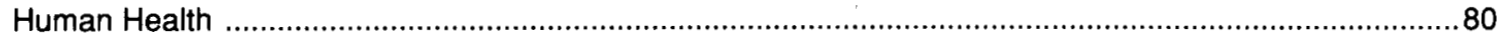

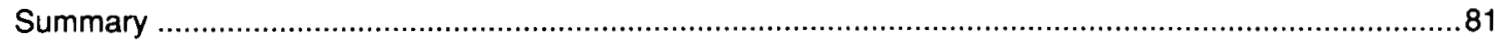

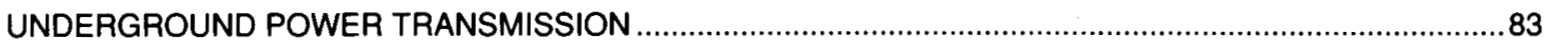

APPENDIX A: Grounding Criteria For Objects

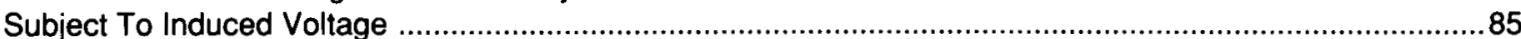

APPENDIX B: Summary of Literature Reviews Published

Since 1985 Involving Biological Effects of Electric

and Magnetic Fields

APPENDIX C: BPA Interim Guidance on Electric and

Magnetic Fields

REFERENCES CITED 
This review was prepared with the assistance of a team of BPA engineers and environmental specialists originally assembled in 1974 to gather information on the effects of transmission lines on plants, animals, and people. The current team would like to acknowledge the contributions of former members and several other people at BPA who assisted in this effort. We would especially like to thank Pam McPherron for typing the many drafts of the review; Judith Montgomery, Ph.D., for editing the final copy; Nancy Eivers for assistance with graphics and typesetting; and Leroy Sanchez for his overall assistance in graphics, production, and printing.

The review was first developed in response to public and scientific interest that developed in the early 1970's about the new extra-high-voltage (EHV) transmission lines (primarily $500 \mathrm{kV}$ and $765 \mathrm{kV}$ ). Interest centered on the possible effects of electric and magnetic fields, audible noise, radio noise, and ozone. This review serves as BPA's generic source of information on these subjects. A primary purpose of this publication is to support BPA documents required by the National Environmental Policy Act and dealing with environmental impacts of proposed electrical transmission facilities.

When the first version of this review was completed in 1975 , few biological studies directly related to transmission lines had been done. The review has since been revised several times (most recently in 1986) to reflect a growing body of research results from throughout the world.

This research has expanded to include low-voltage distribution lines, and a possible association between cancer and the magnetic fields in residences near these lines. The use of electric blankets and electrically heated water beds is also being studied. Several recent studies have found that workers presumed to be exposed to electric and magnetic fields may have a small increased risk of developing cancer. Continued public interest in these issues resulted in a 1987 Congressional Oversight Hearing on health effects of transmission lines (Subcommittee on Water and Power Resources 1988).

Several laboratory studies are still ongoing on the biological effects of electric and magnetic fields, and more cancer studies are underway in the U.S. and several other countries. This extensive research is intended to provide the definitive information needed for determining whether or not powerlines and other electrical devices do affect human health. This review has, therefore, been revised again to include the findings of the most recent research. BPA has also developed Interim Guidance for staff on Electric and Magnetic Fields (see Appendix C).

BPA is unique in the United States in having research and operating experience with commercial 500-kV a-c and $\pm 500-k V d-c$ transmission lines, a $1200-k V$ a-c prototype, and $a \pm 600-k V d-c$ test line. Experience and research with these facilities, information developed through an ongoing literature review, and continued communication with numerous researchers provide the basis for the material presented in this review.

The Biological Studies Task Team would appreciate comments or suggestions regarding this publication. These can be addressed to:

Chair, Biological Studies

Task Team

Environmental Section (EFBG)

Bonneville Power Administration

P.O. Box 3621

Portland, Oregon 97208

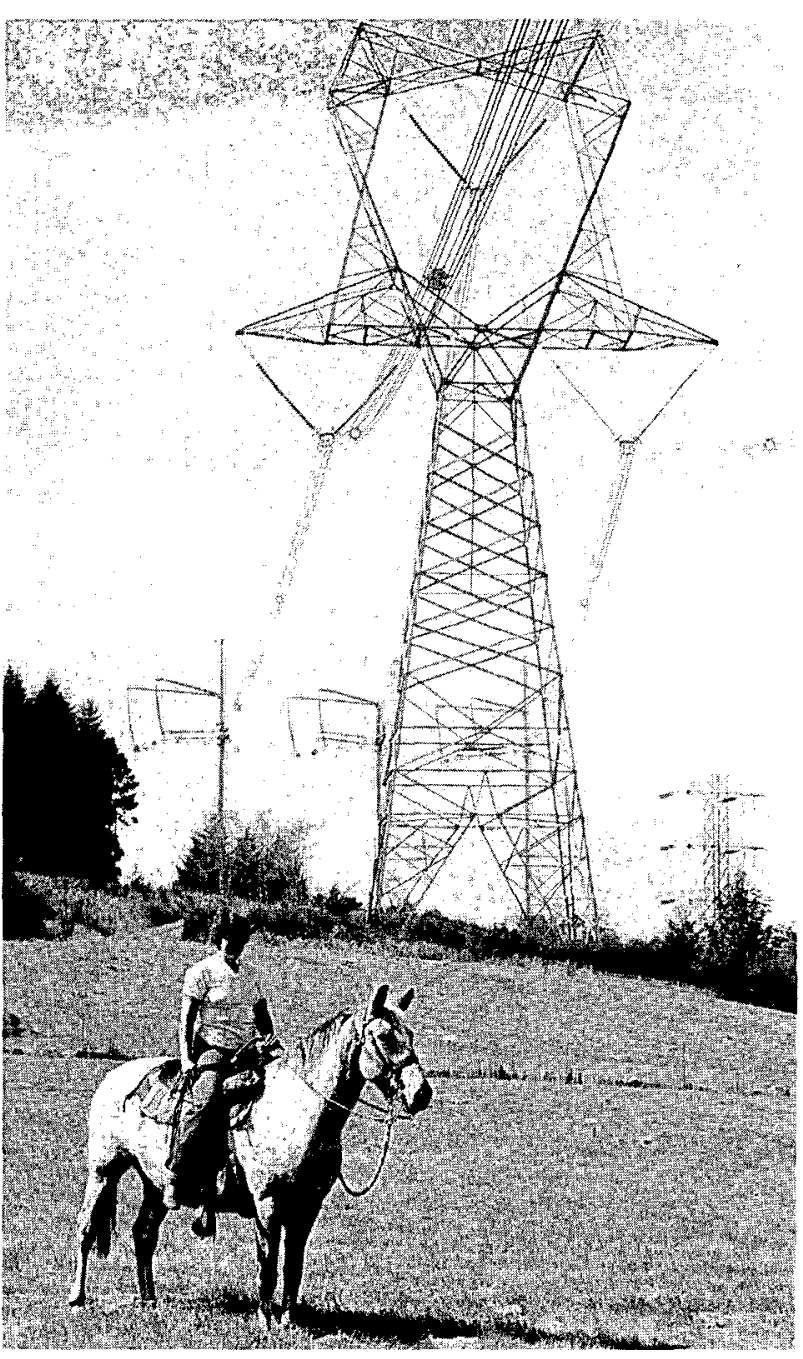




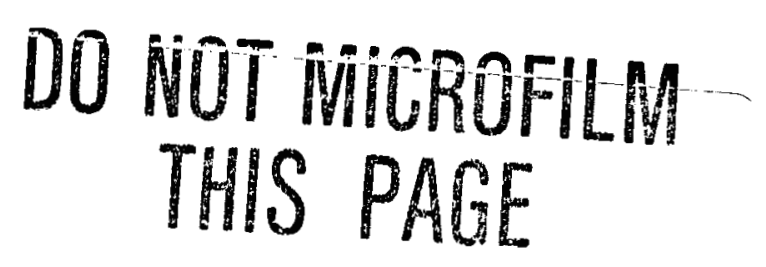


This review describes the electrical properties of a-c and $\mathrm{d}-\mathrm{c}$ transmission lines and the resulting effects on plants, animals, and people. Methods used by BPA to mitigate undesirable effects are also discussed. Although much of the information in this review pertains to high-voltage_transmission lines, information on distribution lines and electrical appliances is included. The electrical properties discussed are electric and magnetic fields and corona: first for alternating-current $(a-c)$ lines, then for direct current $(d-c)$.

\section{A-C ELECTRIC AND MAGNETIC FIELDS}

\section{Characteristics}

In North America, alternating current electric power operates at a frequency of $60 \mathrm{Hertz}(\mathrm{Hz})$, i.e., 60 cycles per second. Voltage on any wire (conductor) produces an electric field in the area surrounding the wire. Power-line electric fields near ground are designated by the difference in voltage between two points (usually 1 meter). For example, the maximum vertical field in the air near the ground on a BPA $500-\mathrm{kV}$ (500,000 volt) line right-of-way is less than $9 \mathrm{kV} / \mathrm{m}(9,000$ volts per meter). The electric field from a powerline gets weaker as one moves away from the line. Electric field strength at the edge of a 500-kV line rightof-way is around $2-3 \mathrm{kV} / \mathrm{m}$. Trees and building material also greatly reduce the strength of power-line electric fields.

In comparison, the electric field created by wiring and appliances throughout the home may be less than $0.01 \mathrm{kV} /$ $m(10 \mathrm{~V} / \mathrm{m})$. Very close to appliances, levels are higher $(0.100 \mathrm{kV} / \mathrm{m}$ or more) and may approach several $\mathrm{kV} / \mathrm{m}$ next to electric blankets.

A magnetic field is produced when electric current flows in a wire. The magnetic field is described in units of tesla (T) or gauss (G). Maximum average magnetic field strength on the right-of-way of BPA transmission lines is around 2-7 $\mu \mathrm{T}$ (20-70 $\mathrm{mG})$. The field averages around 0.5-2.5 $\mu \mathrm{T}(5-25$ $\mathrm{mG}$ ) at the edge of the right-of-way. The magnetic field produced by electrical appliances decreases very rapidly away from the appliances. For example, the field $30 \mathrm{~cm}(12$ in) away from a color TV or kitchen range is around $4 \mu \mathrm{T}$ (40 $\mathrm{mG}$ ). However, at $1-1.5 \mathrm{~m}(3-5 \mathrm{ft})$ from most appliances, the average magnetic field strength is only $0.1 \mu \mathrm{T}(1 \mathrm{mG})$ or less.

Trees and building material do not reduce the strength of magnetic fields. Therefore, powerlines can be the dominant source of magnetic fields found throughout homes near the lines.

\section{Shocks and Perception Effects}

Electric fields induce voltages and currents in people and objects. If a person insulated from ground (e.g., wearing rubber boots) touches a grounded object (e.g., a metal fence) in a strong electric field, a perceptible current or an annoying spark discharge may occur. That discharge may be similar to the shock received after walking across a carpet and touching a door knob. With the electric field strengths normally found on BPA 500-kV rights-of-way, people seldom notice any sensation when contacting grounded objects.

However, if a grounded person were to touch a large conducting object insulated from ground (e.g., a wire fence on dry wood posts), he or she could receive a painful discharge shock. For this reason, fences and other large metallic objects near the larger transmission lines are routinely grounded, as required by BPA policy and the National Electrical Safety Code (see Appendix A).

Studies of the BPA1200-kV prototype line showed that, if wooden bee hives are placed near high-voltage lines, bees can receive shocks inside the hive. These adverse effects can be prevented by proper hive placement, or by shielding and grounding techniques.

Magnetic fields can also induce voltages on objects near transmission lines resulting in nuisance shocks. However, techniques are available which BPA uses effectively to mitigate shocks from magnetic field induction.

\section{Potential Health Effects}

Although shocks associated with electric and magnetic fields are well understood and largely controllable, questions have been raised as to whether there are long-term health effects from these fields. Electric and magnetic fields induce weak currents and electric fields in people and animals. These currents and fields are too small to be felt, other than by hair stimulation. Some scientists, however, suggest that long-term exposures to these fieids are potentially harmful and should be minimized. Hundreds of studies have been done throughout the world to obtain information on this subject.

Several effects of $60-\mathrm{Hz}$ electric and magnetic fields on laboratory animals have been found. Although the effects resulted in functional changes, e.g., a drop in a hormone level, it has not been shown that the fields adversely affect animal health. Other studies have found that these fields can also cause functional changes in isolated cells and tissues. Some scientists believe that the fields cause effects by interacting directly with cell membranes. Consid- 
erable laboratory research is ongoing. The purpose is to obtain the information needed to assess the biological implications of the reported effects, and to understand the causative mechanisms.

Over the last 10 years, a growing number of epidemiological studies suggest that people who live or work near electric powerlines or equipment have an increased risk of cancer. Two of these studies, in Denver, Colorado, suggested an association between power-line magnetic fields and the occurrence of childhood cancer. Other studies have found that workers in various "electrical occupations" seem to die more frequently from leukemia or brain tumors compared to those in other occupations. Exposures to electric and magnetic fields and to chemicals have been suggested as possible factors influencing this finding.

The relative risks reported in these epidemiological studies are low. They are similar in size to other potential (unconfirmed) cancer risks reported in many studies of common environmental factors. Examples include artificial sweeteners, coffee, and water chlorination. In addition to the size of the potential risk, however, people consider other factors in deciding whether various risks are acceptable or not.

There have been several scientific reviews of the biological research on electric and magnetic fields (see Appendix B). These reviews typically conclude that no link has been established between these fields and adverse human health effects. However, they point out that some studies suggest the possibility for adverse effects. The need for long-term research to resolve this issue is universally acknowledged.

Because of the uncertainty over this issue, some scientists have recommended precautionary measures for limiting new human exposures to electric and magnetic fields. As part of BPA's Interim Guidance (see Appendix C), the potential for long-term field exposure increases is now evaluated when new transmission facilities are designed and located. Such increases are avoided if practical alternatives for reducing the exposures exist. The Guidance will be reassessed as newer information becomes available.

\section{FIELD EFFECTS: SPECIAL CASES}

\section{Cardiac Pacemakers}

Under some circumstances, cardiac pacemakers can be affected by extraneous voltages and currents from such things as automobile ignition systems and household appliances. Transmission lines have not caused any reported serious health effects for pacemaker patients. Research, however, has shown that the fields from transmission facilities can affect operation of some types of pacemakers.
The most likely effect would be for the demand-type pacer to revert to the asynchronous mode of operation, i.e., begin pulsing the heart at a regular rate. Reversion is basically a safety feature and is not necessarily harmful. Other studies indicate that the operation of certain pacemaker models can be inhibited by transmission line and substation fields. These represent a small percentage of models in use. As a precaution, pacemaker patients who may spend time outdoors close to a BPA transmission line or in a substation yard should consult with a physician and/or review the reports described in this review to determine whether their pacemaker model is susceptible to $60-\mathrm{Hz}$ interference.

\section{Flammable Materials}

It is possible that a spark discharge occurring from induced voltages could ignite a flammable mixture such as gasoline vapor and air. Circumstances leading to an ignition are unusual, and to date no such event is known to have occurred near a BPA transmission line. As a safety precaution, however, BPA recommends that vehicles be at least $21 \mathrm{~m}(70 \mathrm{ft})$ from transmission lines when they are refueled. Grounding techniques or electrical bonding of the vehicle and the fuel container should be used if refueling must occur nearer to the line.

\section{Blasting}

The electrical effects of a transmission line might cause premature detonation of explosives with electrical blasting caps if they are being used near the line. Persons planning to detonate explosives near a BPA transmission line should first obtain clearance from the nearest BPA office.

\section{Irrigation Equipment}

Metal irrigation systems near transmission lines pose a potential shock hazard because they are large and at times can be insulated from ground. However, with basic precautions, hazards can be eliminated. The precautions, described in this and other BPA publications, mainly involve grounding techniques and keeping pipe and other equipment away from conductors.

\section{A-C CORONA EFFECTS}

Corona (breakdown of air very near conductors) occurs when the electric field is greatly intensified at projections (such as water droplets) on the conductor. Corona is most noticeable on 500-kV and higher-voltage a-c lines during foul weather. Corona may result in audible noise, radio and television reception interference, light, and production of minute amounts of ozone.

Through the years, line designs have been developed that 
greatly reduce audible noise levels and other corona effects. Few noise complaints are now received from persons living near BPA $500-\mathrm{kV}$ lines. Although radio and television interference problems sometimes occur, BPA policy requires that all such problems be investigated and corrected if a BPA facility is involved. Studies of 500-kV and 765-kV lines and of the BPA 1200-kV prototype show that the amount of ozone produced is generally not detectable above average background levels.

\section{D-C TRANSMISSION}

\section{Characteristics}

There are only five high-voltage $d-c$ transmission lines operating in the United States and three in Canada. BPA operates the Oregon portion of the 1,361-km (846-mi) $\pm 500-k V$ Pacific Intertie, the first EHV d-c line constructed in North America. Over long distances, d-c lines can be more economical than a-c lines.

A-c lines have three sets (phases) of conductors. Bipolar $d$-c lines, however, have only two sets (called negative and positive poles). Unlike a-c lines, the corona from $d-c$ lines produces air ions (positive or negative charged molecules) which move away from the conductors. This movement occurs because of forces exerted by electrical charges on the two conductors, and because of wind drift. The electric field from $d-c$ lines is produced by both the charge on the conductors and a "space charge" due to the air ions. Wind, therefore, has a great influence on the electric field near a d-cline.

In contrast to a-c, audible and radio-frequency noise produced by d-c corona is generally greatest during fair weather. The positive conductor is the primary corona source. The $\mathrm{d}$-c audible noise is characterized by an impulsive popping sound at generally lower sound levels than a-c lines. D-c corona may result in radio reception interference. However, as with a-c lines, BPA's policy is to mitigate such problems, should they occur. Ozone production from d-c lines is insignificant.

\section{Biological Effects}

Charge will accumulate on insulated objects near d-c lines. Typically, however, the d-c current coupled by the flow of ions through air to people and objects is very much smaller than the currents induced by a-c transmission lines. Nuisance shocks near a $\pm 500-k V d$-c line are less likely than for 500-kV a-c lines. In both cases, BPA grounding techniques are effective in minimizing shocks. Electromagnetic induction does not occur with d.c. because the current flow which causes the magnetic field is constant rather than alternating.
Operating experience and research has not produced any evidence for long-term biological effects of the Pacific D-C Intertie on people, animals, or plants. Also, a large body of research on air ions and $d-c$ fields indicates that adverse effects are unlikely from $d-c$ lines. Some scientists have suggested that air ion concentrations differing from normal levels can have various beneficial or adverse effects on plants, animals, and people. However, until recently, most air ion research was not done specifically to assess possible effects of $d-c$ transmission lines.

Because of renewed interest in d-c lines, BPA recently conducted an extensive program of electrical and agricultural studies at a research site along the Pacific D-C Intertie in Oregon. The 3-year-long agricultural study found no adverse effects of the $\pm 500-k V$ d-c line on growth and reproduction of beef cattle or crops. 


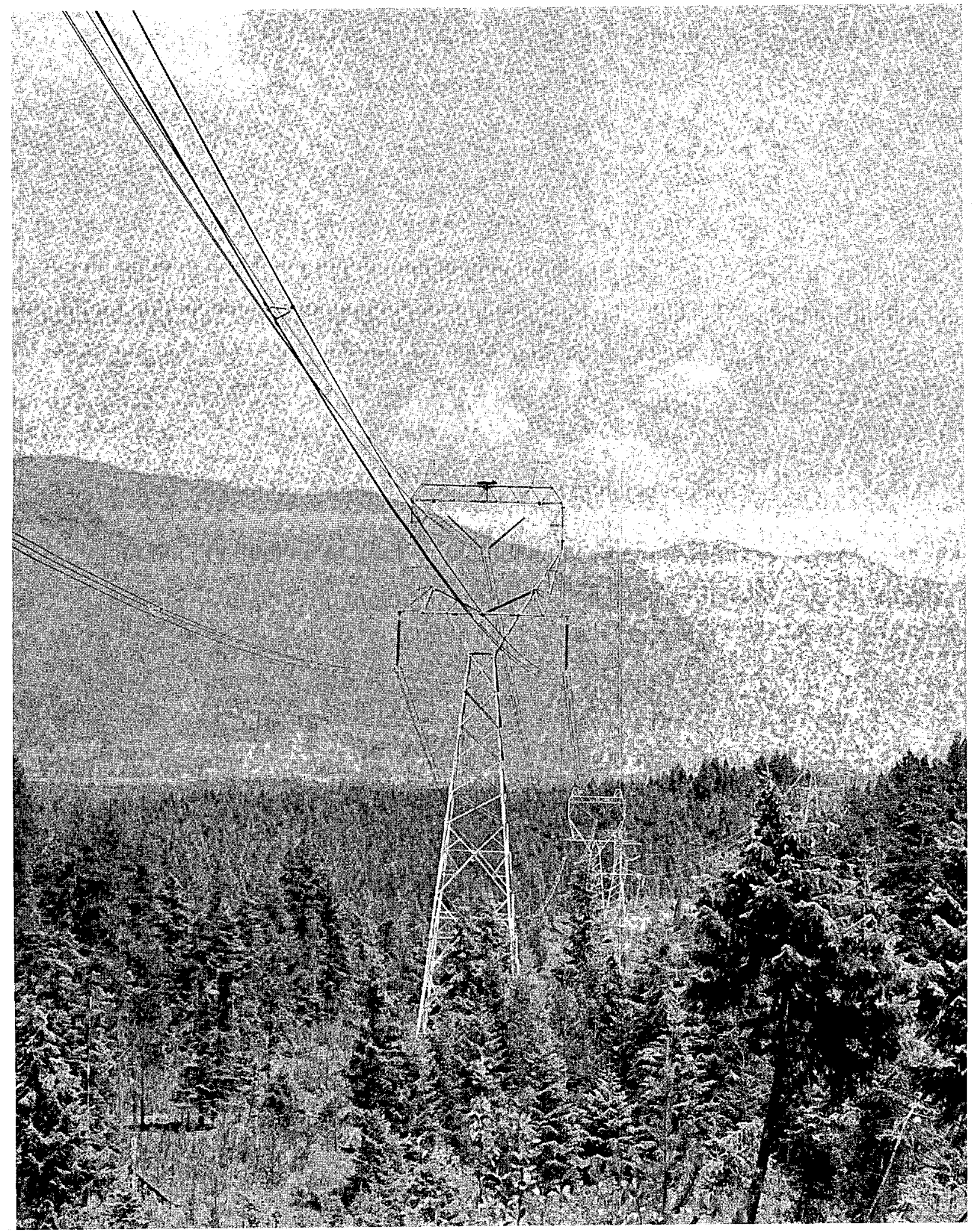


Transmission lines are high-voltage powerlines used to carry electric power efficiently over long distances. Usually, the lines extend from power generating plants to load centers such as cities or large industrial plants. Utilities use lower-voltage lines to distribute power to individual homes and businesses (Figure 1).

Through the years, transmission lines have been built that operate at progressively higher voltages. With each advance in voltage, larger amounts of energy have been moved more efficiently and at less cost over lines with greater individual capacity. Thus, with higher voltages, fewer lines are needed and some types of environmental impacts have been reduced. Table 1 shows when various BPA transmission voltages were introduced; it also compares power-carrying capability.

To market power from Northwest Federal hydroelectric projects, BPA operates around $23,500 \mathrm{~km}(14,600 \mathrm{mi})$ of transmission lines (Figure 2). Most of the transmission is at voltages of $230 \mathrm{kV}, 345 \mathrm{kV}$, and $500 \mathrm{kV}$. BPA's $500-\mathrm{kV}$ system is one of the largest in the world. In addition, BPA operates the Oregon portion of the first commercial \pm 500 $\mathrm{kV}$ d-c line in North America.

Before $345-\mathrm{kV}$ lines were introduced, the most noticeable effects of transmission lines were conflicts with other land uses and changes in the esthetic appearance of the landscape. Additional effects became evident when the EHV (extra-high-voltage: $345 \mathrm{kV}$ and above) lines were introduced in the 1950's. Operating 345-kV lines affected radio reception in residences near the lines. More effects occurred with the introduction of $500-\mathrm{kV}$ and $765-\mathrm{kV}$ lines: television reception interference, audible noise, and electric and magnetic field effects. These additional effects created some problems close to the lines. Through the years, BPA and utilities in general refined designs and procedures so that the effects were greatly reduced.

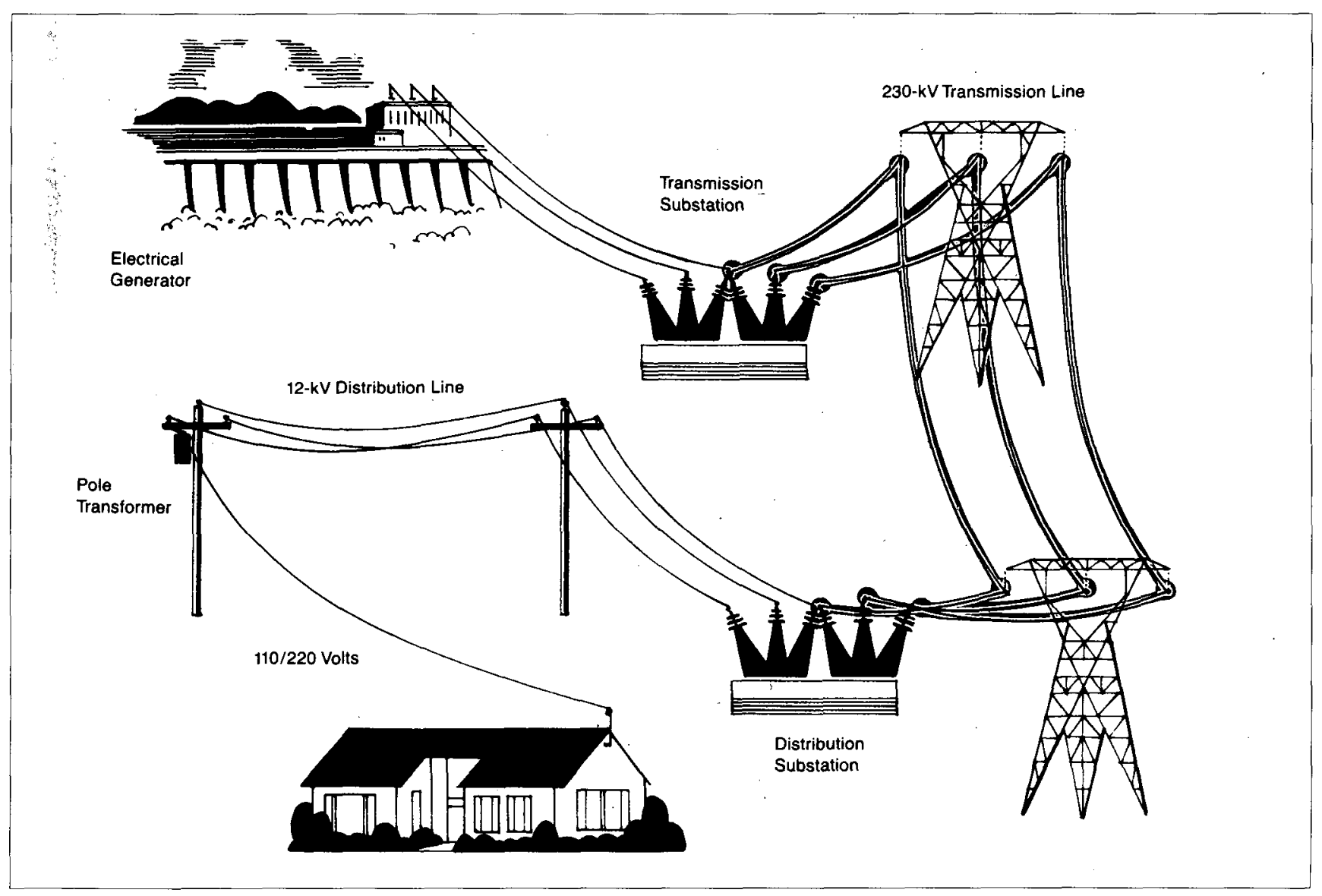

FIGURE 1. Simplified electric power system. BPA is responsible for transmission facilities. 
The next class of transmission lines, sometimes referred to as UHV (ultra-high-voltage, $1000 \mathrm{kV}$ and above), can be designed so that electrical effects are essentially no different from those produced by EHV lines. BPA operated and studied a 1200-kV a-c prototype line near Lyons, Oregon from 1977 to 1984 (Klinger et al. 1984). Lines of this voltage may be needed in the Northwest sometime after the year 2000.

BPA receives relatively few complaints or questions from the public living near existing transmission lines. Many questions are often raised when new lines are proposed, however. Questions are also frequently asked by persons planning on buying property near BPA lines. Many of these questions deal with the electrical properties of powerlines. The purpose of this review is to provide factual information on the electrical characteristics of transmission lines and the resulting effects on plants, animals, and people. Methods used by BPA to reduce or eliminate undesirable effects are also described.

This review does not discuss other effects of transmission lines such as those from construction and clearing of rightsof-way, or from the physical presence of the line (e.g., esthetics). Information on the overall effects of transmission lines can be found elsewhere (e.g., Arner and Tillman 1981, Crabtree 1984, Kroodsma and Van Dyke 1985).

Electrical effects of transmission lines addressed in this review fall into two broad categories: field effects and corona effects. Because there are some major differences in effects of a-c and d-c lines, the two types of lines are discussed separately.

\section{Table 1. Dates of introduction and power carning capability tor various BPA transmission lines.}

\begin{tabular}{|c|c|c|c|c|}
\hline $\begin{array}{l}\text { Line } \\
\text { Voltage }\end{array}$ & $\begin{array}{l}\text { Year First } \\
\text { Energized }\end{array}$ & $\begin{array}{l}\text { Power. } \\
\text { Capability } \\
\text { Per Circuit } \\
\text { (MW) }\end{array}$ & $\begin{array}{l}\text { Circult-km } \\
\text { (mi) } \\
\text { (Sep. 1988) }\end{array}$ & $\begin{array}{l}\text { Typical } \\
\text { Right-of-Way } \\
\text { Widths, } m \text { (f) }\end{array}$ \\
\hline $230 \mathrm{kV}$ & 1939 & 200 & $\begin{array}{c}8132 \\
(5054)\end{array}$ & $\begin{array}{l}27-38 \\
(90-125)\end{array}$ \\
\hline $345 \mathrm{kV}$ & 1955 & 450 & $\begin{array}{c}917 \\
(570)\end{array}$ & $\begin{array}{c}43 \\
(140)\end{array}$ \\
\hline $500 \mathrm{kV}$ & 1967 & $1500-2500^{1}$ & $\begin{array}{c}7030 \\
(4369)\end{array}$ & $\begin{array}{c}32-50 \\
(105-165)\end{array}$ \\
\hline $\pm 500 \mathrm{kV} \mathrm{d.c.}{ }^{2}$ & 1985 & 3100 & $\begin{array}{l}425 \\
(264)\end{array}$ & $\begin{array}{c}41 \\
(135)\end{array}$ \\
\hline
\end{tabular}

1 Power transfer capability was calculated for a $240-\mathrm{km}$ (150-mi) line with series compensation. One MW (megawatt) equals 1 million watts.

2 From 1970 to 1985 , the $d$-c line was operated at $\pm 400 \mathrm{kV}$ before being upgraded to $\pm 500 \mathrm{kV}$. The power capability of the line was increased from $2000 \mathrm{MW}$ up to $3100 \mathrm{MW}$ in 1989 by increasing current-carrying ability. 


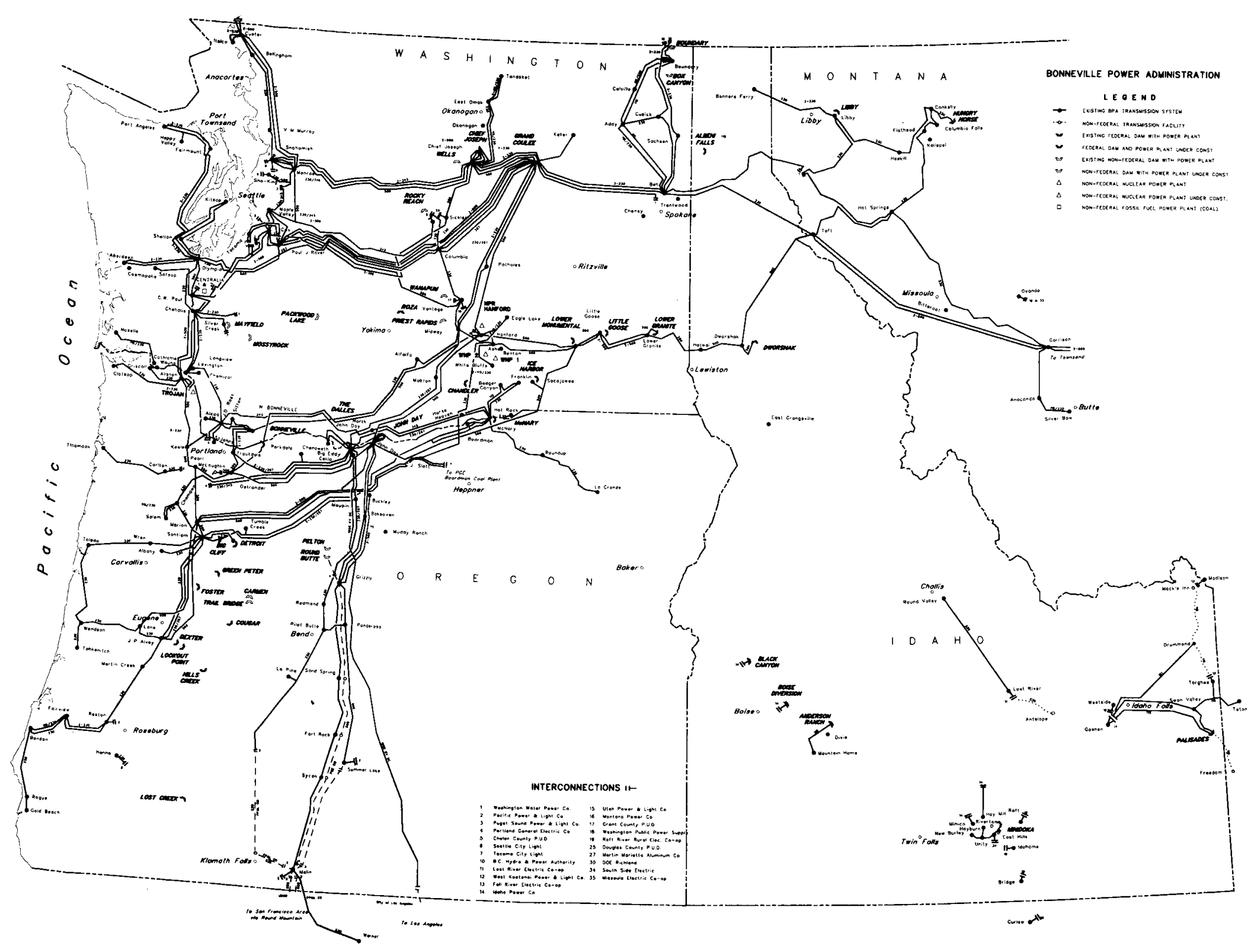




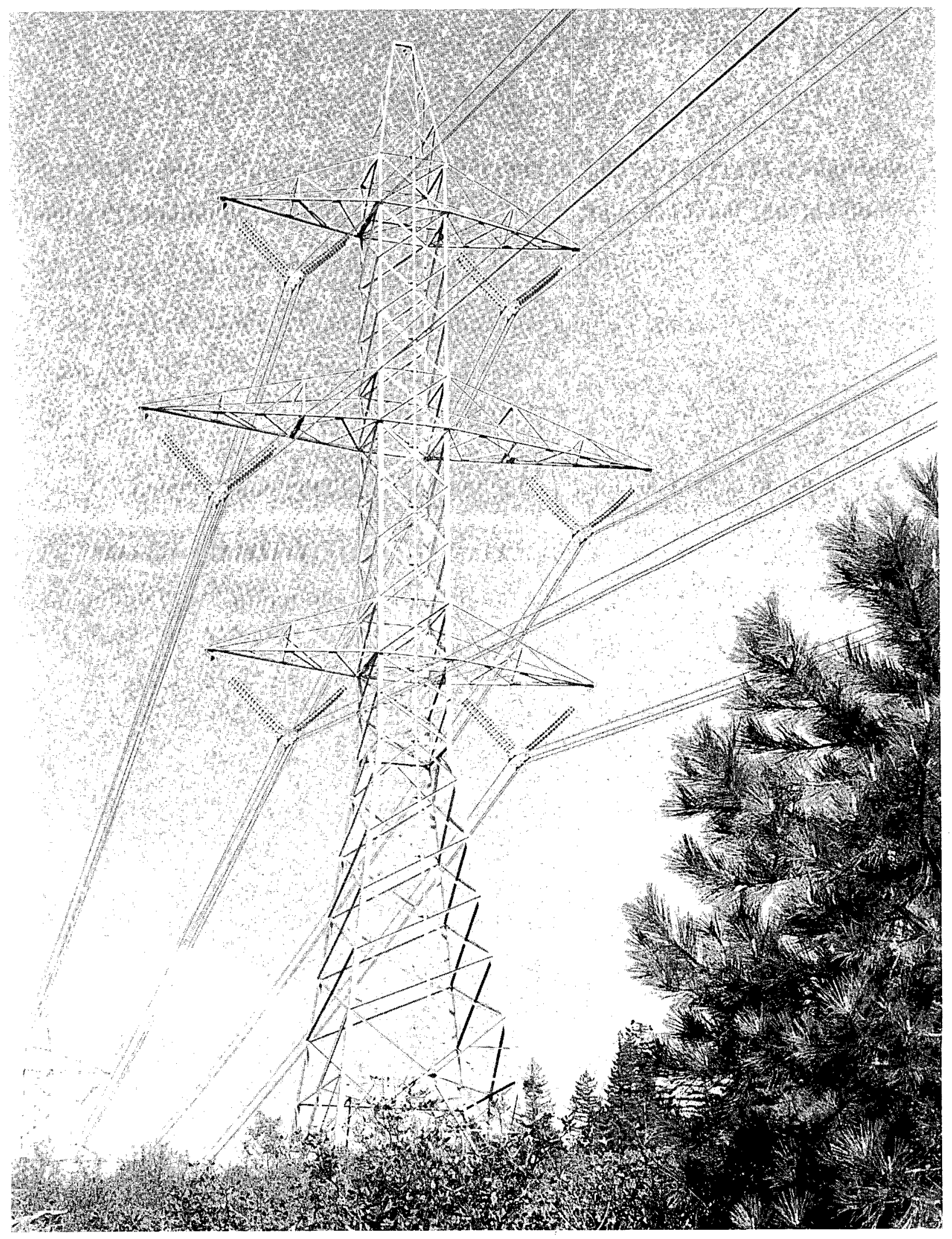




\section{A-C TRANSMISSION}

\section{BASIC ELECTRICAL CONCEPTS}

A-c transmission lines consist of three electrical "phases" (in bundles of one or more conducting wires). Each of these phases carries power. The three phases make up one circuit. Figure 3 shows typical BPA single- and doublecircuit transmission line tower types.

Various classes of transmission lines are referred to by a single voltage level called the "nominal" voltage. The nominal voltage is usually less than the operating voltage, which varies over some range. Further, the operating voltage can be measured in two basic ways. For a-c lines, the measurement usually refers to voltage between any two of the line phases. A BPA 500-kV line (nominal voltage) typically operates around $540-\mathrm{kV}$ phase-to-phase (with a range of 525 to $550 \mathrm{kV}$ ). The voltage measured between a phase and ground is about 58 percent of the phase to phase level (e.g., $312 \mathrm{kV}$ to ground when the line is operated at 540-kV between phases).

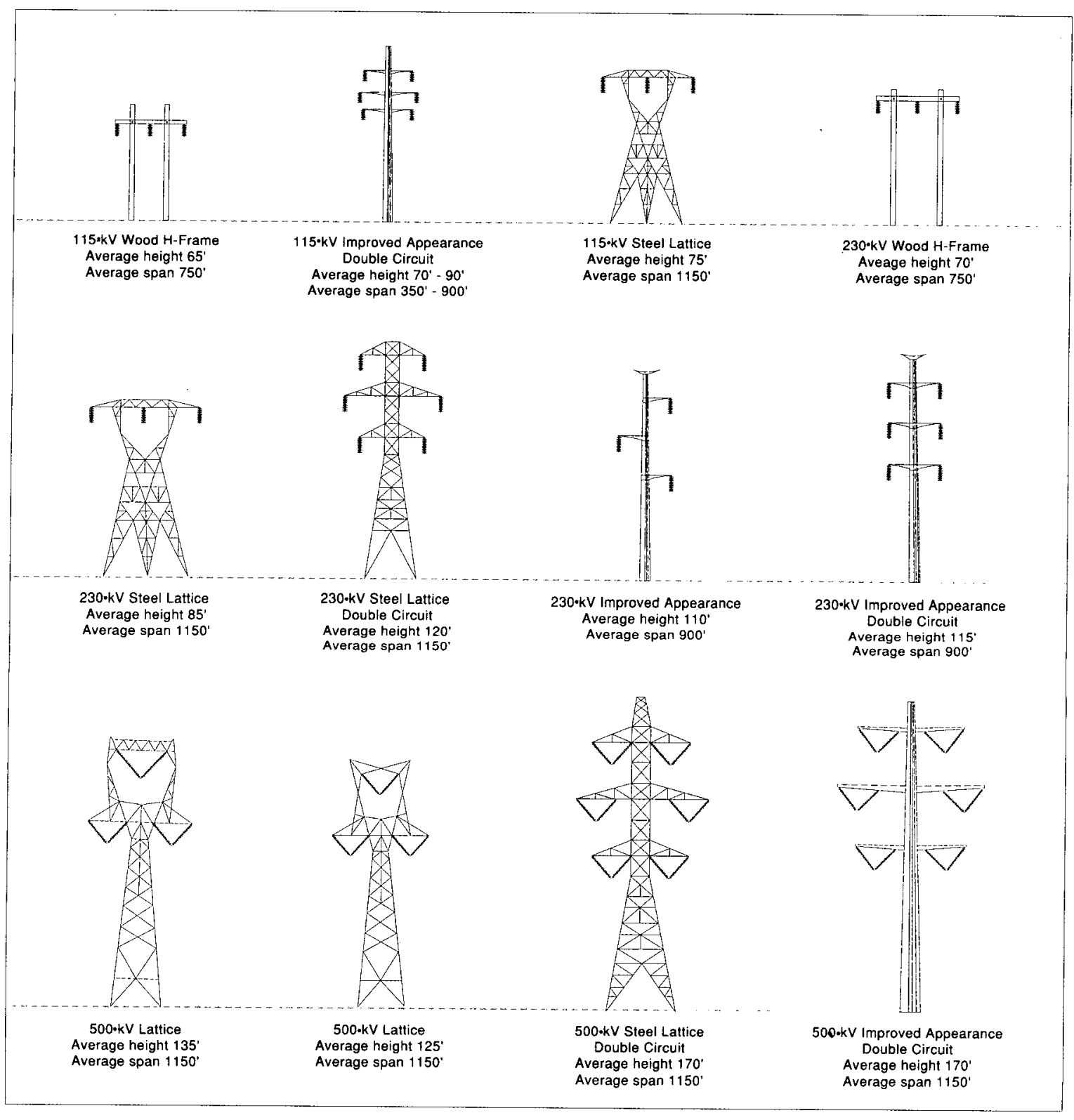

FIGURE 3. Examples of typical BPA transmission line towers. 
The (vector) product of voltage and current, expressed in watts, is a measure of electrical power. Power is carried on transmission lines at very high voltage to reduce energy losses, which are largely related to current flow. In general, the higher the voltage, the lower the losses for equal amounts of energy transmitted. Transformers are used to increase voltage for transmission and to reduce the voltage for distribution to homes, businesses, and factories.

A-c transmission lines in North America operate at a low frequency of $60 \mathrm{Hertz}$ ( 60 cycles-per-second). In Europe and some other countries, $50-\mathrm{Hz}$ a.c. is used. With a.c., both the voltage on the conductors and the current vary continually in magnitude and direction. Voltage is the electrical force that produces current (i.e., movement of electrons) in a conductor.

As a comparison, television transmitters operate at high frequencies in the $55-890 \mathrm{MHz}(\mathrm{MHz}=$ million Hertz) range. Microwaves are even higher frequencies, $1000 \mathrm{MHz}$ and above. The wavelength of microwaves is less than $30 \mathrm{~cm}$ $(1 \mathrm{ft})$ while at the transmission line power frequency of 60 $\mathrm{Hz}$, the wavelength is $5000 \mathrm{~km}$ (3100 mi) (Figure 4).

The energy from higher-frequency fields (shorter wavelengths) is absorbed more readily by biological material, and can produce heating (e.g., microwave ovens). The high energy associated with ionizing radiation (e.g., X-rays) strips electrons from molecules. In contrast, the extremely long wavelength at $60 \mathrm{~Hz}$ allows the transfer of only a minute amount of energy to objects the size of a person. It can be shown that a person-sized object absorbs about one trillion times less energy from a $60-\mathrm{Hz}$ power-line field than from a $60-\mathrm{MHz}$ television frequency field of equivalent power intensity (IITRI 1979: 5-17).

Transmission lines are very poor $60-\mathrm{Hz}$ transmitting "antennas." The low frequency power is not "radiated" away as happens with high-frequency television or radio transmitters.

Notice in Figure 4 that the waveforms have uniform curved shapes. A-c electric power is generated in what is known as a sine curve or wave. There are also a variety of other wave shapes found in various electronic circuits. For example, in video display terminals, one finds both $60-\mathrm{Hz}$ sine waves and pulsed wave forms. The latter might have the sharp appearance of a saw tooth. There is some evidence that different types of wave forms also differ in their potential to cause biological effects.

\section{GENERAL SAFETY}

It is not practical to cover overhead transmission line conductors with insulating material. A specific amount of air space is the insulation. Electricity can, therefore, arc through air from a power-line conductor to any conductive object which enters this space and is connected to ground.
This phenomenon, called "flashover," means that an object does not actually have to touch the conductor, but must simply come close enough for an arc to occur. To prevent flashover, transmission lines are designed and built to have specific clearances between the line and ground and nearby objects. These clearances are specified by the National Electrical Safety Code.

Later sections in this review describe specific safety practices to be followed when living or working around high voltage lines. In general, BPA lines are designed so that vehicles and other objects up to $4.3 \mathrm{~m}$ ( $14 \mathrm{ft}$ ) high can safely pass under the lines. This height has a safety margin built in, but persons who may need to operate equipment somewhat taller than this should first check with a BPA office. General safety precautions are described in a free BPA booklet, "Living and Working Around High Voltage Power Lines."

\section{ELECTROMAGNETIC SPECTRUM}

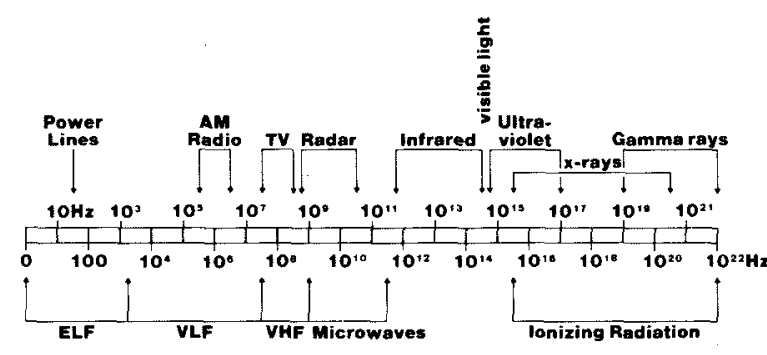

FREQUENCY AND WAVELENGTH

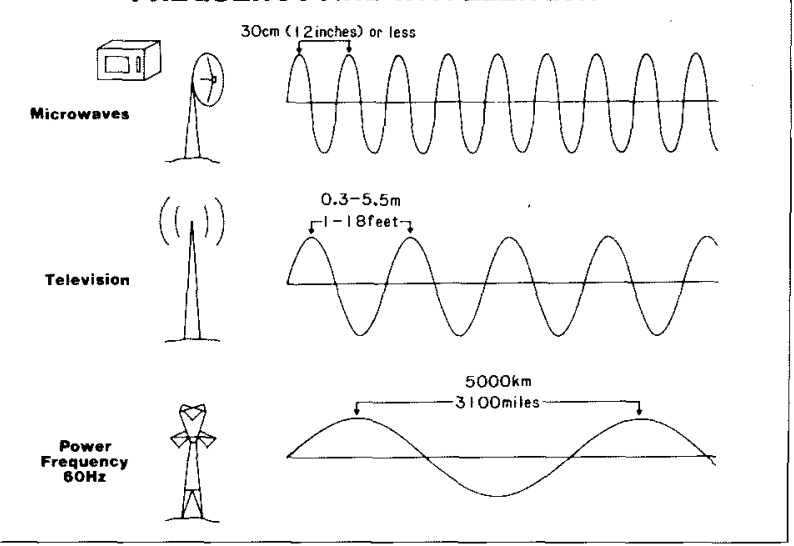

FIGURE 4. Comparison of frequency and wavelength for various electromagnetic sources. Because of the long wavelength and low frequency, transmission lines do not "radiate" energy comparable to that of microwave or radio and television antennas. 


\section{ELECTRIC AND MAGNETIC FIELDS}

Powerlines, electrical wiring, and electrical devices and appliances all produce electric and magnetic fields. We are, therefore, almost continuously exposed to these fields, whether at home, work, or school. The sections below describe the properties of these fields, tell how they are measured, and give examples of field strengths produced by various sources. Next described is the world-wide research aimed at assessing whether exposure to electric and magnetic fields can adversely affect people, animals, and plants.

\section{Electric Fields}

\section{Description and Comparative Levels}

Voltage on any wire produces an electric field in the area surrounding the wire. An electric field is basically invisible lines of force that repel or attract electrical charges. Electric field strength is described in terms of voltage-per-unitdistance at a specified position. Examples of typical electric field strengths found in the home are given in Table 2.

Table 2. Typical examples of $60-\mathrm{Hz}$ electric field strengths In the home.

\begin{tabular}{|c|c|}
\hline Location ${ }^{1}$ & $\begin{array}{c}\text { Electric Field }{ }^{2} \\
(\mathrm{~V} / \mathrm{m})\end{array}$ \\
\hline Broiler & 130 \\
\hline Toaster & 40 \\
\hline Stereo & 90 \\
\hline Hallway & 13 \\
\hline Bedrooms & $2-8$ \\
\hline Electric Blanket & $100-2000^{3}$ \\
\hline \multicolumn{2}{|c|}{$\begin{array}{l}1 \text { Point of measurement was } 30 \mathrm{~cm} \text { ( } 1 \mathrm{ft} \text { ) from appli- } \\
\text { ances (except electric blanket) and in the center of } \\
\text { rooms (source: Miller 1974, from Valentino 1972). } \\
2 \text { In terms of human field exposures, these levels } \\
\text { produced by appliances cannot be directly compared } \\
\text { to equivalent fields from power lines. This is because } \\
\text { of differences in orientation of the fields with respect } \\
\text { to the body. For example, the current density induced } \\
\text { in the chest of a person covered by an electric blan- } \\
\text { ket is comparable to the current density induced in } \\
\text { the chest of a person standing in a } 90-140 \mathrm{~V} / \mathrm{m} \\
\text { power-line field (Florig et al. 1987). } \\
3 \text { These are average values for a person using an } \\
\text { electric blanket (Florig et al. 1987). }\end{array}$} \\
\hline
\end{tabular}

Electric fields found near transmission lines are usually measured in units of $\mathrm{kV} / \mathrm{m}$ (kilovolts per meter). For example, $1 \mathrm{kV} / \mathrm{m}$ means that there is adifference of $1 \mathrm{kV}$ (1000 volts) between two points in air, 1 meter ( $3.3 \mathrm{ft}$ ) vertically apart. The electric field near an a-c line is easily measured by the use of a hand-held meter (Figure 5).
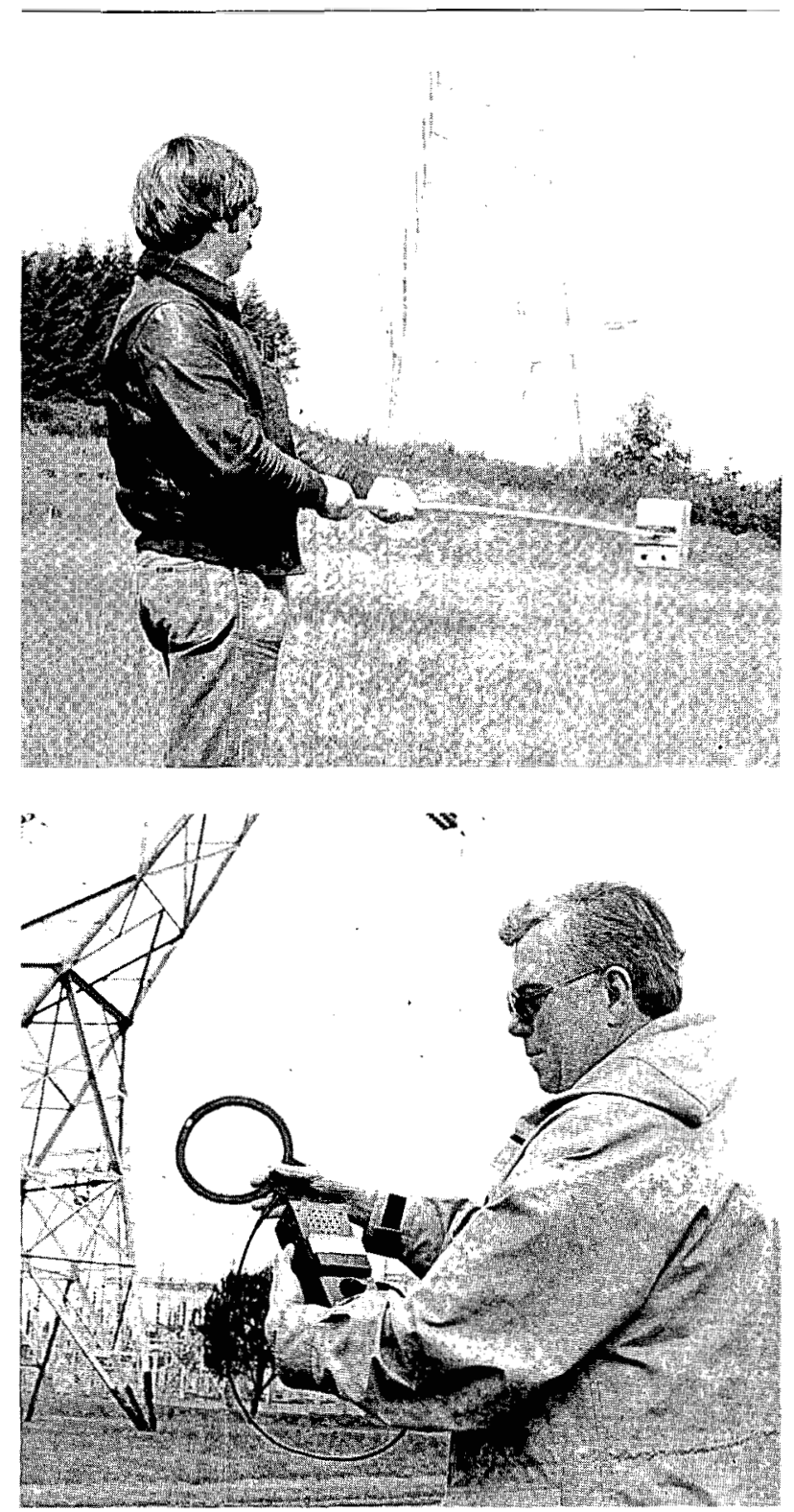

FIGURE 5. Electric field strength near an a-c transmission line is easily measured (upper). The meter is on the far end of a non-conducting long handle because the field is distorted near a person's body. A hand-held coil can be used to measure the magnetic field because this field is not affected by the body (lower). 
Figure 6 shows typical vertical electric field strength at various lateral distances away from BPA transmission lines. The values are for a point 1 meter $(3.3 \mathrm{ft})$ above ground (the standard reference height). For a fixed conductor-to-ground height, the electric field strength does not vary more than 10 to 15 percent for heights up to $3 \mathrm{~m}(9.8$ $\mathrm{ft}$ ) above ground. There is also a small horizontal electric field component.
The maximum electric field near the ground usually occurs just outside the outer conductors at mid-span. The field strength dips right under the center of the lines because the three phases partialiy cancel each other. The highest commercial a-c transmission line voltage is $765 \mathrm{kV}$. These lines, found in the eastern United States, produce maximum electric fields of around 10 to $12 \mathrm{kV} / \mathrm{m}$. In the BPA system, the largest commercial line is $500 \mathrm{kV}$ and the maximum electric field is $9 \mathrm{kV} / \mathrm{m}$.

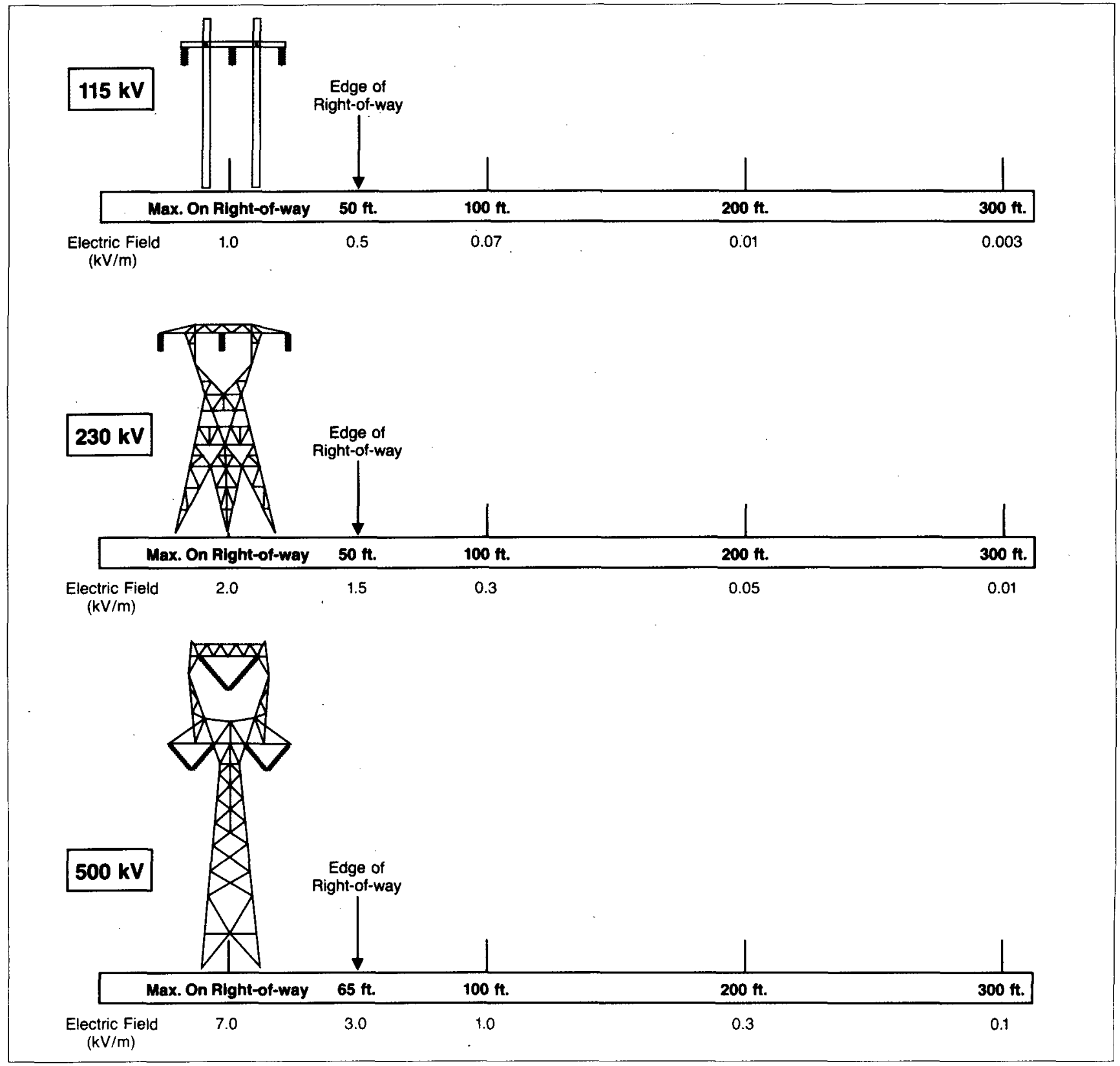

FIGURE 6. Typical electric field strengths at various distances from BPA transmission lines. Actual field strength and right-ofway width depend on line design and voltage levels. 
Figure 7 shows the distribution of the electric field beneath a $500-\mathrm{kV}$ transmission line. Notice that the maximum field occupies a relatively small area near mid-span. This is where the conductors sag closest to the ground.

The presence of an electric field can sometimes be demonstrated with a hand-held fluorescent tube (Figure 8). This phenomenon has been associated with transmission lines and distribution lines. Fluorescent tubes also glow in some other electric fields-near an automobile engine, a CB radio antenna, or when simply scuffing your feet across a carpet. In all these instances, the illumination is much less than that produced by normal use.

The electric field strengths shown in Figures 6 and 7 are calculated levels for flat terrain that would occur with maximum conductor sag, i.e., when line current and air temperature conditions are highest. In actuality, maximum conditions seldom occur and measured field levels near operating transmission lines are typically much less than the calculated maximum design levels. Measurements made of 359 spans of BPA 500-kV lines during late winter showed the average maximum electric field strength was only $3.7 \mathrm{kV} / \mathrm{m}$ (Bracken and Ray 1980). Fewer than 5 percent of the spans measured had maximum fields greater than $6 \mathrm{kV} / \mathrm{m}$.

The symmetry in field strength shown in Figures 6 and 7 would exist only if the line were located above an ideal, level-ground surface. Irregular ground or the presence of conducting objects such as vegetation or structures greatly perturbs (distorts) the field. Beneath tall vegetation, or within buildings or automobiles, the electric field from a nearby transmission line is considerably reduced because these objects act as a partial shield. For example, Caola et al. (1983) reported that the electric field inside a brick home near a 500-kV line was 8 times less than the field strength that existed outside. The amount of shielding depends on the type of building material.

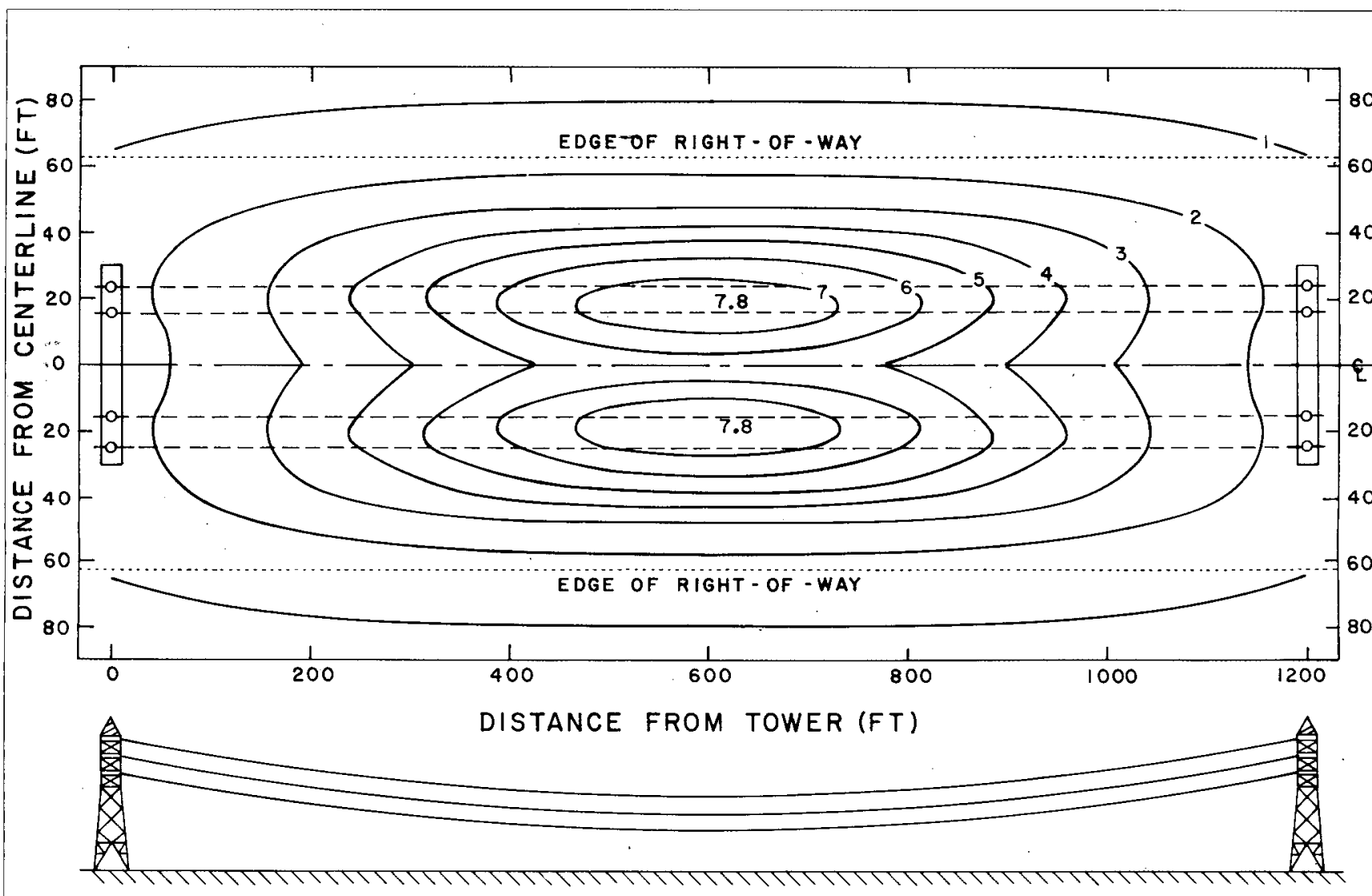

FIGURE 7. Maximum calculated electric field strength $(\mathrm{kV} / \mathrm{m})$ contours at 1 meter $(3.3 \mathrm{ft}$ ) above ground for a BPA 500-kV doublecircuit line. Measured values are typically less than calculated levels. Note the horizontal and vertical distances are at different scales. 

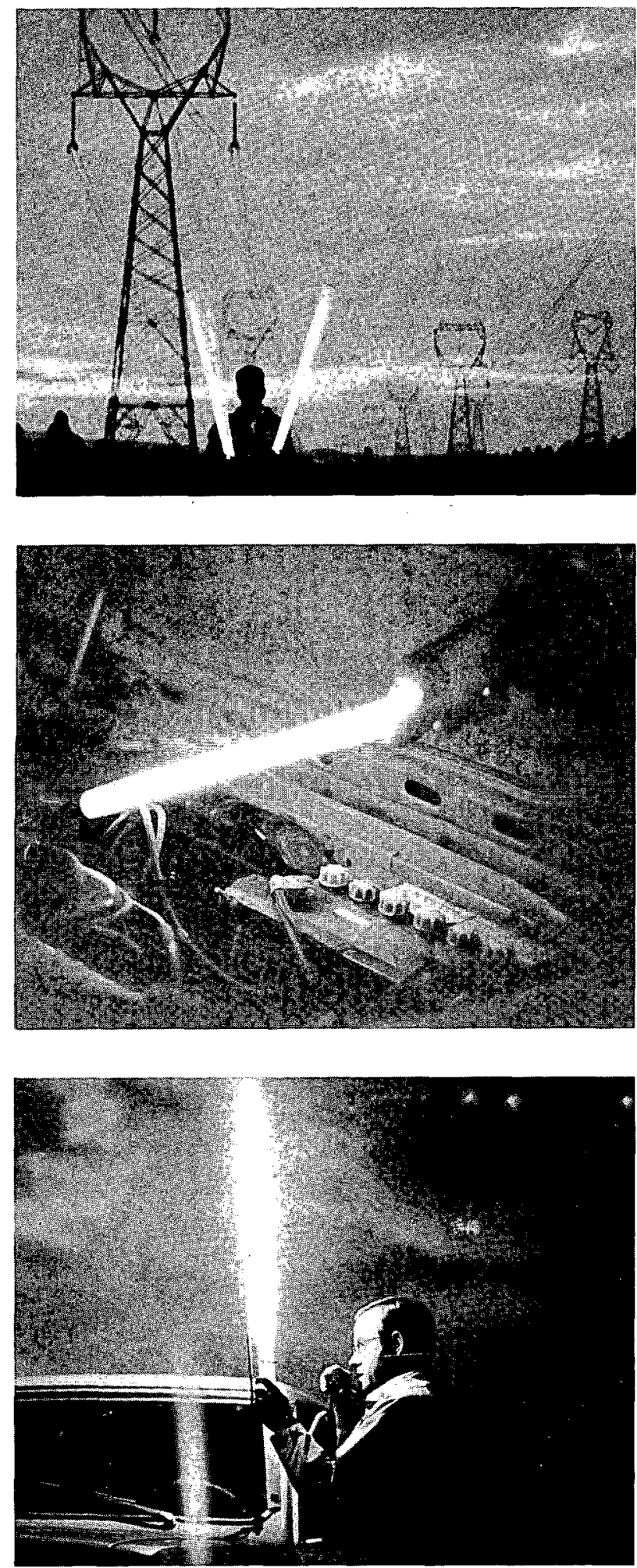

FIGURE 8. The presence of an electric field is sometimes demonstrated with a hand-held fluorescent tube. These time-exposure photographs (several seconds) show tubes glowing near 500-kV a-c transmission lines, an automobile ignition, and a $C B$ radio antenna.
Another factor that determines field strength is the conductor configuration - the spacing and arrangement of the conductors (see Figure 3 ). The electric fields created by the three phases of high-voltage lines tend to cancel one another. In a delta (triangular configuration), the three phases are more compact than they are in a flat configuration. Thus, the electric field strength near the ground for a delta configuration is less than that of a comparable flat configuration at the same height.

Depending on phase arrangements, similar cancellation effects can occur with two or more adjacent transmission lines and with double-circuit lines. The maximum ground level electric field strength beneath multiple BPA lines is about the same as would be found beneath the highest voltage line alone. In other words, the electric fields from multiple lines do not simply add together: two adjacent 500 $\mathrm{kV}$ lines do not represent a 1000-kV line.

\section{Induced Currents and Voltages}

When conducting objects, such as vehicles or people, are in an a-c electric field, currents and voltages are induced in them (Figure 9). The induced current varies with the electric field strength, the frequency of the field, the size and shape of the object, and the object-to-ground resistance. The actual current consists of minute movements (oscillations)

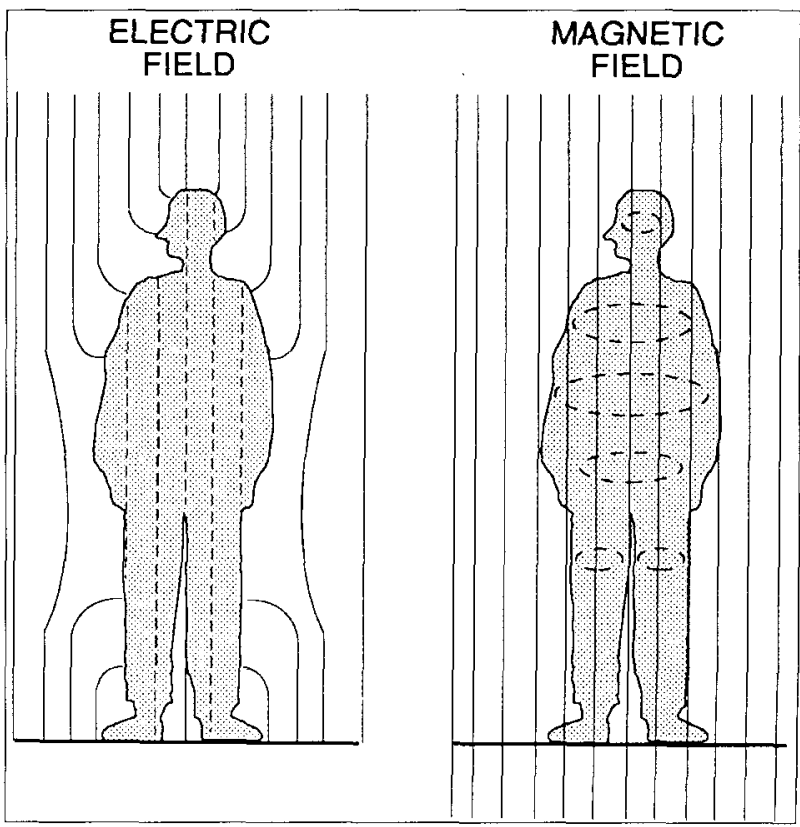

FIGURE 9. Electric and magnetic fields from electrical appliances and from power lines induce weak electrical currents in people and animals. Solid lines represent invisible field lines. Dotted lines indicate direction of induced current flow. Figure depicts person standing directly under a powerline. 
of charged particles. These particles in metallic conductors are mainly electrons, whereas in body tissues and fluids, ionic conduction predominates (Adey and Bawin 1977:61).

If an object is grounded, the induced current to ground is called the short-circuit current of the object. Measured short-circuit currents for a person and some objects in a 60$\mathrm{Hz}$ electric field of $1 \mathrm{kV} / \mathrm{m}$ are tabulated below in milliamperes $(\mathrm{mA})(1 \mathrm{~mA}=$ one-thousandth of an ampere):

Person ( $1.75 \mathrm{~m}$ ( $5 \mathrm{ft} 9 \mathrm{in}$ ) height)
Farm Tractor
Station Wagon
Camper Truck
Combine
Large School Bus
Large Trailer Truck

$$
\begin{aligned}
& 0.016 \mathrm{~mA} \\
& 0.10 \mathrm{~mA} \\
& 0.11 \mathrm{~mA} \\
& 0.28 \mathrm{~mA} \\
& 0.30 \mathrm{~mA} \\
& 0.41 \mathrm{~mA} \\
& 0.63 \mathrm{~mA}
\end{aligned}
$$

The total short-circuit current in any other field strength is found by multiplying the field strength in $\mathrm{kV} / \mathrm{m}$ by the value given above. For example, a person standing in a $10-\mathrm{kV} /$ $\mathrm{m}$ field would receive approximately $0.16 \mathrm{~mA}$ of total induced body current, which is below the level of perception. The induced current from a $10-\mathrm{kV} / \mathrm{m}, 60-\mathrm{Hz}$ electric field produces small internal electric fields in a person ranging between 0.001 and $0.028 \mathrm{~V} / \mathrm{m}$ in upper body parts and internal current densities (across sections of the body) of only $0.0006 \mathrm{~mA} / \mathrm{cm}^{2}$ (Kaune and Phillips 1980).

The weak fields and currents induced in the body by the transmission line field are far less than those of many natural levels. The threshold current density associated with human nerve triggering is around 0.1 to $1.0 \mathrm{~mA} / \mathrm{cm}^{2}$. Natural tissue gradients for human brainwaves (around 10 $\mathrm{Hz}$ ) are between 0.1 and $2 \mathrm{~V} / \mathrm{m}$ (Adey and Bawin 1977). Some studies suggest that the small currents induced by external fields may significantly alter biological processes. Research on this controversial subject is described later in this report.

Induced subperception body currents are not unique to a transmission line environment. For example, according to one study, currents induced in a person's neck and waist by an electric blanket were equivalent in magnitude to currents induced by a transmission line field of $40-50 \mathrm{~V} / \mathrm{m}$ (Silva 1985).

The American National Standards Institute (ANSI) allows up to $0.5 \mathrm{~mA}$ leakage current from portable household appliances and $0.75 \mathrm{~mA}$ from fixed appliances (ANSI 1973).

\section{Perception Effects}

When a person or animal contacts a conducting object isolated from ground within an electric field, a perceptible current (tingling sensation) or a shock may occur (Figure 10). This can also happen when the person or animal is insulated and the object is grounded. The amount of current is determined by the electric field strength, the size of the object, and how well both the object and the person or animal are insulated from ground.

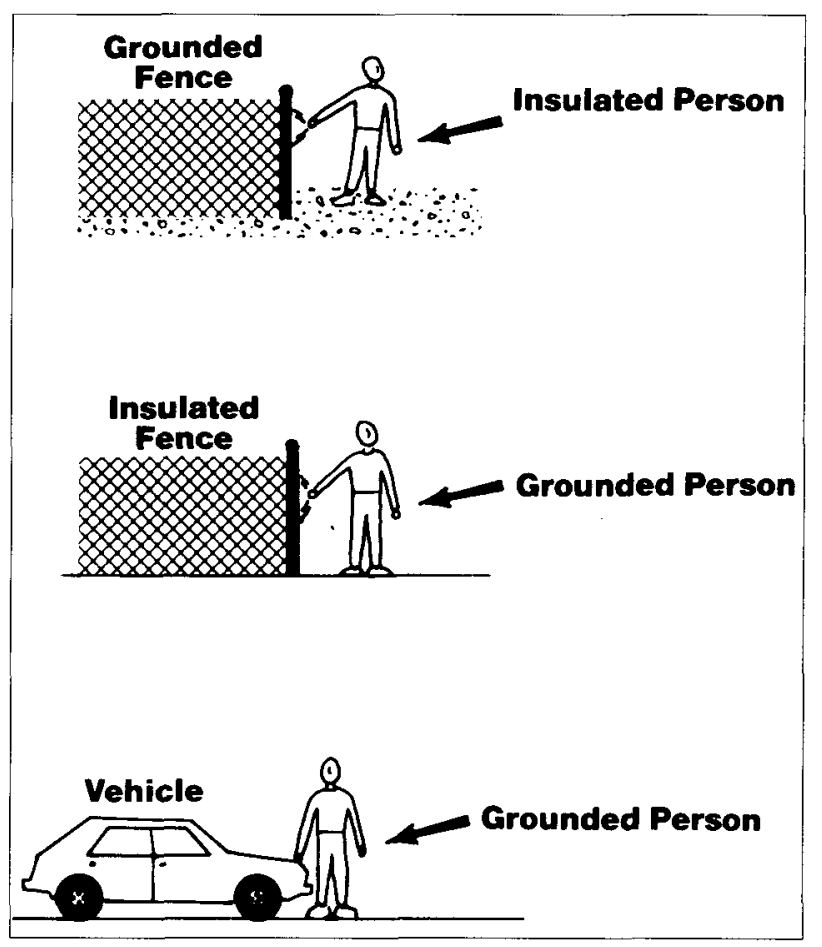

FIGURE 10. Typical situations where perceptible currents or nuisance shocks can be experienced by persons or animals in a transmission line electric field. The electric field induces a voltage on people or objects insulated from ground. See text for discussion (adapted from Sheppard and Eisenbud 1977).

The short-circuit currents listed in the previous section are the maximums an individual could experience from the field or from touching various objects. The values represent worst-case estimates, because they were made with the objects placed on special rubber mats to insulate them completely from ground. Conditions conducive to maximum current in normal situations are rare. People and animals are usually grounded to some degree through their feet. Likewise, most vehicle tires are actually semi-conductive. In addition, soil and vegetation in contact with the tires or the vehicle provide additional paths for electrical charge to move to ground.

Shocks can be classified as below perception, above perception, secondary, and primary. The mean perception level for a $82-\mathrm{kg}(\mathbf{1 8 0}-\mathrm{lb})$ man is about $1.0 \mathrm{~mA}$. It is about two-thirds of that value for a $55-\mathrm{kg}(120-\mathrm{lb})$ woman (Keesey 
and Letcher 1970). Secondary shocks cause no direct physiological harm, but they may annoy a person and cause muscles to react involuntarily.

Though difficult to define precisely, the lower average secondary shock level for an average-sized man is about $2 \mathrm{~mA}$ (Deno and Zaffanella 1975).

Primary shocks can be harmful. Their lower level is described as the current at which 99.5 percent of subjects can still voluntarily "let go" of the shocking electrode (conductor). Keesey and Letcher (1970) fixed the mean let-go level for $82-\mathrm{kg}(180 \mathrm{lb})$ men at $9 \mathrm{~mA}$ and for $55-\mathrm{kg}(120 \mathrm{lb})$ women at $6 \mathrm{~mA}$. Their estimate for children was $5 \mathrm{~mA}$. Dalziel (1943) earlier suggested $4.5 \mathrm{~mA}$ as a safe let-go current level for children. The work of Dalziel and others involved with the development of the let-go current research was reviewed by Banks and Vinh (1984).

The National Electrical Safety Code (NESC) specifies $5 \mathrm{~mA}$ as the maximum allowable short-circuit current to ground from vehicles, trucks, and equipment near transmission lines. Even under worst-case conditions, induced currents from vehicles near BPA lines would be less than $5 \mathrm{~mA}$ (see the section on "Field Standards and Limits"). We are not aware of any instances where adults or children have been injured by induced currents from BPA lines.

The discussion above has dealt primarily with steady-state current that occurs while a person is in contact with the ground or an object. In the instant before contact, a spark discharge can occur. The effect is similar to the static discharge shock a person can experience after walking across a carpet and then touching a door knob. In the a-c field of a transmission line, however, both charging and discharging is continuous, so long as there is a slight space between the objects involved. Spark discharges are a function of both voltage and energy. Energy is measured in joules $(\mathrm{J})$ and is dependent on the size of the object which is discharged and the voltage on the object. For 50 percent of adult men, spark discharges reach the perception level (fingertip-touch) when they measure about $0.14 \mathrm{~mJ}$ (millijoule) (IEEE Subcommittee 1985).

Fingertip touch annoyance occurs around the $1.3 \mathrm{~mJ}$ level and hand-grab annoyance is estimated at $4 \mathrm{~mJ}$. The magnitude of spark discharges beneath transmission lines depend greatly on ground conditions, but, even under worst-case conditions for large vehicles, would be less than $30 \mathrm{~mJ}$. Although painful shocks are possible under certain conditions, shock levels are far below the $50 \mathrm{~J}$ level believed to represent a danger threshold in humans (IEEE W.G. 1972).

BPA and other utilities have for years mitigated problems associated with electric shocks from induced currents under transmission lines. Utilities have internal standards for grounding stationary objects such as fences, metal roofs, and antennas (see Appendix A). Other examples of precautions necessary to avoid electrical hazards are pointed out in subsequent sections of this report and elsewhere (Reiner 1972; IEEE W.G. 1972, 1973; REA 1976). BPA publishes safety information in a free nontechnical booklet titled, "Living and Working Around High-Voltage Powerlines." An IEEE booklet also addresses the electrical effects of transmission lines (IEEE 1983).

In addition to nuisance shocks, another short-term effect is direct perception of the electric field. The alternating charges induced by an electric field on the body surface may cause a detectable sensation through hair vibration. However, with field strengths produced by BPA lines, most people normally would not detect even the maximum field in this manner. By standing near mid-span of a 500-kV line on a still day, some people can feel a gentle vibration of hair on their head or on an upraised arm.

In one study, 110 men were asked to describe their perceptions of various electric field strengths (Reilly 1979). Approximately 20 percent of the men could perceive a $9-\mathrm{kV} / \mathrm{m}$ field through stimulation of head hair. At field strengths of 2 to $3 \mathrm{kV} / \mathrm{m}$, less than 5 percent reported that they could perceive the field. At the lower field strengths, a gentle breeze can cause enough hair movement to overshadow that produced by the electric field.

Cabanes and Gary (1981) assessed men's and women's perception of a $50-\mathrm{Hz}$ electric field in an indoor high-voltage laboratory. With both arms held by the sides, only 5 percent of the people could perceive a $5-\mathrm{kV} / \mathrm{m}$ field. With one arm raised above the head, 10 percent perceived a $2-\mathrm{kV} / \mathrm{m}$ field.

\section{Magnetic Fields}

\section{Description and Comparative Levels}

A magnetic field is produced from current in a conductor. The magnetic field is measured in terms of lines of force per unit area (i.e., magnetic flux density) (Figure 5). Measurements are given in tesla's $(T)$ or gauss $(G)(1 G=0.1 \mathrm{mT})$. (The following prefixes are used: $m=$ milli, one-thousandth; $\mu=$ micro, one-millionth; $n=$ nano, one-billionth). The magnetic field near transmission lines (Figure 11) is comparable to fields close to common household appliances. However, in the case of appliances, the magnetic fields are localized in the immediate vicinity of the device. Gauger (1985) reported that 95 percent of his measurements of magnetic fields at a distance of $0.3 \mathrm{~m}(1 \mathrm{ft})$ from electrical appliances were below $0.01 \mathrm{mT}(0.1 \mathrm{G})$. At a distance of 1.5 $\mathrm{m}(5 \mathrm{ft})$, most appliance fields were less than $100 \mathrm{nT}(1 \mathrm{mG})$. Figure 12 shows magnetic field strength at various distances from some common electrical appliances.

Electric blankets represent a special case of appliance field exposure because they are used close to the body for long 


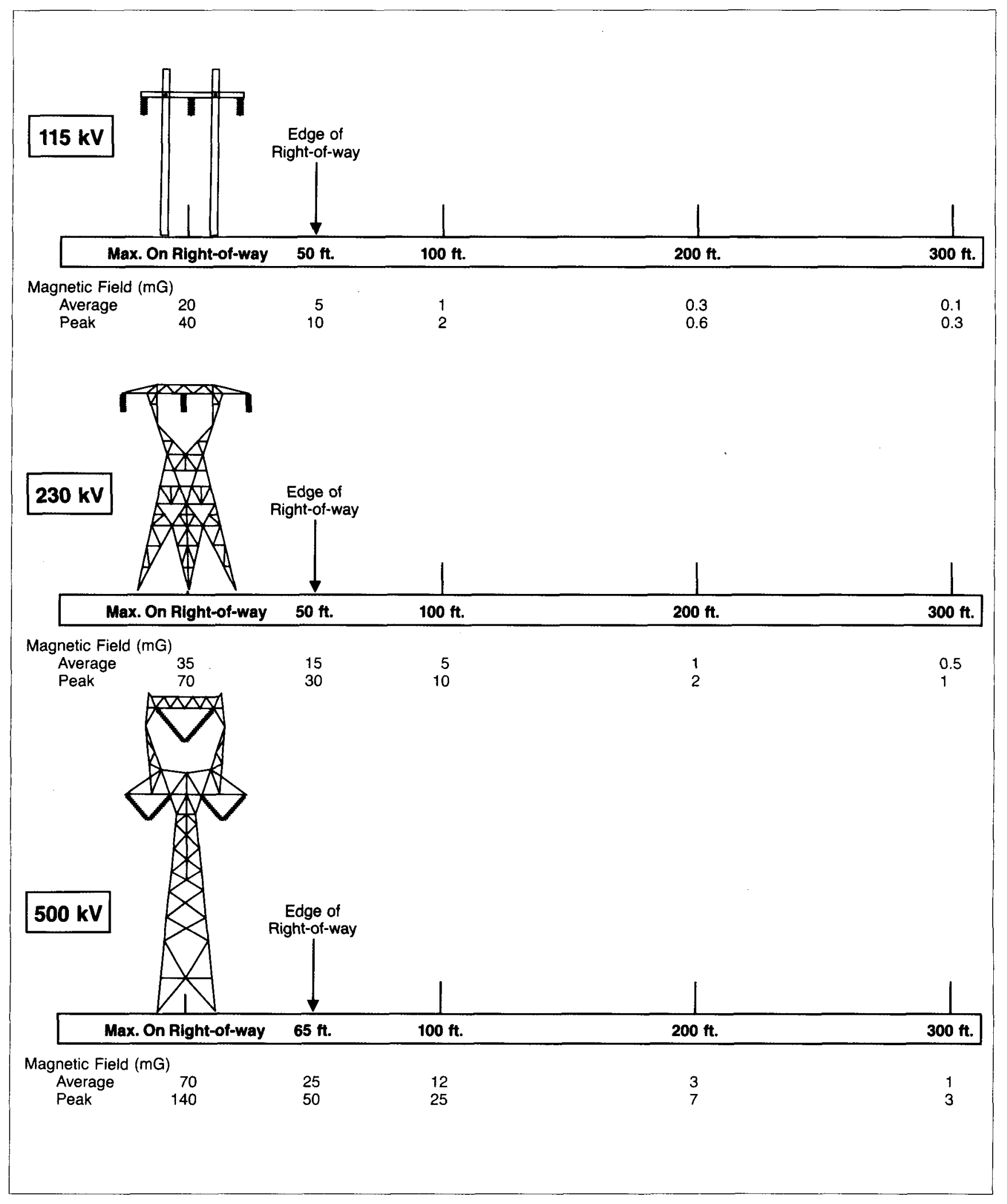

FIGURE 11. Typical magnetic field strengths at various distances from BPA transmission lines. Actual field strength and rightof-way width depend on line design and current levels. Current levels vary widely throughout the year due to fluctuations in electricity use. Therefore, both annual average and peak values are given (peak values occur less than 1 percent of the time). 


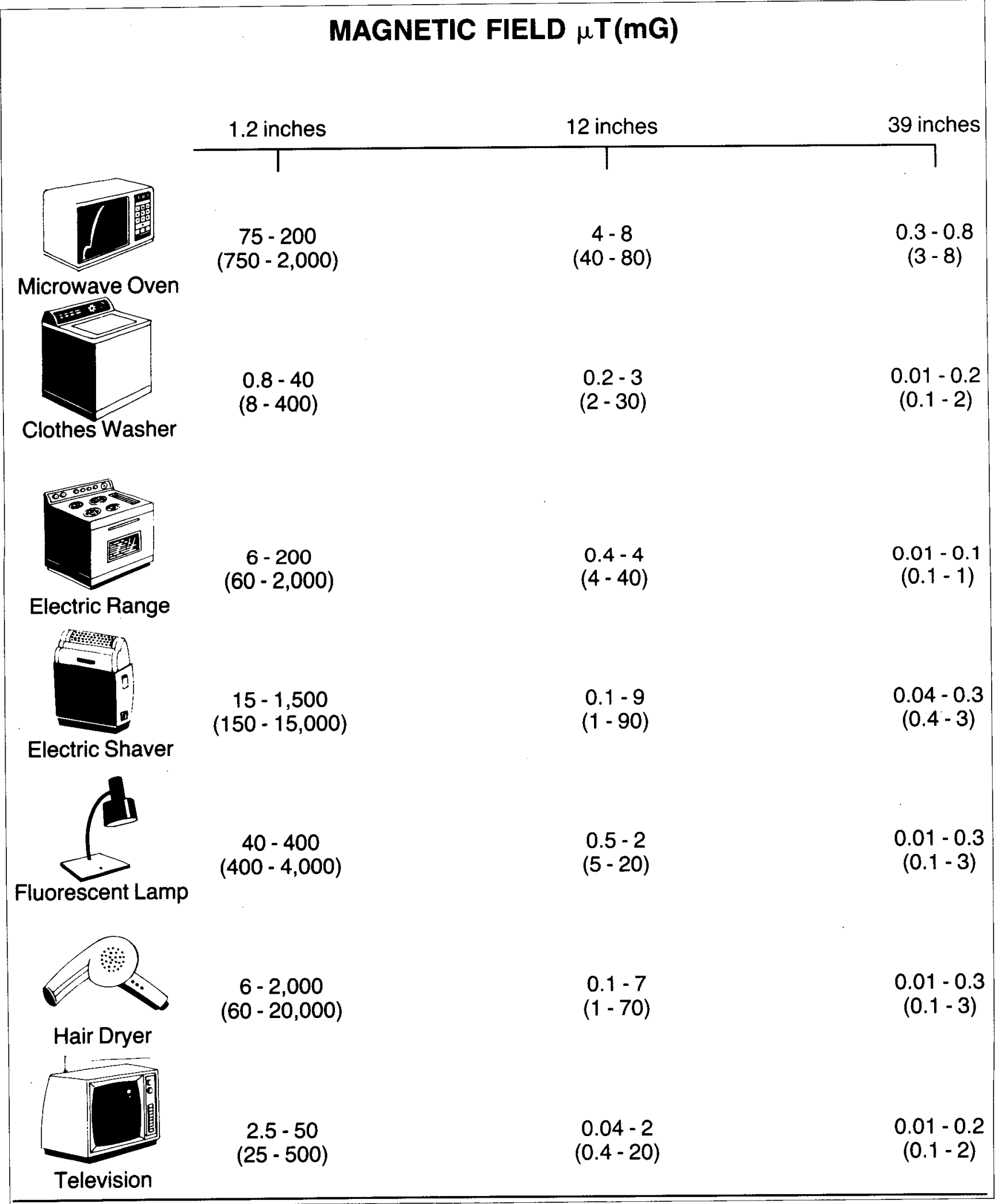

FIGURE 12. Typical 60- $\mathrm{Hz}$ magnetic fields measured at various distances from some electrical appliances (adapted from Gauger 1985). 
periods of time. Florig and Hoburg (1988) studied the fields produced by electric blankets. They found that the magnetic fields were very non-uniform and ranged in intensity up to $10 \mu \mathrm{T}(100 \mathrm{mG})$ at a distance of $1 \mathrm{~cm}(0.4 \mathrm{in})$ from the blanket. The average magnetic field in the body of a person using an electric blanket was estimated at about $1.5 \mu \mathrm{T}$ (15 mG).

Unlike electric fields, $60-\mathrm{Hz}$ magnetic fields easily pass through most objects, including buildings and people. Therefore, powerlines can significantly contribute to the magnetic field found throughout homes near the lines. Savitz et al. (1988:82) reported that the average magnetic field measured throughout homes near "low current" powerlines in Denver, Colorado was around 50-100 nT (0.5 to $1 \mathrm{mG}$ ). In homes near "high current" lines, the field averaged around 100-300 nT ( 1 to $3 \mathrm{mG}$ ). There was considerable variation in the measurements, however.

Measurements made in 138 homes in the Seattle area also indicated that use of household appliances made a relatively small contribution to the magnetic field strength in homes. With most appliances off, the average field was 90 $\mathrm{nT}(0.9 \mathrm{mG})$; with appliances on, the average field only increased to $110 \mathrm{nT}(1.1 \mathrm{mG})$ (Severson et al. 1988). The study also found no relationship between daily home electricity consumption and magnetic field strength measured in rooms in the home (Kaune et al. 1986).

There is considerable interest in magnetic fields in residential and occupational environments. This is due to recent epidemiological studies suggesting a link between these fields and cancer (see the section on "Potential Long-Term Health Effects"). A report by an IEEE Task Force describes the numerous sources of magnetic fields and the problems involved in measuring and modeling these fields (MFTF 1988). Among the factors influencing magnetic field levels in human environments are: amount of current carried on nearby powerlines, how well the current is balanced, powerline configuration, and location of return currents (Figure 13).

Silva et al. (1988) made magnetic field measurements in 91 buildings in 6 states. Average field levels in rooms was around $0.1 \mu \mathrm{T}$ (1 mG). Average levels measured near appliances as they would normally be used ranged from 0.9 to $2 \mu \mathrm{T}$ (9-20 mG). The way homes are grounded and wired can have a big effect on the magnetic field strength in the home. Silva et al. also found that the dominant magnetic field in homes located close to powerlines appeared to be due to the lines.

Alternating magnetic fields induce electric fields and currents inside organisms (see Figure 9). From a transmission line, however, these fields and currents are even weaker than the internal fields and currents produced by the electric field. For example, consider the maximum fields produced by a transmission line. A $0.03 \mathrm{mT}(0.3 \mathrm{G}) 60-\mathrm{Hz}$ magnetic field induces an electric field of around $0.7 \mathrm{mV} / \mathrm{m}$ in a person's abdomen (Kaune 1986:18). In comparison, a 10 $\mathrm{kV} / \mathrm{m}$ electric field induces an internal electric field of around $13 \mathrm{mV} / \mathrm{m}$.

It should be noted that current pathways in an organism caused by a magnetic field (called eddy currents) are different from those from an electric field. The magnetically induced body current flows primarily in peripheral loops perpendicular to the field, and current at the center of a body is near zero (Janes 1980). Most early interest in transmission line fields was concerned with the electric rather than the magnetic field component.

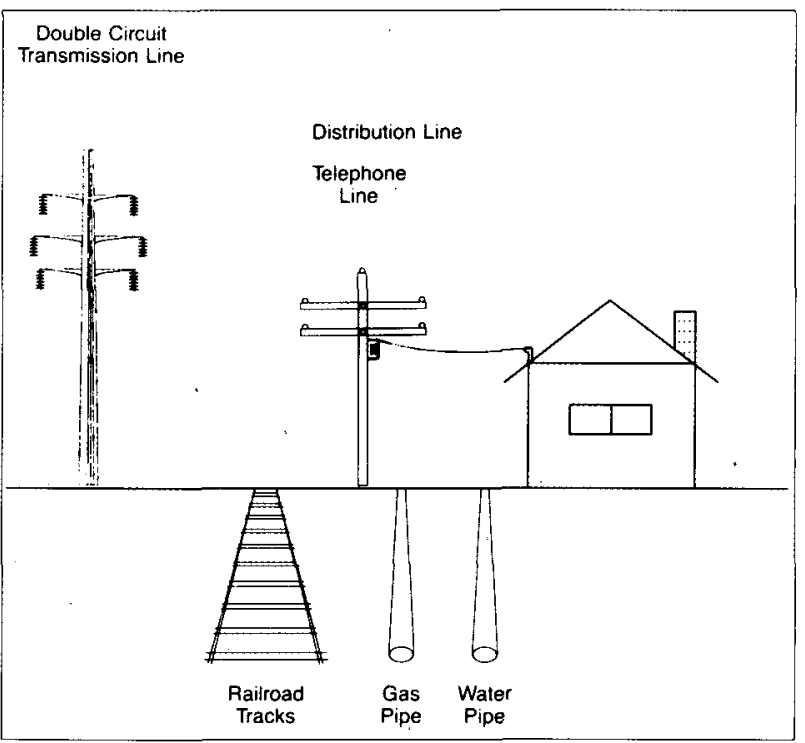

FIGURE 13. Magnetic fields inside homes are due to wiring and appliances and outside sources. Outside sources include electrical current in powerlines and currents induced by the lines in pipes, railroad tracks, and telephone lines. Ground return currents from the power system are also important sources of magnetic fields (adapted from MFTF 1988).

\section{Induced Currents and Voltages}

Magnetic fields can induce voltages at the open ends of long, partially grounded conducting loops such as fences, irrigation pipes, and distribution lines parallel to transmission lines. Normally, one end of the conductor is grounded and the earth serves as the remainder of the loop. A person or animal that closes the loop can experience steady state or spark discharge shocks.

Threshold and let-go levels are the same as for electric field coupled currents. Magnetically induced voltages usually 
are lower and the current higher than in the electric field case. Here again, proper grounding of objects near transmission lines prevents shocks. Grounding is very effective because objects long enough to create a hazard are usually permanent. For long parallel metal objects, such as fences, it may be necessary to break the electrical continuity. Further discussions of practical problems and safeguards appear in an IEEE paper (IEEE Working Group 1973) and in papers by Jaffa (1981) and Jaffa and Stewart (1981).

\section{Perception Effects}

Humans cannot perceive the $60-\mathrm{Hz}$ magnetic fields produced by transmission lines. An extensive study involving 200 people found that they could not perceive magnetic fields more than 30 times stronger than those beneath transmission lines (Tucker and Schmitt 1978).

Very strong a-c magnetic fields, $10 \mathrm{mT}(100 \mathrm{G})$ or more, can cause a flickering sensation in human vision (Tenforde 1985). However, the effect, called magnetophosphenes, disappears when the field is removed and there are apparently no reported harmful effects on the visual system.

\section{Potential Long-Term Health Effects}

Although the short-term shocks and perception described above are recognized and fairly well understood, questions have been raised as to whether there are long-term health effects from exposure to electric and magnetic fields. This section presents a comprehensive overview of issues and research findings. Conclusions from recent scientific reviews of research on electric and magnetic fields are found in Appendix B. BPA's response to this body of information, in the form of interim guidance, is given in Appendix $C$.

\section{Background}

Most of the interest that first developed about possible longterm health effects can be traced to three sources: (1) Soviet reports in the 1960's about health problems experienced by men working in 400-kV and 500-kV switchyards (Asanova and Rakov 1966); (2) popular literature critical of the ways transmission lines were constructed and operated (e.g., Young 1974); and (3) some early laboratory studies that attributed adverse biological effects to electric fields (e.g., Marino et al. 1976).

Reports on the Soviet switchyard studies were first given wide distribution during an International Conference in 1972 (Korobkova et al. 1972; related papers in Knickerbocker 1975). The Soviet switchyard workers were exposed to $50-\mathrm{Hz}$ electric fields with intensities of from 2 to 26 $\mathrm{kV} / \mathrm{m}$. The reported effects included such things as headaches, fatigue, reduced sexual potency, and a number of other changes among a high electric-field exposure class as compared with a low exposure class. As a result, regulations were established for Soviet substation workers that allowed unlimited exposure to fields less than $5 \mathrm{kV} / \mathrm{m}$ and limited exposure times in fields higher than $5 \mathrm{kV} / \mathrm{m}$.

Other than reports involving some substation workers in Spain (Fole 1972, Fole et al. 1974), the complaints by Soviet workers have generally not been reported for substation workers in other countries, including those at BPA. The Soviet effects remain speculative because of the difficulty of showing a direct causal relationship in a complex work environment.

In addition to the Soviet substation studies, research conducted by Drs. Marino and Becker in the U.S. were referenced by some as evidence that transmission line electric fields are hazardous. While with the Veterans Administration Hospital in Syracuse, New York, these researchers conducted studies of rodents exposed to electric fields. In fields of $15 \mathrm{kV} / \mathrm{m}$, reported effects included decreased growth, increased mortality, and changes in blood composition. The researchers stated, however, that shocks received by animals when drinking or eating may have been responsible for at least some of the effects (Marino et al. 1976:566).

The research of Marino et al. did indicate the need for further research to resolve inconclusive or contradictory research findings. Many research projects involving electric fields have now been done, and others are still underway. In the United States, most of this research has been sponsored by the U.S. Department of Energy (DOE), the Electric Power Research Institute (EPRI), and various utilities (DOE/EPRI 1988). The State of New York sponsored a program of 16 studies which involved both electric and magnetic fields (Ahlbom et al. 1987). The DOE and EPRI programs have now been expanded to include magnetic field studies.

To date, these research programs have not confirmed any hazardous effects of electric or magnetic fields. However, several biological effects of these fields have now been documented. Research is ongoing to determine the mechanisms for these effects and to determine whether any are of potential significance in terms of human health.

\section{Literature Reviews}

When BPA completed the first version of this review in 1975, major research projects involving $60-\mathrm{Hz}$ fields were just beginning. Only a handful of literature reviews had been published. By 1989, a large number of reviews of the "biological effects" literature had been published.

Appendix $B$ presents a summary of the most recent (since 1985) reviews of the literature involving biological effects of electric and magnetic fields. Most reviews concluded that electric and magnetic fields such as those produced by transmission lines have not been shown to be a health hazard to people or animals. Because of the uncertainty in the research findings, a number of reviews have included 
cautionary recommendations for measures to limit human exposures to electric and magnetic fields.

Because the number of studies is large, it is not practical to cover all of them in a review of this type. The sections below summarize the most often cited earlier research, and describe the most recent studies involving effects of electric and magnetic fields on plants, insects, wildlife, livestock, laboratory animals, and people.

\section{Plants}

The possible effects of electricity on plants have been studied since the 18th century (Wheaton 1970, Diprose et al. 1984). Most of the early interest was in the possible use of electricity to increase crop yields. Some investigators claimed big increases in crop production by exposure to ac and d-c fields and currents. Others, however, using similar methods, could find no effects. Many of the early studies were poorly controlled and technical details of the electrical test setups were sketchy.

Laboratory Studies. Beginning in the mid-1970's, research programs were initiated specifically to investigate the possible effects of $60-\mathrm{Hz}$ electric fields on plant growth. A team of researchers from the Westinghouse Electric Corporation and Pennsylvania State University studied 85 plant species grown in a laboratory while exposed to electric fields of up to $50 \mathrm{kV} / \mathrm{m}$ (Bankoske et al. 1976, McKee et al. 1978). This group later studied crops (alfalfa, fescue, corn, wheat) grown in a greenhouse in a $30-\mathrm{kV} / \mathrm{m}$ field (McKee 1985). Sharp-pointed plant parts on some species exhibited minor tip damage beginning at field intensities of 15 to $20 \mathrm{kV} / \mathrm{m}$. The strength of an electric field is greatly enhanced around a sharp-pointed conducting object such as a grass leaf because the field lines of force are drawn to and converge around such objects. If the field is strong enough, corona can occur, producing heat and drying of leaf tips. In contrast, rounded plant parts were not damaged by even the $50-\mathrm{kV} / \mathrm{m}$ fields. Overall, germination and plant growth and productivity were not affected by electric fields over five times stronger than those found beneath BPA transmission lines.

In a laboratory study at the University of Rochester, effects of an electric field on root growth were studied (Miller et al. 1979). Electrodes were placed in the water medium containing the roots. A $40-50$ percent decrease in growth was detected at field strength levels of 360 to $430 \mathrm{~V} / \mathrm{m}$ in the water medium.

The researchers pointed out that it is impossible to induce electric fields of this strength in water or soil if the electrode is in air, because the required fields would exceed the breakdown strength of air. Obviously, transmission line electric fields could not cause such fields around plant roots because transmission conductors are located in the air.
The effects found in the University of Rochester studies are believed due to a decrease in root-cell elongation rather than to any change in the proportion of cells in mitosis (Brulfert et al. 1985). The studies also suggest that normal cell membrane functions are altered but not blocked by the strong electric fields.

Another laboratory study reported that a $1-\mathrm{kV} / \mathrm{m} 60-\mathrm{Hz}$ field had no effect on germination rate of sunflower seeds but that a $5-\mathrm{kV} / \mathrm{m}$ field seemed to reduce the rate by an average of 5 percent (Marino et al. 1983). However, the effect was observed in only 4 out of 11 replicates of the study. Although the effect was small and inconsistent, the researchers concluded that plant physiology can be altered by weak fields involving non-thermal mechanisms (other than air ionization).

Field Studies. Studies have also been done of plants growing near transmission lines. The American Electric Power System sponsored research conducted by Purdue University and the University of Notre Dame (Hodges et al. 1975, Hodges and Mitchell 1979, Greene 1979, Roy and King 1983, Hodges and Mitchell 1984). Corn and other crops commonly grown in Indiana were studied near 765$\mathrm{kV}$ lines in electric fields up to $12 \mathrm{kV} / \mathrm{m}$, and near a UHV test line in a field reaching $16 \mathrm{kV} / \mathrm{m}$. Overall results of the studies indicated that the transmission lines had no noticeable influence on the growth or productivity of the crops. Some crops growing in the maximum electric field area of the test line had some leaf tip damage from induced corona. However, overall plant growth was not impaired.

Greene (1983) studied mitotic activity (cell division) in the tips of onion roots grown in containers beneath the UHV test line in Indiana. He concluded that this activity was not affected by exposure to air electric fields of $15.5 \mathrm{kV} / \mathrm{m}$ for 15 days.

By contrast, research in Tennessee indicated that corn grown beneath a 500-kV line showed lower yields in electric fields of up to $8.5-\mathrm{kV} / \mathrm{m}$, compared to corn grown in plots shielded from the field (Hilson et al. 1983). However, other crops (cotton, soybeans, clover) and trees (tulip poplar, loblolly pine) showed no effects. The researchers concluded that data for the corn study were insufficient to reach definite conclusions and that further investigation was warranted.

Parsch and Norman (1986) published a brief report on a study of crop growth near a 500-kV transmission line in Arkansas. No differences in yields of rice and soybeans were found between crops growing under the line and crops growing away from the line. Cotton yield was about 15 percent less under the line. The authors could not determine whether the effect was related to electric or magnetic fields, or to ineffective aerial application of agricultural chemicals to crops near the line. 
BPA sponsored long-term research involving plants growing near a 1200-kV prototype line in western Oregon (Rogers et al. 1980, Warren et al. 1981, Lee and Clark 1981, Rogers et al. 1982). The research, conducted by Battelle Pacific Northwest Laboratories, included trees, shrubs, grasses, and crops. Branches of some trees purposely left growing as close as $12 \mathrm{~m} \mathrm{(40} \mathrm{ft)} \mathrm{to} \mathrm{the} 1200-\mathrm{kV}$ line were damaged by induced corona (Figure 14). Height growth in alder and Douglas-fir trees purposely planted directly beneath the line was also reduced, as corona damaged branch tips (Rogers et al. 1984a).

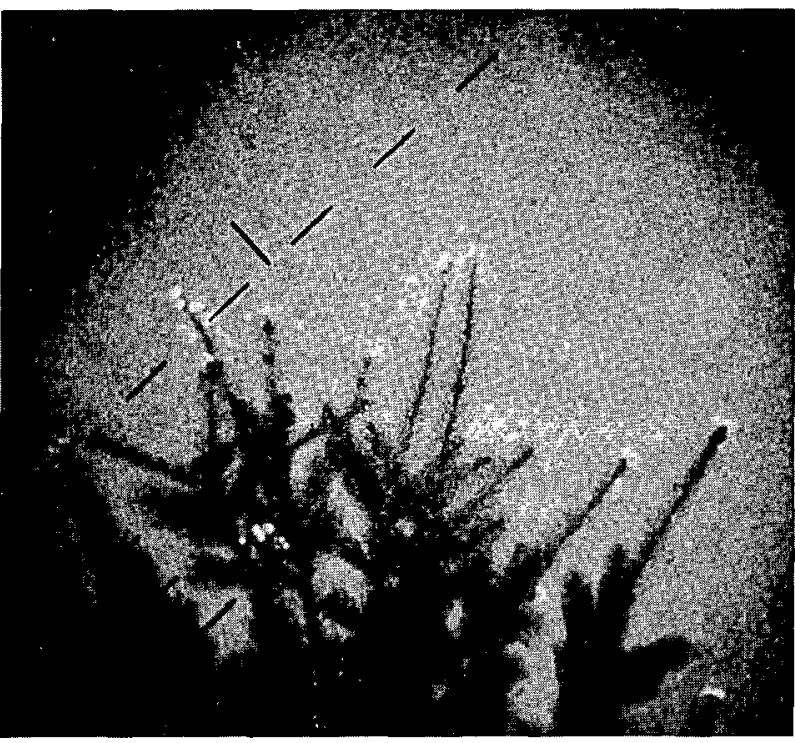

FIGURE 14. Induced corona on a Douglas-fir tree purposely left growing close to the BPA 1200-kV prototype line. The same effect also occurs if trees grow too near $500-k V$ or 765-kV lines. Photograph taken with a night vision device.

This "self-pruning" effect has also been found in trees that grew too close to 500-kV and 765-kV lines (Zaffanella and Deno 1978, Miller and Kaufman 1978). For the 1200-kV line, slight damage was noted in treetops as far as $18 \mathrm{~m}$ $(60 \mathrm{ft})$ from the line. For a commercial $1200-\mathrm{kV}$ line, trees within this distance would likely be removed during construction of the line. Shrubs growing beneath the 1200-kV line were not affected by the electric field.

Barley and peas were grown under the $1200-\mathrm{kV}$ line in plastic tubes (lysimeters) filled with uniform soil mixtures (Figure 15). Electric field strength during 5 years of study ranged between 7 and $12 \mathrm{kV} / \mathrm{m}$. Although weather and natural variability accounted for wide differences in crop production among the years, no consistent differences were found to indicate that the $1200-k V$ line affected plant growth. Germination studies showed no effects of the line on the viability of pea and barley seeds.

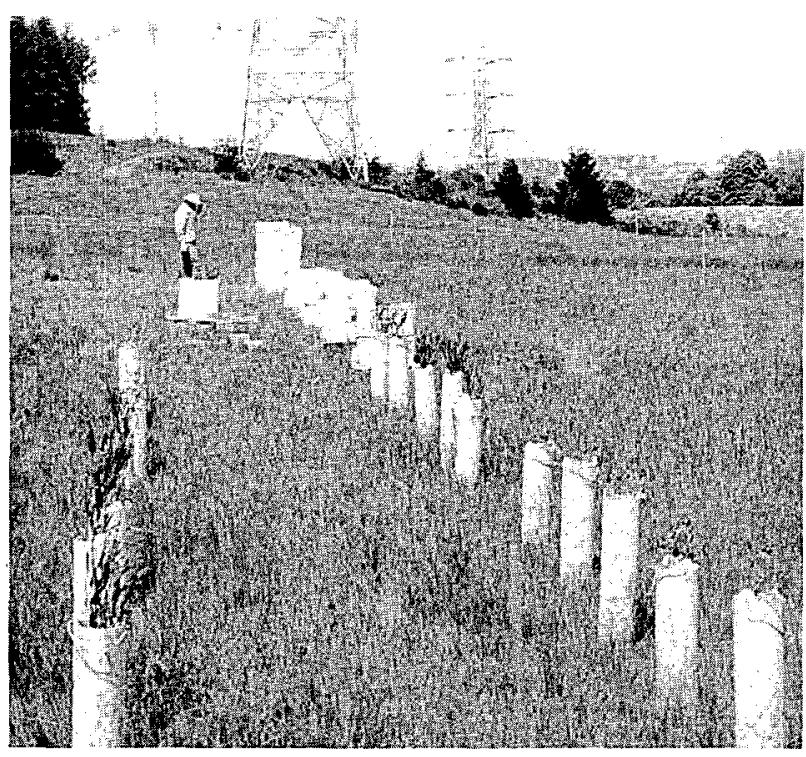

FIGURE 15. An electric field of up to $12 \mathrm{kV} / \mathrm{m}$ from a $B P A$ $1200-\mathrm{kV}$ prototype line had no effect on the overall growth of barley and peas. Plants were grown in plastic tubes (lysimeters) so that uniform soil mixtures could be used.

Growth of pasture grasses beneath the $1200-\mathrm{kV}$ line was not inhibited by electric fields of up to $12-\mathrm{kV} / \mathrm{m}$ (Rogers et al. 1984b). Growth was compared among plants shielded by wire mesh from the field, plants covered by simulated shielding, and plants exposed directly to the field.

Finally, researchers in Japan also found no effects of a 7.7$\mathrm{kV} / \mathrm{m}$ field on growth of wheat (Endo et al. 1979). The plants were grown in pots beneath an outdoor test line.

As described above, fields produced by transmission lines do not affect the growth of crops and other low-growing vegetation. Tree branches allowed to grow near conductors can be damaged by induced corona from strong electric fields, although overall tree growth and survival apparently is not decreased.

\section{Insects}

Almost all work involving insects and powerlines has involved honeybees. In the early 1970 's, reports from Europe indicated that powerlines had caused harmful effects in honeybee colonies in wooden hives under the lines (e.g., Wellenstein 1973). To date we are not aware of any documented cases where BPA commercial lines have caused problems for beekeepers. 
Because of the reported effects on bees, both BPA and the Electric Power Research Institute initiated research with honeybees in 1977. The BPA study was part of the 1200kV research program conducted by Battelle Northwest (Rogers et al. 1982) (Figure 16). The EPRI study was done by Bioconcern near a $765-\mathrm{kV}$ line in Illinois (Greenberg et al. 1981).
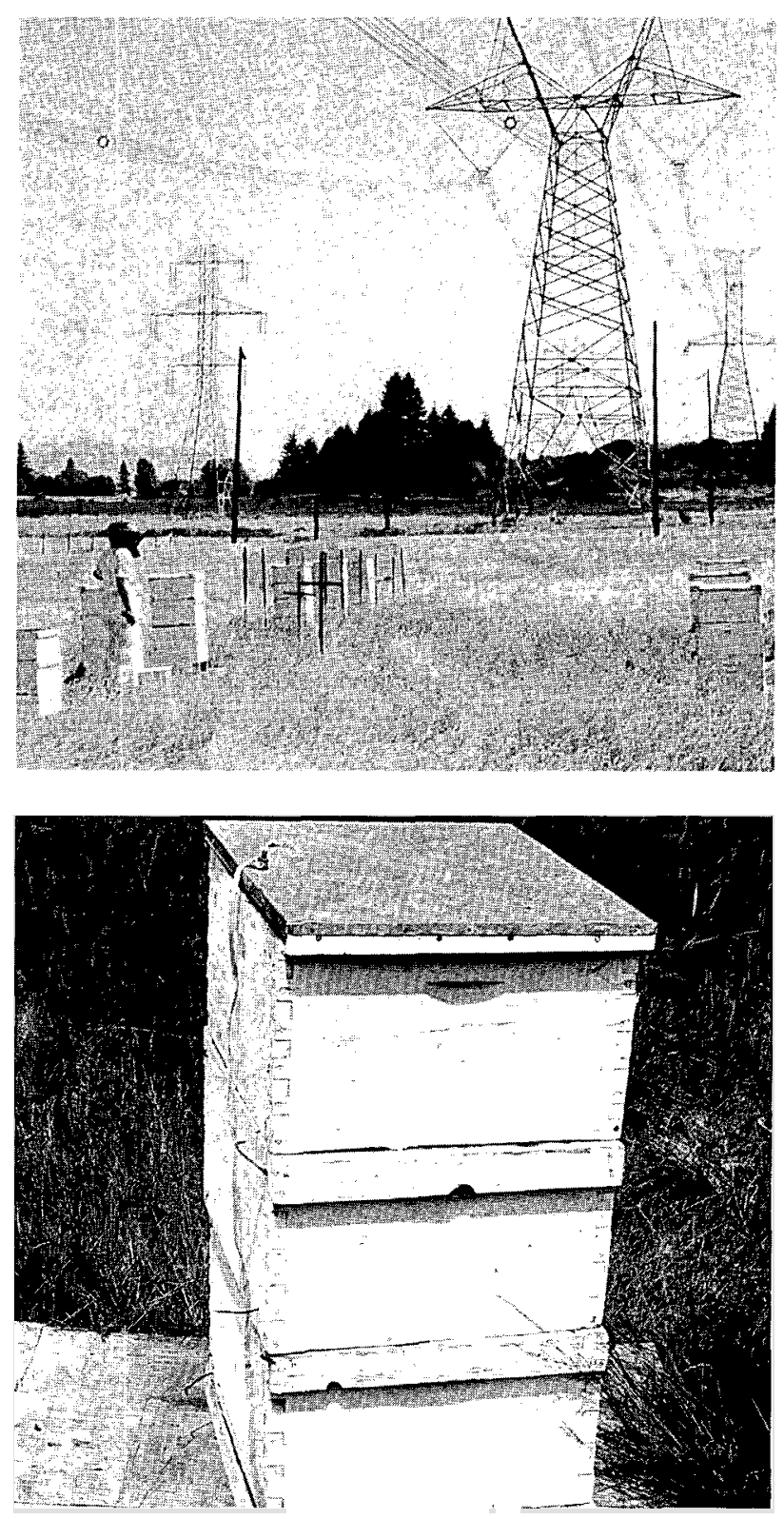

FIGURE 16. Studies of the BPA 1200-kV prototype line showed that electric fields can adversely affect honeybee colonies inside wooden hives. Effects can be mitigated by placing grounded wire screen (top, center) over the hives, or by attaching a ground wire to a standard metal hive lid (bottom). These measures greatly reduce the amount of current induced inside the hive.
Both studies confirmed that transmission line electric fields can affect honeybees inside wooden hives. A most noticeable effect was excessive propolization within the hive. Propolis is a resinous material, normally collected from various plants and used as a sealer by bees. There were also decreases in colony weight gains, increased irritability and mortality, and poor over-winter colony survival.

Since wood is not a perfect insulator, a current is induced in a wooden hive placed in an electric field, whether there are metal parts in the hive or not. The strength of the current is influenced by the electric field strength, hive height, and moisture conditions. Long-term automatic monitoring at the BPA $1200-k V$ prototype site showed that current in a given hive varies daily and seasonally. Some effects become noticeable when induced current exceeds 0.02 to $0.04 \mathrm{~mA}$. Depending on hive height, this can occur in field strengths between 2 and $4 \mathrm{kV} / \mathrm{m}$. Effects are most evident in electric fields of 7 to $12 \mathrm{kV} / \mathrm{m}$.

The effects found in honeybee colonies are most likely caused by frequent shocks experienced by bees while inside the hive (Greenberg et al. 1985, Bindokas et al. 1988). The effects can be prevented by placing a grounded wire screen over the hive, which greatly reduces the electric field and current flow through the hive. The use of a standard metal hive cover, connected by wire to a ground rod, also mitigated effects on a colony placed beneath the 1200-kV prototype.

The shielding studies indicated that the effects were not caused by the bees flying through an external electric field of up to $11 \mathrm{kV} / \mathrm{m}$. Greenberg et al. (1981) also concluded that a $7-\mathrm{kV} / \mathrm{m}$ field outside the hive had no impact on colonies shielded by wire. In a related study, the electric field did not prevent insects from pollinating clover planted beneath the 1200-kV line (Warren et al. 1981). The study design could not reveal subtle effects, if present, on pollination.

Although a-c transmission line electric fields can affect honeybee colonies, the magnetic field appears to have no significant effect. This was shown in a study of a $765-\mathrm{kV}$ line in which grounded wire screen was placed over hives to eliminate the electric field (Greenberg et al. 1981). The magnetic field easily penetrates the screened hive. The performance of honeybee colonies in the screened hives under the line was no different than that of colonies in the control area.

The effects found in the BPA and EPRI-sponsored studies have, to our knowledge, not generally been reported by beekeepers in the United States. As a precaution, BPA recommends that bee hives not be placed on a 500-kV rightof-way, especially near mid-span between towers where the electric field is strongest. If for some reason a person wants to locate hives near such lines, BPA will provide information on methods for mitigating the kind of effects found in the research described above. 


\section{Wildlife}

This section addresses the possible effects of electric and magnetic fields on wild birds, mammals, and fish. Almost all the research involving wild ife has consisted of studies of transmission lines in natural environments. Emphasis in most of the studies involving powerlines was on the effects of the right-of-way, and only rarely was specific attention given to possible field effects (see papers in Arner and Tillman 1981, and Crabtree 1984). However, this research does suggest that, compared to effects of construction and maintenance, any effects of electric and magnetic fields on wildlife are subtle and difficult to identify (Lee et al. 1979).

In the typical situation where mammals or birds are within or beneath vegetation, that vegetation largely shields them from a transmission line electric field. When mammals such as deer and elk move through areas of low-growing vegetation, they may be subject to induced body currents, shocks, and perception effects. Because the larger animals are normally grounded to a degree through their feet, it is unlikely that they experience shocks in these fields. It is possible that some wildlife species are able to detect weak induced currents. Based on studies with laboratory animals, wild life may be able to detect electric fields through such means as hair or feather stimulation (e.g., Cooper and Graves 1981, Stern and Laties 1982). Research to date, however, has not shown that these fields adversely affect wildlife behavior or health.

Mammals. Goodwin (1975) observed no apparent effects of the electric or magnetic field of a 500-kV line in Idaho on movement of deer and elk. Some animals were attracted to the cleared right-of-way for feeding. However, during the hunting season, game animals tended to avoid the right-ofway and other similar clearings during daylight.

Schreiber et al. (1976) examined the effects on small mammals of a right-of-way in Tennessee containing two $500-\mathrm{kV}$ lines. In hardwood forests, small mammals were more abundant on the cleared right-of-way than in the adjacent forest. In pine forests, the reverse occurred. In both areas, the right-of-way was used by some species not present in the adjacent forest. Use of the various areas by small mammals appeared to be strongly influenced by vegetation composition and distribution, which affects cover and food availability.

Small mammals were studied for several years as part of a research program for the BPA $1200-k V$ prototype (Rogers et al. 1980, Warren et al. 1981). No adverse electric field effects on mammals were found. Animals were most abundant on the right-of-way and in the nearby control areas during the first 2 years of construction and operation. Mammal abundance on the right-of-way and control areas declined in subsequent years. After initial right-of-way clearing, tall brush had become re-established on the rightof-way, thus shielding small mammals from the electric field.
Birds. Studies of song birds near transmission lines also indicate that vegetation on the right-of-way, rather than electric or magnetic fields, is the primary factor influencing usage and behavior (e.g., Rogers et al. 1980, Anderson et al. 1977, Kroodsma 1984). Far birds, however, some additional considerations arise.

Where transmission lines cross open country, some birds such as hawks and eagles often use the towers for perching and nesting (Howard and Gore 1980). Although there are some shielding effects from tower parts, birds nesting on these structures can be exposed to electric fields for long periods. Birds nesting on BPA lines have been studied to determine whether there are harmful effects from the energized line. A sample of hawks nesting on 500-kV and 230$\mathrm{kV}$ line towers produced about the same average number of young as were reported for hawks nesting in trees and cliffs (Lee 1980) (Figure 17).

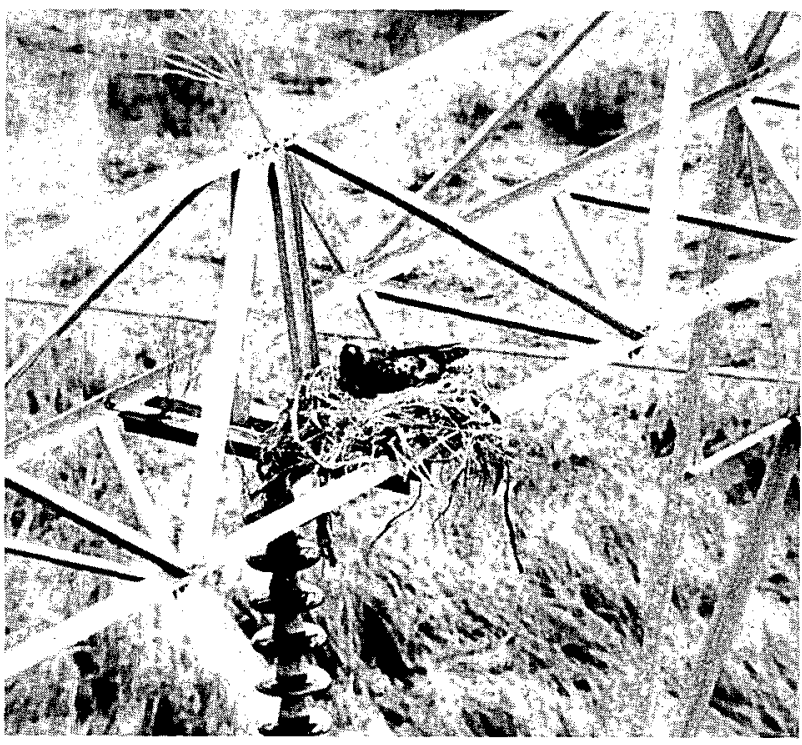

FIGURE 17. Hawks nesting on BPA 500-kV transmission towers produce about the same average number of young as hawks nesting on trees and cliffs.

Large birds such as eagles can be electrocuted if they contact a conductor and grounded hardware, or if they contact two conductors (different phases). These problems are generally associated with distribution lines of $12 \mathrm{kV}$ to $69 \mathrm{kV}$ (Olendorff et al. 1981). Transmission line conductors are usually far enough away from other conductors or hardware so that bird electrocutions seldom occur. Special line designs have been developed for protecting raptors and other birds from power-line electrocutions. These are described in a report distributed by the Raptor Research Foundation (Olendorff et al. 1981). 
Some studies have produced evidence indicating that birds can perceive a-c magnetic fields at strengths comparable in magnitude to those of the earth's $d$-c fields (e.g., Larkin and Sutherland 1977). Whether such fields disrupt avian flight orientation, provide environmental location information to flying birds, or have no effect at all is not clear. During migration, birds must routinely fly over probably hundreds (or thousands) of electrical transmission and distribution lines. We are not aware of any evidence to suggest that such lines are disrupting migratory flights.

Research on bird collisions with BPA transmission lines does not suggest that transmission line magnetic and/or electric fields cause noticeable disorientation in flying birds. Most waterfowl and other birds during low altitude flight typically react to the presence of transmission lines by altering flight direction or altitude to avoid colliding with the lines (Lee 1978, Meyer and Lee 1981, Beaulaurier et al. 1984).

Fish. Some fish are known to be sensitive to very weak, low-frequency electric and magnetic fields in water. Sharks and some other species have special organs (ampullae of Lorenzini) for detecting biofields from other fish and probably the earth's fields (Kalmijn 1966). For example, skates were shown to respond to $5-\mathrm{Hz}$ square wave fields of only $0.001 \mathrm{mV} / \mathrm{m}$, and stingrays oriented to uniform electric fields as small as 500 nanovolts $/ \mathrm{m}$ ( 1 nanovolt $=$ onebillionth of a volt) (Kalmijn 1982).

American eels and Atlantic salmon reportedly can also perceive low frequency electric fields of 7 to $70 \mathrm{mV} / \mathrm{m}$ (McCleave et al. 1974). However, 45 to $75-\mathrm{Hz}$ electric fields up to $20 \mathrm{~V} / \mathrm{m}$ had little, if any, effect on behavior of bluegill fry (McCleave et al. 1974, Coate et al. 1970).

A $10 \mathrm{kV} / \mathrm{m}$ transmission line electric field in air would produce a field in water of around $1 \mathrm{mV} / \mathrm{m}$ (Miller and Kaufman 1978). This field tends to be even less because conductor clearances are often higher than minimum over navigable waters. Also, streams and rivers are often in a narrow topographical depression and thus partially shielded. In this last situation, support towers may be located at higher elevations, resulting in large conductor clearances over the water.

\section{Livestock}

Utility operating experience and results of research generally show that transmission line electric fields do not affect livestock behavior or health (Lee and Reiner 1983). Livestock of all types can often be seen feeding or resting beneath transmission lines.

Occasionally utilities receive reports that a transmission line was related to some livestock illness or death. Typically, when these reports are investigated, or when livestock owners are surveyed, no evidence is found to substantiate such reports (Ware 1974, Busby et al. 1974).
A comprehensive study of livestock living near a $765-k V$ line in Indiana was sponsored by American Electric Power Service Corporation (Figure 18). Included in the study were beef and dairy cattle, sheep, hogs, and horses on 11 farms. Farmers were interviewed bi-monthly and periodic inspections were made by a veterinarian. The $765-\mathrm{kV}$ line produced electric fields on some of the farms of up to $12 \mathrm{kV} /$ $\mathrm{m}$. The study found no evidence that health, behavior, or performance of livestock were affected by electric fields (Amstutz and Miller 1980).

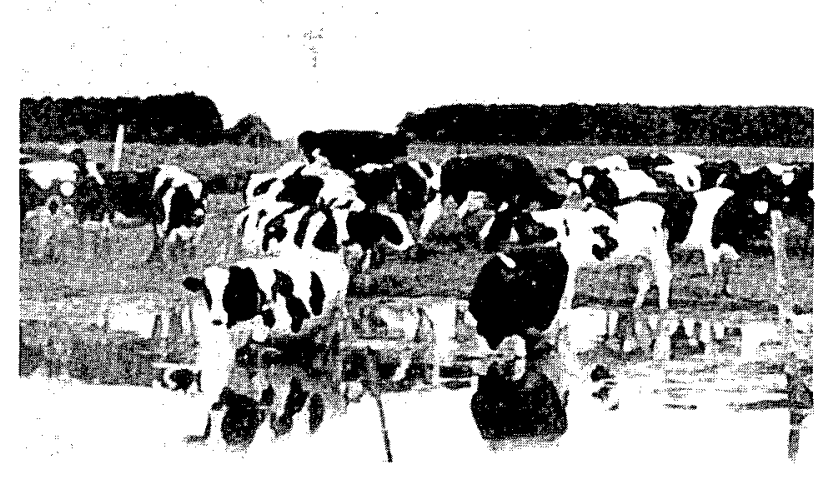

FIGURE 18. Studies in the Midwest have found no effects of electric fields on dairy cattle and other livestock.

A 6-year-long study in Ohio investigated 55 dairy farms located near 765-kV lines (Williams and Beiler 1979). There was no indication that the presence of the lines had any long-term effects on milk production. After the lines had been constructed, the incidence of calf mortality and birth defects per farm increased. The researchers believed this may have been a reflection of a trend for larger herd sizes per farm during the study period. The dairymen interviewed during the study believed there was no evident change in health problems after the lines were energized.

Research in Sweden involved cattle near 400-kV lines. Studies were prompted because of reports that cattle fertility decreased on two farms following energization of 400-kV lines (Algers et al. 1981). In pilot studies involving 36 herds near $400-\mathrm{kV}$ lines and where artificial insemination was used, no effects on cattle fertility were found compared to a control group. A larger study was conducted that involved 106 farms throughout Sweden (Hennichs 1982). The study, conducted primarily by mail survey, 
found that, on the average, cows exposed to $400-\mathrm{kV}$ lines for more than 15 days per year did not have decreased fertility. The maximum electric field strength beneath 400 $\mathrm{kV}$ lines measured on 11 farms in Sweden was $5 \mathrm{kV} / \mathrm{m}$ (Algers et al. 1981).

To obtain more definitive information on fertility, Swedish researchers conducted an experimental study (Algers and Hultgren 1987). Fifty-eight cows were placed in pens crossed by a $400-k V, 50-\mathrm{Hz}$ transmission line. Another 58 cows were maintained in control areas away from the line. During the 120-day exposure period, the electric field averaged $4 \mathrm{kV} / \mathrm{m}$, and the average magnetic field was $2 \mu \mathrm{T}$ $(20 \mathrm{mG})$. Breeding was done with artificial insemination. None of the fertility parameters studied were affected by exposure to the 400-kV line. These included the estrous cycle, number of inseminations per pregnancy, and conception rates.

In lowa, a study was done of crossbred swine purposely raised beneath a 345-kV transmission line (Mahmoud and Zimmerman 1983). The line produced a maximum electric field of $4.2 \mathrm{kV} / \mathrm{m}$. The behavior and performance of 30 swine under the line over a 91-day period was compared to those of 30 control animals located away from the line. No effects of the line were found on body weight, carcass quality, behavior, or feed intake. A second phase of the swine study involved reproduction. Findings indicated no effect of the 345-kV line on pregnancy rate, frequency of birth defects, or on weight gain of young (Mahmoud and Zimmerman 1984).

Each summer during 1977-1981, cattle behavior was studied near the BPA 1200-kV prototype line (Figure 19). Each year five different steers were placed in a pasture where the animals could range both beneath and away from the line. The location of the cattle throughout the day was monitored with time-lapse cameras. Forage, salt, and water consumption were also measured. The line was alternately deenergized and energized at times during the study. The animals showed no reluctance to graze or drink beneath the line, which produced a maximum field of $12 \mathrm{kV} / \mathrm{m}$. A refined statistical analysis of the $1980-81$ data indicated the cattle spent somewhat more time near the line when it was deenergized (Rogers et al. 1982). This may or may not indicate a transient effect of audible noise and/or the electric field. During the 1980 study of the $1200-k V$ line, one steer died of a bacterial infection. The other cattle studied, in this and other years, remained healthy and no abnormal conditions developed.

Although not a transmission line electric field effect, "stray voltages" on equipment in barns have been found to affect adversely the health and production of dairy cows and other livestock (Gustafson and Albertson 1982). The sources of the voltages, which result in annoying shocks, include ground faults, improper wiring, and unbalanced loads on electrical distribution systems. Methods are available for identifying the sources and for mitigating problems caused by stray voltages (Surbrook and Reese 1981).

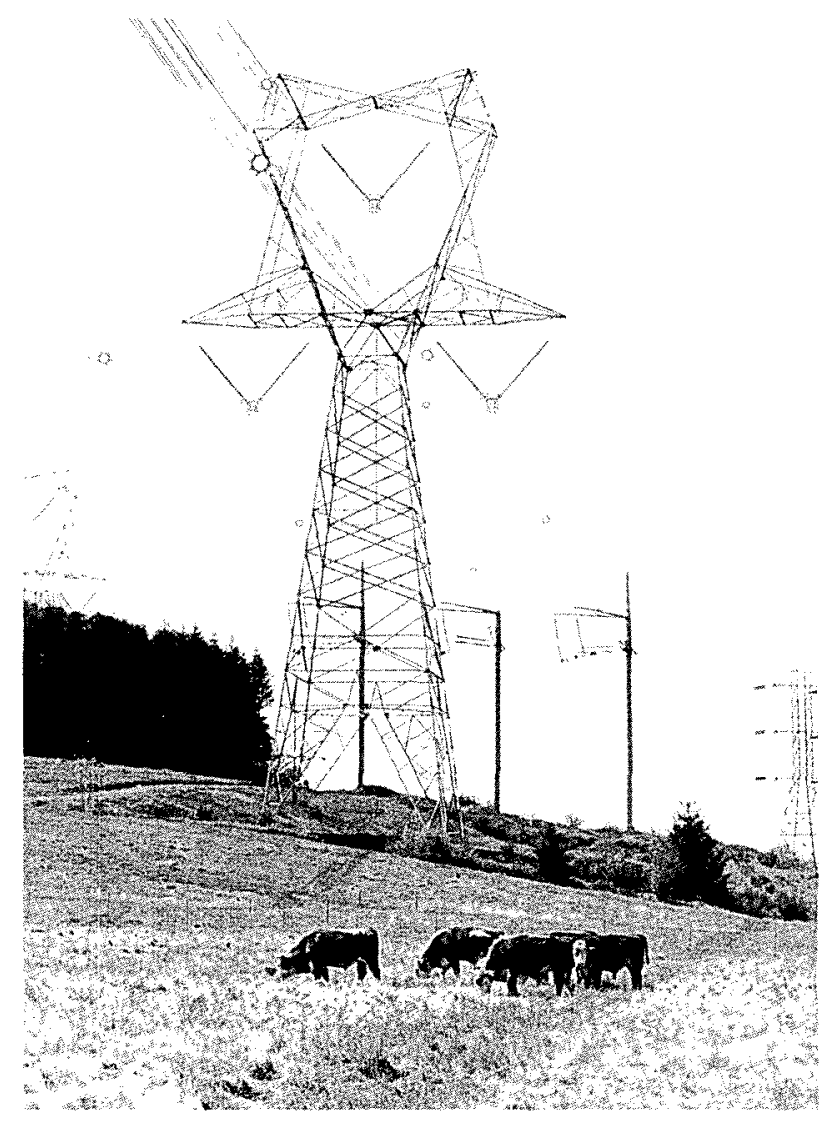

FIGURE 19. Cattle showed no reluctance to drink or graze beneath the 1200-kV prototype line.

\section{Laboratory Animals}

Experimental Considerations. The research described in the sections above often involved transmission lines in a variety of environmental settings. However, it may be difficult to determine which of several factors may have been related to any observed effects. An additional approach is to isolate one factor (e.g., the electric or magnetic field) and conduct a study in a laboratory where other factors are eliminated or controlled.

Before discussing results of laboratory studies, it is important to point out some basic concepts. As mentioned earlier, the presence of animals or people perturbs (distorts) an electric field. Figure 20 shows a person and two kinds of animals standing in a $10-\mathrm{kV} / \mathrm{m}$ electric field. Note that the electric field is concentrated on the uppermost body parts, especially near a person's head. The current density induced in the person (e.g., average through the chest) is also higher compared to animals. The electric field strength cited in most studies is the unperturbed value, i.e., the value before the study animal is placed in the field. 


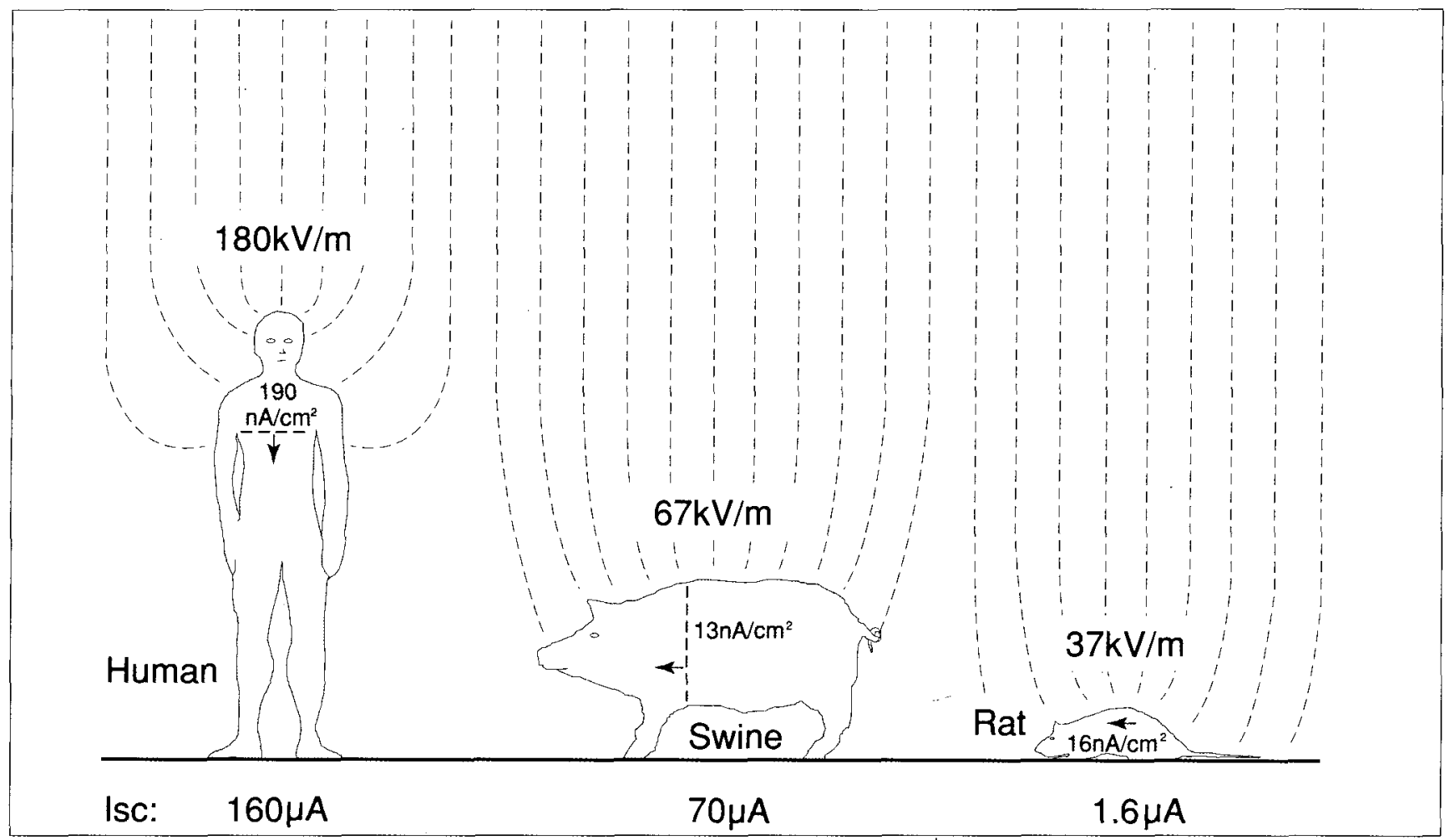

FIGURE 20. Lines of force in an electrical field $(e . g ., 10 \mathrm{kV} / \mathrm{m})$ are concentrated on upper body parts, which intensifies the electric field at the body surface (values above each figure). Internal body current densities (e.g., through $1 \mathrm{~cm}^{2}$ of the chest) and total short-circuit current $\left(l_{s d}\right)$ through the body are also influenced by body size and shape ( $1 n A=1$ billionth of an ampere, $1 \mu A=$ 1 millionth of an ampere) (source: Kaune and Phillips 1980).

Because animals do not perturb magnetic fields, the field inside the animal is the same as the external field regardless of body shape or position. However, in terms of magnetically induced electric fields, body shape and size is a consideration. Dr. William Kaune of Enertech Consultants calculated that magnetically induced electric fields in the rat and the mouse are, respectively, 5.6 and 12 times smaller than those in a human, for a given external field strength. Therefore, to achieve induced electric fields in rodents comparable to those induced in humans by a given magnetic field, stronger external fields would be needed for the rodents.

Plastic rodent cages slightly decrease the actual exposure of animals to the electric field (Free et al. 1981). Likewise, there is some shielding from electric fields when several animals are exposed close to each other.

Some researchers have acknowledged the field interaction concepts in order to select (scale) electric field levels used with laboratory animals. In the Battelle Northwest studies, for example, swine were exposed to unperturbed electric fields of $30 \mathrm{kV} / \mathrm{m}$, and rodents to fields of $100 \mathrm{kV} / \mathrm{m}$. To some degree, this reflects the situation (e.g., in terms of maximum surface electric field) where a person is standing beneath a $765-\mathrm{kV}$ line (in a 10-kV/m field) (Kavet 1982, Free et al. 1981). However, internal current densities and internal electric fields would not necessarily scale in the same relationship. In fact, it is not possible to duplicate human electric field exposure exactly using laboratory animals.

An animal's interaction with an electric field is also influenced by the design of cages and feeding and watering devices. Unless care is taken, animals can receive shocks inside the cage. Also, the possible production of noise, vibrations, or ozone from the electric field source must be considered. With proper methodology, these factors can be largely eliminated. These factors may have been present to varying degrees in the early research on $60-\mathrm{Hz}$ fields. A report by the National Bureau of Standards (now the National Institute of Standards and Technology) provided information on the proper techniques for generation and measurement of $60-\mathrm{Hz}$ electric fields in bioeffects laboratory studies (Misakian 1984).

When evaluating research results, it is important to consider the meaning of the word "effect." For example, 
consider what happens if a laboratory animal is suddenly exposed to a strange noise of low or moderate intensity. Several functional changes may occur in the animal. The pulse rate increases, and there may be a change in hormonal secretions to the blood, although both changes (i.e., effects) are within normal variation. If the noise stops or if it is not strong enough to cause continued arousal, the effect may disappear. On the other hand, if the noise is very loud, the effects on the animal may include pathological changes such as severe stress and impaired hearing. Both effects may be reported as statistically significant (i.e., greater in treatment animals compared to nonexposed control animals than would be expected by chance). However, the latter effect is also biologically significant (i.e., hazardous) because it affects the health of the animal.

These are only some of the many factors that have to be considered when evaluating results of laboratory studies. All published studies are not equal in terms of how they were designed and conducted. Similarly, their results are seldom directly comparable because certain details on methods may have been different or were not described. The results of many studies must be evaluated to reach some overall conclusion as to the potential effects of electric and magnetic fields (see the section on "Literature Reviews").

Early U.S. Studies. The first long-term laboratory study in the United States designed to investigate the possible effects of $60-\mathrm{Hz}$ electric fields was conducted at the Johns Hopkins University (Knickerbocker et al. 1967). Twentytwo male mice were exposed to a $60-\mathrm{Hz}$ electric field of $160 \mathrm{kV} / \mathrm{m}$ for 6.5 hours per day for $10-1 / 2$ months. For the exposed males, no effects were found in behavior, reproduction, or health. The males were mated with nonexposed females. The male offspring of the exposed males were, on the average, smaller in weight than the male offspring of the controls. The researchers said it was not clear whether the effect was caused by the electric field, and they recommended further research. The exposure system used in the study caused corona on the animals if they stood up on their rear legs. Also, animals apparently received shocks from the drinking water devices, so animals in the field were not given water during the daily 6.5hour exposure periods.

A number of studies were done in the late 1960's to assess the possible effects of the U.S. Navy's Submarine Communication Project Sanguine (renamed Seafarer and, more recently, ELF). Several laboratory studies were done using weak $45-\mathrm{Hz}$ and $75 \cdot \mathrm{Hz}$ electric fields up to 20 volts per meter $(\mathrm{V} / \mathrm{m})$ and relatively strong magnetic fields up to 0.2 $m T(2.0 \mathrm{G})$.

Some of the early Sanguine studies reported effects; others were inconclusive (Coate et al. 1970). The Sanguine/ Seafarer research was reviewed by a special committee set up by the National Research Council (CBEELFR 1977). The committee concluded that the electric and magnetic fields produced by the project would not cause any significant biological disturbance other than shocks. The submarine communication project has remained controversial and the U.S. Navy requested the American Institute of Biological Sciences to review the scientific literature published since the 1977 report. The conclusion of the AIBS review was consistent with the earlier NRC report (see Appendix B, AlBS Committee 1985).

Veteran's Hospital - Syracuse. Beginning in the 1970's, several American laboratory studies began that dealt with $60-\mathrm{Hz}$ electric fields comparable to those produced by transmission lines. Researchers with the Veteran's Administration Hospital in Syracuse, New York, conducted a pilot study of three generations of mice continuously exposed to electric fields up to $15 \mathrm{kV} / \mathrm{m}$ (Marino et al. 1976). Mice were allowed to breed, gestate, and give birth in the electric field. Compared to the controls, the exposed animals experienced higher mortality rates and slower growth. The researchers indicated that the effects may have been related to microcurrents and shocks from feeding and watering devices.

Another study by Marino et al. involved rats exposed to a $15-\mathrm{kV} / \mathrm{m}$ electric field for 1 month (Marino et al. 1977). In some of 10 experiments, water consumption and body weight were depressed, adrenal and pituitary gland weights increased, and blood components changed. The results were interpreted by the researchers as an indication that a $60-\mathrm{Hz}$ electric field is a biological stressor.

The stress concept was further evaluated in a study by Marino et al. (1979) of bone-fracture healing. A leg bone (fibula) was fractured in rats exposed to $1-\mathrm{kV} / \mathrm{m}$ and $5-\mathrm{kV} /$ $\mathrm{m}$ fields. At 14 days after fracture, rats in the $5-\mathrm{kV} / \mathrm{m}$ field showed a slower rate of healing compared to the control animals. The authors pointed out, however, that because the study terminated at 14 days, the eventual outcome of the bone healing process was not determined.

Battelle Pacific Northwest Laboratories. The most extensive long-term U.S. laboratory research involving $60-\mathrm{Hz}$ electric fields was conducted by the Battelle Pacific Northwest laboratories (Figure 21). The Battelle researchers took great care to eliminate or minimize secondary factors associated with electric field exposure, e.g., corona, ozone, vibration, noise, and spark discharge. A report described results of 20 studies in 12 major areas of investigation involving rats, mice, and chickens (Phillips et al. 1981).

No consistent effects were found in the Battelle studies of the heart and blood, of susceptibility to disease, growth and metabolism, and of overall hormone production. The latter included no significant change in serum corticosterone levels. Plasma testosterone concentration tended to decrease for male rats exposed to $100 \mathrm{kV} / \mathrm{m}$ for up to 120 days (Free et al. 1981). The researchers suggested that this may have been related to the fact that the animals' scrotums contacted the ground-plate electrode, possibly causing 
large current densities around the testes. They also stated that the few effects seen on the endocrine system did not threaten life or impair reproduction.

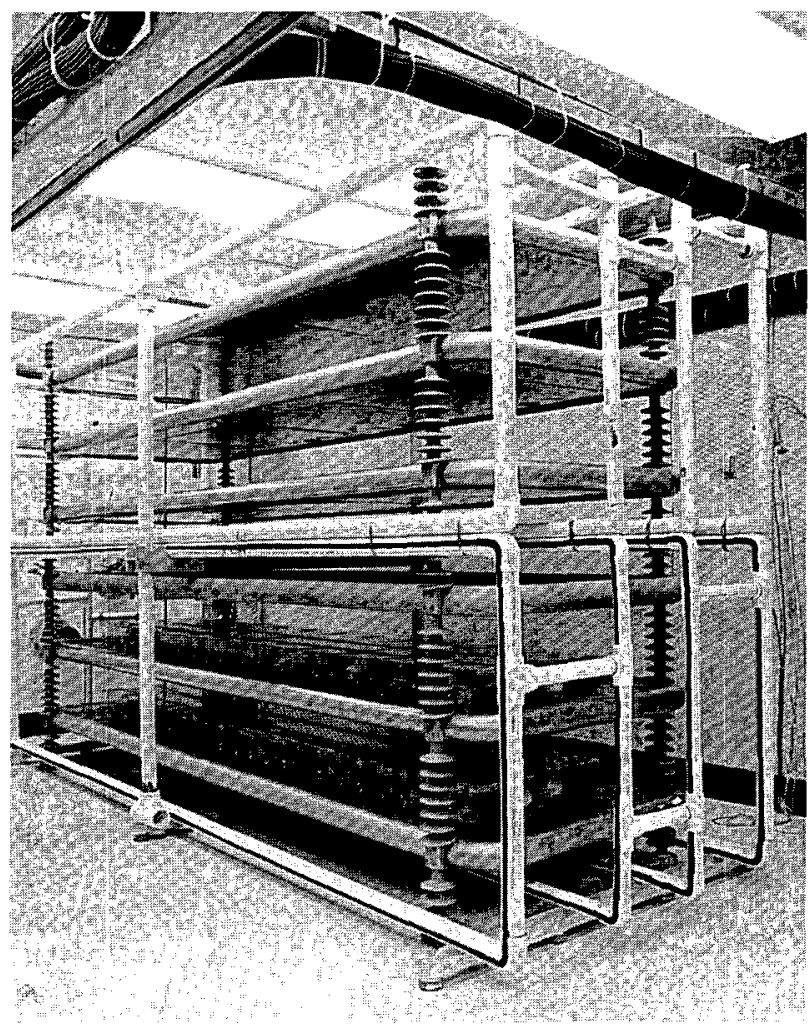

FIGURE 21. Exposure system developed by Battelle Northwest Laboratories to study laboratory animals exposed to $60-\mathrm{Hz}$ electric and magnetic fields.

In a study of four successive generations of mice (1400 animals) conceived, born, and raised in a weak 125-to-250 $\mathrm{V} / \mathrm{m}$ electric field, no consistent effects on reproduction or body weight were found. Limited data suggested that the field may have slightly delayed the age at which incisor teeth erupted in young mice. A $2-\mathrm{kV} / \mathrm{m}$ electric field had no effect on the incidence or rate of development of leukemia in chickens. The weak fields used in these two studies were a result of a problem in a transformer in the exposure system; the problem was not discovered until the studies had been completed.

Other Battelle studies did find some consistent effects, primarily in behavior and in excitability of the nervous system. In 45-minute-long tests, rats preferred the side of a shuttle box shielded from the electric field at field strengths of $90 \mathrm{kV} / \mathrm{m}$ or higher. Over a 24 -hour period, rats preferred the shielded part of the box where field strengths were at 75 $\mathrm{kV} / \mathrm{m}$ and above (Hjeresen et al. 1980). During the rat's sleeping period, however, the animals preferred the area with an electric field of $50 \mathrm{kV} / \mathrm{m}$ or $25 \mathrm{kV} / \mathrm{m}$.

For male rats exposed to $100 \mathrm{kV} / \mathrm{m}$ for 30 days, no clinically observable effects on the nervous system were detected (Jaffe et al. 1980). Certain nerves removed from rats, however, showed minor but consistent increases in excitability when impulses were injected into the nerve. No effects were found on muscle excitability or on speed of muscle contraction. One neuromuscular test indicated that the recovery from fatigue of certain muscles was enhanced in animals exposed to the electric field.

Later studies at Battelle included the use of a sensitive visual-evoked response test to detect possible subtle effects of an electric field on the developing nervous system of the rat (Jaffe et al. 1983). Continuous exposure of rats to a $65-\mathrm{kV} / \mathrm{m}$ field from conception to 20 days of age did not affect nervous system development.

When rats were exposed to electric fields of around $2 \mathrm{kV} / \mathrm{m}$ or $65 \mathrm{kV} / \mathrm{m}$ for at least 3 weeks, significant changes were detected in the normal levels and patterns of neurohormones associated with biological rhythms (Wilson et al. 1981, 1983, 1986) (see Figure 25). These hormones, melatonin and serotonin, are associated with the pineal gland located in the brain. The normal high nocturnal rise in melatonin did not occur in animals exposed to the field. The hormone patterns returned to normal conditions about 3 days after animals were removed from the field. The Battelle researchers suggested that the electric field appears to cause low-level stimulation of the nervous system. This may mimic the effects of light stimulation on the rats' normal day/ night hormone activity cycles.

More recent research at Battelle indicated that the threshold for the melatonin effect with $60-\mathrm{Hz}$ electric fields is between $200 \mathrm{~V} / \mathrm{m}$ and approximately $2 \mathrm{kV} / \mathrm{m}$ (Anderson et al. 1988). Researchers elsewhere have reported that changes in weak d-c magnetic fields can also significantly affect melatonin levels in rodents (Welker et al. 1983, Olcese and Reuss 1986).

The Battelle research led to a collaborative study with researchers from Loma Linda University, and the Pettis Memorial VA Hospital (Vasquez et al. 1988). This study looked at the daily fluctuations of brain neurotransmitters (transmit nerve impulses). Animals were exposed to a 39 $\mathrm{kV} / \mathrm{m}$ electric field for 4-weeks. In the exposed animals, concentrations of a metabolite of one neurotransmitter (DOPAC) was significantly increased during dark in the straitum (brain area involved in motor control). In the hypothalamus, exposure shifted the daily rhythms of three transmitters (norepinephrine, dopamine, 5-HIAA). This part of the brain is involved in neuroendocrine regulation. It also contains a "biological clock" and inputs to the pineal gland. The authors said that the health implications of their results are unclear. 
Battelle researchers hypothesized that effects on melatonin may also affect production of prolactin and estrogen, thus possibly increasing the risk of mammary cancer (Stevens 1987). Two experiments were conducted to look at development of mammary tumors on rats (Leung et al. 1988). The animals were given a drug that induces mammary tumors and then exposed to $40 \mathrm{kV} / \mathrm{m} 60-\mathrm{Hz}$ electric fields. Results indicated no differences in the number of animals with tumors between the exposed and control groups. However, when results of the two experiments were combined, the number of tumors per tumor-bearing anima/ was significantly higher in the exposed groups. The researchers suggested that this may indicate that the electric field was not causing but was promoting the development of tumors. An earlier study by French researchers found no increase in mammary tumors in rats exposed to a $50 \mathrm{kV} / \mathrm{m}$ electric field (LeBars et al. 1983).

The Battelle research confirmed the earlier finding by Marino et al. (1979) in which the rate of bone fracture repair was retarded in rats exposed to an electric field (McClanahan and Phillips 1983). However, the Battelle work showed that there was no permanent effect on bone strength. The slowing of bone repair may be due to an effect on bone cells, or may be influenced if the animal's activity is increased by an electric field, causing movement of the broken bone. The Battelle work was done with $100 \mathrm{kV} / \mathrm{m}$ electric fields, compared to the $5 \mathrm{kV} / \mathrm{m}$ field used by Marino et al.

In a 6-year study by Battelle Northwest, an inbred strain of female swine was exposed to $30-\mathrm{kV} / \mathrm{m}$ electric fields for 20 hours per day (Figure 22) (Sikov et al. 1987). Another group of females not exposed to the field served as control. No adverse effects were noted in adults, even after long-term exposure. In one test, animals preferred to spend more time at night in an area shielded from the electric field.

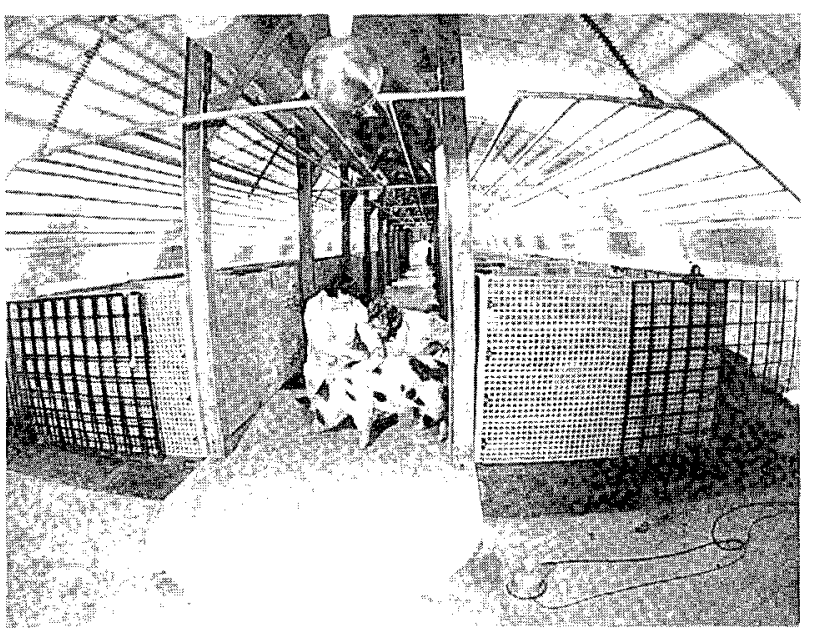

FIGURE 22. Researchers with Battelle-Northwest Laboratories conducted a long-term study of swine exposed to $60-\mathrm{Hz}$ electric fields.
When the swine were first bred with unexposed boars, the control group had slightly greater fetal mortality levels and malformations compared to the exposed group. The second breeding, however, resulted in a significantly higher incidence of fetal malformations in a sample of the exposed swine compared to controls. Also, the second-generation females conceived and raised in the electric field exhibited poor mating performance at first breeding. (The animals were removed from the electric field during mating.) After first breeding, fetuses from a sample of these animals also showed more malformations in the electric-field-exposed group than the controls. However, for the second breeding of the second-generation females, there were no differences in malformation rates between treatment and control animals.

It is not clear whether the reproduction problems in swine were related to long-term electric field exposure, to an outbreak of disease that occurred during the study, or to other factors. They may also simply represent events within the range of normal biological variability for the species under conditions of the study.

Follow-up research was done with rodents in an effort to simulate the swine study (Douglas 1984). Results of the first experiment with rats did show a similar trend toward a higher incidence of fetal malformations in exposed animals. When the experiment was repeated, however, no effects were found.

Because of ambiguous results of the follow-up study, a much larger rat study was designed to model the swine study (Rommereim et al. 1988). This study included a range of field exposures including 0 (control), 10,65, and $130 \mathrm{kV} / \mathrm{m}$. Compared to control animals, the field-exposed animals showed no significant increase in the incidence of litters with malformations. Battelle researchers did find a curious rust-colored deposit on the ears of rats exposed to the strong electric fields.

Subsequent research by Battelle identified the substance as a porphyrin (pigment) secreted by the Harderian gland (Leung 1988). This gland, located behind and around the eye, is also a source of melatonin (Norris 1985). Stress, including direct electrical stimulation of the gland, is known to cause secretion of porphyrins. The Battelle researchers suggested that a $60-\mathrm{Hz}$ electric field may, therefore, act as a chronic, low-level stressor on the rat.

Pennsy/vania State University. Studies done at Pennsylvania State University tested the hypothesis that $60-\mathrm{Hz}$ electric fields act as biological stressors (Graves et al. 1979). Male mice were exposed to electric fields of 25 and $50 \mathrm{kV} / \mathrm{m}$ for 6 weeks. No effects were found in body weights. The blood of animals in the $50-\mathrm{kV} / \mathrm{m}$ field had a white blood cell count (WBC) higher than that of the control animals. The authors pointed out, however, that stressed animals are typically expected to show a drop in the WBC. 
In a 2-hour test, a hormone (corticosterone) level in the blood was higher after the first 5 minutes in the animals exposed to 25 and $50-\mathrm{kV} / \mathrm{m}$ fields. This hormone is secreted by the adrenal gland during stress. Because there was no increase found in corticosterone during the 6-week study, the investigators suggested that the mice may simply have been aware that the field was turned on.

Graves (1985) attempted to eliminate complications from spark discharge and peripheral stimulation (hair or feather vibration) by studying chick embryos. Large numbers of eggs were exposed to a range of $60-\mathrm{Hz}$ fields of up $100 \mathrm{kV} /$ $\mathrm{m}$ through the 21-day incubation period (Figure 23). More than 20,000 embryos were evaluated. There were no discernable effects from the electric field on mortality, deformity, and weights of the embryos and 1-day-old chicks. Also, by using several exposure levels between 0 and 100 $\mathrm{kV} / \mathrm{m}$, the study found no evidence for any dose-response effects from $60-\mathrm{Hz}$ electric fields.

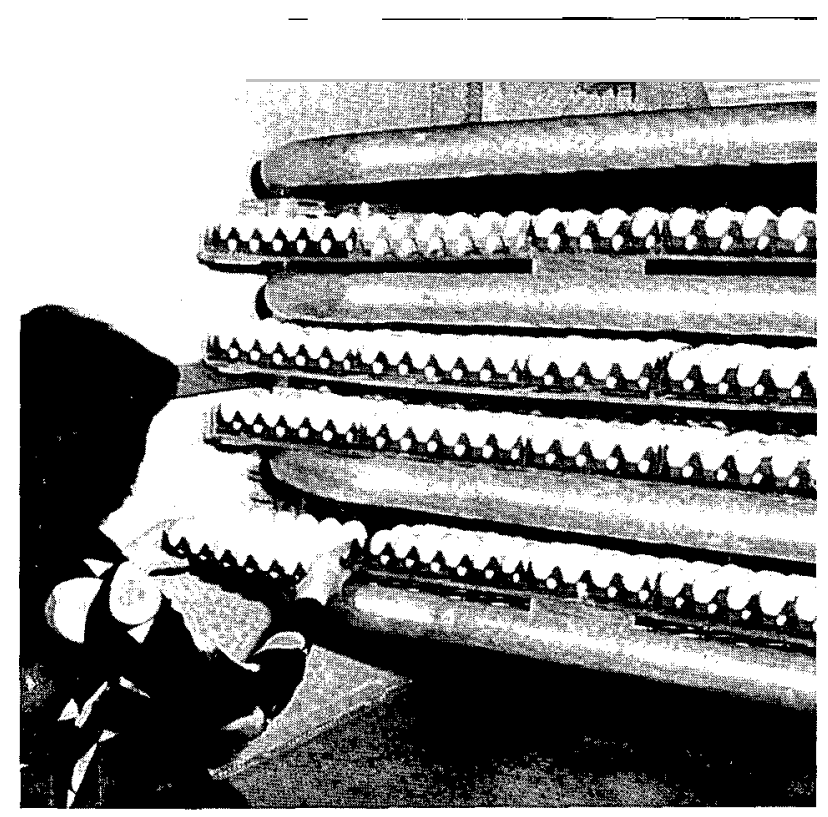

FIGURE 23. Researchers at the Pennsylvania State University found no effects of strong electric fields on development of chicken embryos.

University of Rochester. Researchers at the University of Rochester conducted extensive studies of stress-related hormones in rats exposed to strong electric fields (Quinlan et al. 1987, Michaeison and Lu 1988). Blood samples were obtained with an implanted tube (cannula) so the animals did not have to be handled as in other studies. Changes in hormone levels from known stressors (e.g., footshock) were compared to levels in rats exposed to $80-\mathrm{kV} / \mathrm{m}, 60-\mathrm{Hz}$ electric fields. Results indicated that the animals responded to continuous and intermittent exposures with subtle regu- latory adjustments of hormone balance. These changes were below the threshold for changes caused by known stressors, and the researchers concluded that the effect was of no clinical significance.

Other studies at the University of Rochester showed that the threshold for $60-\mathrm{Hz}$ electric field detection in rats was around 3 to $10 \mathrm{kV} / \mathrm{m}$ (Stern et al. 1983, Stern and Laties 1985). This was determined by training rats to receive food by pressing a lever in the presence of the electric field. There were no significant differences between male and female rats in behavioral detection of the field. The authors suggested that detection of the field by rats may be by hair stimulation.

The research in Rochester was expanded to include magnetic fields and cancer. One of the first studies ever done to examine the possible influence of $60-\mathrm{Hz}$ magnetic fields on leukemia in rodents was recently completed (Thomson et al. 1988). This study was prompted by recent epidemiological studies that have suggested a possible association between weak magnetic fields and human cancers (see the following section on "Humans"). Adult mice were implanted with leukemia cells at the start of field exposure to assess whether magnetic fields promote the development of leukemia. Results indicated no effect of $60-\mathrm{Hz}$ magnetic fields of $1.4 \mu \mathrm{T}(14 \mathrm{mG}), 0.2 \mathrm{mT}(2 \mathrm{G})$, and $0.5 \mathrm{mT}(5 \mathrm{G})$ on survival time, spleen weight, or body weight. Groups containing about 10 mice were used in each of the exposure conditions. The researchers recommended further studies, including the use of immature animals.

Argonne National Laboratory. The Argonne National Laboratory conducted studies directed at the possible biological effects of transmission line electric fields on biological rhythms (Ehret et al. 1980). Initial work did not indicate any such effects on laboratory animals. The studies did show that mice detected the onset of electric fields of 35 $\mathrm{kV} / \mathrm{m}$ and above, as indicated by both behavioral and metabolic responses. The animals, however, appeared to adapt quickly to the fields. Later work at Argonne indicated that electric fields resulted in phase shifts in circadian rhythms and in some cases caused torpor (a state of decreased temperature and metabolism) in wild-type mice (Duffy and Ehret 1982).

Tulane University. Another long-term study of rodents exposed to electric fields was conducted at Tulane University. Four generations of rats were exposed to $80-\mathrm{kV} / \mathrm{m}, 60$ $\mathrm{Hz}$ electric fields. The study used large numbers of animals so that very small effects could be detected, if present. Results indicated that the electric field had no effects on fertility, fecundity, survival, health, or food or water consumption, and that the field did not cause birth defects (Seto et al. 1984). Some slight increases (i.e., 2 to 6 percent) in weights of kidneys and testes and in levels of the hormone corticosterone were found in exposed animals. These, along with effects seen on white blood cells, transient effects on growth, and some diminished sexual responsive- 
ness in males, suggested to the researchers an overall pattern of mild stress (Seto et al. 1982, Seto et al. 1983, Burack et al. 1984).

New York Power Lines Project. Five of the 16 projects in the New York State Powerlines Project completed in 1987 involved laboratory animal studies. In one of these, researchers found that a 1 -hour exposure to $60-\mathrm{Hz}$ magnetic fields at night decreased the pain-reducing effect of morphine in mice (Ossenkopp and Kavaliers 1987a, 1987b). The response to morphine was measured by observing the reactions of mice placed on a warm hot plate. Results were statistically significant and indicated a linear dose-response relationship. The effect of morphine was progressively weakened as the field was increased from $0.05 \mathrm{mT}(0.5 \mathrm{G})$, to $0.1 \mathrm{mT}(1.0 \mathrm{G})$, to $0.15 \mathrm{mT}(1.5 \mathrm{G})$ (see Figure 26). Because the effect was not found when magnetic field exposure occurred during the day, the researchers suggested that the effect may involve the pineal gland, which is associated with biological rhythms.

Ossenkopp and Cain (1987) found that rats exposed to a $60-\mathrm{Hz}$ magnetic field had reduced mortality rates from drug-induced seizures. Groups of 12 to 20 rats per exposure level were used in the study. Unlike the study with morphine, this study seemed to show a magnetic field "intensity window" effect. Rats exposed to fields of $0.1-0.15 \mathrm{mT}(1.0$ - $1.5 \mathrm{G}$ ) had significantly reduced mortality, while fields of $0.05 \mathrm{mT}(0.5 \mathrm{G})$ and $0.185 \mathrm{mT}(1.85 \mathrm{G})$ showed no differences from controls. Mortality at $0.1 \mathrm{mT}(1.0 \mathrm{G})$ was only 8.3 percent compared to 37.2 percent in the controls.

Another study looked at the behavior of adult rats exposed to both electric and magnetic fields before birth and for the first 8 days after birth (Salzinger et al. 1987). The two exposure levels were $30 \mathrm{kV} / \mathrm{m}$ and $0.1 \mathrm{mT}(1 \mathrm{G})$, and $10 \mathrm{kV} /$ $\mathrm{m}$ and $0.03 \mathrm{mT}(0.3 \mathrm{G})$. The exposed rats showed about a 20 percent lowered response rate in pressing a lever in a behavioral test. However, the effect did not appear until after the rats had experienced considerable conditioning to the test.

Thomas et al. (1987) also studied the behavior of rats exposed to electric and magnetic fields. Sixty- $\mathrm{Hz}$ electric fields of $1 \mathrm{kV} / \mathrm{m}$ and magnetic fields of $0.05 \mathrm{mT}(0.5 \mathrm{G})$ to 0.5 $\mathrm{mT}(5 \mathrm{G})$ produced no effect on the rate or pattern for rats responding to a lever to obtain a food reward. However, a significant increase in response rate was found in five animals exposed simultaneously to a $0.05 \mathrm{mT}(0.5 \mathrm{G}) 60$ $\mathrm{Hz}$ magnetic field anda d-c magnetic field of $0.026 \mathrm{mT}(0.26$ G) (about one-half the strength of the earth's magnetic field). The effect disappeared less than 24 hours after field exposure was stopped.

Two of the New York-sponsored studies involved monkeys. In one, the possible effects of 2-week exposures to electric and magnetic fields on the circadian rhythm of 10 squirrel monkeys was examined (Sulzman and Murrish 1986). (The animals served as their own controls during field-off condi- tions.) In the two monkeys exposed to $2.6 \mathrm{kV} / \mathrm{m}$ and $0.1 \mathrm{mT}$ (1 G) fields, there was no effect on the feeding rhythm. Slight increases in the length of the feeding period were seen in three of nine monkeys exposed to $26 \mathrm{kV} / \mathrm{m}$ and 0.1 $\mathrm{mT}(1 \mathrm{G})$, and in three of four exposed to $39 \mathrm{kV} / \mathrm{m}$ and 0.1 $\mathrm{mT}(1 \mathrm{G})$. Similar results were also found in the rhythm of oxygen consumption. The researchers suggested that the field effects found in the study may not occur in natural conditions where numerous environmental cues are available to time circadian rhythms.

Wolpaw et al. (1987) used 10 pigtailed macaques to study possible effects of electric and magnetic fields on the function of the primate central nervous system. Six animals were exposed to fields of $3 \mathrm{kV} / \mathrm{m}$ and $0.01 \mathrm{mT}(0.1 \mathrm{G})$, and $30 \mathrm{kV} / \mathrm{m}$ and $0.09 \mathrm{mT}(0.9 \mathrm{G})$ over three 21 -day periods. No effects of field exposure were found on the animals' daily rhythms, blood cell counts, pathology, or general behavior. Significant declines were detected in concentrations of two neurotransmitters (HVA and 5-HIAA) in cerebrospinal fluid measured at the end of the exposure periods. One of these (5-HIAA) remained depressed for up to 21 days after exposure occurred. The researchers suggested that further studies are needed to confirm the results and to evaluate their implications.

Southwest Research Institute. Another large animal, the baboon, is under study by researchers at the Southwest Research Institute (Bulawka et al. 1982, Cory et al. 1987) (Figure 24). Preliminary research involved the behavior of animals in $60-\mathrm{Hz}$ electric fields of $30 \mathrm{kV} / \mathrm{m}$. Exposures averaged 4.25 hours per day for 25 or 57 days. Some shortterm behavioral changes were observed in animals exposed to the field. The researchers believed the changes were not harmful to the animals. As with rodents and swine, the baboons can detect the presence of the electric field.

In more recent behavioral studies, baboons were exposed to electric fields of 30 and $60 \mathrm{kV} / \mathrm{m}$ (Rogers and Smith 1987, Orr et al. 1987). Some temporary effects were found again including alterations in the body postures and positions assumed by the exposed animals. Other studies showed that the animals' behavior in responding to a food-reward test was also altered for the first few days following the start of field exposure. Most animals eventually returned to normal performance. The researchers noted that one animal would not respond to the food reward at all during exposure to the strong $60 \mathrm{kV} / \mathrm{m}$ electric field.

The baboon study has been expanded to include magnetic field exposure and collection of data on physiological parameters. This will include serum melatonin levels since other studies have shown that this hormone is affected by electric and magnetic fields. 


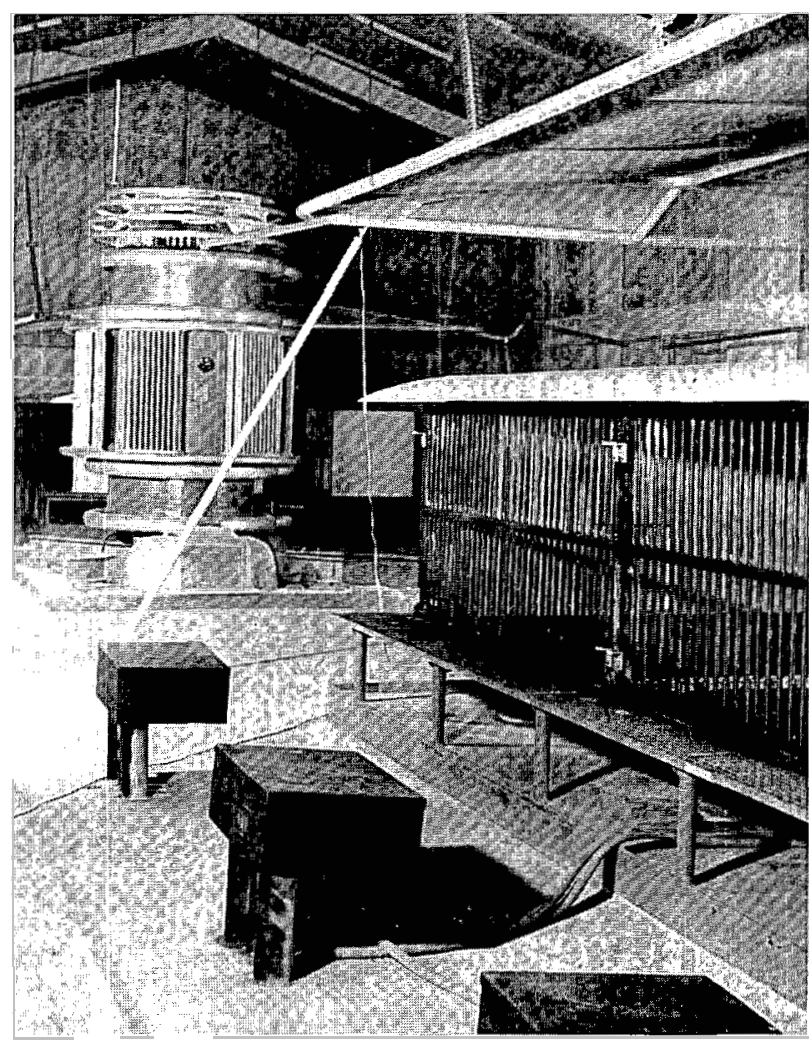

FIGURE 24. The Southwest Research Institute is studying baboons exposed to $60-\mathrm{Hz}$ electric fields. An energized plate is located above the fiberglass cage which rests on a grounded plate.

Other U.S. Studies. In a follow-up to an earlier study with humans, rhesus monkeys were periodically exposed to an $0.2 \mathrm{mT}$ ( $2 \mathrm{G}$ ) 72 to $80-\mathrm{Hz}$ magnetic field over a 1 -year period (Grissett et al. 1977). A weak horizontal electric field of up to $28 \mathrm{~V} / \mathrm{m}$ was also present. The study found that exposed males gained weight at a slightly greater rate than males in the control group. Also, compared to controls, exposed females had slightly lower serum triglycerides and respiratory quotients. The researchers reported the exposed animals appeared to be quite healthy, and there was no indication that the observed effects had any adverse clinical significance.

The National Academy of Sciences Committee organized to evaluate Project Seafarer research reviewed the studies involving triglycerides. The Committee concluded, "We believe that the studies that reported triglyceride increases associated with ELF fields had serious control deficiencies and that the well-controlled studies did not show any such association", (CBEELFR 1977:198).

The Navy conducted a second experiment in which 30 monkeys were again exposed to the field levels used in the first study. Through 54 months of exposure, the animals remained healthy, although at 30 months of age the exposed males began to grow faster than the control animals (Lotz and Saxton 1987). Although the study confirmed the earlier finding of increased growth, the researchers were unable to explain the reason for the effect.

Research conducted at the University of Rhode Island involved chick embryos, and chicks exposed to 0.1 to $3 \mathrm{mT}$ (1 to $30 \mathrm{G}$ ) magnetic fields at frequencies of $45-, 60-$, and $75-\mathrm{Hz}$ (Durfee et al. 1976). These fields had no harmful effects on hatchability of eggs, or on the development and survival of embryos or chicks. The fields may have slightly prolonged the incubation period.

U.S.S.R. Studies. In Europe and the U.S.S.R., laboratory studies involved $50-\mathrm{Hz}$ fields. One of the first Soviet laboratory studies of $50-\mathrm{Hz}$ electric fields was reported on by Dumansky et al. (1976). Rats exposed to fields of from 1 to $5 \mathrm{kV} / \mathrm{m}$ reportedly experienced a variety of effects involving behavior and changes in blood chemistry elements. The report, however, gave few details about the exposure system or whether the animals were subject to shocks.

Later Soviet studies were done with rats exposed intermittently over 4 months to $15-$ to- $20-\mathrm{kV} / \mathrm{m}$ electric fields (Shandala et al. 1979). Several behavioral and physiological effects of the fields were reported. The researchers stated, however, that the effects were feebly expressed and generally did not exceed the limits of physiological norms.

In another Soviet study, mice were exposed to $50-\mathrm{Hz} 200-$ $\mathrm{kV} / \mathrm{m}$ electric fields for 2 hours per day (Savin and Sokolva 1985). The study was done over $1-1 / 2$ years and involved five generations totalling 640 animals. There were no statistically significant consistent differences in performance between the control and exposed animals. This included such factors as number of live embryos and offspring, and development and mortality of young.

In a recent review paper, Soviet researchers concluded that their research shows that electric fields cause functional (not pathological) changes in the nervous, cardiovascular, endocrine, and reproductive systems (Shandala et el. 1988). They believe that the effects are due to activation of the body's compensatory mechanisms. The Soviet researchers said that there are still many unanswered questions about electric fields and that research is also needed on magnetic fields.

Italian Studies. Italian researchers found no effects of 10 $\mathrm{kV} / \mathrm{m}, 50-\mathrm{Hz}$ electric fields on mice, rabbits, or dogs (Cerretelli et al. 1979). No birth defects were detected among the offspring of rats exposed to a $100-\mathrm{kV} / \mathrm{m}$ field for 48 days. Growth rates of rats appeared to decrease at field levels of $25 \mathrm{kV} / \mathrm{m}$ and above.

Studies were also done in Italy beneath a 1000-kV test line (Veicsteinas et al. 1987, Conti et al. 1985, Conti et al. 1988). Electric fields of 2 to $15 \mathrm{kV} / \mathrm{m}(50 \mathrm{~Hz})$ had no effect on the 
behavior or on blood chemistry of dogs. A slight change of heart rate in dogs was noted at $25 \mathrm{kV} / \mathrm{m}$, along with some change in blood chemistry. Chickens exposed to a $15-\mathrm{kV} /$ $\mathrm{m}$ field, showed no effects on fertility, egg hatchability, malformations, or growth. However, when eggs were incubated in a stronger field $(25 \mathrm{kV} / \mathrm{m})$ and the chicks raised in a $15-\mathrm{kV} / \mathrm{m}$ field, the exposed birds grew more slowly for a time.

German Studies. A study in the Federal Republic of Germany investigated rats exposed to a $100-\mathrm{kV} / \mathrm{m} 50-\mathrm{Hz}$ field for 1 year (Bayer et al. 1977, Sander et al. 1982). No effects were seen on growth rate, organ weight, heartbeat, red blood cell counts, or hemoglobin. Animals in the field reportedly showed a decrease in white blood cell counts and a decrease in overall activity. Given a choice, the rats preferred to rest in an area out of the electric field, and they could apparently detect a field of 10 to $20 \mathrm{kV} / \mathrm{m}$.

French Studies. A French study of rabbits exposed to a $50-\mathrm{kV} / \mathrm{m}, 50-\mathrm{Hz}$ electric field found that animals in the field ate less than the control animals during the first week of exposure (Le Bars and Andre 1976). However, during the first 9 weeks after bith, there was no difference in the growth rate between exposed and control animals. Following the accidental outbreak of a disease in both exposed and control animals at about week 12, growth rate of the exposed animals was less than the controls.

As a result of a report by a Swedish researcher (Hansson 1981), French researchers conducted a study in which rabbits were exposed to $50-\mathrm{Hz}$ electric fields of $50 \mathrm{kV} / \mathrm{m}$ (Portet et al. 1984). Twenty-eight female rabbits and their offspring were involved; seven females served as nonexposed controls. For the other animals, various electric field exposures were used. The largest consisted of exposure during the last 2 weeks of pregnancy and continuing for 6 weeks after birth. No effects of the field were found on the growth and development of the rabbits. Also, the effects on Purkinje brain cells reported by Hansson (see below) were not confirmed in this study.

Portet and Cabanes (1988) reported on newer studies designed to determine whether strong electric fields affected the development of young rats and rabbits. Fifty rats and 21 rabbits were exposed to $50-\mathrm{Hz}, 50-\mathrm{kV} / \mathrm{m}$ electric fields for varying periods of time. Efforts were taken to avoid complications from extraneous factors such as shocks. The researchers saw no significant effects of exposure on growth or development, or on the weights or condition of adrenal glands. Compared to control animals, twice as many of the exposed rats showed increased histological stimulation of the thyroid gland. However, circulating levels of thyroid hormones were identical in both groups, so the researchers concluded that the function of the thyroid gland had not been affected by the electric field.

Swedish Studies. A Swedish researcher initially reported several effects in rabbits which were attributed to the electric field from a $400-\mathrm{kV}, 50-\mathrm{Hz}$ substation (Hansson 1981). A female rabbit and her seven offspring (Group I) were caged within a $14-\mathrm{kV} / \mathrm{m}$ field and near a strong corona source until the young were 7.5 weeks old. Compared to non-exposed control groups, the young rabbits suffered from undernutrition, were inactive, did not keep their fur clean, had structural changes in certain brain cells, and developed eye inflammation. Animals placed nearby (but covered with a grounded screen to eliminate the electric field) experienced only eye inflammation, apparently due to UV-light from a strong corona discharge. Another group exposed to the electric field and no corona experienced all the effects as in Group I, except there were no eye problems.

Follow-up studies were described by Hansson during a DOE/EPRI contractor's review meeting in November 1983. When the rabbit experiment was repeated indoors, rather than in the substation, the effects on growth, activity, and fur condition were not found. Apparently the earlier effects were related to animal husbandry problems. Changes in certain brain (Purkinje) cells were again observed, this time in mice, rabbits, rats, and in samples from Hanford miniature swine. However, discussion at the meeting indicated the methods used to identify the changes were more qualitative than quantitative.

The research by Hansson prompted a study in the United States in which brain cells from rats exposed to $100-\mathrm{kV} / \mathrm{m}$ electric fields were examined (Albert et al, 1984). The Purkinje cells of the exposed animals showed some changes which were not found in the controls. However, the researchers cautioned that no conclusions could be reached because of small sample sizes and highly variable data.

Also in the United States, Gona and Yu (1987) examined Purkinje cells from rats exposed pre- and postnatally to fields of $100-\mathrm{kV} / \mathrm{m}$ and $1 \mathrm{mT}(10 \mathrm{G})$. There were no detectable pathological changes in the cells. The researchers concluded that the fields did not induce any abnormal effects in the developing rat brain.

Spanish Studies. Researchers in Spain first reported that weak, pulsed magnetic fields adversely affected developing chick embryos (Delgado et al. 1982). The fields ranged from 120 to $12000 \mathrm{nT}(1.2$ to $120 \mathrm{mG}$ ) and the pulse frequencies were $10-\mathrm{Hz}, 100-\mathrm{Hz}$, and $1000-\mathrm{Hz}$. Apparently the pulse shape is an important parameter in the observed effects. Initial attempts to replicate the results by researchers in the U.S. were mixed (Microwave News 1984).

Six laboratories in Europe, Canada, and the U.S. eventually joined in a project in an attempt to replicate the findings of Delgado et al. (1982). Each of the laboratories used identical exposure facilities and attempted to use the same research protocol. Only two of the six laboratories found significant increase in abnormal embryos in eggs exposed to weak, pulsed magnetic fields (Berman et al. 1988). The combined results of the six laboratories, however, showed a statistically significant increase in abnormal embryos. 
Spanish researchers also conducted a study of two generations of mice exposed to 83 and $2300 \mu \mathrm{T}(0.83$ and $23 \mathrm{G})$ pulsed magnetic fields (Rivas et al. 1987). In the first generation, there were no differences between the exposed and control groups, in body weight or in blood chemistry. In the second generation, the exposed animals weighed slightly less than the controls after 60 days. Their blood glucose and triglyceride levels were also reduced. The animals remained healthy throughout the experiment, however.

Finnish Studies. Researchers in Finland studied chick embryos exposed to $50-\mathrm{Hz}$ magnetic fields during the incubation period (Juutilainen and Saali 1986, Juutilainen et al. 1987). For eggs exposed to fields of $1.25-13 \mu \mathrm{T}$ (12.5 - $130 \mathrm{mG}$ ), there were approximately twice as many abnormal embryos as in the non-exposed controls. Threshold for the effect appeared to be between 1.13 and $1.25 \mu \mathrm{T}$ (11.3 and $12.5 \mathrm{mG}$ ). The authors of the study could not identify a mechanism to explain how weak magnetic fields could cause such an effect.

Summary. Research with laboratory animals has not shown any hazardous effects from exposure to 50 - or $60-\mathrm{Hz}$ electric or magnetic fields. However, a variety of functional changes has been reported in exposed animals. Confidence in these findings is increased when more than one laboratory can produce the same results. However, there are relatively few effects of electric and magnetic fields which have been fully replicated by multiple laboratories.

Following are general kinds of effects for which there appears to be some (not necessarily complete) consistency in results of studies by two or more research groups. The effects were found at scaled field strengths comparable to those produced by transmission lines.

\section{Electric Magnetic Field. Field}

retardation in bone fracture healing avoidance of strong fields decrease in nocturnal melatonin levels

transient changes in stress hormone levels

field detection

changes in biological rhythms changes in white blood cell counts transient effects on growth changes in performance in behavioral tests
As described in the sections above, other effects of power-frequency fields have been replicated by a single laboratory. It remains to be seen whether these effects will be independently confirmed by other laboratories.

Effects attributed to electric and magnetic fields exhibit a variety of dose-response relationships. While some effects seem to show a linear response to field strength, other effects occur only at certain frequency or field strength "windows." Still other effects demonstrate a threshold response.

There is also evidence that weak, pulsed, magnetic fields can affect the development of chick embryos. Research on this effect using sine-wave fields (as found in electric power systems) is inconsistent.

Results of the laboratory research cannot yet be used to answer questions about potential effects of electric and magnetic fields on human health. This is due to 1) inconsistencies in research findings, 2) uncertainties over the mechanisms for the reported effects, and 3) inherent problems in extrapolating from animals to humans. This last point includes both the biological differences between laboratory animals and people, and differences in field exposures between laboratory conditions and actual human exposures.

\section{Cell and Tissue Studies}

Possible effects of electric and magnetic fields have also been investigated by studying isolated preparations of cells or tissues directly exposed to the fields (Figure 25). Such studies are termed in vitro. This approach has been used by some researchers in an effort to find possible mechanisms for field/biological interactions. Some of the research is also secondary to more basic scientific goals of learning about how cells function and communicate. As a result, the relevance of thein vitro studies to possible transmission line health effects is not straightforward.

In vitro studies are further complicated because they have involved a wide variety of exposure conditions. Although some studies have used $60-\mathrm{Hz}$ fields, many have used microwave or radio-frequency fields which were "modulated" with $60-\mathrm{Hz}$ or other ELF (extremely-low-frequency) fields. Still others have used pulsed fields, or currents injected into the sample. As a result, there are often difficulties in comparing the field strengths in the cell and tissue preparations to the fields induced by powerlines.

A number of publications have reviewed thein vitro studies (e.g., Sheppard 1985, Adey 1988). Although some consistent effects have been documented, generally they are not of a pathological nature. This is consistent with the studies of laboratory animals described above. However, the in vitro studies provide information on how electric and mag- 
netic fields interact with biological systems. Some studies also suggest mechanisms by which these fields could influence human and animal health.

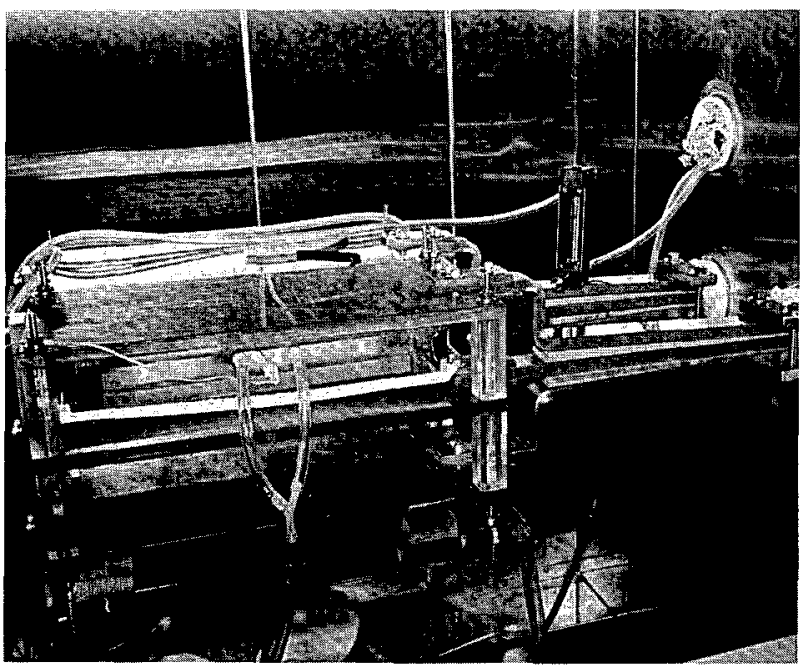

FIGURE 25. Example of exposure system used in laboratory studies of cells and tissue exposed to $60-\mathrm{Hz}$ fields. BattelleNorthwest system being used to study human lymphocytes.

Scientists generally agree that the fields induced in the body by even the largest transmission lines are orders of magnitude smaller than the natural fields existing across cell membranes. Thus, the induced current does not penetrate the membrane, and direct effects on internal cell components, including genetic material (DNA), are unlikely. However, normal biological processes do cause changes in the cell membrane that produce various cell functions. Such changes that result in altered cell functions have been attributed, for example, to some toxic chemicals. Some studies have now shown that the tiny currents induced by external electric and magnetic fields can also affect the cell membrane (Adey 1981, Marron et al. 1983).

Adey (1988) and Grattarola et al. (1985) discussed ways that weak electric and magnetic fields may affect cell membrane functions. In brief, the cell membrane is now thought to consist of a lipid bilayer in which numerous protein structures are embedded. These structures protrude outside the membrane. They are, therefore, in close contact with the chemical and electrical environment existing in the narrow channels surrounding the cells.

The protruding protein strands are negatively charged and are receptor sites for antibodies, hormones, and neurotransmitters. Various ions, including calcium, bind to these receptors. Binding results in the coupling of a signal through the membrane. In this way, a weak external stimulus is transmitted and amplified, causing stimulation of specific enzymes inside the cell. This causes a specific cellular function, depending on the nature of the coupled signal, i.e., whether from an antibody or a hormone. The authors above believe that external electric fields induce weak electrical currents that flow along the surface of cells, and affect this signal-coupling process.

Some of the recent research that "has examined possible effects of electric and magnetic fields at the cellular level is summarized below. Much scientific interest is focused on a series of papers which indicated that electric and magnetic field exposure can influence the rate of calcium ion movement out (efflux) of brain tissue (e.g., Blackman et al. 1985,1988 ). Calcium is involved in many important physiological functions, so such an effect could be of significance if the effect also occurred in whole animals and people. One study reported evidence that the effect was observed in cats, although the exposure involved a strong microwave field modulated at $16 \mathrm{~Hz}$ (Adey et al. 1982).

An interesting aspect of the in vitro studies is that some effects appear related to certain field frequency and amplitude "windows" (see Figure 26). For example, the calcium efflux effect is most pronounced at $16 \mathrm{~Hz}$, although some effect was also noted at other frequencies, including $60-\mathrm{Hz}$. Another study found that the hormone response of rat adrenal tissue was affected by a $60-\mathrm{Hz}$ field of $10 \mathrm{kV} / \mathrm{m}$ but not by fields of $5 \mathrm{kV} / \mathrm{m}, 100 \mathrm{kV} / \mathrm{m}$, or $1000 \mathrm{kV} / \mathrm{m}$ (Lymangrover et al. 1983).

A mechanism (cyclotron resonance) was proposed to explain the frequency- dependent effects of magnetic field exposure on calcium efflux (McLeod and Liboff 1986, Liboff and McLeod 1988). Basically, this hypothesis proposed that movement of ions (such as calcium) through cell membranes can be controlled by "tuning" the externally applied $a-c$ and $d-c$ magnetic fields for the ion in question. One study successfully predicted the calcium and potassium resonance conditions that led to an observed effect on behavior of diatoms (unicellular organisms) in an experimental study (Smith et al. 1987). However, in a study involving turtle colon cells, resonance conditions did not result in predicted effects on sodium ion movement (Liboff 1988).

Based on a theoretical assessment, Halle (1988) concluded that the cyclotron resonance model violates the laws of classical mechanics. He argued that the role of dynamic friction was severely underestimated by the model. He, therefore, suggested that other phenomena should be sought for explaining certain magnetic field "window" effects.

Goodman and Henderson (1988) studied protein synthesis in dipteran (fly) salivary gland cells. Cells were exposed for up to $\mathbf{4 5}$ minutes to electric and magnetic fields at four frequencies, from 1.5 to $72 \mathrm{~Hz}$. The pattern in protein synthesis was different in all the exposed groups compared to the controls. For example, exposure to the $60-\mathrm{Hz}$ fields, $1.5 \mathrm{mT}(15 \mathrm{G})$ and $0.5 \mathrm{mV} / \mathrm{m}$, resulted in synthesis of three 
proteins not found in the control cells. The researchers suggested that the observed effects were a stress response, but the mechanism is unknown. Blank and Sisken (1988) reported a similar effect on protein synthesis in excised sciatic (leg) nerves of rats exposed to pulsed electromagnetic fields.

A growing number of in vitro studies are investigating the possible influence of electric and magnetic fields on the tumor promotion process. Several studies have found no damaging effects of $60-\mathrm{Hz}$ fields on DNA (e.g., Reese et al. 1988). It is, therefore, not likely that these fields can directly initiate the cancer process. Some studies suggest that the fields may in some way act as cancer promoters, thus increasing the chance of tumor formation following initiation by some other agent.

A study in Texas found that the growth of human tumor cells was markedly increased following 24-hour exposure to a $60-\mathrm{Hz}$ magnetic field of $0.1 \mathrm{mT}(1 \mathrm{G})$ and an electric field of $30 \mathrm{kV} / \mathrm{m}$ (Phillips and Winters 1987). Follow-up research sponsored by the state of New York, however, did not support these findings (Ahlbom et al. 1987).

Researchers in California reported that $60-\mathrm{Hz}$ electric fields $(10 \mathrm{mV} / \mathrm{m}$ to $1 \mathrm{~V} / \mathrm{m}$ in the medium) caused an increase in activity of a growth hormone (ODC) that is also known to be increased by all chemical tumor promoters (Byus et al. 1987). However, they pointed out that some other chemicals which are not promoters can cause the same effect. Therefore, this test alone is not sufficient to determine if something is a promoter. The results of the in vitro study did suggest to the researchers that electric and magnetic fields may act as tumor promoters.

Lyle et al. (1988) reported that a 48-hour exposure to a 60$\mathrm{Hz}$ electric field $(1 \mathrm{~V} / \mathrm{m}$ in the medium) resulted in a 25 percent inhibition in the ability of lymphocytes to kill cancer cells. Inhibition dropped to 19 percent at $0.1 \mathrm{~V} / \mathrm{m}$, and to a nonsignificant 7 percent when the field was reduced to 0.01 $\mathrm{V} / \mathrm{m}$. (Electric fields up to about $0.01 \mathrm{~V} / \mathrm{m}$ can be induced in humans by maximum transmission line electric fields.) The researchers pointed out several reasons why results of their in vitro study cannot be extrapolated to humans.

Parola et al. (1988) reported in a brief abstract that chick embryo cells underwent malignant transformation after a 24-hour exposure to a $100-\mathrm{Hz}, 0.7 \mathrm{mT}(7 \mathrm{G})$ sinusoidal magnetic field. Those authors believed that the results of the study indicated a magnetic rather than a thermal effect. Few details of the study were presented, and the study has apparently not been replicated by other researchers.

\section{Dose-Response Considerations}

One observation emerging from the laboratory research on electric and magnetic fields is that reported effects exhibit a variety of dose-response relationships. Therefore, one cannot generalize and indicate that stronger fields always give larger effects than weaker fields. Similarly, some

effects appear to be very frequency-dependent. Also, as described in sections above, some effects appear to be due to precise combinations of a-c and $d-c$ fields.

All of this further complicates the interpretation of the vast literature on field effects research. Until the mechanisms causing the various reported effects are understood, this difficulty will persist. Figure 26 is an example of some of the kinds of dose-response relationships reported in electric and magnetic field laboratory studies.

\section{Humans}

Research is also continuing on persons who live or work around electrical power equipment and facilities and on human volunteers in controlled laboratory settings. Research with people in real-world situations is termed "epidemiology." This is the study of the frequency and distribution of a disease, or a physiological condition in human populations, and of the factors that influence the frequency and distribution. (See Tables 3 and 4 for a summary of epidemiological methods).

Table 3. Summary of basic types of epidemiological studies (sources: IERE Working Group 1988, Aldrich and Easterly 1985). (See Table 4 for definitions of risk ratios, PMR, OR, RR.)

Study Description

Correlational

(cross-sectional)

Cohort
A broad, screening type study that correlates occurrence of disease or death in some group (e.g., occupation or geographical area) with assumed presence or absence of exposure to some agent. A common measure of relative risk is the PMR.

Case-Control People with a particular disease (cases) are compared to people without the disease (controls) to see whether there is any difference in their amount of exposure to some agent. The exposures have already occurred (retrospective), so they must somehow be estimated. Measure of risk is the OR.

Ideally, a group of people (the cohort) including those exposed and not exposed to some agent, are followed forward (prospective) in time to determine who develops specific diseases. Study results in a true measure of risk, RR. 
(A)

LINEAR DOSE RESPONSE: Effectiveness of morphine in rats decreased with increasing magnetic field

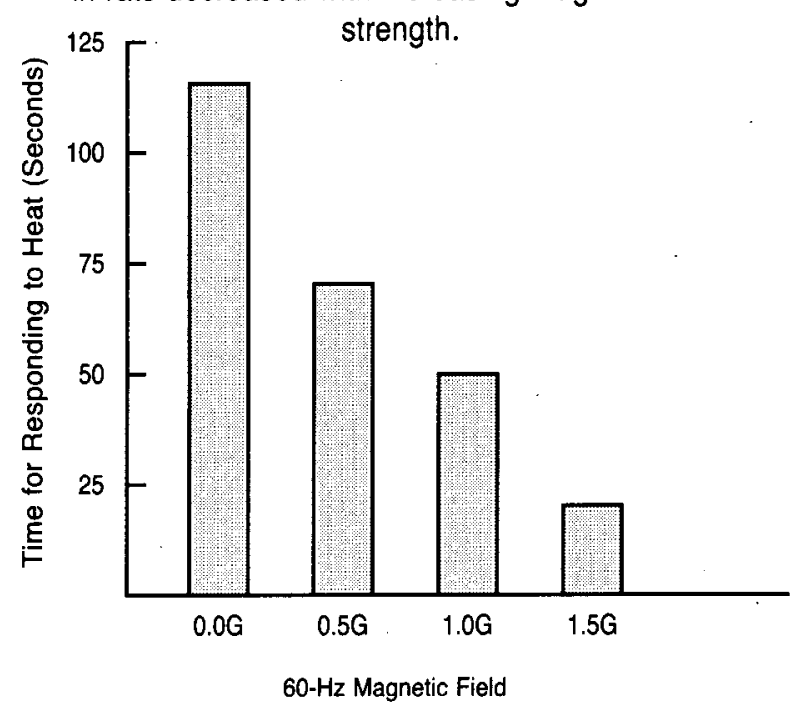

(C)

FREQUENCY WINDOW RESPONSE: Mobility of diatoms (one-celled organisms) is maximal at one

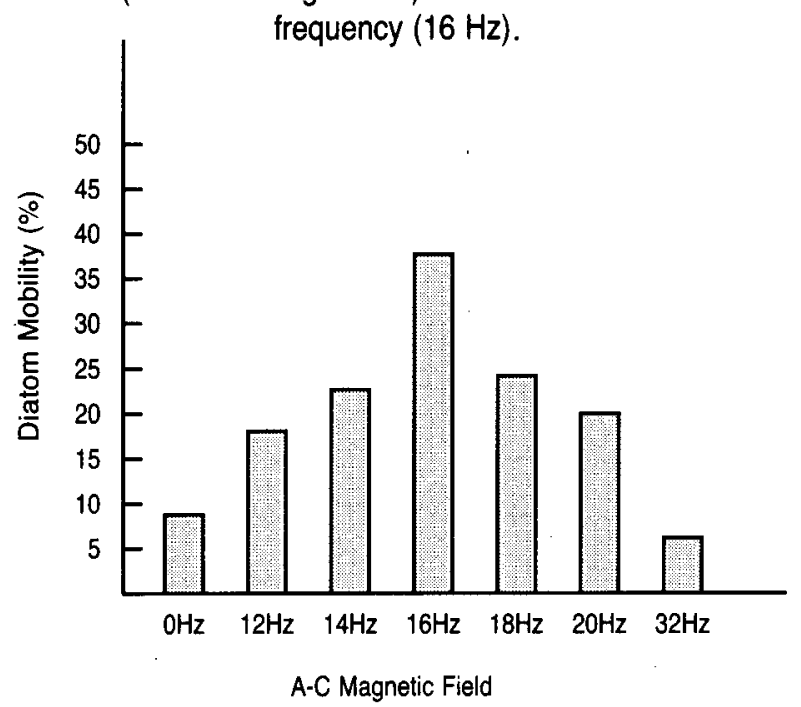

(B)

THRESHOLD RESPONSE: Nighttime rise in melatonin in rats similarly decreased by $2 \mathrm{kV} / \mathrm{m}$ and $65 \mathrm{kV} / \mathrm{m}$

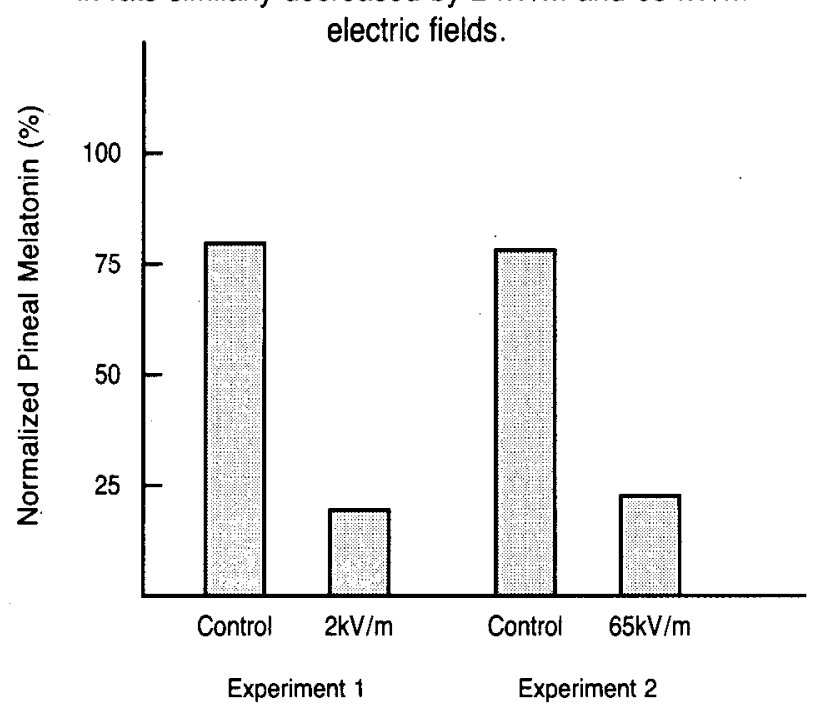

(D)

INTENSITY WINDOW RESPONSE: Production of a hormone by rat adrenal tissue is maximal

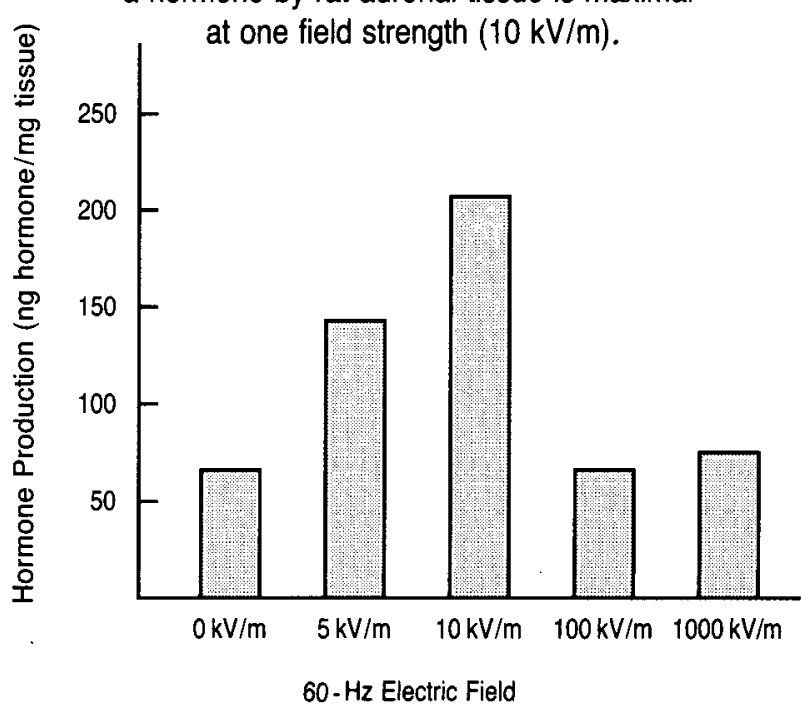

FIGURE 26. Examples of the variety of dose-response relationships reported in studies of electric and magnetic fields. Sources: (A) Ossenkopp and Kavaliers 1987b, Fig. 1; (B) Adapted from Wilson et al. 1981, Fig. 1, and Wilson et al. 1986, Fig. 2; (C) Smith et al. 1987, Fig. 6; (D) Lymangrover et al. 1983, Fig. 2. 
Table 4. Summary of riskand exposure ratios used in epidemiological studies (adapted from IERE Working Group 1988). In general, a ratio of 1.0 means no difference in risk (or exposure) between the two groups. (See Table 3 for a description of types of epidemiological studies.)

Risk Ratio Definition
SMR -

Standardized

Mortality Ratio

PMR -

Proportionate Mortality Ratio

RR -

Relative Risk (also Rate Ratio)

R -

Odds Ratio
In a cohort study, compares the number of deaths in the exposed group to the number expected on the basis of national or regional rates adjusted for age and sex.

In exploratory studies, such as of death certificates, compares the proportion of deaths from specific causes in a particular group (e.g., occupation), to all causes of death in a reference group (e.g., all other occupations). Indicates relative importance of causes of death, not actual risk.

Ratio of rate of death (or disease) in the exposed group to that in the unexposed group. (Sometimes used as a synonym for all risk ratios.) Technically, RR is a measure of direct risk from a cohort study.

In cohort studies, the ratio of chance of death or disease in the exposed compared to unexposed groups. In case control studies, the ratio of chance of exposure among cases, to that in the controls.
Epidemiological research establishes statistical associations which may or may not indicate cause-and-effect relationships. The latter may require additional data from studies of laboratory animals and/or studies of human volunteers in experimental or clinical settings. In some cases (e.g., asbestos and lung disease, smoking and lung cancer and heart disease), results of epidemiological studies are convincing evidence for cause-and-effect relationships. In many other cases, however, results of epidemiological studies are in conflict, and cause-and-effect relationships have not been established (e.g., saccharin and bladder cancer, coffee and pancreatic cancer).

Because most people are normally exposed to electric and magnetic fields, it is not practical to conduct an epidemiological study involving unexposed persons. The following sections describe research that has tried to deal with this problem. A basic assumption is that the use of electrical appliances, and exposure to household or office wiring, represents the normal or background exposure level. Studies are done to determine whether people who are exposed to field levels above background show any measurable difference in disease rates. These higher exposure groups have included people living close to powerlines, workers in various "electrical" occupations, and people who use electrically heated beds.

Community Health Studies. An early study in France showed that families living within $25 \mathrm{~m}(82 \mathrm{ft})$ of transmission lines, on the average, sought medical consultation and purchased medical supplies with about the same frequency as families living at least $125 \mathrm{~m}(410 \mathrm{ft})$ away from such lines (Strumza 1970).

In a study from England, a correlation was reported between suicides in the West Midlands and very weak a-c magnetic fields (Reichmanis et al. 1979, Perry et al. 1981). In the Perry report, the number of suicides from a 7-year period was related to a-c magnetic fields measured near the front door of residences. The mean a-c field for the suicide residences was only $87 \mathrm{nT}(0.87 \mathrm{mG})$; for controls, only 71 $\mathrm{nT}(0.71 \mathrm{mG})$, a difference of only $16 \mathrm{nT}(0.16 \mathrm{mG})$. The highest measured a-c field was $1500 \mathrm{nT}$ (15 mG).

In a later study from the UK (McDowall 1986), there was no indication of an association between suicide and proximity of residences to powerlines or substations.

Perry and Pearl (1988) looked for correlations between human illness and magnetic field strength found in multistory buildings in Wolverhampson (U.K.). Measurements of $50-\mathrm{Hz}$ magnetic field strength were made to characterize persons who lived "near" power cables, average $290 \mathrm{nT}$ (2.9 mG), and those "distant", average $112 \mathrm{nT}(1.12 \mathrm{mG})$. No statistically significant differences were found between the two groups for overall illnesses involving pregnancy, cardiovascular disease, pediatric problems, malignancy, or psychiatric problems. When heart and psychiatric disease were further delineated, statistically significant differences were found in only three of twelve tests. The researchers said that their findings were not conclusive.

Community Cancer Studies. An exploratory case-control study in Colorado first suggested a correlation between the incidence of childhood cancer and proximity of homes to high-current-carrying distribution and service lines (primarily 13-kV and 240-V) (Wertheimer and Leeper 1979). Table 5 describes the way the powerline configurations were defined in this and subsequent studies. Maximum magnetic fields associated with the lines ranged from 0.4 - 3.5 $\mu \mathrm{T}$ (4-35 mG). Researchers compared residence locations of persons who died of cancer before age 19 over a 27-year period in the greater Denver area with a group of control addresses. The children with cancer were two to three times more likely to have lived near high-current powerlines 
than were the children without cancer. The authors suggested the findings may be related to return current flows through household plumbing or to magnetic fields.

A study similar to the one in Colorado was done in Rhode Island (Fulton et al. 1980). This study found no relationship between childhood leukemia (the only cancer type studied) and electric powerline configurations. The authors concluded that if a relationship exists between high-current sources and cancer, it must be very small.

The two cancer studies above were evaluated in a report prepared for the Electric Power Research Institute (Roth 1985). The report indicated that the conclusions of both studies were difficult to evaluate. This was in part because of problems in quantifying presumed exposure to $60-\mathrm{Hz}$ magnetic fields, and in part because inappropriate statistical methods were used for analyzing data. However, when the Wertheimer and Leeper data were reanalyzed by Roth Associates, many of the original findings were confirmed (including a significant association between wiring configuration and cancer). Reanalysis of the data from Fulton et al. also confirmed there was no powerline effect demonstrated in that study.

In a Swedish case-control study, childhood tumor cases were around twice as frequent in dwellings near $50-\mathrm{Hz}$, $200-k V$ lines (Tomenius 1986). Magnetic fields of $0.3 \mu \mathrm{T}$ ( 3 $\mathrm{mG}$ ) and greater occurred twice as often at case dwellings compared to controls. However, this finding was significant only if this field level were chosen as the cut-off point. The average magnetic field measured for all case and control homes was identical, $0.07 \mu \mathrm{T}(0.7 \mathrm{mG})$. Tomenius concluded that his findings suggested a causal effect of the magnetic field, but he said the results might also be due to another factor correlated to the field.

A study from the UK did not find any association between childhood cancer and powerlines (Myers et al. 1985, Clayden and Myers 1988). The study involved 374 cancer cases and 588 matched controls. Authors of the study indicated that their study had relatively low statistical power (i.e., low ability to detect an effect). This was because so few children lived close to powerlines or in high magnetic fields.

Wertheimer and Leeper (1982) extended their earlier study to include cancers in adults living near powerlines. This case-control study reported possible associations between magnetic fields and cancers of the nervous system, uterus, breast, and lymphomas. Risk for leukemia was not increased. The overall odds ratio for adult cancer (1.4) was weaker than the 2-3 that they previously reported for childhood cancers. Wertheimer and Leeper proposed that weak magnetic fields may have a tumor-promoting rather than an initiating effect.

In a preliminary report of an unusual clustering of a rare type of tumor in five Florida girls, Aldrich et al. (1984) speculated that proximity of the girls' homes to a $69-\mathrm{kV}$ powerline may have been one causative factor. However, the report showed that the homes were also in proximity to highways, railroads, and a lead smelter. Thus, the clustering could have been due to other factors or to chance.

Table 5. Description of powerline overhead wiring configurations developed by Wertheimerand Leeper $(1979,1982)$ used in community cancer studies.?

\begin{tabular}{|c|c|}
\hline $\begin{array}{l}\text { Line } \\
\text { Configuration' }\end{array}$ & Home Is In This Category if:2 \\
\hline $\begin{array}{l}\text { VHCC - Very } \\
\text { High Current } \\
\text { Configuration }\end{array}$ & $\begin{array}{l}\text { 1) A transmission line and/or thick } \\
\text { three-phase primary distribution line } \\
\text { is within } 15 \mathrm{~m} \text { ( } 50 \mathrm{ft} \text { ) of home, or } 2) \\
\text { Six or more primary distribution con- } \\
\text { ductors are within } 15 \mathrm{~m}(50 \mathrm{ft}) \text {, or } 3 \text { ) } \\
\text { a thin three-phase primary distribu- } \\
\text { tion line is within } 7.6 \mathrm{~m}(25 \mathrm{ft}) \text {. }\end{array}$ \\
\hline $\begin{array}{l}\text { OHCC - } \\
\text { Ordinary High } \\
\text { Current } \\
\text { Configuration }\end{array}$ & $\begin{array}{l}\text { 1) A transmission line and/or thick } \\
\text { three-phase primary distribution line } \\
\text { is within } 15-39.5 \mathrm{~m} \text { ( } 50-129 \mathrm{ft}) \text { of } \\
\text { home, or } 2) \text { Six or more primary dis- } \\
\text { tribution conductors are within } 15- \\
39.5 \mathrm{~m}(50-129 \mathrm{ft}) \text { of home, or } 3) \mathrm{A} \\
\text { thin three-phase primary distribu- } \\
\text { tion line is within } 7.5-19.5 \mathrm{~m}(25-64 \\
\mathrm{ft}) \text {, or } 4) \mathrm{A} \text { first span secondary is } \\
\text { within } 15 \mathrm{~m}(50 \mathrm{ft}) \text {. }\end{array}$ \\
\hline $\begin{array}{l}\text { OLCC - } \\
\text { Ordinary Low } \\
\text { Current } \\
\text { Configuration }\end{array}$ & $\begin{array}{l}\text { 1) A thin three-phase primary distri- } \\
\text { bution line is within } 20-36 \mathrm{~m} \text { ( } 65-130 \\
\mathrm{ft} \text {, or 2) A first-span secondary dis- } \\
\text { tribution line is within } 15-39.6 \mathrm{~m} \text { (50- } \\
130 \mathrm{ft} \text { ), or } 3 \text { ) Any non-endpole sec- } \\
\text { ondary line is within } 39.6 \mathrm{~m} \text { (130 ft). }\end{array}$ \\
\hline End Pole & $\begin{array}{l}\text { 1) No transmission lines, or three- } \\
\text { phase primary, or secondary distri- } \\
\text { bution lines are within } 39.6 \mathrm{~m} \text { ( } 130 \\
\mathrm{ft} \text { ), or 2) Where any secondary or } \\
\text { three-phase primary line within this } \\
\text { area is an endpole line. }\end{array}$ \\
\hline
\end{tabular}

1 The 1979 Wertheimer and Leeper childhood cancer study used only two general categories, i.e., High Current Configuration (VHCC and OHCC), and Low Current Configuration (remaining homes).

2 Description based on classification as used in the Seattle study by Kaune et al. (1986). 
A more recent study in the UK assessed mortality among 7,631 people living near powerlines and substations (McDowall 1986). Results did not indicate any association between $50-\mathrm{Hz}$ magnetic fields and leukemia or most other cancers. There was an excess of lung cancer in women near electrical facilities, which the researchers said was hard to interpret without data on smoking.

Preliminary results of a smaller study in the UK indicated no excess in leukemia risk for residences ( 7 cases, 10 con-

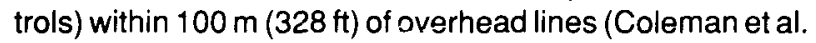
1985). For residences within $50 \mathrm{~m}(164 \mathrm{ft})$ of lines, there was a small increase in leukemia risk $(O R=1.87)$ based, however, on only 3 cases and 3 controls.

Two of the 16 studies in the New York Powerlines Project were case-control studies of cancer in people who lived close to powerlines. The study by Savitz at al. (1988) was designed essentially to repeat the methods used by Wertheimer and Leeper (1979) in their childhood cancer study. It is important to point out, however, that Savitz used newer childhood cancer cases from the Denver area which had occurred since the earlier study. In the new study, there were 252 cases of children less than 15 years old diagnosed with any form of cancer between 1976 and 1983. The 222 controls were children without cancer chosen to be similar in age to the cases.

The Savitz study also included actual measurements of both electric and magnetic fields inside study homes. The method developed by Wertheimer and Leeper (1982) to classify homes based on their proximity to high- and lowcurrent overhead lines was also used (see Table 5). Savitz also identified those homes served by buried cable as the lowest magnetic field exposure class.

The Savitz study confirmed that there was some correlation between powerline configurations and the measured magnetic field strength in nearby homes (Figure 27). The average field in homes near very-high-current lines was around 0.2 to $0.3 \mu \mathrm{T}$ ( 2 to $3 \mathrm{mG}$ ). In homes served by buried cable, or near low-current lines, the field averaged only 0.1 $\mu \mathrm{T}(1 \mathrm{mG})$ or less. There was considerable variation, however, among the measurements. There was no correlation between powerline configurations and the electric field inside homes.

A large number of different types of comparisons were made to relate powerline configurations and measured fields to the cancer cases and controls. The following are among those results emphasized by Savitz and his associates. Powerline configurations associated with the higher currents were 1.5 times (i.e., the odds ratio) more common near homes of cancer cases (all types) than were the low current and buried cable types. Statistically, this finding was of marginal significance, however.

When homes near the very-high-current lines were compared to those served by buried cable, odds ratios were 2.3

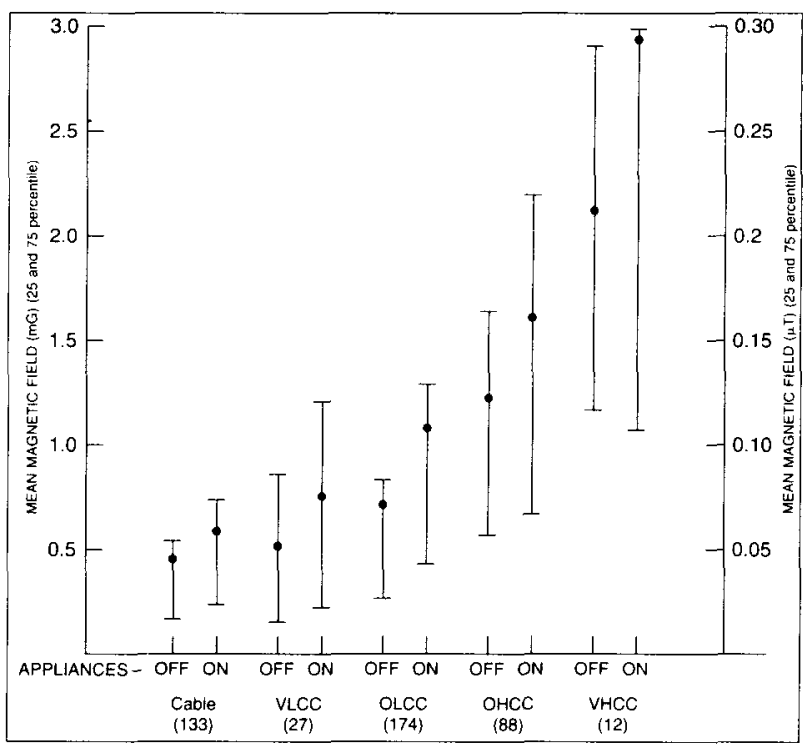

FIGURE 27. Average magnetic fields measured in 434 homes in the Denver, Colorado area with most appliances off and when they were on. The measurements are grouped by homes near certain types of powerlines (cable $=$ buried cable, $\mathrm{VLCC}=$ very low current configuration, $\mathrm{OLCC}=$ ordinary low current configuration, $\mathrm{OHCC}=$ ordinary high current configuration, and $\mathrm{VHCC}=$ very high current configuration. Numbers below types indicate sample size.) (Source: Savitz 1987:39.)

for all cancers, 2.9 for leukemias, and 3.3 for lymphomas. None of these were statistically significant.

For homes where the measured magnetic field strength (with appliances off) averaged $0.2 \mu \mathrm{T}(2 \mathrm{mG})$ or above, the odds ratio for all cancer cases was 1.4 , and 1.9 for leukemia. Neither of these was statistically significant.

Several factors were evaluated which could have biased or confounded the study results. For example, traffic density was associated with both powerline configurations and cancer occurrence. However, the association wasn't strong enough to confound the association between powerlines and cancer. No other important confounding was identified. As with most epidemiological studies, however, it was not possible completely to rule out the possibility that the results were influenced by factors other than magnetic fields. Savitz et al. characterized the combined results of their and other powerline/cancer studies as suggestive but inconclusive.

The scientific panel (Ahlbom et al. 1987) that oversaw the Savitz study pointed out that childhood cancer is a rare occurrence (approximately 1 per 10,000 per person-year). If risk of this disease were doubled, this rate would increase to 2 per 10,000 per person-year. The panel speculated that 
if one assumed a causal effect, and assuming that exposures as in Denver also occurred elsewhere in the U.S., then from 10-15 percent of all childhood cancer cases might be attributable to magnetic fields from high-current powerlines. This would amount to around $600-900$ cases per year.

Figure 28 is a summary of the results of the five childhood cancer studies as presented by Ahlbom (1988). Ahlbom stated that although there is some consistency among the results, the data are insufficient to conclude that exposure to magnetic fields increases the risk of cancer.

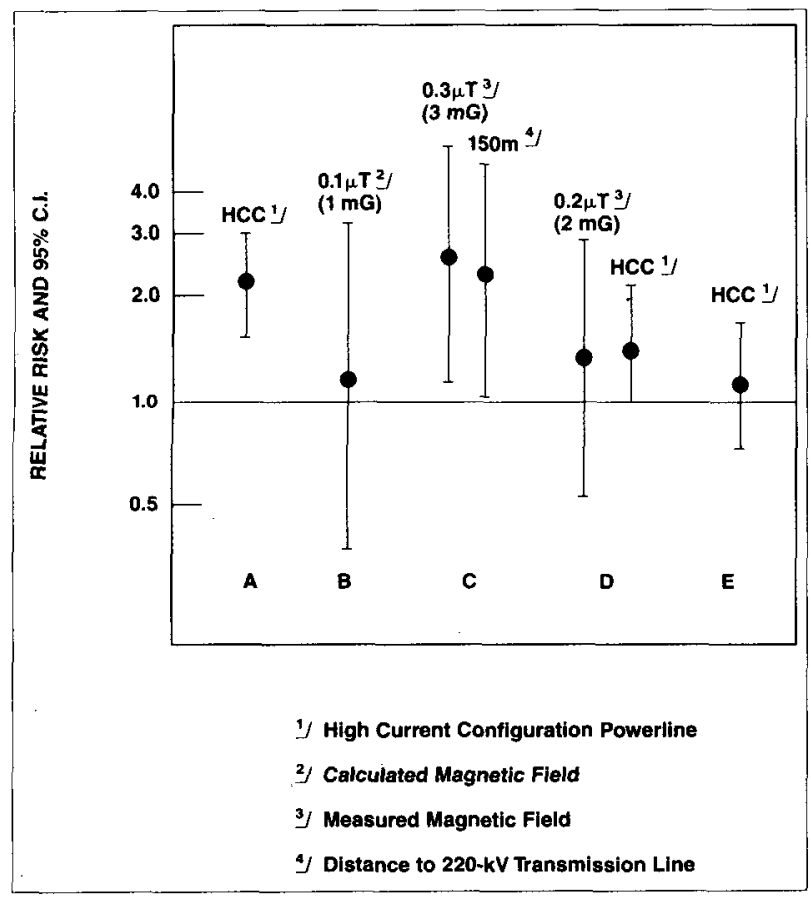

FIGURE 28. Summary of relative risks reported in studies of childhood cancer and powerlines. $A=$ Wertheimer and Leeper 1979, $B=$ Myers et al. 1985, $C=$ Tomenius 1986, $D$ $=$ Savitz et al. 1988, $E=$ Fulton et al. 1980. Studies $A-D$ included all cancer types; study E included only leukemia. (Source: Ahlbom 1988:339.)

The other New York-sponsored epidemiological study looked for an association between acute nonlymphocytic leukemia in adults, and residential magnetic field exposure (Severson et al. 1988). This study, conducted in the Seattle area, used methods similar to those used in the Savitz study. Measurements of magnetic field strength in 138 homes showed that use of household appliances made only a small contribution to the magnetic field environment in the home.

For homes where the average magnetic field (with appliances off) was between 51 and $199 \mathrm{nT}$ (0.51 and $1.99 \mathrm{mG}$ ), the leukemia odds ratio was 1.16 . For homes averaging $200 \mathrm{nT}(2 \mathrm{mG})$ and above, the odds ratio increased to 1.50 . Statistically, however, neither of these two risk estimates was significant, so they could have resulted by chance.

Severson et al. (1988) also found no statistically significant associations between power-line wiring configuration and leukemia. Those authors concluded that their negative findings are consistent with the study of adult cancer in the Denver area by Wertheimer and Leeper (1982). Although the Denver study reported significant associations between certain types of cancer in adults and proximity to highcurrent powerlines, leukemia was not one of them.

Results of the Seattle study were re-analyzed by Wertheimer and Leeper (1988). Their analysis included collapsing the four powerline configuration classes into two, and combining powerline and electrically heated bed exposures. Wertheimer and Leeper concluded that their analysis indicated a clear association between field exposure and leukemia. A co-author (Stevens 1988) of the Seattle study was critical of the post hoc analysis. He replied that the Wertheimer-Leeper analysis did not alter his conclusion that the Seattle study was essentially negative.

Occupational Health Studies. In the early 1960's, the American Electric Power Company sponsored the first occupational studies done in North America of workers exposed to high-voltage transmission lines. Ten linemen who performed hot-line maintenance on $345-\mathrm{kV}$ lines were repeatedly given complete physical examinations at the Johns Hopkins Hospital throughout a 42-month interval (Kouwenhoven et al. 1967, Barnes et al. 1967). The study found no significant changes of any kind in the general physical examinations, and the men remained essentially healthy. The linemen were further observed by a team of physicians over a 9-year period (Singewald et al. 1973). The physicians found that exposure to high-intensity electric fields caused no long-term health effects in this small sample of linemen.

A Soviet paper discussed during a US/USSR symposium in February 1975 reiterated earlier Soviet reports that EHV substation workers had experienced problems (Lyskov et al. 1975). During the oral discussion on the paper, the Soviets added that they attributed the reported effects to long-term field exposure. They also said the effects disappear in about 1 month when workers are assigned to jobs outside a high-electric-field environment.

The Soviets have also apparently conducted studies of families of men who worked around substations and lines of 330- to 750-kV (Dyshlovoi and Kachura 1977, cited in Savin et al. 1978). No effects linked to electric fields were found on male/female offspring ratios, miscarriages, stillborns, or hereditary illnesses.

In Canada, the Soviet reports prompted research on personnel who worked in 735-kV substations (Roberge 1976). The 56 men examined in the study did not report complaints 
related to the work environment except for the fear of electric shocks. Another Canadian study involved 30 men who worked around transmission lines (up to $500 \mathrm{kV}$ ) and in switchyards (Stopps and Janischewskyj 1979). Based on medical examinations, there were no differences in the health status of the workers when compared to their agematched controls.

Malboysson (1976) reported on a study in Spain of 84 men who worked in electrical substations and near high-voltage lines (to $400 \mathrm{kV}$ ). The health of these workers was compared to a control group consisting of men who worked on low-voltage lines. Data from medical examinations and sick leave records indicated that electric and magnetic fields caused no pathological effects on the workers.

Another European study involved electrical workers in Czechoslovakia (Peceny et al. 1983). Health data from 37 men who worked in $400-\mathrm{kV}$ switch rooms was compared to data from 19 men who worked in $200-\mathrm{kV}$ switch rooms. The researchers found no symptoms in the workers which would indicate an occupational disease related to highvoltage fields. The frequency of certain subjective health complaints was greater among the $400-\mathrm{kV}$ switch room workers. The authors suggested that work in the stronger fields may lead to earlier manifestations of such complaints in predisposed persons.

In China, an extensive study of 942 electrical workers was conducted (Jingyi and Fanghua 1980). Detailed medical evaluations were done in 1978 of workers exposed to lines of 44 to $220 \mathrm{kV}$. In 1979, additional data were collected on 124 workers exposed to the highest fields. Compared to a control group, no significant differences were found in the percentage of workers experiencing subjective ailments. Some differences were found in blood cholesterol levels, blood pressure, ECG, and EEG. The authors concluded the differences may have been related to the electric field, and/or to work involving bare-hand contact with energized conductors.

Knave et al. (1979) reported that medical evaluations of 53 people who worked in Swedish 400-kV substations did not indicate any direct effects of the electric field on the workers. The substation workers did father fewer children, especially boys, as compared to a control group. The researchers pointed out, however, that the difference in number of children existed 10 to 15 years before the fathers began to work in electrical substations.

The Swedish State Power Board sponsored follow-up research of 542 electrical workers (Nordstrom 1981, Nordstrom et al. 1983). Results indicated a slight tendency in a sample of 20 substation workers for increased chromosome breakage in somatic cells (blood lymphocytes). A higher percentage of substation workers reported fertility problems compared to men in other occupations. There were also increased birth defects in offspring of substation workers. Nordstrom recommended caution in the interpretation of these preliminary results.
Mild et at.-(1982) reported on follow-up work designed to clarify possible electrical factors responsible for the chromosome breaks reported by Nordstrom (1981). Samples of human blood leucocytes were exposed to high-voltage pulses in an effort to simulate spark discharge shocks received by substation workers. The pulses did damage the blood cells, but the researchers pointed out that further work was needed to determine whether transient currents cause chromosomal damage. In more recent work (Nordenson et al. 1984), comparisons were made between human blood samples subjected either to spark discharge or to a-c current. The latter simulated the effect of the electric field. Results showed that the spark discharges in the test increased the frequency of chromosome breaks in blood lymphocytes, but the current did not.

Chromosomal aberrations were again found in blood samples from 19 men who worked in Swedish 400-kV substations (Nordenson and Mild 1985). The researchers suggested that, based on the above in vitro studies, the effects were possibly related to transient currents and shocks received by the workers. An extensive 10-year-long investigation of the possible health risks associated with working in a high-voltage environment is underway in Sweden (Knave 1981).

The Swedish research prompted a study in Germany that involved 32 workers occupationally exposed for more than 20 years to $50-\mathrm{Hz}$ fields of up to $12 \mathrm{kV} / \mathrm{m}$ in $380-\mathrm{kV}$ switchyards (Bauchinger et al. 1981). Analyses of chromosomes from 32 switchyard workers were compared to those of 22 men who did not work in electric fields. There was no significant difference in the frequency of chromosome breaks between the two groups. It is not clear to what extent the workers experienced spark discharge shocks during their work. There were no indications of fertility disturbances, and no apparent effects in children of the workers.

In some industrial occupations, workers are exposed to magnetic fields of tens or even hundreds of $\mathrm{mT}(100$ to 1000 G) (Tenforde 1978). One physician with nearly 30 years experience in industrial medicine reported that he had never found any health damage to workers caused by highintensity magnetic fields (Hauf 1981:25). This included workers exposed to $10 \mathrm{mT}(100 \mathrm{G})$ fields for up to 8 hours per day.

An occupational health study was also done in England and Wales (Broadbent et al. 1985). Health questionnaires were administered to 390 men who worked on lines from $11 \mathrm{kV}$ to $400 \mathrm{kV}$. The study found that the general level of health of the workers was higher than that for workers from other industries. Differences in health measures were found associated with such factors as working overtime, working alone, and changing of shifts. No significant correlations existed between health measures and $50-\mathrm{Hz}$ electric field exposure. 
Occupational Cancer Studies. Milham (1982) first reported that men in ten "electric" occupations had excess deaths due to leukemia. Included were such diverse occupations as electricians, linemen, motion-picture projectionists, streetcar and subway motormen, and others. The study was based on an analysis of death certificates from a 30-year period in Washington State. In an updated review with 3 more years of data, Milham (1985a) reported that eight of nine electrical occupations again showed increased numbers of leukemia deaths.

The analysis of the Washington data consisted of calculating proportionate mortality ratios (PMR's). The PMR is an index for the relative importance of a particular cause of death compared to other causes. It is not an actual mortality rate. It is relatively easy to calculate and is used by some epidemiologists as a preliminary screening technique. In the Milham report, the electrical occupations had a combined excess of death from leukemia (all types) of 36 percent; i.e., a PMR of 136. The PMR for acute leukemia was 163. Other occupations in Washington also having elevated PMR's for leukemia included farmers, bankers, building contractors, chemists, and several others (Milham 1983).

The Washington report prompted other epidemiologists to look at occupational data in their locales. In California, Wright et al. (1982) reported a trend for increased leukemia incidence in men in 11 electrical occupations in Los Angeles County. Similarly, McDowall (1983) and Coleman et al. (1983) reported higher-than-expected numbers of leukemias for electrical workers in England and Wales.

Calle and Savitz (1985) calculated PMR's for Wisconsin men using the same 10 electrical occupations defined by Milham (1982). For the group, no significant excess in leukemia mortality was found, although PMR's were elevated in two categories (electrical engineers, radio and telegraph operators).

Savitz and Calle (1987) also performed an analysis by combining their results with 10 other cancer studies which had used the electrical occupation categories as defined by Milham (1982). Of these studies, five reported elevated risk estimates for the combined occupations; only two were statistically significant. Combining the results of all 11 studies, however, resulted in a statistically significant 1.2to 1.5-times increased risk for various types of leukemia. Telegraph, radio, and radar operators; power and telephone linemen; and electrical and electronic engineers showed the most consistent results. Figure 29 shows the combined relative risks for acute leukemia in the various electrical occupations.

In a similar review of recent research, Coleman and Beral (1988) concluded that certain electrical workers seem to have an 18 percent average increase in the risk of leukemia. Without further research, which includes exposure assessment, the cause or causes of the small-to-moderate

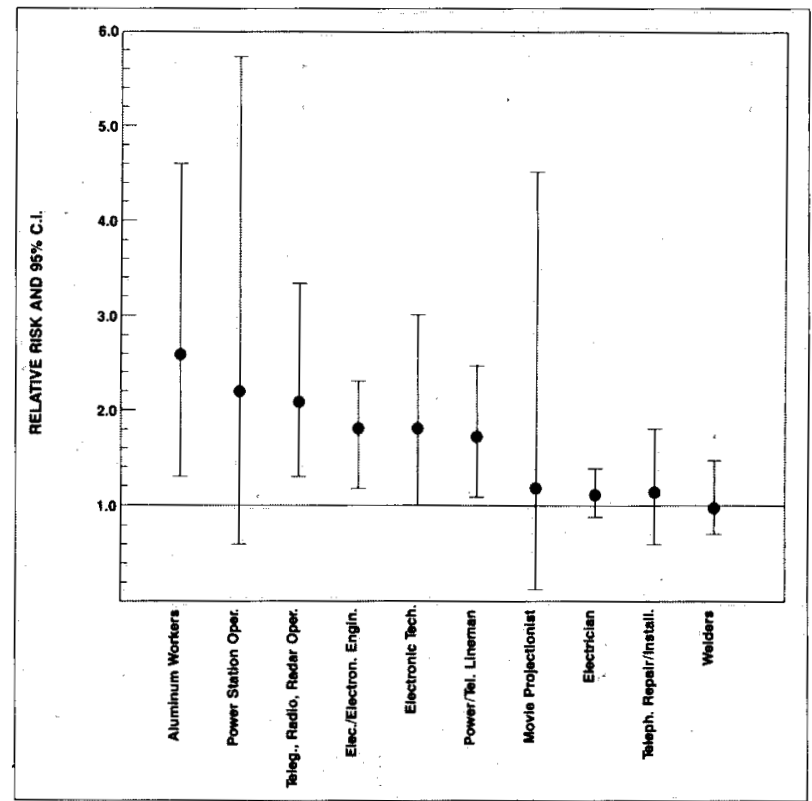

FIGURE 29. Summary of relative risks for acute leukemias in various electrical occupations, from combined data reported in 11 studies. The data were mainly proportional measures (e.g., PMR), not actual leukemia rates. (Source: Savitz and Calle 1987:49.)

increased leukemia risk in some electrical occupations cannot be determined.

Bowman et al. (1988) reported on a survey of short-term measurements of electric and magnetic fields within workplaces for the electrical occupations first studied by Milham (1982). Most of the occupations did show higher magnetic field levels than levels measured in offices and homes. A smaller difference was found in the electric field levels.

Lindsay and Howe (1986) reported on preliminary results of a long-term study in Canada to monitor cancer mortality in a 10-percent sample of the labor force. Among those occupations showing elevated SMR's (standardized mortality ratios) were linemen and servicemen (telephone and power). For non-Hodgkins lymphoma, the SMR was 2.79; for leukemia the SMR was 2.43. However, these ratios were based on a total of only 3 deaths.

Researchers from Johns Hopkins University studied acute nonlymphocytic leukemia in telephone company employees (Matanoski et al. 1988). A total of 222 leukemia cases were matched to 687 company controls. Preliminary results of the study indicated no statistically significant association between telephone line work and leukemia (EPRI, EMF Research Review, September 1988). The telephone line workers are exposed to electric and magnetic fields from powerlines located on shared utility poles. Preliminary 
exposure assessment indicated that the telephone line workers are typically exposed to magnetic fields of around $0.2-0.8 \mu T$ (2- $8 \mathrm{mG}$ ) (Breysse et al. 1988).

Juutilainen et al. (1988) briefly reported on a study of cancer among electrical workers in Finland. The risk ratio for leukemia for combined electrical occupations was 1.23. The highest risk, 3.13, was recorded for linemen and cable jointers (no statistical testing for significance was indicated for any of the reported risks). The authors of the study said that because the number of cases was small (17), they could not draw any conclusions from their data.

A report from England and Wales indicated an excess of eye cancer among electrical and electronics workers (Swerdlow 1983). A later study in Canada, however, did not confirm an elevated risk of eye cancer in electrical workers (Gallagher et al. 1985).

A report from Sweden found that mortality from cancer for electrical engineers was only half of the expected level (Olin et al. 1985). This study was based on standardized mortality ratios (SMR) calculated for a group of engineers and for a control group of architects. Mortality rates were also compared to the population at large.

Milham (1985b) reported on an analysis of 1,691 death certificates for amateur radio operators from Washington and California. The group showed elevated PMR's for certain leukemia cell types. Milham concluded that the results were further support for a hypothesis that electromagnetic fields are carcinogenic. Presumably, the radio operators were exposed to both $60-\mathrm{Hz}$ and radio-frequency fields.

Milham (1988) obtained additional data on amateur radio operators in Washington and Oregon and conducted an SMR analysis involving 2,485 deaths. In terms of all causes of mortality and all cancer mortality, the operators actually had lower death rates than the general population (SMR's of 71 and 89 respectively). For all leukemias, however, there was an elevated, but nonsignificant SMR of 124 . Statistically significant increased SMR's were found for acute myeloid leukemia (SMR = 176) and for other lymphatic tissues (SMR $=162)$. Milham again suggested that electric and magnetic fields were possible factors in explaining the excess mortality from these cancer types.

A case-control study in New Zealand found that men from a group of nine electrical occupations had a combined odds ratio for leukemia of 1.7 (although not statistically significant) (Pearce et al. 1985, Pearce 1988). Within the group, odds ratios for radio/television repairmen (8.17) and electricians (4.75), however, were significant. Pearce suggested that the excess leukemia risk may be associated with exposure to electric and magnetic fields and/or to solvents and metal fumes.

Gilman et al. (1985) also acknowledged that multiple expo- sures may have been predisposing factors associated with an increased risk of leukemia in underground miners. Exposure to benzene, for example, may explain a slightly elevated risk of acute myelogenous leukemia among miners. The researchers suggested that electric and/or magnetic fields (from electrical wiring and equipment) may be associated with an increased risk of chronic lymphocytic leukemia for which no chemical causes are apparently known.

Another study of multiple exposures involved 53 leukemia deaths in workers at a U.S. Naval nuclear shipyard (Stearn et al. 1986). The primary purpose was to assess whether there was an association between leukemia deaths and exposure to ionizing radiation or to organic solvents. No such associations were found. Additional data analysis, however, showed that two job categories were associated with significantly increased leukemia deaths. Electricians showed an odds ratio of 3.00 for all leukemias and electric welders had an odds ratio of 3.83 for myeloid leukemia.

A more recent report also found an association between chronic myeloid leukemia and prior employment as a welder (Preston-Martin and Peters 1988). The study involved 130 leukemia cases and 130 controls from Los Angeles County. Twenty-two cases and four controls had previously worked as welders, and the age-adjusted odds ratio was 25.4 . The authors of the report suggested a causal connection between welding exposure (or a closely associated factor) and development of leukemia.

A Swedish study concerned with a possible association between acute myeloid leukemia (AML) and background ionizing radiation also mentioned electrical occupations (Flodin et al. 1986). Gamma radiation in concrete houses in Sweden is reportedly twice as high as in wooden houses. The study found that AML incidence associated with concrete houses was also doubled compared to wooden houses. Supplementary analyses showed significant increased risk ratios associated with medical x-ray treatment (3.5), styrene exposure (18.9), and with electrical worker occupations (3.8). The latter category included electrical technicians, electrical welders, and computer and telephone mechanics.

In Maryland, researchers suggested a possible link between occupational exposure to magnetic and electric fields and brain tumors (Lin et al. 1985) A case-control analysis was done involving 951 men who had died of brain tumors. For the occupations assumed to have had definite exposure to electric and magnetic fields, tumor cases were more than twice as frequent as expected (odds ratio $=2.15$ ). This group included such jobs as electric and telephone company linemen and engineers, railroad and telecommunications engineers, and industrial electricians.

A case-control study of 435 death certificates from parts of Pennsylvania, New Jersey, and Louisiana also examined brain tumor mortality among electrical occupations (Thomas et al. 1987). Relative risk for men who had exposure 
to microwave/radio frequency radiation and worked in electrical and electronic equipment jobs was approximately doubled. Electricians and power and telephone linemen had a relative risk of brain tumors of 1.8 , but the risk was not statistically significant. The authors concluded that a specific causative agent could not be identified because of the wide variety of both electrical and chemical exposures.

Spitz and Johnson (1985) analyzed the occupation of fathers of children that died of tumors of the central nervous system over a 14-year period in Texas. The case-control study showed that children of fathers with presumed exposure to electromagnetic fields had a significantly increased risk of tumors (odds ratio $=2.13$ ). Occupations considered in this group included electricians, electric and electronics workers, linemen, welders, and utility workers. For electronics workers alone, the risk was further increased (odds ratio $=11.75$ ). These researchers also pointed out that electrical workers are exposed to numerous kinds of chemicals.

A more recent case-control study in New York State also looked for associations between central nervous system (CNS) tumors in children and parental occupational exposures (Nasca et al. 1988). For children whose fathers were assumed to have had higher exposures to electric and magnetic fields, odds ratios for CNS tumors ranged from 1.14 to 1.7 . None of these were statistically significant. Also, no significant risks were found for parental exposure to hydrocarbons, or employment in the aerospace industry or pulp and paper manufacturing. A possible association was observed with the father's exposure to ionizing radiation.

A study in Sweden found no consistent excess risk of brain tumors or leukemia in linemen and power station operators (Tornqvist et al. 1986). The study compared cancer incidence in 10,061 men from the two groups with the incidence in other blue-collar workers. There was possibly a slight tendency for excess risk of cancer of the urinary organs in both groups.

A more recent study from Sweden (Linet et al. 1988) reported that electrical line workers showed a statistically significant increased incidence ratio for chronic lymphocytic leukemia (CLL). Risk ratios for other leukemia types were not elevated, however. The researchers suggested that the earlier study by Tornqvist et al. (1986) did not find the elevated risk for CLL, because that study established an age cut-off limit of 64 years.

Another new study that suggested a relationship between brain cancer and exposure to electric and magnetic fields was conducted in Texas (Speers et al. 1988). Researchers compared occupations listed on 202 death certificates from persons who had died from brain cancer with occupations for 238 controls (persons who had died from other causes). The only broad category to show an increased cancer risk (odds ratio $=2.26$ ) was the transportation- communications-utilities group. For utility workers alone, the odds ratio increased to 13.10 , statistically significant. For occupations associated with electricity, the odds ratio was also elevated (2.11); however, it was not statistically significant. Combining the latter occupations with utility workers resulted in a statistically significant odds ratio of 3.94. When occupations were grouped according to presumed degree of exposure to $60-\mathrm{Hz}$ fields, there was a statistically significant trend for higher risk with increased exposure. The authors of the study concluded that the acknowledged limitations of a death certificate study prevented them from specifying the actual factors that were responsible for the elevated risks.

An editorial accompanying the study above briefly reviewed the literature involving electric and magnetic fields and brain cancer. Modan (1988) concluded that the results of the few studies done on this subject should be accepted extremely cautiously because of methodological problems, e.g., lack of good exposure assessment. However, he suggested that electric and magnetic fields should be considered an environmental hazard until proven otherwise.

Electrical Appliances and Heating. A few studies have looked for an association between the use of electrical appliances and electrical heating, and human health effects. Appliance studies have involved electric blankets or heated waterbeds because of the relatively high and prolonged exposures to electric and magnetic fields associated with these devices (Figure 30). One study looked at homes with ceiling cable electric heat.

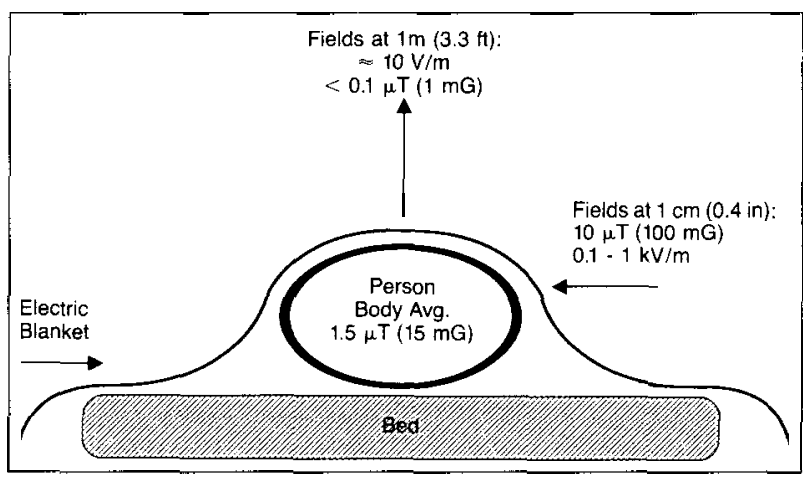

FIGURE 30. Electric and magnetic fields associated with electric blankets. The fields are very non-uniform and field strength decreases rapidly with distance. Magnetic fields penetrate the body; electric fields do not. Both fields, however, induce small body currents. (Source: Adapted from Florig and Hoburg 1988.)

Wertheimer and Leeper (1986) published the first study that investigated possible health effects of electric blankets and heated waterbeds. Those authors conducted telephone 
interviews with 1,318 families in the Denver area which had been identified by published birth announcements. Additional data were obtained from birth records. Some seasonal patterns were found in those cases where electric blankets or heated waterbeds were used. In this group, for conceptions occurring from September through June, the gestation period was approximately 1 -week longer than for conceptions in July and August. Fetal losses (miscarriages and abortions) were also more frequent in this group than in the non-users group. Wertheimer and Leeper suggested their findings could be related to field exposures, or to heat from the electrically-heated beds.

Wertheimer and Leeper conducted another study in an effort to determine whether heat, or $60-\mathrm{Hz}$ fields, were influencing the seasonal differences in fetal losses. This time they looked at data on fetal losses among women in Eugene-Springfield, Oregon, who lived in homes with ceiling cable heat (Wertheimer and Leeper 1989). Field strength in the cable heat homes was reportedly about $1 \mu \mathrm{T}(10 \mathrm{mG})$ and $10-50 \mathrm{~V} / \mathrm{m}$. Fields in homes with electric baseboard heat were assumed to be around $0.1 \mu \mathrm{T}(1 \mathrm{mG})$ and $10 \mathrm{~V} /$ $m$. Results indicated no overall difference in the ratio of fetal losses to live births between women living in homes with the two types of heat. However, women in the cable heat homes reported fetal losses disproportionately often during onset of the cold season when field exposure was assumed to be increasing.

Preston-Martin et al. (1988) looked for a possible association between electric blanket use and myelogenous leukemia in Los Angeles, California. The 224 cancer patients and matched controls were interviewed by telephone to determine their use of electric blankets. Results indicated no differences in the percentages of cases and controls in their use of electric blankets. The researchers suggested that such a study might be more effectively tested in an area where there is a longer and colder winter than in Los Angeles.

Both of the New York-sponsored powerline epidemiological studies also included questions about electric blanket use in their interviews with study participants. Savitz (1987) reported that only 5 percent of the case and control children in his study in Denver used electric blankets. Children with cancer were 1.5 times more likely to have used electric blankets than controls. However, this odds ratio was not statistically significant. The study by Severson et al. (1988) in Seattle found no association between use of electrically heated beds and adult leukemia.

Effects of $60-\mathrm{Hz}$ electric fields on melatonin in rodents (Wilson et al. 1986) prompted a study to determine whether the same effect occurred in people who used electric blankets (Wilson et al. 1988). Forty-two adults participated in the study. They used conventional a.c., and special d.c., electric blankets. The latter do not induce body currents but they still produce heat comparable to the conventional blankets. The people in the study alternately used both the a.c. and d.c. blankets and, therefore, served as their own controls.

Preliminary results indicated that night-time melatonin production was not significantly lowered when the a-c blankets were used. Some individual women appeared to have different melatonin secretion with a-c blankets compared to $d-c$. In addition, when using the a-c blankets, some women reported changes in menstrual cycle length. Further analysis of the data is continuing.

A case-control study of congenital birth defects and use of electrically heated beds is underway in New York state (Dlugosz 1987). No results of this study were available when this report was written.

Exposure Measurements. A major overall problem in epidemiological research is the difficulty in quantifying field exposures. For example, it has been assumed that certain types of electrical workers (e.g., linemen and substation personnel) are exposed to relatively strong fields. If the health status of these workers were to differ from that of other, less-exposed workers, then electric and/or magnetic fields would be likely associated factors. Initial efforts were directed at measuring electric field exposures.

BPA personnel developed a small electric field exposure monitor (EFEM) to measure the electric field environment for high-voltage workers (Chartier and Bracken 1987). The EFEM can be worn on a hard hat, in a shirt pocket, or on a lanyard (Figure 31). Results of the BPA study indicated that, even for the most exposed personnel (230-kV and 500-kV workers), exposure to unperturbed fields above 4 $\mathrm{kV} / \mathrm{m}$ occurs for only minutes per day (Bracken and Chartier 1987). However, accumulated exposure for these personnel was approximately three orders of magnitude greater than exposures for office workers (Chartier et al. 1985).

A study in the United Kingdom also employed a small monitor to assess $50-\mathrm{Hz}$ electric field exposures (Broadbent et al. 1985). The meter was worn on the worker's upper arm. During a 2-week period, only 28 of 287 electrical workers received exposures above $6.6 \mathrm{kV} / \mathrm{m} / \mathrm{hour}$. Estimates were made independently, for a 6 -month period, of percentages of working time spent in fields of 1.5 to $5.5 \mathrm{kV} /$ $\mathrm{m}, 5.5$ to $9.5 \mathrm{kV} / \mathrm{m}$, and greater than $9.5 \mathrm{kV} / \mathrm{m}$. For the most highly exposed group, estimated percentages of working time in the three ranges were 5.6 percent, 15 percent, and 2.2 percent respectively.

In another study, a specially designed vest was used to measure electric field exposures received by people in various farming, recreational, and household situations (Silva 1985) (Figure 32). For the 18 farms studied, the average time a farmer spent in fields above the threshold of perception $(3 \mathrm{kV} / \mathrm{m})$ was estimated as 1 hour per year for farms with $500-\mathrm{kV}$ lines, and a few hours per year for those with 765-kV lines. The total cumulative exposure (in $\mathrm{kV} / \mathrm{m}$ hours) for farmers working near transmission lines was 




FIGURE 31. Electric field exposure monitor (EFEM) developed at BPA to measure occupational exposure to $60-\mathrm{Hz}$ electric fields.

comparable to the cumulative domestic exposures. About half the latter exposure was related to the use of electric blankets. The recreational exposures studied (jogging, bicycling, horseback riding, skiing) were in general lower than estimated for both agricultural and domestic exposures.

Exposure assessment has now expanded to include magnetic fields. The BPA electric field monitor described above was modified to permit measurement of $60-\mathrm{Hz}$ magnetic fields. A recent report described a small BPA study that used the new monitor to measure occupational exposures (Bracken 1988). During 8 exposure days, operators in a $230-\mathrm{kV}$ substation were exposed to an average daily magnetic field of $410 \mathrm{nT}(4.1 \mathrm{mG})$. In contrast, during 9 days, office workers were exposed to an average field of only 74 $\mathrm{nT}(0.74 \mathrm{mG})$.

Canadian researchers used a new type of meter to assess occupational exposures to electric and magnetic fields (Deadman et al. 1988). The meters were worn on a belt or

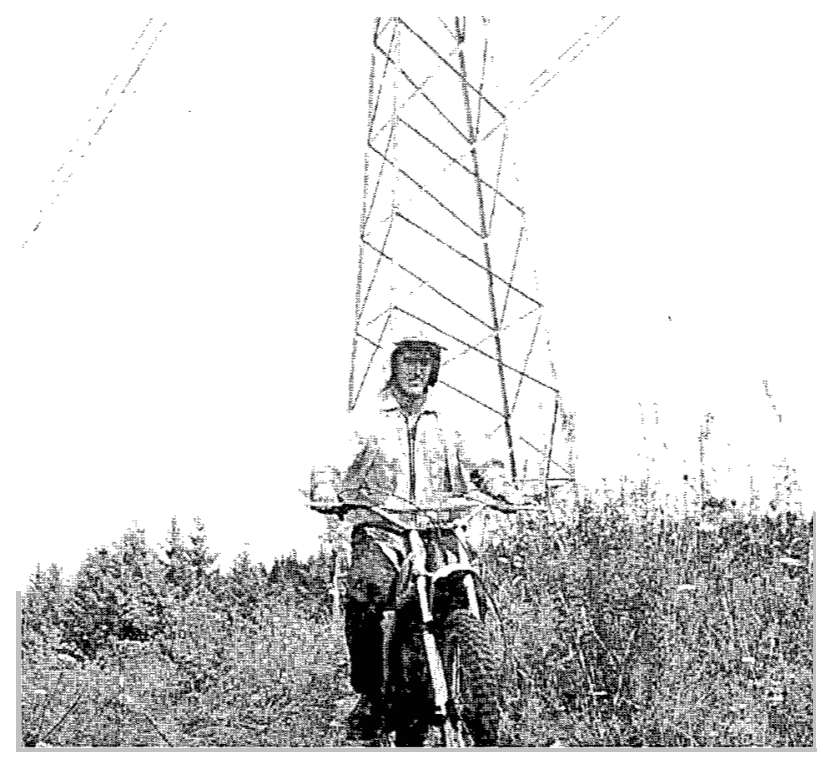

FIGURE 32. Motorcycle rider wearing special vest developed by General Electric and Enertech used to measure electric field exposure during recreational and farming activities.

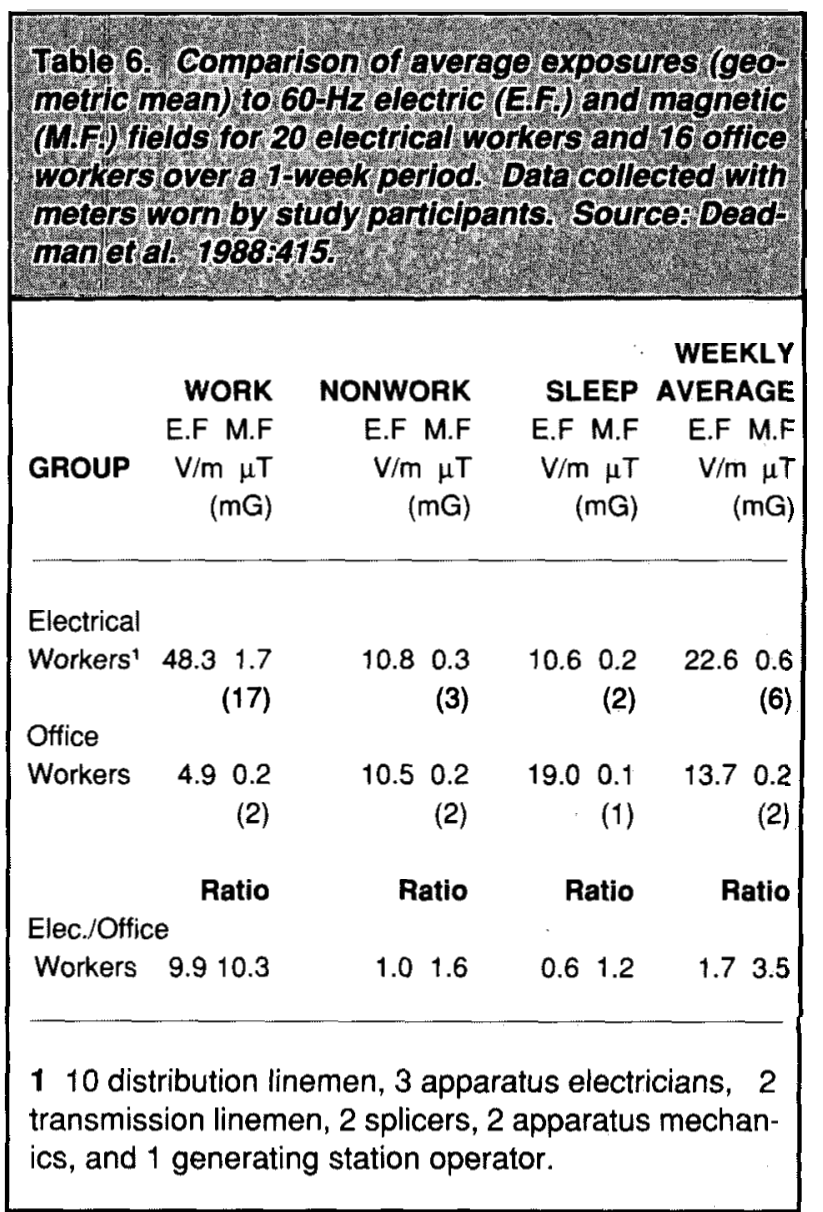


in a shirt pocket at work and at home during a 1-week period. At night, study participants placed the instrument near their beds. Results of the study are shown in Table 6. The electrical workers did receive higher field exposures than the office workers.

EPRI sponsored development of a new digital exposure monitor called the EMDEX (Silva et al. 1988) (Figure 33). This portable unit measures both electric and magnetic fields, and it can operate for up to several days on one charging. A large multi-utility study is underway to obtain information on performance of the EMDEX under actual
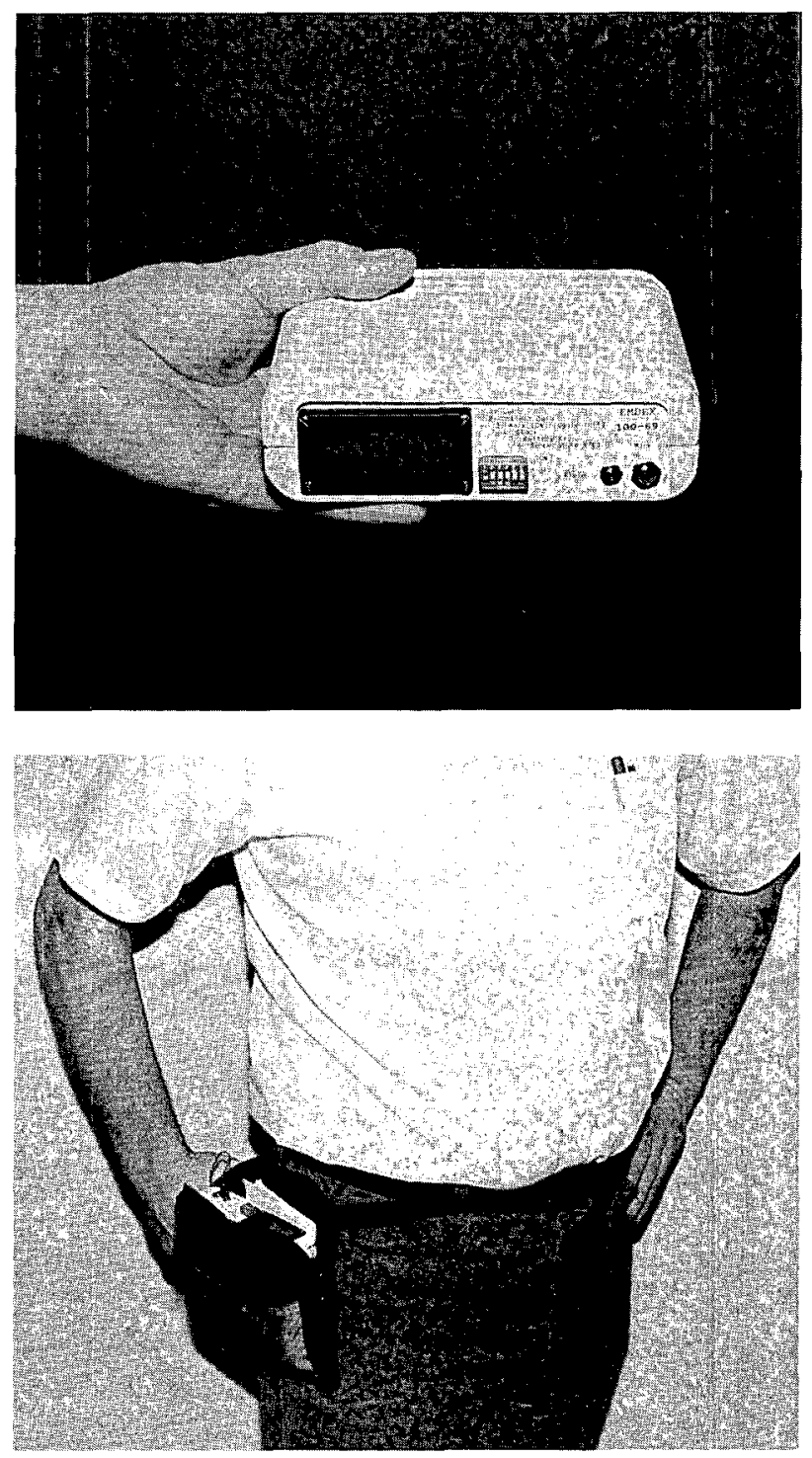

FIGURE 33. EMDEX (Electric and Magnetic Field Digital Exposure) system developed by the Electric Power Research Institute. operating conditions. EPRI is also sponsoring development of a small wrist-worn meter (AMEX) to measure magnetic fields.

A computer program, EXPOCALC, was also developed by EPRI to model human exposures to electric and magnetic fields. It combines data on human activity patterns with data on transmission lines to compute human field exposures near the lines. Output is in the form of exposure histograms and field contour plots.

Swedish researchers developed portable instrumentation to measure exposure to electric and magnetic fields ( $\mathrm{Lindh}$ et al. 1987). The meter is worn on a harness consisting of three pieces containing the field sensors and electronic circuits.

Laboratory Studies. Some work has also been done in the laboratory, with human volunteers exposed to electric and/ or magnetic fields. An early study in Sweden (Johansson et al. 1973) measured the influence of a $50-\mathrm{Hz}$ electric field (of the intensity that exists in high-voltage switchyards) on human reaction time, attention, memory, and motor function. The study reported no significant differences in the performance or on the subjective well-being of the test group compared to a control group.

The Naval Aerospace Medical Research Laboratory exposed 10 men to a magnetic field of $0.1 \mathrm{mT}(1 \mathrm{G})$ at $45 \mathrm{~Hz}$ for periods of up to 24 hours (Beischer et al. 1973). No effects were noted that could be definitely linked with the magnetic field. However, the researchers found that a delayed increase in serum triglycerides (fats) occurred in the men. (Follow-up studies using laboratory animals were conducted-see the earlier section, "Other U.S. Studies.")

Extensive studies with human volunteers exposed to $50-\mathrm{Hz}$ electric and magnetic fields were conducted in the Federal Republic of Germany (see reviews by Hauf 1981, 1982). Electric field strengths ranged from 1 to $20 \mathrm{kV} / \mathrm{m}$, and exposures lasted from 45 minutes to 22 hours. Subjects were seated during the tests. They could detect $50-\mathrm{Hz}$ fields as low as $10 \mathrm{kV} / \mathrm{m}$ by vibrations of skin and hair. There were no effects on ECG, EEG, or blood pressure. Some small changes were seen in some blood components, but they were generally within the normal ranges. The researchers concluded that, under conditions of their study, $50-\mathrm{Hz}$ electric fields to $20 \mathrm{kV} / \mathrm{m}$ did not cause stress or any other harmful effects on human health.

Soviet researchers studied eight men exposed to $10-\mathrm{kV} / \mathrm{m}$ and $15-\mathrm{kV} / \mathrm{m} 50-\mathrm{Hz}$ electric fields (Kalyada et al. 1985). The volunteers sat at a table during daily exposures of up to 2 hours over a 20-day period. EEG readings indicated a slight stimulation effect of field exposure; however, no effect was noted on the men's ability to perform a mental arithmetic test. Some slight changes in the cardiovascular system, e.g., pulse rate, were noted. No significant changes occurred in the concentrations of various blood compo- 
nents. The report did not indicate whether the volunteers could detect the presence of the electric field.

In the United States, researchers at the Midwest Research Institute studied men exposed in a specially-constructed room to $60-\mathrm{Hz}$ fields of $9 \mathrm{kV} / \mathrm{m}$ and $0.02 \mathrm{mT}(0.2 \mathrm{G})$ (Graham et al. 1987, Maresh et al. 1988) (Figure 34). Prior testing had indicated that the threshold for perception of the electric field exceeded $9 \mathrm{kV} / \mathrm{m}$ for 90 percent of the subjects in the sitting position. Twelve men participated in the study, which involved four, 10-hour-long sessions. Exposure had no effects on vital signs, physical symptoms, or on performance in conducting various tests. An interac-
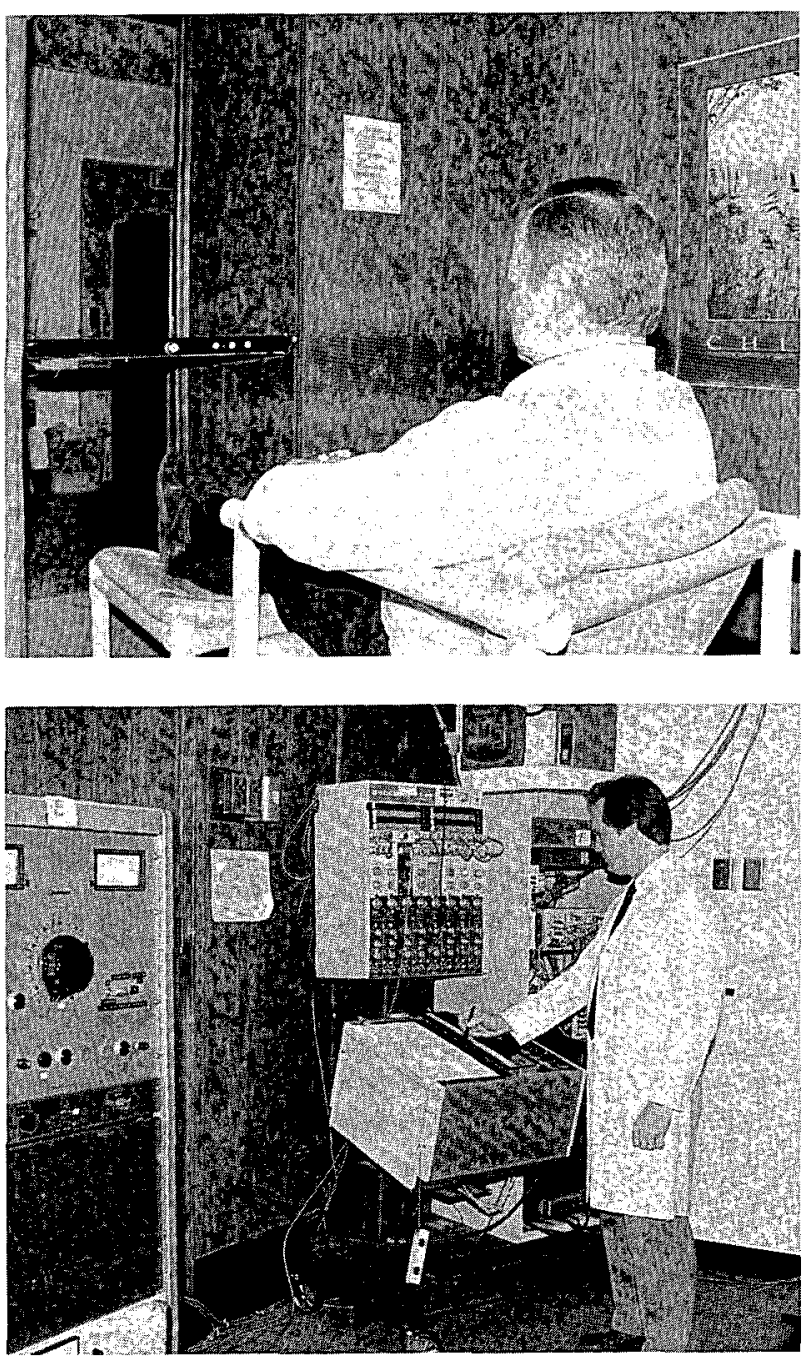

FIGURE 34. Facilities developed at the Midwest Research Institute for short-term studies of people exposed to electric and magnetic fields. Subjects are seated (upper) in the exposure room during the tests. Various parameters are measured and recorded by instruments in a near-by room (lower). tion was found involving field exposure and interbeat cardiac interval (slightly slower heart rate during resting baseline) and some changes were seen in auditory and visual-evoked potentials. The investigators had no initial explanation for the possible significance of the findings, which were based on a small sample size.

Graham et al. (1988) conducted further studies, using a larger number of subjects. Forty-five men were exposed to fields of $9 \mathrm{kV} / \mathrm{m}$ and $0.02 \mathrm{mT}(0.2 \mathrm{G})$. Two physiological effects from the earlier study were again found: changes in brain activity and a slight slowing of resting heart rate. When the field strengths were increased to $12 \mathrm{kV} / \mathrm{m}$ and $0.03 \mathrm{mT}(0.3 \mathrm{G})$, however, the effects were not found. The researchers suggested that conditions associated with when the fields are turned on and off may be more important than field strength. They also suggested that the results may indicate an exposure "window" for the observed effects. The studies are continuing.

Two studies examined the possible effects of electric currents on people not exposed to electric fields. A researcher in the Federal Republic of Germany applied a $50-\mathrm{Hz}, 0.2-$ $\mathrm{mA}$ current between the wrists and ankles of 10 volunteers (Eisemann 1975, cited in Hauf 1982). Although a decrease in pulse rate was noted, there were no significant changes in ECG, EEG, blood pressure, reaction time, and certain blood elements after 3-hour exposures.

In the United Kingdom, researchers used stronger $50-\mathrm{Hz}$ currents $(0.5 \mathrm{~mA})$ injected by electrodes into the head and upper arm of 76 male volunteers (Stollery 1987, Bonnell et al. 1985). Exposures lasted for 5.5 hours. The current did not appear to affect serial reaction time, semantic reasoning, or self-reported stress. In one test involving the ability to evaluate sentences, the response time appeared to be related to exposure to current but not in a straightforward way. The researchers indicated that the current level used is associated with an electric field of $35 \mathrm{kV} / \mathrm{m}$. Because of the mildness of the apparent effects (even at the highcurrent levels), they concluded that no health effects should result to people living near powerlines where field and current levels are much weaker.

Summary. During the last 10 years, the number of studies looking for an effect of powerlines on human health has continued to increase. Laboratory studies have documented some short-term changes in physiological functions in people exposed to electric and magnetic fields. No harmful effects have yet been identified, however.

Most research with people has involved residents living near powerlines, or people who work around power facilities or other electrical devices. Three of the five studies done to investigate a possible association between childhood cancer and powerline magnetic fields 
reported some positive results. Only one of four residential studies reported a possible association between adult cancer and powerlines. About half of the approximately 30 reports on various "electrical occupations" and cancer report some statistically significant elevated risks. Cancer types most frequently mentioned were leukemia and brain tumors. Relative risk levels cited in most of the residential and occupational cancer studies are small (i.e., less than 3.0 ).

Three studies suggested possible effects on reproductive physiology in women who used electrically heated beds or lived in homes with ceiling cable heat.

A major problem with the body of research described in this section is that actual exposures to electric and magnetic fields have, to date, been rather crudely

Table 7. Summary of epldemiological research undormay or planned to assess a possible assoclation between cancer and exposure to $50 / 60-H z$ electric and magneticifields (Primay source: Coloman of al. 1989).

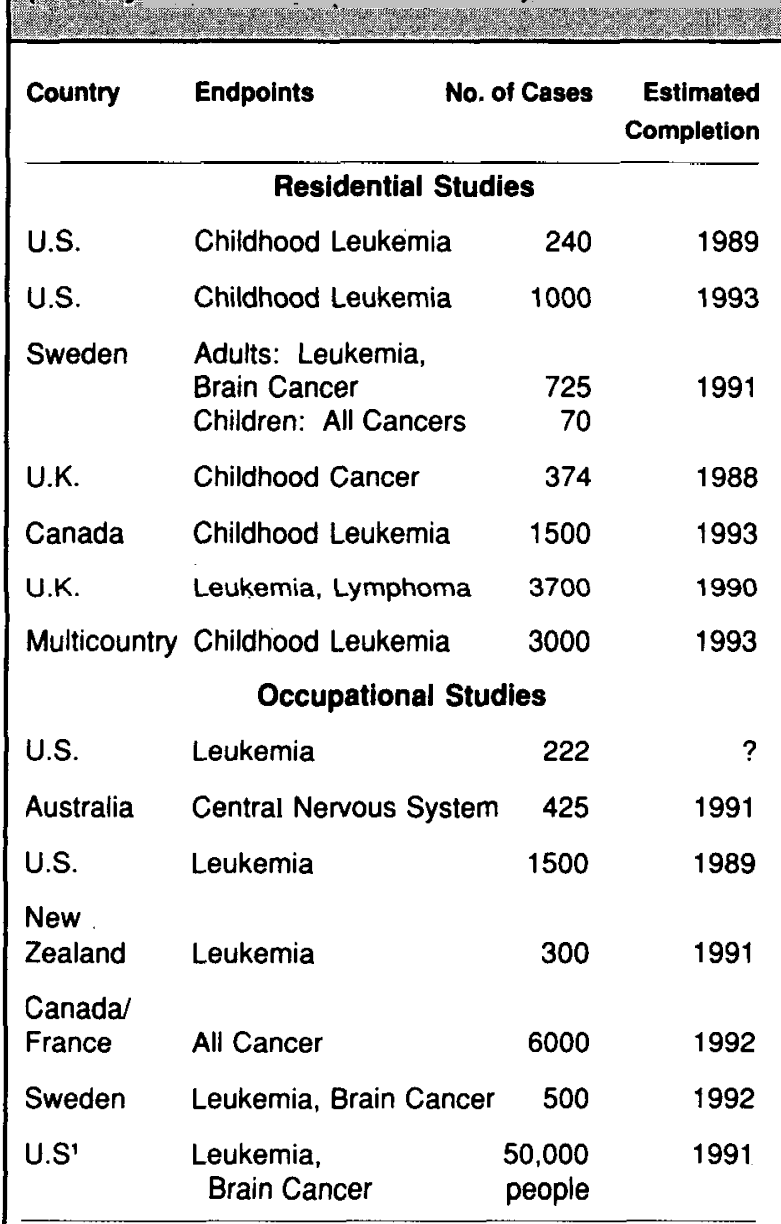

1 This is a planned cohort study with a 20 -year follow-up. measured, or have not been measured at all. In addition, for the occupational studies especially, it is necessary to obtain measurements of other exposures such as those to chemicals.

Overall, the research with humans, supplemented by laboratory animal research, suggests the possibility for adverse effects from human exposure to electric and/or magnetic fields. Only further research will allow this uncertainty to be resolved. Extensive research is underway in the U.S. and in several other countries, mostly focusing on the cancer issue (Table 7).

It remains to be seen whether future epidemiological studies will establish electric and magnetic fields as a human health hazard, or whether they will show that earlier reports were a false alarm. Because of difficulties with epidemiological research in general, Feinstein (1988:1263) concluded that ". . . nonepidemiologic scientists and members of the lay public will have to use common sense and their own scientific concepts to evaluate the reported evidence [on menaces of daily life]."

\section{Medical Applications}

Much of the research described in this review is oriented primarily toward assessing the potential health hazards of electric and magnetic fields. There is also considerable interest in the use of electrical currents and fields for medical diagnosis and treatment. A large variety of field strengths and frequencies has been used, from direct current to microwave. Several such applications are now in routine use (Barker and Freeston 1985). There is, however, continued controversy about the true effectiveness of many of the treatment applications. Following is a brief summary of some medical uses of electric and magnetic fields.

Pulsed magnetic fields have been used to stimulate nerves for both diagnosis and treatment of conditions (such as lower back pain) (Barker 1985). High- frequency fields (e.g., $27 \mathrm{MHz}$ ) at high power are also used in diathermy (heating) treatments for various ailments, including cancer (Shupe and Hornback 1985).

Both $d-c$ and radio-frequency magnetic fields are used in combination in magnetic resonance imaging devices used to provide high-resolution diagnostic scans of the body (WHO/IRPA Task Group 1987) (Figure 35). The d-c fields used range in strength up to $1 \mathrm{~T}(10,000 \mathrm{G})$.

Electricity has been used for many years by some physicians in efforts to stimulate bone formation in the repair of fractures (Bassett 1988). Many applications involved d-c currents injected directly in or near the bone, although 
externally applied electric and magnetic fields (often with pulsed radio-frequencies) have also been used. Many patients have been treated with the method with an overall success rate reported as close to 80 percent (Shupe and Hornback 1985). Although good success is claimed by some, in a review of this technique, Spadaro concluded, "... the clinical evidence is fundamentally uncontrolled and suffers from an abundance of mitigating circumstances ...." (Spadaro 1982:110.)
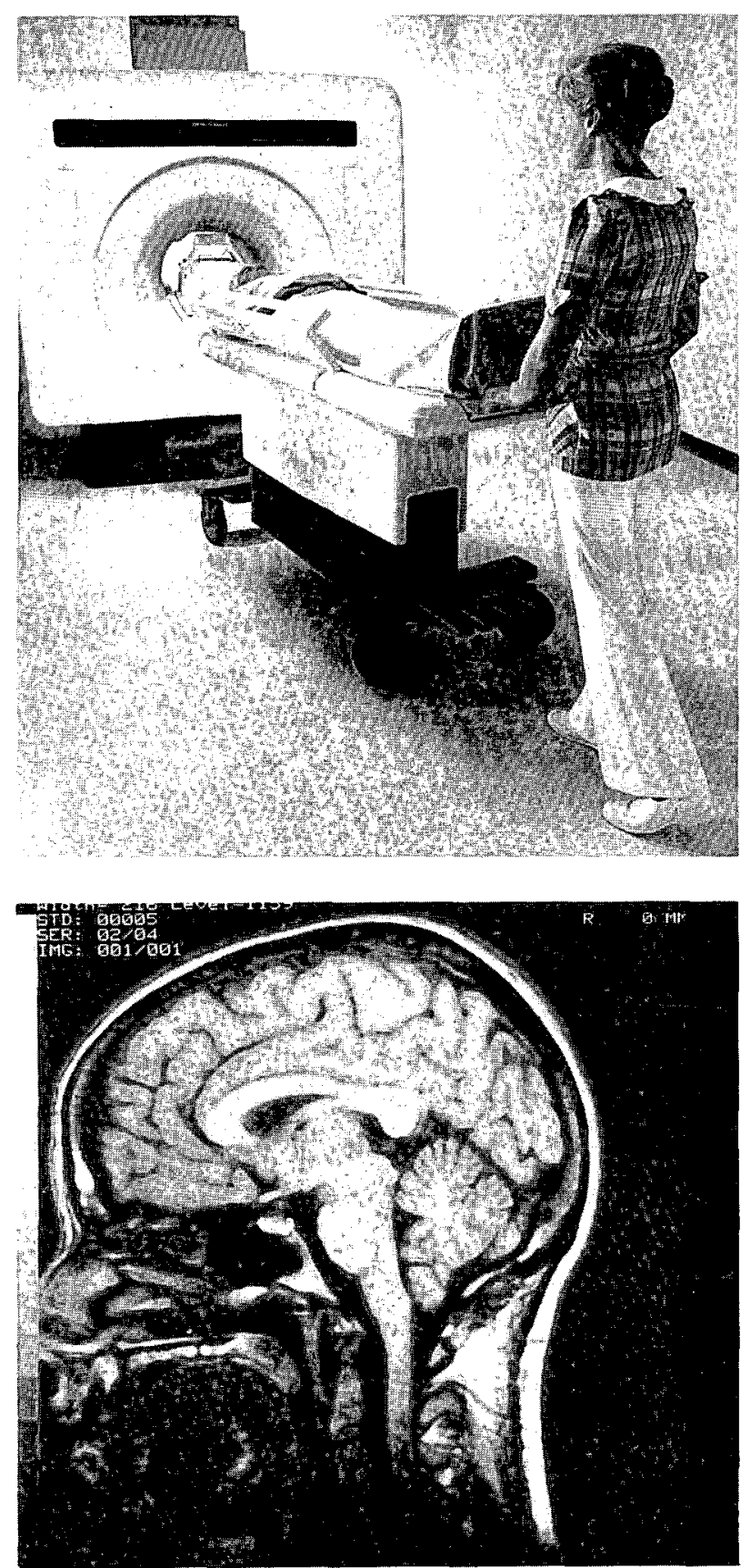

FIGURE 35. A combination of $d-c$, and radio-frequency ac, magnetic fields are used in Magnetic Resonance Imaging. This technique produces high-resolution images of internal body structures. (Source: General Electric Co.)
In a more recent review, a leading researcher in this field reported that the clinical effectiveness of pulsed electromagnetic fields has been strengthened by several recent studies (Bassett 1988). Bassett believes that this technique represents a major therapeutic advance which will expand into many facets of medical practice.

Eabry (1987) observed that, as with many things in life, there are both benefits and risks associated with electric and magnetic fields. He suggested that the apparent therapeutic benefits of these fields should not be fostered without carefully examining the side effects.

\section{Risk Assessment}

A primary use of the data developed by the many research programs described above is to provide a basis for assessing the possible health risks associated with living or working near powerlines. Risks can be defined as quantitative measures of hazard consequences (Hohenemser et al. 1983). Hazards are the threats to humans and what they value. For example, driving an automobile is hazardous. The risks can be defined by such measures of hazards as the probability (likelihood) of being involved in a fatal traffic accident during a lifetime of driving.

Risks have been calculated for many aspects of our technological society, including exposure to toxic chemicals or ionizing radiation, or the chance of dam failures, and so on. in such cases, prior experience or research has confirmed that hazards exist. For powerline fields, however, no hazards have as yet been confirmed for people or animals (except for the special cases of cardiac pacemakers and honeybees). Thus, it is not possible to develop parallel risk estimates for field exposures.

As a result, there are fundamental differences between the scientific controversy over biological effects of electric and magnetic fields, and other well-known controversies such as those over ionizing radiation, microwaves, and toxic chemicals. For the latter three, there is no debate over the existence of hazardous effects above certain levels of exposure. There is controversy over whether there are significant effects associated with low-level, long-term exposures.

Even strong $60-\mathrm{Hz}$ fields have not been shown to cause obvious harmful effects to people or animals. The controversy and continued interest is basically over whether the subtle effects observed in some studies may eventually be shown to have some significant consequences for public or worker health. This situation also applies to many other common factors in our society.

Table 8 gives some examples of relative risk levels for some confirmed and possible cancer factors as reported in epidemiological studies. Notice that confirmed factors tend to have the highest relative risks. This means that the factor 


\begin{tabular}{|c|c|c|}
\hline Factor (Cancer Type) & Relative Risk ${ }^{1}$ & References \\
\hline Smoking (Lung Cancer) ${ }^{2}$ & $10-40$ & Wynder and Hoffman1982 \\
\hline $\begin{array}{l}\text { Benzene, Occupational } \\
\text { Exposure (Leukemia) }{ }^{2}\end{array}$ & $1.5-20$ & Sandler and Collman 1987 \\
\hline $\begin{array}{l}\text { Asbestos, Occupational } \\
\text { Exposure (Lung Cancer) }{ }^{2}\end{array}$ & $2-6$ & Fraumeni and Blot 1982 \\
\hline $\begin{array}{l}\text { Prenatal X-ray Exams } \\
\text { (Childhood Cancer) }\end{array}$ & 2.4 & Harvey et al. 1985 \\
\hline $\begin{array}{l}\text { Environmental Tobacco } \\
\text { Smoke (Lung Cancer) }\end{array}$ & $2-3$ & Fielding and Phenow 1988 \\
\hline Hair Dye (Leukemia) & 1.8 & Cantor et al. 1988 \\
\hline Powerlines (Childhood Cancer) & $1.5-3$ & $\begin{array}{l}\text { Wertheimer and Leeper 1979, } \\
\text { Savitz et al. } 1988\end{array}$ \\
\hline Saccharin (Bladder Cancer) & $1.5-2.6$ & IARC 1987 \\
\hline $\begin{array}{l}\text { Excessive Alcohol } \\
\text { (Oral Cancer) }^{2}\end{array}$ & $1.4-2.3^{3}$ & Tuyns 1982 \\
\hline Electrical Work (Leukemia) & $1.4-1.9$ & Savitz and Calle 1987 \\
\hline $\begin{array}{l}\text { Coffee (Bladder Cancer) } \\
\text { Chlorinated Surface Water }\end{array}$ & $1.3-2.6$ & Morrison and Cole 1982 \\
\hline (Bladder Cancer) & $1.3-2.3$ & $\begin{array}{l}\text { Subcommittee on Disinfectants } \\
\text { and Disinfectant By-Products } 1987\end{array}$ \\
\hline $\begin{array}{l}1 \text { Monson (1980) characterized the significance of } \\
\text { relative risk levels as follows: }\end{array}$ & \multicolumn{2}{|c|}{$\begin{array}{l}2 \text { Generally considered as confirmed cause-and- } \\
\text { effect associations. }\end{array}$} \\
\hline $\begin{array}{cc}\text { Relative Risk } & \text { Association } \\
1.0-1.2 & \text { None } \\
1.2-1.5 & \text { Weak } \\
1.5-3.0 & \text { Moderate } \\
3.0-10.0 & \text { Strong } \\
\text { Above } 10.0 & \text { Infinite }\end{array}$ & \multicolumn{2}{|c|}{$\begin{array}{l}3 \text { Alcohol, combined with heavy smoking, increases } \\
\text { the risk of oral cancer up to } 15.5 \text {. }\end{array}$} \\
\hline
\end{tabular}

is considered an important cause of the particular type of cancer. Smoking, for example, is the main cause of lung cancer. When several factors may cause a given disease, relative risk (i.e., the degree of association) is weaker for any one of the factors (Lilienfeld and Lilienfeld 1980:307). For example, excessive alcohol use and smoking are both important causes of oral cancer. Relative risks for each factor, however, are smaller than for the two factors com- bined. In general, it becomes very difficult to establish causation when relative risks are small (e.g., below 3 ).

One well-known epidemiologist (Cole 1988) suggested that cause and effect associations are only clearly established when relative risks are large (i.e, 5 or more) and when results of epidemiological studies are consistent. Cole doubted whether future studies will be able to confirm a 


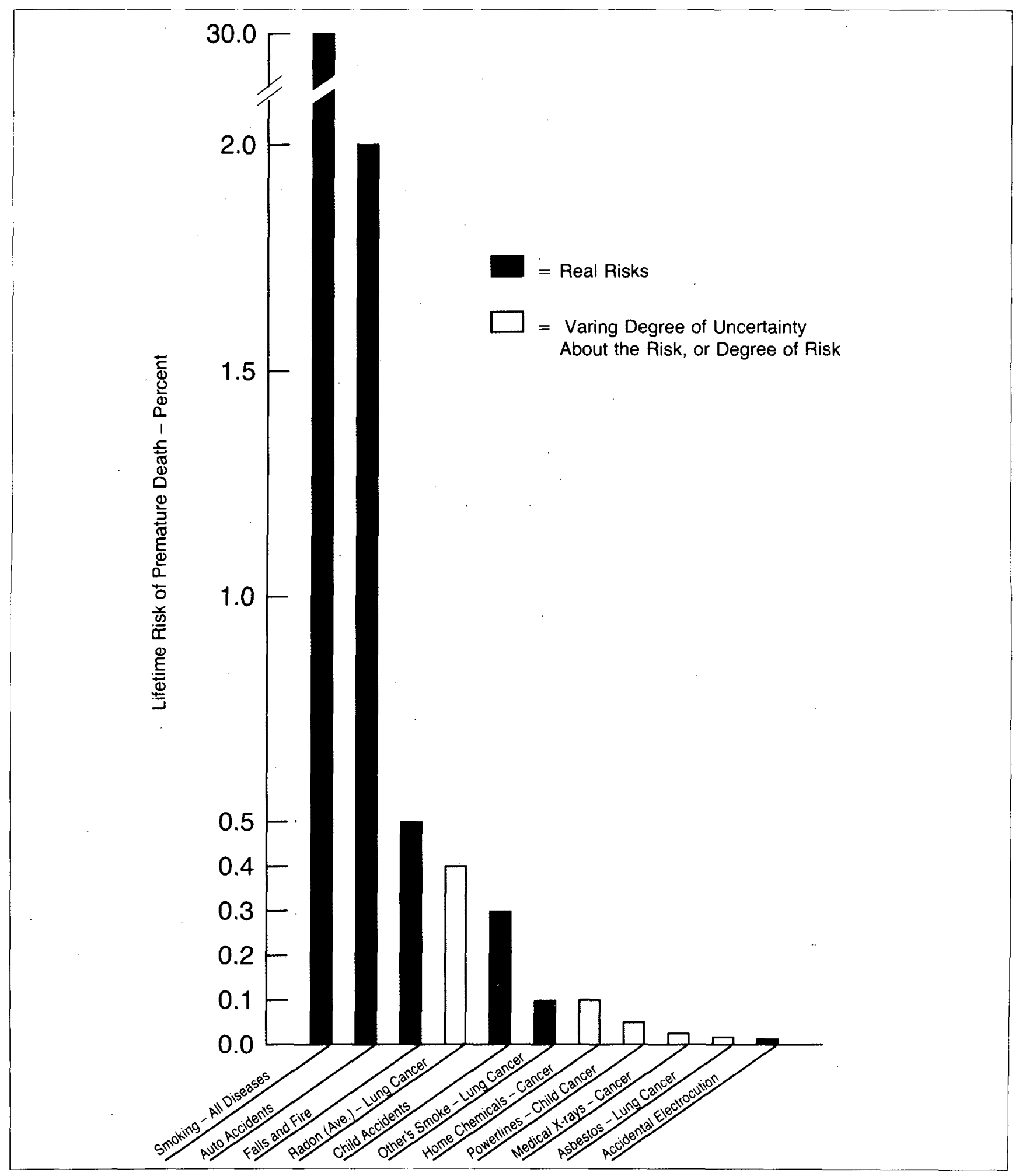

FIGURE 36. Comparison of possible lifetime risk of premature death (in percent) associated with various factors. Except for risks associated wtih accidents, the other risks represent only likely estimates based on available information. In addition, there is much variation among people about whether various real and potential risks are acceptable to them or not. No cause-and-effect link has been established for powerlines and childhood cancer. The potential risk presented here is based on estimates by the New York Science Panel (see text for discussion). (Sources: Nero 1988, Wilson and Crouch 1987, Ahlbom et al. 1987). 
causal association between magnetic fields and cancer. The dean of a school of public health, however, suggested that the evidence for serious effects of magnetic fields is increasing yearly (Carpenter 1988).

To estimate actual population risks, assumptions have to be made about the size of the exposed populations. Figure 36 is an attempt to place the potential cancer risks of power-line field exposures in context with some other known and suspected risk factors. The estimate for powerlines and childhood cancer is highly uncertain. It is based on the preliminary estimate by the New York Science Panel (Ahlbom et al. 1987). The Panel, extrapolating from the study by Savitz (1988), suggested that $10-15$ percent of childhood cancer cases may be due to magnetic fields from high-current powerlines. In terms of mortality, this could amount to around 200-300 deaths per year. The estimate in Figure 36 also assumes that about 20 percent of children live near high-current powerlines. It is important to point out that a cause-and-effect link between powerlines and cancer has not been established, and that information on population exposures to $60-\mathrm{Hz}$ electric and magnetic fields is incomplete.

The evidence suggesting a link between cancer in adults and powerlines is even more uncertain. Therefore, no lifetime risk estimate for adults was included in Figure 36.

Although at present it is not possible to develop actual health risk estimates for exposure to power-line fields, there is some interest in assessing perceived risks. In general, a person's perception of a risk is influenced by such factors as knowledge of the subject, whether the risk is voluntary or involuntary, and the perceived benefits (Slovic et a!. 1980). Therefore, the importance that people place on various risks, such as those in Figure 36 , may vary greatly among individuals.

In terms of the siting and construction of transmission lines, perceived risks are an important concern. Future efforts at risk assessment will have to incorporate not only the results of biological research, but must also consider social perceptions and concerns. The U.S. Department of Energy sponsored research at Carnegie-Mellon University on methodology for risk assessment applicable to transmission lines (Morgan et al. 1985a, 1985b).

Morgan et al. (1987) discussed some of the problems in attempting to apply conventional tools of risk analysis to electric and magnetic field exposures. They reiterated that the available scientific data do not allow one to specify what effects these fields have on human health, or the number of people affected. In this situation, however, Morgan et al. believe that prudence should be exercised. For example, they questioned the use of electric blankets by pregnant women. They also suggested that while new electric power facilities could be planned so as to avoid some field exposures, to date there is no reason to consider relocating existing facilities.

\section{Field Standards}

There are no national standards in the United States for exposure to $60-\mathrm{Hz}$ electric or magnetic fields. However, requirements of the National Electrical Safety Code for induced currents place some upper limits on field strength for powerlines.

In 1975, the U.S. Environmental Protection Agency (EPA) issued a request for information (Federal Register, March 18,1975 ) on health and environmental effects of EHV transmission lines. EPA wanted to determine whether guidance was needed for electric field standards for transmission lines of 700-kV and above. The report on the final analysis of the information received concluded, "However, the work which has been performed to date has not provided convincing evidence that any threat to the public health or welfare has been caused by existing [electric field] exposure levels." (Janes 1980:X).

EPA has continued to monitor the research involving electric and magnetic fields. In 1984, EPA commissioned the National Council on Radiation Protection and Measurements to conduct a critical appraisal of the world-wide literature on this subject. The review is suppose to provide EPA with updated information for presumably another assessment as to the possible need for exposure guidance. By mid-1989, however, this review was still not completed.

Several states have addressed the "biological effects" issue, usually during regulatory proceedings for proposed transmission lines. This has resulted in some states establishing electric field limits, but apparently only three states (Oregon, Florida, and Montana) have formally adopted electric field standards. Florida was the first state to adopt magnetic field standards (see Table 9). The state regulatory activities are summarized below.

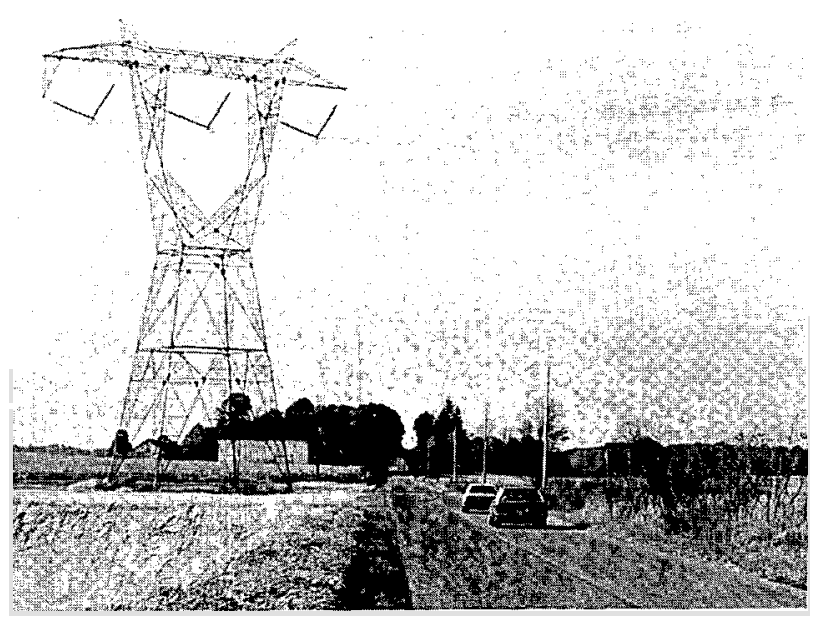

FIGURE 37. The highest operational transmission voltage in the U.S. is $765 \mathrm{kV}$. These lines are used in the Eastern U.S. 


\begin{tabular}{|c|c|c|c|c|}
\hline \multirow[t]{2}{*}{ State/BPA } & \multicolumn{2}{|c|}{ Electric Field } & \multicolumn{2}{|c|}{ Magnetic Field } \\
\hline & $\begin{array}{c}\text { On } \\
\text { Right-of-Way }\end{array}$ & $\begin{array}{c}\text { Edge of } \\
\text { Right-of-Way }\end{array}$ & $\begin{array}{c}\text { On } \\
\text { Right-of-Way }\end{array}$ & $\begin{array}{c}\text { Edge of } \\
\text { Right-of-Way }\end{array}$ \\
\hline Florida & $\begin{array}{l}8 \mathrm{kV} / \mathrm{m}^{1} \\
10 \mathrm{kV} / \mathrm{m}^{2}\end{array}$ & $2 \mathrm{kV} / \mathrm{m}$ & - & $\begin{array}{l}150 \mathrm{mG} \text { (max. load) } \\
200 \mathrm{mG} \text { (max. load) } \\
250 \mathrm{mG} \text { (max. load) }\end{array}$ \\
\hline Minnesota & $8 \mathrm{kV} / \mathrm{m}$ & - & - & - \\
\hline Montana & $7 \mathrm{kV} / \mathrm{m}^{4}$ & $1 \mathrm{kV} / \mathrm{m}$ & - & - \\
\hline New Jersey & - & $3 \mathrm{kV} / \mathrm{m}$ & - & - \\
\hline New York & $11.8 \mathrm{kV} / \mathrm{m}$ & $1.6 \mathrm{kV} / \mathrm{m}$ & $\dot{-}$ & $100 \mathrm{mG}^{5}$ \\
\hline North Dakota & $9 \mathrm{kV} / \mathrm{m}$ & - & - & - \\
\hline Oregon & $9 \mathrm{kV} / \mathrm{m}$ & - & - & - \\
\hline BPA & $\begin{array}{l}9 \mathrm{kV} / \mathrm{m} \\
5 \mathrm{kV} / \mathrm{m}^{4} \\
3.5 \mathrm{kV} / \mathrm{m}^{6} \\
2.5 \mathrm{kV} / \mathrm{m}^{7}\end{array}$ & $5 \mathrm{kV} / \mathrm{m}$ & - & - \\
\hline
\end{tabular}

1 For $230-\mathrm{kV}$ or smaller lines.

2 For $500-k V$ lines.

3 For 500-kV double-circuit lines.

4 Maximum for highway crossings.
5 Proposed interim standard.

6 Maximum for shopping center parking lots.

7 Maximum for commercial/industrial parking lots.
The New York State Public Service Commission conducted extensive hearings from 1975 to 1977 on the potential health and environmental effects of proposed 765-kV transmission lines (Figure 37) (see a review by Scott-Walton et al. 1979). In the final decision, the New York Commission concluded that, "Although the record before us is, in many ways, reassuring-it does not show that the electric and magnetic fields of the lines as proposed will produce effects endangering human health and safety-it contains unrefuted references of possible risks that we cannot responsibly ignore" (SNYPSC 1978:39).

The Commission decided to require that the width of rightsof-way for new 765-kV lines be set so that electric field strength at the right-of-way edge would not exceed that produced by existing $345-\mathrm{kV}$ lines (about $1.6 \mathrm{kV} / \mathrm{m}$ ). (In some other states, $765-\mathrm{kV}$ lines operate with electric fields of $3-4 \mathrm{kV} / \mathrm{m}$ at the edge of the right-of-way.) Also, the New York Power Authority was ordered to fund a program of biological research on electric and magnetic fields.

The New York research program on electric and magnetic fields was completed in 1987 (Ahlbom et al. 1987). In evaluating this program, the New York Public Service Commission concluded that the program was not able to provide a definitive answer about potential health risks of transmission lines (Power Lines Evaluation Task Force 1988).

The Commission decided to retain the $1.6-\mathrm{kV} / \mathrm{m}$ interim limit as a conservative action. The New York PUC also concluded that, even though magnetic fields have not been shown to be hazardous, an interim magnetic field standard was needed. A level of $10 \mu \mathrm{T}(100 \mathrm{mG})$ at the edge of the right-of-way was suggested based on the levels assumed typical of 345-kV lines (NYPSC 1988). New York utilities will make additional measurements of magnetic fields produced by $345-\mathrm{kV}$ lines to define this level better. The utilities were also ordered by the PUC to support research on means of power delivery and use that would reduce magnetic field exposures.

Oregon's state standard allows up to $9 \mathrm{kV} / \mathrm{m}$ on the right-ofway in areas accessible to the public (OAR 345-80-055). Oregon initiated a process in 1988 to review the adequacy of the existing standard and to consider the need for a magnetic field standard. The New Jersey Commission on 
Radiation Protection (1981) set an interim guideline of $3 \mathrm{kV} /$ $\mathrm{m}$ for the electric field at the edge of a transmission line rightof-way. The Minnesota Environmental Quality Board specified in construction permits that the maximum transmission line electric field shall not exceed $8 \mathrm{kV} / \mathrm{m}$ on the right-of-way (Banks et al. 1977).

In 1984, Montana adopted a state standard for electric field strength for new transmission lines constructed in residential and subdivided areas. In that state, the field strength shall not exceed $1 \mathrm{kV} / \mathrm{m}$ at the edge of the right-of-way, although affected landowners can waive the standard. The standard does not apply to existing transmission lines in Montana. In that state, $230-\mathrm{kV}$ and $500-\mathrm{kV}$ lines have operated for many years with edge-of- right-of-way field strengths greater than $1 \mathrm{kV} / \mathrm{m}$. As in New York, the Montana standard is conservative (Berry 1984). It is based on a consultant's report (Sheppard 1983a) which indicated considerable flexibility and uncertainty in attempting to define a single electric-field criterion.

In 1985, an interdisciplinary Science Advisory Commission in Florida evaluated the potential for adverse health effects of exposure to transmission line fields. In a final report submitted to the state of Florida, the Commission concluded that it is unlikely that $60-\mathrm{Hz}$ electric and magnetic fields can lead to public health problems (FEMFSAC 1985). The commission found no scientific basis for recommending risk management strategies such as limiting the electric field strength at the edge of the right-of-way.

In 1986, another Advisory Panel was appointed to advise the Florida Department of Environmental Regulation (DER) on electric and magnetic fields. Because of uncertainties raised by recent research, the Panel concluded that it would be prudent to keep long-term field exposures to the population to low values (Parker et al. 1987). The Panel recommended that, when possible, new transmission lines be routed outside of residential areas. Interim standards for both electric and magnetic fields were also recommended.

The Florida Environmental Regulation Commission (ERC) subsequently recommended that the DER adopt the interim standards recommended by the Advisory Panel. For electric fields, these levels were $1-2 \mathrm{kV} / \mathrm{m}$ at the edge of the right-of-way, and $8 \mathrm{kV} / \mathrm{m}$ maximum on the right-of-way. For magnetic fields, the recommended levels for the edge of the right-of-way were $10 \mu \mathrm{T}(100 \mathrm{mG})$ for maximum loads, and $5 \mu \mathrm{T}(50 \mathrm{mG})$ for normal load conditions. The final standards adopted by the Florida ERC in early 1989 are shown in Table 9.

In 1988, legislation was passed in California that will establish a $\$ 2$ million Health Electromagnetics Field Study Fund. Research will be conducted to determine whether electrical transmission facilities represent an unreasonable cancer risk, and whether legislation is needed to reduce that risk. Such legislation could include limits on electric and magnetic field exposures.
A committee within the American Conference of Governmental Industrial Hygienists looked at the potential for electric fields to affect workers adversely (Sliney et al. 1987). The committee concluded that there was inadequate information for establishing a Threshold Limit Value (TLV). (TLV's have been established for various physical agents to limit worker exposures to the agents.) The committee did suggest that $25 \mathrm{kV} / \mathrm{m}$ be considered as the maximum unprotected work place field strength. They further suggested that "Prudence dictates the use of protective devices (suits, gloves, insulation, etc.) in all fields exceeding $15 \mathrm{kV} / \mathrm{m}$."

At the international level, a committee formed by the World Health Organization (WHO) concluded that, in terms of intermittent exposures, there is no need to limit access to areas where the electric field strength is less than $10 \mathrm{kV} / \mathrm{m}$ (WHO/IRPA 1984). As for long-term public exposures, the committee found no evidence for pathological effects resulting from field exposure. However, because of effects reported in some studiès, they recommended that efforts be made to limit field exposures to levels as low as can be reasonably achieved. The committee did not, however, recommend any specific field strength standard. Another WHO committee reviewed literature on magnetic fields. Their conclusion for a-c fields is given in Appendix $\mathrm{B}(\mathrm{WHO} /$ IRPA 1987). It should be noted that the WHO/IRPA review covered literature published through about mid-1986. Therefore, it did not include the Savitz (1988) study of childhood cancer, and other more recent research on the cancer/magnetic fields issue.

BPA criteria for allowable electric field levels are intended to result in a low probability of human perception or annoyance from field effects. Therefore, the levels are normally much lower than those needed to meet requirements of the National Electrical Safety Code (NESC). BPA 500-kV transmission lines (BPA's largest operational a-c lines) are allowed a maximum electric field of $9 \mathrm{kV} / \mathrm{m}$ on the right-ofway (measured at $1 \mathrm{~m}$ above ground). BPA's maximum allowable field at the edge of the right-of-way is $5 \mathrm{kV} / \mathrm{m}$. However, the maximum calculated edge-of-right-of-way field strength for BPA 500-kV lines is typically around 2-3 $\mathrm{kV} / \mathrm{m}$. As discussed above, the actual field strength is often less than calculated because of conductor ground clearance differences and shielding effects of trees and buildings near rights-of-way. BPA has not established criteria for allowable magnetic field levels.

The NESC specifies that induced currents from transmission lines not exceed $5 \mathrm{~mA}$. BPA policy is to limit induced current to less than annoyance levels ( $2 \mathrm{~mA}$ ) for conductive objects permanently located on or near the right-of-way. This is done by grounding fences and other objects or by reducing electric field strength by increasing conductor-toground clearance.

To meet the NESC $5 \mathrm{~mA}$ limit (for induced currents from the largest anticipated vehicles), the electric field level is limited 
to $5 \mathrm{kV} / \mathrm{m}$ at highway crossings. Across shopping center parking lots, the field is limited to $3.5 \mathrm{kV} / \mathrm{m}$ so that the current induced into sedans and pickup trucks is generally not perceptible (1 mA or below) (Figure 38). Electric field strength is further limited to $2.5 \mathrm{kV} / \mathrm{m}$ on commercial/industrial parking lots to limit the induced current to less than the annoyance level ( $2 \mathrm{~mA}$ ) for personnel working around large trucks.

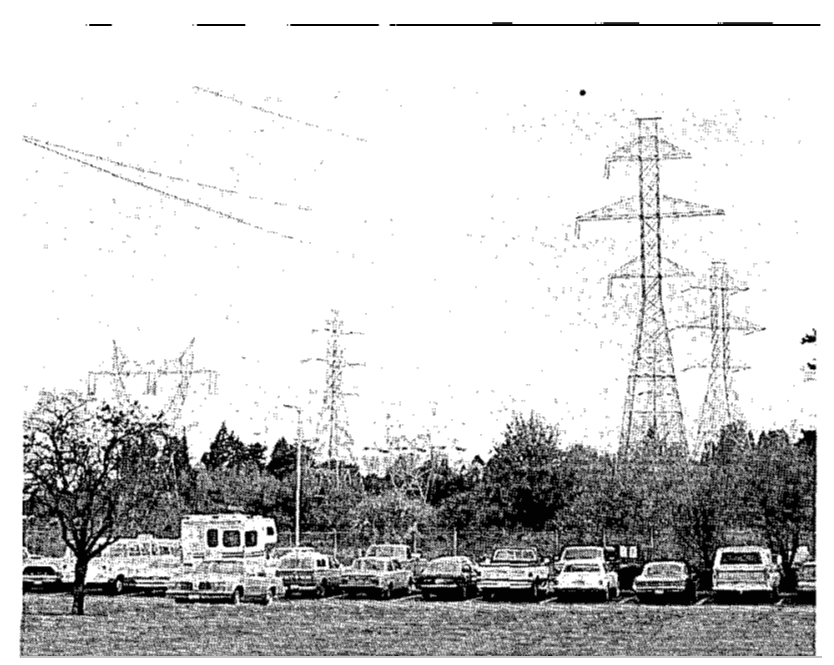

FIGURE 38. Across parking lots, BPA transmission lines are designed with greater conductor-to-ground clearance. This decreases the field strength and reduces nuisance shocks from vehicles.

\section{Field Effects: Special Cases}

\section{Cardiac Pacemakers}

Under some circumstances, voltages and curtents from such things as automobile ignition systems and household appliances can interfere with the operation of implanted cardiac pacemakers (Sowton 1982, Sager 1987). Instruction manuals accompanying pacemakers typically describe the precautions that should be taken by people who have these devices. We know of no published report of a case where a transmission line has harmed the wearer of a pacemaker.

Early pacemaker models which pulsed the heart at a preset rate (asynchronous type) were less likely to be influenced by electrical interference. The newer and more widely used pacemakers (synchronous) are normally in the off mode (inhibited), and send electrical pulses to the heart only when the normal heartbeat slows or stops. These pacemakers function by sensing the electrical activity (R-wave) pro- duced when the heart beats. Electrical interference in some cases may mask the $R$-wave. If this occurs, $R$-wave inhibited pacemakers are designed to revert to pulsing in a regular (asynchronous) mode even though the heart may be functioning normally. Reversion is basically a safety feature. Cardiologists do not agree on whether prolonged operation in the asynchronous mode constitutes a health hazard (Bridges and Frazier 1979).

The sensitivity to electrical interference (e.g., voltage) depends not only on the pacemaker type but also on how it is implanted in the body. The pacemaker is placed beneath the skin and one or two wire leads are inserted through veins to the heart (Figure 39). Electrical current in the body causes a voltage difference between the leads of a pacemaker. Body current can be induced by electric and magnetic fields, or can enter directly through contact with electrical appliances (leakage current) or with charged objects near a transmission line.

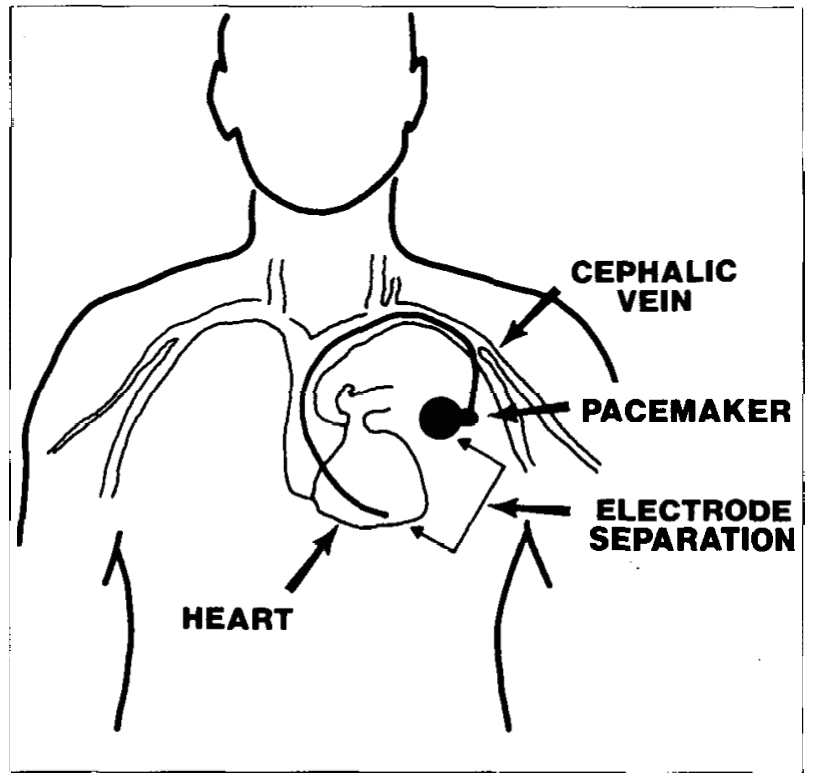

FIGURE 39. Example of monopolar cardiac pacemaker implant. This type of implant tends to be more susceptible to interference than the bipolar configuration, due to the wider electrode separation. (Source: Bridges and Frazier 1979: 3-6.)

Implants with bipolar leads (two wires) are unlikely to be affected by transmission line fields because leads are usually close together (resulting in a small voltage). Depending on the distance between the pacer unit and the single lead, some monopolar implants could revert to asynchronous operation when the wearer is on an EHV line right-of-way (Bridges and Frazier 1979). This would not apply to persons temporarily exposed while inside vehicles 
because the metal vehicle largely shields occupants from the electric field. It is unlikely the weak magnetic field from a 500-kV line would affect pacemaker operation.

In a study from the United Kingdom, 10 volunteer patients with a monopolar, multiprogrammable pacemaker (Medtronic 5985) were exposed to a $20-\mathrm{kV} / \mathrm{m}, 50-\mathrm{Hz}$ electric field (Butrous et al. 1982). Although body currents in the field were up to $0.3 \mathrm{~mA}$, the pacemakers did not revert to the asynchronous mode nor were any other effects found. The researchers expanded the study to include 35 patients and 16 pacemaker models representing 6 companies (Butrous et al. 1983a). Again, the Medtronic unit was not affected by fields to $20 \mathrm{kV} / \mathrm{m}$. However, all the other makes exhibited some response to the field, with most responses occurring in fields of $5 \mathrm{kV} / \mathrm{m}$ or above.

Butrous et al. (1983b) also reported on two cases where pacemakers in electrical substation workers were affected by $50-\mathrm{Hz}$ electric fields. In one case, a Telectronics 174 Programmable pacer reverted to the interference mode in a $2.5-\mathrm{kV} / \mathrm{m}$ field. In the other case, a Cordis $334 \mathrm{~A}$ pacer produced inappropriate pacing in fields above $13 \mathrm{kV} / \mathrm{m}$. The problems were corrected by the use of a protective suit.

Researchers from the University of Rochester evaluated the performance of various pacemaker models in 11 volunteer patients while in a $345-k V$ substation (Moss and Carstensen 1985). The seven pacemaker models from four manufacturers were tested in electric fields ranging from 2 to $9 \mathrm{kV} / \mathrm{m}$. The study found various alterations in pacemaker function in three models from two manufacturers (Cordis 190A, 190F and Cardiac Pacemakers, Inc. 0505). The alterations were detected by monitoring instruments. The patients, who were not life-dependent on their pacers, essentially reported no symptoms. However, the researchers pointed out that, for certain other pacemaker patients, the effects observed in the study could result in serious problems. They also indicated that because some models were not affected, it is possible for manufactures to design pacemaker circuits to eliminate potential problems from $60-\mathrm{Hz}$ interference.

The Florida Science Advisory Commission recommended that the U.S. Food and Drug Administration be urged to revise testing procedures so as to exclude pacemaker designs whose operation is affected by transmission line fields (FEMFSAC 1985:180). The Commission estimated that, at that time, only 1 to 3 percent of the estimated 350,000 to 500,000 pacemaker patients in the United States may be at some risk from $60-\mathrm{Hz}$ electric fields.

As a precaution, persons with pacemakers who may have reason to be outdoors near high-voltage transmission lines should consult with a physician and/or review the reports referenced above, to determine whether their particular type of pacer may be susceptible to $60-\mathrm{Hz}$ interference.

\section{Flammable Materials}

In designing an electric transmission system, one concern is the possibility that a spark discharge could ignite a flammable mixture, such as gasoline vapor. Theoretically, such an incident could occur if a vehicle were fueled under a transmission line. However, no case of a flammable mixture being ignited has been reported for a BPA transmission lines. BPA sponsored a study to determine the conditions under which an ignition might occur (Engle 1982).

For gasoline vapor to ignite, it would require a voltage of 1 $2 \mathrm{kV}$ between the fuel can and a large vehicle. To achieve these conditions, the vehicle would have to be well insulated, the pouring spout well grounded, and a spark would have to occur where the fuel air mixture was close to optimal. The chances that all these conditions would be met is slight.

The distance between the transmission line conductors and highway and road surfaces normally is increased to provide adequate clearances for cars, buses, and trucks. This reduces the field strength at ground level and even further reduces the likelihood that an ignition could take place.

As a conservative precaution, vehicles should be at least 21 $\mathrm{m}(70 \mathrm{ft})$ from an $\mathrm{EHV}$ transmission line when refueling. If a vehicle must be refueled closer, the operator should first connect the fuel can by a jumper wire to some metal on the vehicle (well away from the fuel inlet), before removing the vehicle's fuel cap.

\section{Blasting}

This general discussion on blasting near transmission lines is taken verbatim from a recent report from the IEEE Subcommittee (1985:30). "Explosives are frequently detonated by electric energy carried by long wires from a battery. There have been instances of premature detonation caused by radiated fields from nearby radio transmitters or microwave antennas. A number of devices and procedures can be used to prevent such a potentially catastrophic event. Typically these involve the use of a filter to block out radio-frequency energy. However, these filters will not block out power-frequency interference. Reduction of this interference is possible with shielded cables which lead to the blasting caps. Mitigation procedures with shielded cables must be carefully followed to be effective. Alternatively, nonelectric detonating devices exist which are not sensitive to transmission line fields."

BPA contracted for a study of the safety aspects of electrical blasting near high-voltage transmission lines (Bracken 1985). Several parameters which may constitute a "high level" of hazard were identified. 
These were:

1. Direct contact of the blasting wires (after detonation) with transmission line conductors.

2. Current induction into the blasting wires from transmission line magnetic fields.

3. Magnetic field induction caused by switching or other transmission line disturbances.

4. Lightning within $16 \mathrm{~km}$ (10 mi) of electrical blasting circuits.

Blasting within $300 \mathrm{~m}(1,000 \mathrm{ft})$ of a high-voltage transmission line should be confined to nonelectric systems. All blasting operations, regardless of location, should employ a qualified blaster who complies with all Federal, state, and local regulations.

Persons planning to detonate explosives near a BPA transmission line should notify the nearest BPA office well in advance. The layout of electrical circuits for blasting near the right-of-way should be cleared with that office.

\section{Irrigation Equipment}

Metal irrigation systems near transmission lines pose a potential shock hazard because they are large and at times can become insulated from ground. However, with simple precautions, the hazards can be eliminated. These precautions are discussed in a report available from BPA (Nichols 1978). This section summarizes effects on irrigation activities and points out the basic safe working practices when irrigating near transmission lines.

When moved manually, irrigation systems usually are laid on soil. This ground contact means that they present little or no shock hazard. To minimize the occurrence of nuisance shocks, or electrical contact with conductors, pipe

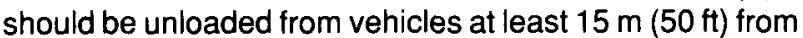
the center of the transmission line.

Great care should be exercised when handling lengths of metallic pipe near any overhead powerline. The pipe should be kept in a horizontal position (Figure 40). The big danger near any power line is the chance of electrocution if a person were to up-end a section of pipe into or near the conductors. Electricity from a 500-kV line can arc 1 to $2 \mathrm{~m}$ $(3$ to $7 \mathrm{ft}$ ) through air to a grounded object.

In general, no equipment or vehicle should be higher than

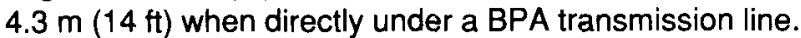
This limitation can be exceeded in some cases. Persons who need specific information on safe working distances for a particular BPA transmission line should contact the nearest BPA office.

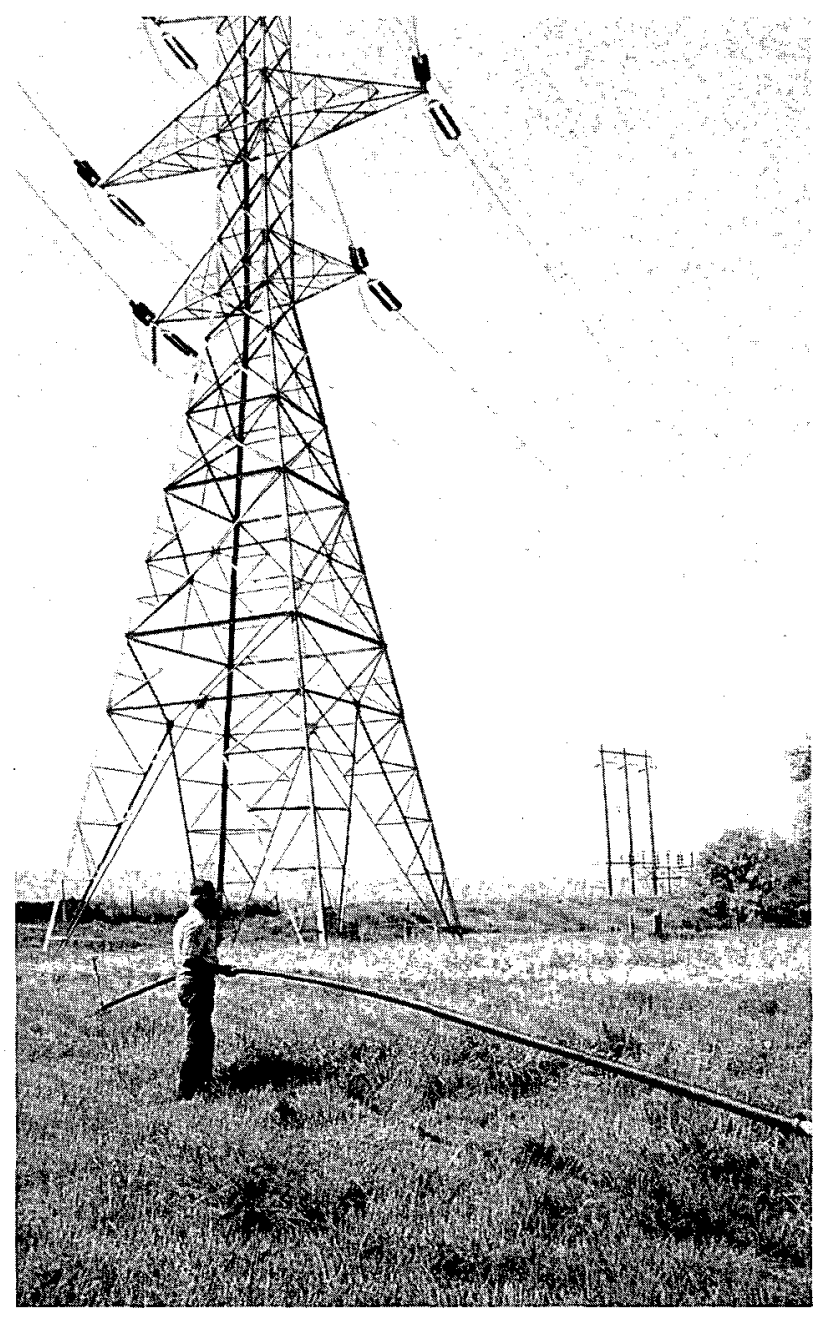

FIGURE 40. Irrigation pipe and other large objects should always be carried in a horizontal position when near an overhead powerline.

Mobile irrigation systems which move on wheels (such as the wheel line and center pivot type) can develop voltages if well insulated from ground and if parked parallel to a highvoltage transmission line. However, in realistic situations, it is difficult to get a high degree of insulation. The insulation is influenced by the type of wheels (metal or rubber), moisture conditions in the soil, and other contact points to ground, such as the central pivot point on a circular system. Safety practices for wheel-type systems can be found in Appendix A.

All irrigation systems should be operated at distances sufficient to avoid direct contact between the water stream and conductors. A solid (continuous) stream of water should never be directed on or near the conductors. When contact between a well-broken water stream and transmis- 
sion line conductors cannot be avoided, the distance between the conductors and the irrigation nozzle should exceed the minimum distances listed in Table 10.

Table 10 gives suggested clearances between transmission line conductors and solid-stream high-pressure irrigation nozzles. If the water stream is broken, there is actually a greater margin of safety if the distances in Table 10 are adhered to. Because of the small size of a Vermeer (impulse) system, no problems should occur due to induced voltages; however, extreme care should be taken in moving these systems to avoid tipping them into the conductors.

\section{Fences/Metal Structures}

In general, induced voltages on fences and structures can be reduced to safe, low levels by grounding at intervals and by using metal fence posts with proper bonding to the posts (see Appendix A). For very long fences parallel to a transmission line, it may be necessary to break the electrical continuity. BPA routinely installs proper grounding for all fences and structures when new transmission lines are constructed. Persons who may have questions about grounding practices should contact the nearest BPA office.

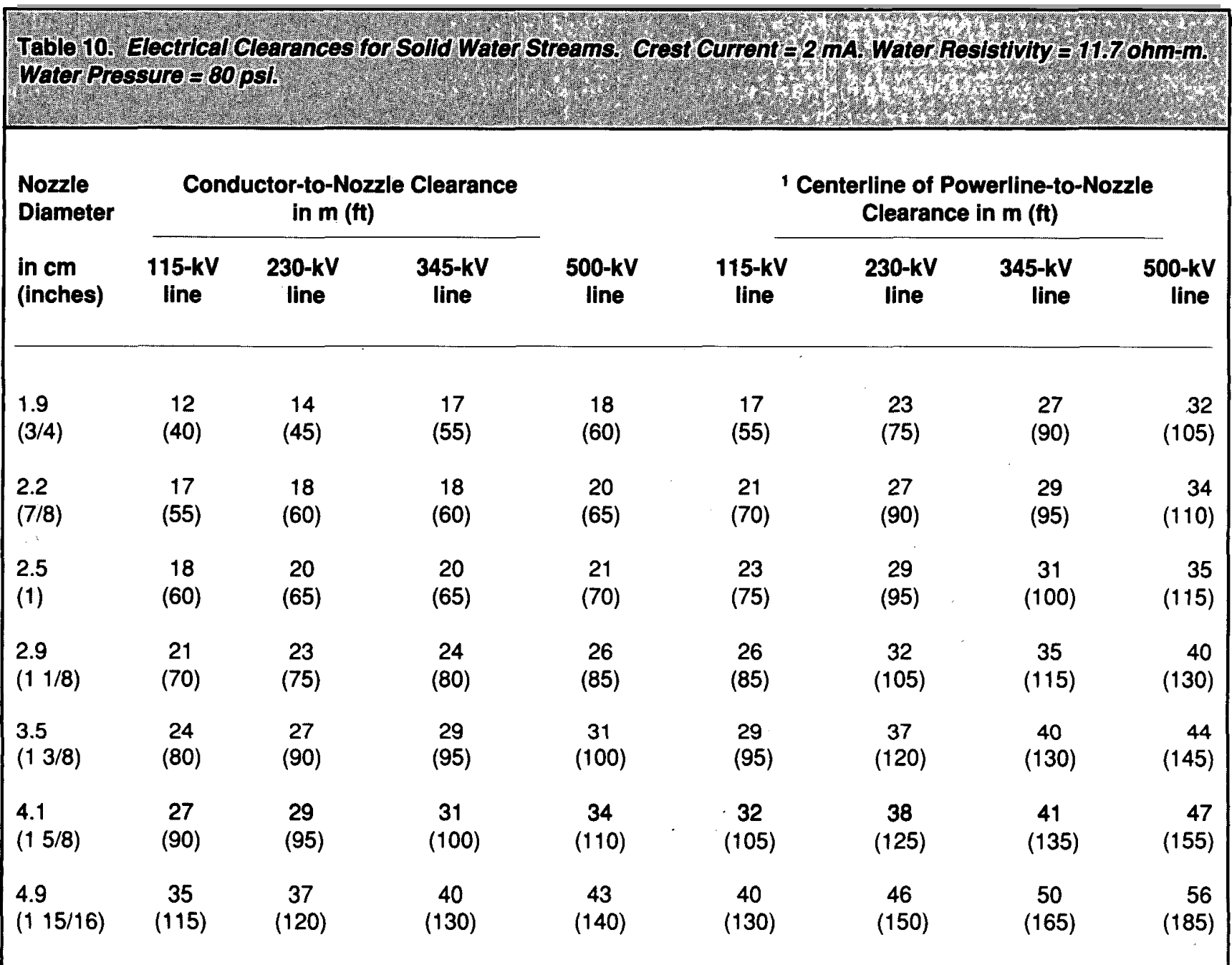

1 These values based on phase to phase spacing of $4.6 \mathrm{~m}(15 \mathrm{ft})$ for $115-\mathrm{kV}, 9.1 \mathrm{~m}(30 \mathrm{ft})$ for $230-\mathrm{kV}, 10.7 \mathrm{~m}$ $(35 \mathrm{ft})$ for $345-k V, 13.7 \mathrm{~m} \mathrm{(45} \mathrm{ft)} \mathrm{for} 500-\mathrm{kV}$. 


\section{CORONA EFFECTS}

Corona occurs in regions of high electric field strength on conductors, insulators, and hardware when sufficient energy is imparted to charged particles to cause ionization (partial breakdown) of the air (Figure 41). Corona may result in radio and television reception interference, audible noise, light, and production of small amount of oxidants (ozone and nitrous oxides). However, engineers can and do produce line designs that keep the generation of corona and its effects within limits acceptable to the public.

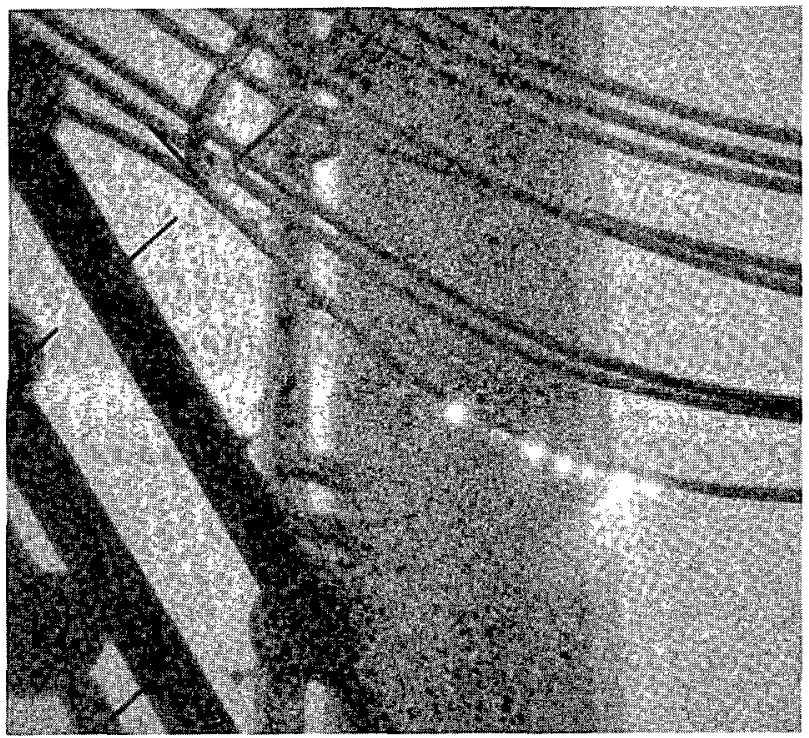

FIGURE 41. Corona visible on conductors of the 1200-kV prototype line. Photograph taken with a night vision device.

Another source of radio and television interference is arcing across small gaps in loose hardware (Loftness 1977). Arcing, which may occur at any voltage, will not be discussed here because it is not unique to high-voltage lines. It can be prevented by good design and proper maintenance.

At higher elevations, the breakdown strength of air is less than that at sea level, so the incidence of corona discharge increases. For all corona- generated noise, a BPA study confirmed that with each $300 \mathrm{~m}(1000 \mathrm{ft})$ increase in elevation, noise increases by about $1 \mathrm{~dB}$ (Chartier et el. 1987). All noise levels in this section are for a line located at sea level.

Corona is created during all types of weather, when air ionizes near isolated irregularities (e.g., nicks, scrapes, insects) on the conductor surface of operating transmission lines. Raindrops, fog, snowflakes, and condensation add to the isolated corona sources that exist in fair weather. Foul weather, therefore, causes a significant increase in corona activity on a-c lines and the audible noise and radio noise produced by it. The noise is generally caused when drops of water form on the surface of the conductor.

\section{Audible Noise}

\section{Description and Comparative Levels}

Audible noise produced by transmission line corona is a hissing, popping, or crackling sound. Near an a-c line, a $120-\mathrm{Hz}$ hum is occasionally super- imposed. The sound level near a transmission line depends on the ambient noise level present, on the electric field strength at the conductor surface (conductor geometry and operating voltage), and on the weather. Transmission line audible noise is usually measured in decibels (dB) on what is called the "A Scale"; 'it models how the human ear perceives sound. Table 11 shows some typical sound levels from various environmental sources.

With the introduction of 500-kV transmission lines, audible noise began to be an environmental concern. The first 500$\mathrm{kV}$ lines constructed by BPA had one $6.4-\mathrm{cm}(2.5-\mathrm{in})$ diameter conductor for each phase. Audible noise on the right-of-way averaged about $62 \mathrm{~dB}(\mathrm{~A})$ during rain for these lines. Experience has shown that, with average line noise of approximately 53 to $59 \mathrm{~dB}(\mathrm{~A})$ at the edge of the right-ofway, some complaints can be expected from persons living near the line. Numerous complaints can be expected when levels are above $59 \mathrm{~dB}(\mathrm{~A})$ (Perry 1972). Because of problems with audible noise, BPA improved line designs. Some existing lines of the older type were reconductored to a newer design having three subconductors per phase (Yasuda and Dewey 1980). 


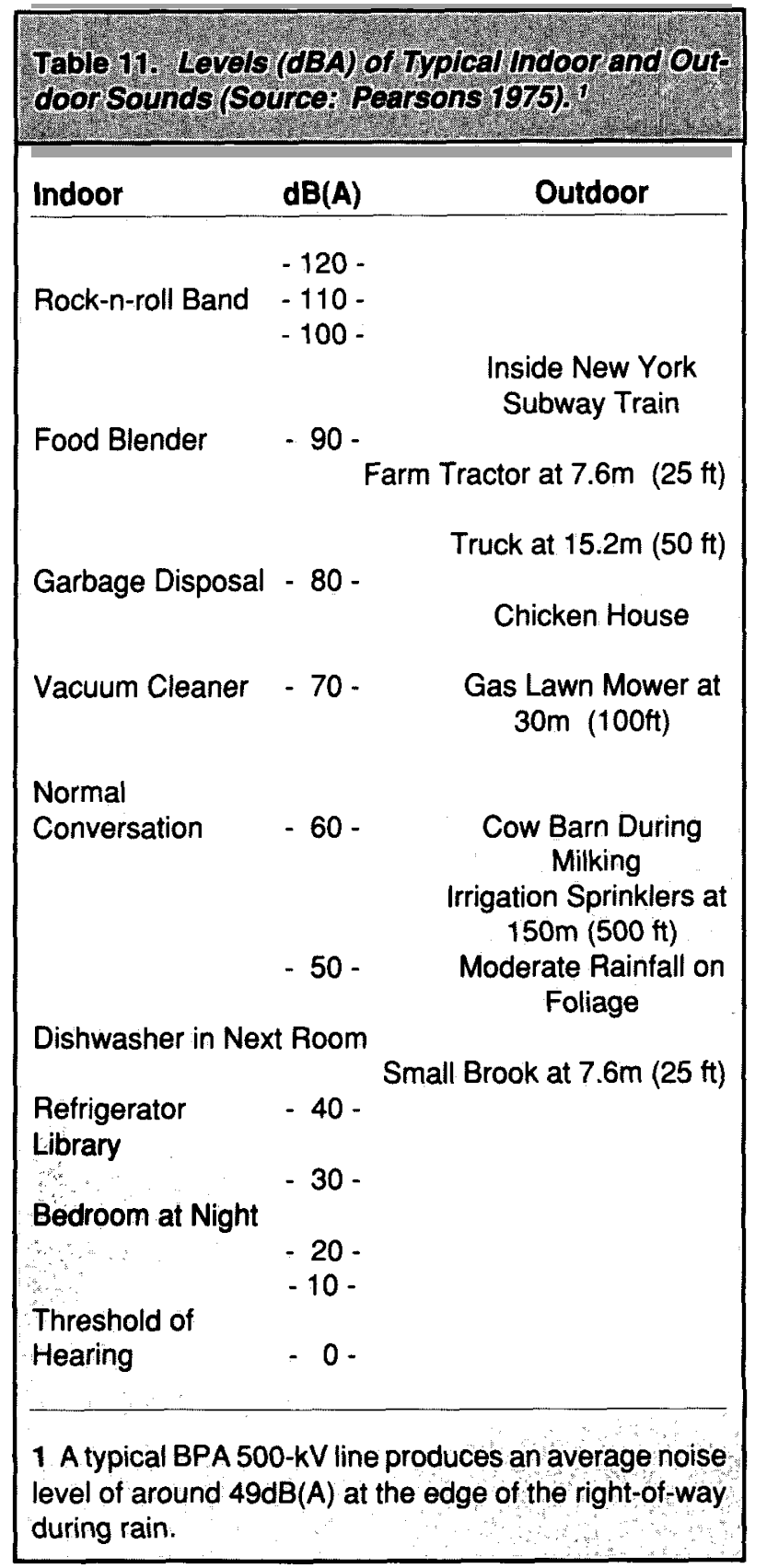

Figure 42 shows calculated audible noise levels for typical transmission lines (average levels during steady rain). Transmission line audible noise decreases at a rate of 3 to $4 \mathrm{~dB}$ as distance from the line doubles. For example, 45 $\mathrm{dB}(\mathrm{A})$ at $30 \mathrm{~m}(100 \mathrm{ft})$ decreases to 41 to $42 \mathrm{~dB}(\mathrm{~A})$ at $61 \mathrm{~m}$ $(200 \mathrm{ft})$. Trees, buildings, and other large objects near a line tend to reduce this sound further. It is estimated that a sound, as heard by the human ear, is cut in half with a 10 $\mathrm{dB}(\mathrm{A})$ decrease in the sound level.

The range of ambient (background) noise levels, and the variety of sources, is considerable. In areas remote from human development, levels as low as $15-20 \mathrm{~dB}(\mathrm{~A})$ may be measured. In urban areas, levels may reach 80-90 dB(A). High noise levels occur even in the natural environment; for example, waterfalls may produce levels of $85 \mathrm{~dB}(\mathrm{~A})$ or higher (EPA 1974). During rain, ambient noise levels average 30 to $70 \mathrm{~dB}(A)$ in rural areas (Miller 1978).

\section{Noise Standards}

BPA's typical single-circuit 500-kV design using three subconductors per phase produces an average noise $\left(L_{50}\right)$ of $49 \pm 2 \mathrm{~dB}(\mathrm{~A})$ at the edge of the right-of-way during rain. The A-weighted average sound level for 24 hours, with a $10 \mathrm{~dB}$ penalty for the time between $10 \mathrm{p.m}$. and $7 \mathrm{a.m}$., is termed $\mathrm{L}_{\mathrm{dn}}$ (day-night). Assuming rain for 17 percent of the time (e.g., western Oregon), noise from the latest BPA 500 $k V$ design is around $49 \mathrm{~L}_{\mathrm{dn}}$. This is less than the $55 \mathrm{~L}_{\mathrm{dn}}$ level, below which the EPA feels no effects on public health and welfare will occur (EPA 1974). BPA's 500-kV noise policy limits the $L_{50}$ level during rain to $50 \mathrm{~dB}(A)$ or less, where a rain rate of 0.8 to $5.0 \mathrm{~mm} / \mathrm{hr}(0.03$ to $0.2 \mathrm{in} / \mathrm{hr})$ occurs more than 1 percent of the time.

In Washington State, transmission lines are Class C EDNA (Environmental Designation for Noise Abatement) noise sources. Applicable limitations are $60 \mathrm{~dB}(\mathrm{~A})$ during day and $50 \mathrm{~dB}(\mathrm{~A})$ at night for Class $A$ EDNA receivers, which include residential areas (Washington Administrative Code Chap. 173-60). Oregon noise control regulations (OAR 340.35) limit noise to $50 \mathrm{~dB}(\mathrm{~A})$ at night for noise-sensitive property such as residential areas. Montana requires that noise from transmission lines not exceed $50 \mathrm{~L}_{\mathrm{dn}}$ at the edge of the right-of-way in residential and subdivided areas (ARM 36.7 3507). However, the affected landowner can waive this requirement. BPA works with state and local agencies to determine the compatibility of transmission line noise with current and planned noise regulations.

\section{Human Studies}

Some laboratory research has been done to measure human response to transmission line audible noise. Molino et al. (1979) studied people's reactions to maximum corona noise levels as found within a transmission line right-ofway, i.e., 54-62 dB(A). The people tested found these noise levels as aversive as other environmental sounds (e.g., air conditioner, traffic) that were $3 \mathrm{~dB}(\mathrm{~A})$ higher in noise level.

Pearsons et al. (1979), in a preliminary study, compared human response in a laboratory to corona noise of around $45 \mathrm{~dB}(\mathrm{~A})$ with responses to other noises such as those from lawnmowers, dishwashers, and rain. This study also indicated that annoyance from corona noise is greater than annoyance from other noises of the same level. Corona noise needed to be $10 \mathrm{~dB}(\mathrm{~A})$ lower to be judged as annoying as other environmental sounds. The annoyance properties of corona noise appear to be related to its high-frequency components. 


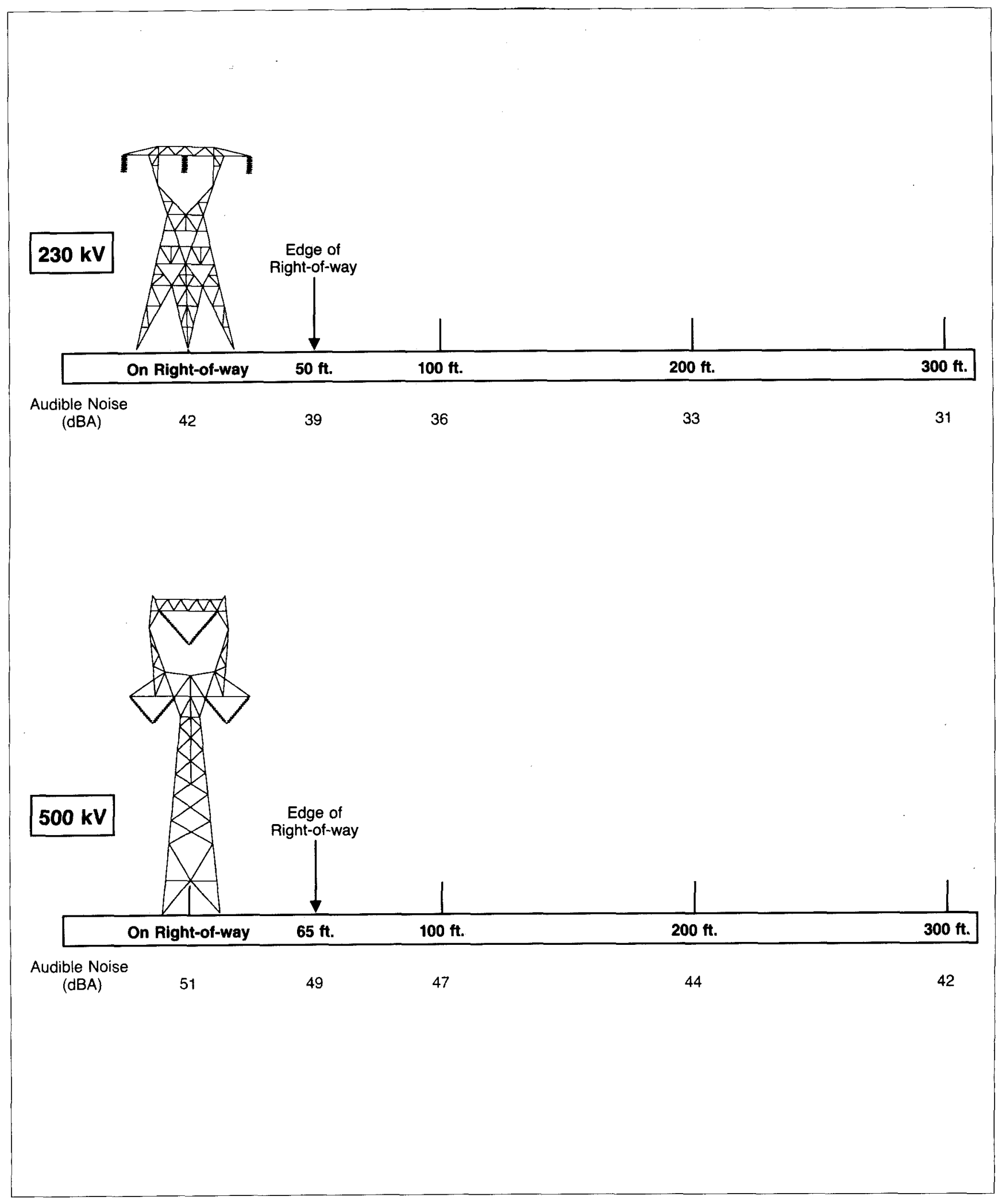

FIGURE 42. Typical audible noise levels during rain at various distances from BPA transmission lines. Actual noise levels and right-of-way width depend on line design and current levels. Fair weather noise levels are typically $25 d B A$ less than levels during rain. 
A preliminary study involving reactions of residents to the noise produced by actual transmission lines was done in California. Fidell et al. (1979) interviewed 403 people living near 230-kV and 500-kV lines and transformer substations. Only 2 percent of the people spontaneously mentioned powerlines or transformers as noises heard in their neighborhoods. Overall, transmission line noise did not interfere with listening to radio or TV, nor did it startle or frighten people or interfere with sleep.

\section{Wildlife Studies}

During rainy weather, when corona noise is highest, domestic animals and many kinds of wildlife are often seen on or near 500-kV rights-of-way. Goodwin (1975) used track counts, direct observation, and time lapse photography to study the effects of a BPA 500-kV line in northern Idaho on migrating deer and elk. Portions of the line were constructed with a single conductor per phase. He found that line noise levels up to $68 \mathrm{~dB}(\mathrm{~A})$ - the highest level he measured-did not deter elk, deer, and several other species from crossing or foraging on cleared rights-of-way in a manner consistent with their use of other forest clearings. Lee and Griffith (1978) also reported no effects of audible noise on wildlife inhabiting areas near $a \pm 400-k V$ $\mathrm{d}-\mathrm{c}$ line and near 500-kV a-c lines.

Picton et al. (1985) found that a 500-kV double-circuit line did not act as a barrier to elk using a high-elevation winter range in Montana. However, elk use of grassland habitat near the line appeared to be less than that in surrounding grassland. The effect was in part related to the transmission line access road and to towers, both of which removed some habitat. Audible noise from the line may also have contributed to the decreased habitat use. The $L_{50}$ noise level on the right-of-way during precipitation was around $60 \mathrm{~dB}(\mathrm{~A})$. Other factors also affected elk distribution, however, including weather, and cattle grazing near the line.

Two older reports (Klein 1971, Villmo 1972) mentioned that in Scandinavia, reindeer herders claimed that noise from powerlines (no voltages or levels stated) adversely affected reindeer behavior and that the animals were reluctant to cross under newly constructed power lines. It is not clear, however, whether the cleared right-of-way or factors other than noise were responsible for the reported effects. Overall, it appears unlikely that BPA transmission line noise results in any significant effects to wild or domestic animals (See discussions in: Lee and Griffith 1978, Dufour 1980).

\section{Radio and Television Interference}

Corona also generates high-frequency noise called electromagnetic interference (EMI) which can disrupt radio and television reception in some cases. EMI is the static sometimes heard over an automobile radio when driving beneath high-voltage lines.
The same designs that have been used to decrease audible noise (e.g., multiple conductors) have also served to reduce EMI. Over 90 percent of the EMI attributed to powerlines is caused by arcing across gaps in hardware and can be corrected (Loftness et al. 1981).

Since BPA's high-voltage lines are designed for low audible noise levels, BPA does not design its transmission lines for a specific radio interference $(\mathrm{Rl})$ or television interference (TVI) level. In 1971, the IEEE Radio Noise Subcommittee published a Radio Noise Design Guide which, in essence, has a recommended radio noise limit. Figure 4 of the document (reproduced here as Figure 43) shows the range of operating conductor surface electric fields (gradients) and conductor size for single or bundle conductors for comparable noise levels. Industry experience has shown that lines that have been designed and built with conductor surface gradients that fall below the top curve on this figure have successfully avoided both radio and audible noise and TVI. The conductor surface gradient on BPA's new generation of 500-kV lines fall well below this curve.

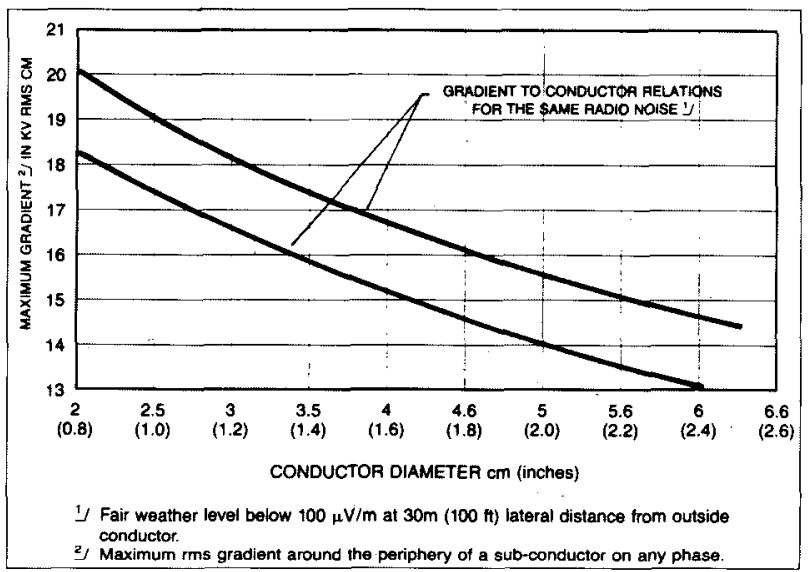

FIGURE 43. Range of operating gradient and conductor size for single or bundle conductors for comparable noise levels. (Source: Adapted from, IEEE Radio Noise Subcommittee 1971.)

Foul weather TVI due to corona is usually limited to occasional residences within about $183 \mathrm{~m}(600 \mathrm{ft})$ of a transmission line, where broadcast signals are weak. In outer fringe (weak signal) areas, interference may occur in exceptional

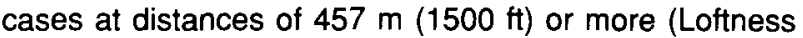
1977). In areas with strong broadcast signals, TVI is usually not a problem, even at the edge of the right-of-way. 
TVI occurs most frequently in channels 2 to 6 . The problem primarily involves the picture, which is amplitude modulated (AM), rather than the frequency modulated (FM) sound. FM reception is inherently more free from static. FM radio is also not usually affected by transmission line corona, although $\mathrm{RI}$ can develop with AM radios (Loftness 1980).

Federal Communications Commission (FCC) regulations require that incidental radiation devices (such as transmission lines) be operated so that no harmful $\mathrm{Rl}$ is produced. Further, FCC regulations require that the operators of these devices eliminate such interference (FCC Rules and Regulations, Part 15, Section 15.25).

BPA policy is to comply with FCC requirements. Each complaint about EMI is investigated. If a BPA transmission line is found to be the source of television interference with reasonably good reception, measures are taken to restore the picture to a quality as good or better than before the interference. Depending on the individual situation, corrective measures may include one of the following \& Loftness et al. 1981):

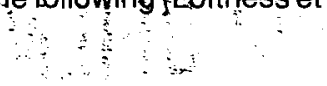

1. Improve the receiving antenna system,;

2. Install a remote antenna;

3. Install an antenna for TV stations not previously received but which are less sensitive to TVI;

4. Connect TV to an existing commercial cable system, or;

5. Install a translator station.

Correcting for residential AM radio interference usually involves installation of a new antenna for the radio.

Overall, BPA receives very few $\mathrm{RI}$ or TVI complaints. Essentially, all legitimate complaints are satisfactorily corrected.

\section{Ozone}

During corona, chemical reactions take place in the small volume of air immediately surrounding a conductor. These reactions include the production of small amounts of ozone $\left(\mathrm{O}_{3}\right)$ and nitrous oxides $\left(\mathrm{NO}_{x}\right)$. This discussion will be confined to ozone, as the amount of nitrous oxides produced by transmission lines is considerably less than the amount of ozone and as $\mathrm{NO}_{\mathrm{x}}$ has not been an issue (Roach et al. 1974).

Ozone is a naturally occurring, though unstable, form of oxygen. Its peculiar odor can be detected in concentrations as low as $0.01 \mathrm{ppm}$ (parts per million by volume) by persons with keen smell. Most people detect ozone at $0.02 \mathrm{ppm}$ (Jaffe 1967). At such low levels, however, ozone odor detection diminishes rapidly and one becomes unable to notice the ozone during a lengthy period of exposure.

Ozone occurs naturally in the atmosphere, diffusing slowly to sea level from the ozone layer 21 to $26 \mathrm{~km}$ (13 to $16 \mathrm{mi}$ ) above the earth's surface. This layer is a major source of ozone. Another major source is the action of sunlight on nitrogen dioxide, an important component of automobile exhaust. An electrical discharge through oxygen can dissociate oxygen molecules into free oxygen; some of these molecules then recombine to form ozone. Lightning and electrical discharges from transmission lines, however, produce only minor amounts of ozone.

Average ozone concentrations usually reported for rural areas are between 0.01 and 0.03 ppm. In some rural areas, however, ozone concentrations exceeding $0.1 \mathrm{ppm}$ have been measured (Coffey and Stasiuk 1975). Concentrations of $0.5 \mathrm{ppm}$ occur in cities such as Los Angeles and reportedly stem from the action of sunlight on emissions from autos and industrial combustion. The national primary air quality standard for ozone is 0.12 ppm (EPA 1979).

When this review was first prepared in 1975 , there was considerable interest about the amounts of ozone generated by transmission lines (e.g., Young 1974). Extensive research projects have been conducted since that time. They show that the amount of ozone produced by even the largest lines in operation $(765-\mathrm{kV}$ ) is insignificant. (See reviews in: SNYPSC 1978, Scott-Walton et al. 1979, Janes 1980.) BPA monitored ozone levels near the 1200-kV prototype line for 2 years and found no increase in ambient ozone levels due to the line (Bracken and Gabriel 1981).

Calculations of ozone production from transmission lines show why such production is generally not measurable. For example, under severe conditions [a rain rate of $2.5 \mathrm{~mm}$ ( $0.1 \mathrm{in}$ ) per hour and no wind], a double-circuit 500-kV line would increase ambient ozone concentrations at ground level by no more than $0.00135 \mathrm{ppm}$. This assumes that the

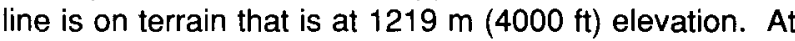
$1830 \mathrm{~m}(6000 \mathrm{ft})$ elevation, ozone production would be about 1-1/2 times this level. At lower elevations it would be proportionately less.

Ozone concentrations produced by transmission lines appear to be too low to have any significant effects on humans, animals, or plants. 
$$
\text { . }
$$ 


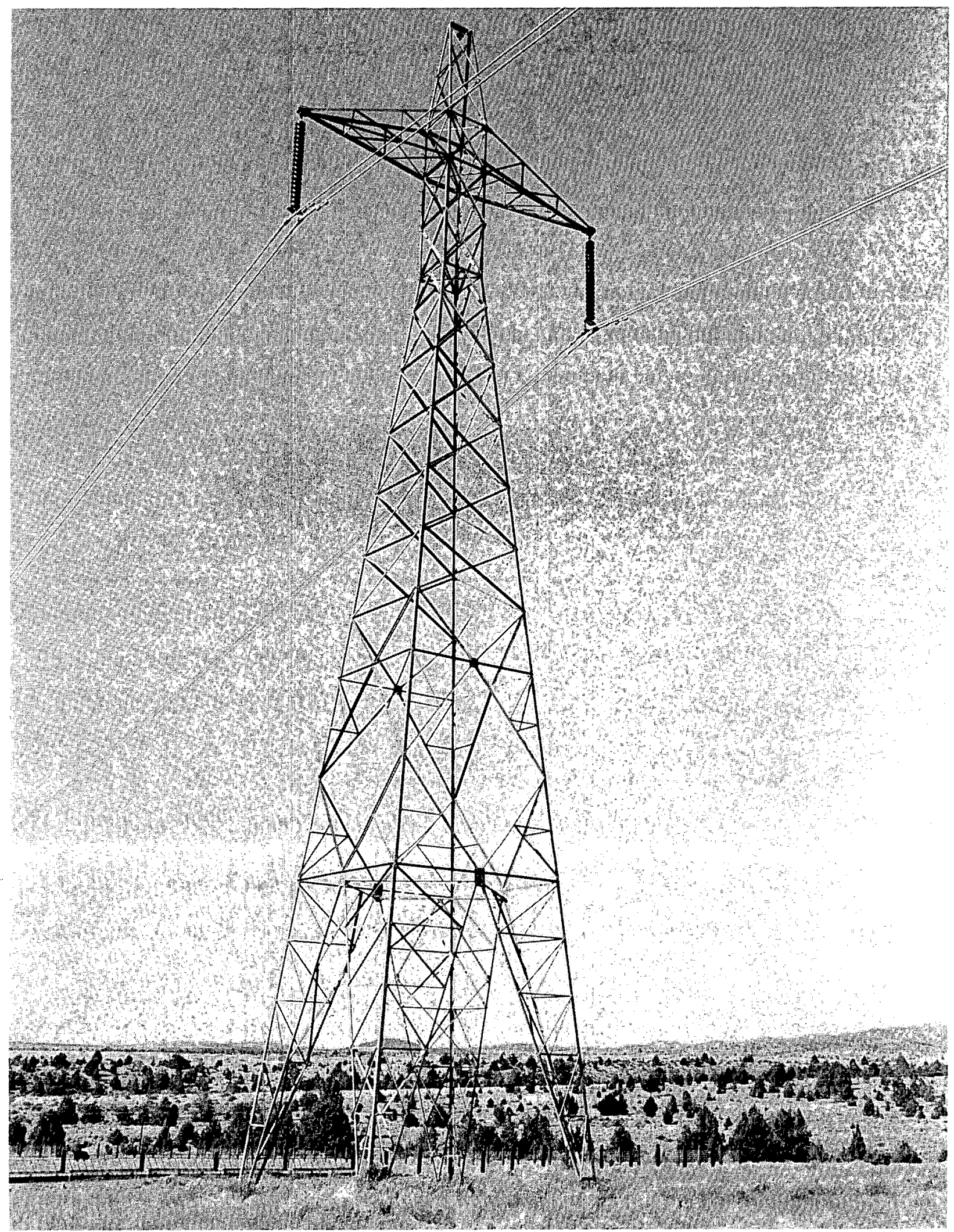


In 1882, the first commercial electrical distribution system developed in the United States by Thomas Edison was a dc (direct-current) system. The use of d.c., however, was limited to short distances because it was difficult to convert between high transmission and low distribution voltages. With the development of a-c (alternating-current) generators, transformers, and other equipment, a.c. became established by the early 1900's as the dominant technology for both distribution and transmission.

Engineers knew that d.c. had advantages over a.c. for some applications, and research continued on ways to improve d-c technology. In the 1930's, equipment was developed for economically converting between high-voltage a.c. and d.c. A 30-kV, 27-km (17-mi) d-c line was constructed in New York in 1936 (Hingorani 1978). The first EHV d-c line in the United States was energized in 1970.

\section{BASIC CONCEPTS}

Advantages of $d$-c electrical transmission include lower power losses because the current is not continuously reversing direction as in an a-c system. (Engineers call this reactive power loss.) D-c lines are also cheaper to build. A bipolar $\mathrm{d}$-c line needs only two sets of conductors (compared to three for an a-c line), requires smaller towers and fewer insulators, and generally requires a narrower right-ofway than an equivalent a-c line.

However, even with modern equipment, facilities needed for converting between a.c. and d.c. are very expensive. Therefore, HVDC (high-voltage direct- current) transmission lines become practical when large blocks of power are to be transmitted over long distances, with no need to tap power off along the way. These are exactly the conditions in the western United States, that led to the construction of the first commercial EHV d-c line in North America.

The Celilo-Sylmar d-c line, energized in 1970; transmits surplus electrical power $1361 \mathrm{~km}(846 \mathrm{mi})$ from the Pacific Northwest to the Pacific Southwest. The D-C Intertie, as the line is also called, operated at $\pm 400 \mathrm{kV}$ until 1985 , when the voltage was upgraded to $\pm 500 \mathrm{kV}$.

The voltage for a $d-c$ line is usually referenced as \pm , indicating the voltage from each pole (conductor) to ground. However, a d-c line can also be referenced by the voltage difference between the positive and negative poles. For instance, $a \pm 500-k V$ d-c line can also be called a 1000-kV $\mathrm{d}$-c line. Similarly, $\mathrm{a} \pm 400-\mathrm{kV}$ line is the same as an $800 \mathrm{kV}$ d-c line.

There are now five d-c overhead transmission lines operating in the United States (Table 12). Worldwide, there is a total of 10 major overhead $d-c$ lines operating at $\pm 400 \mathrm{kV}$ and above. Research was done in Massachusetts (Johnson 1984) and Montreal, Canada, (Maruvada et al. 1981) on d$c$ transmission lines of over $\pm 1000 \mathrm{kV}$, and BPA investigated the possible use of $500-k V$ a-c/d-c hybrid lines (Chartier et al. 1981). Short d-c back-to-back links in substations are increasingly being used to tie asynchronous a-c electrical systems together.

Since 1963, BPA has periodically operated a high-voltage direct-current test facility at The Dalles, Oregon. From 1984 to 1987 , BPA engineers also conducted long-term monitoring of the electrical performance of the D-C Intertie line before and after it was upgraded to $\pm 500 \mathrm{kV}$. This research, coupled with many years of operational experience with the Pacific D-C Intertie, provides the basis for much of the discussion in this section. BPA experience is based on a d$c$ line in the semiarid climate of Central Oregon. There may be variations in the magnitudes of effects in more humid climates. However, the basic principles of $d$-c transmission phenomena are the same in both cases.

More details of the technical characteristics of d-c transmission can be found in a publication from the Electric Power Research Institute (Hill et al. 1977), and in reports by Bracken (1979) and Johnson (1982, 1984).

\section{AIR IONS AND D-C FIELDS}

Air ions are natural components of the atmosphere. They are basically molecules with either extra electrons (negative ion) or with missing electrons (positive ion) and are formed through collisions among particles. Air ions are produced by such things as storms, sunlight, waterfalls, radioactive materials, corona, cosmic rays, and blowing dust. Some highly-charged windstorms, such as the Santa Ana of California, occur regularly.

Clean rural air typically contains around 500 to 2,000 small positive ions $/ \mathrm{cm}^{3}$ and a slightly smaller number of negative ions (Kotaka 1978). Polluted city air contains depleted levels of small air ions but high levels of large air ions (aerosols). Near waterfalls, negative air ion concentrations of 35,000 ions $/ \mathrm{cm}^{3}$ have been measured (Krueger 1980). Johnson (1982) reported that air ion concentrations in a residential room rose from 800 ions $/ \mathrm{cm}^{3}$ to 27,600 ions $/ \mathrm{cm}^{3}$ when 9 candles were lit.

It is important to keep in mind that air ions occur in extremely small concentrations. For example, Krueger (1980) estimated that, in rural air, there may be only one air ion for every 10 quadrillion uncharged air molecules. Some scientists have questioned how air ions could have significant biological effects if they occur in such minute concentrations. 
When an a-c line is in corona, air ions formed in the process are alternately repelled and attracted, as voltage polarity changes on the conductors at $60 \mathrm{~Hz}$. Therefore, there is little movement of these ions away from an a-c conductor. However, voltage polarity (positive or negative) is constant on a d-c line conductor. Also, HVDC lines are typically in constant corona. During corona, ions move away from the conductor of like polarity and are attracted to the conductor of opposite polarity (e.g., positive ions are repelled by the positive conductor and attracted to the negative conductor). Some ions are also carried away from a d-c line by wind and flow to the ground.

Table 12. All direct-current overhead transmission lines in the U.S., and only thosed-clines in other countries of $1400 \mathrm{kV}$ and above (as of Nov, 1988).

Line

Voltage

(kV)

Year

Energized

Location

$\pm 400$

1962

$\pm 400$

1970

$\pm 250$

1977

$\pm 250$

1978

$\pm 400$

1978

$\pm 533$

1979

$\pm 500$

1984

$\pm 600$

1984-87

$\pm 500$

1985

$\pm 500$

1985

$\pm 500$

$\pm 450$

1986

$\pm 500$

1986

1989

\section{Operational}

U.S.S.R., Volgograd-Donbass

U.S., Pacific Intertie, Oregon - California

U.S., Square Butte line, Minnesota, North Dakota

Canada, Nelson River (Bipole I)

U.S., CU Project, North Dakota and Minnesota

Mozambique South Africa, Cabora - Bassa

Zaire, Inga - Shaba

Brazil, Itaipu - Sao Paulo

Canada, Nelson River (Bipole II)

U.S., Pacitic Intertie Voltage Upgrade, Oregon - California

U.S., Intermountain Power Project

U.S./Canada DesCantons - Comerford Phase I

U.S., Pacific Intertie 3100 MW Upgrade, Oregon - California

\section{Proposed or Under Construction}

$\begin{array}{ll} \pm 500 & ? \\ \pm 500 & ? \\ \pm 750 & ? \\ \pm 500 & 1989 \text { (est.) } \\ \pm 500 & 1989 / 90 \text { (est.) } \\ \pm 400 & 1990 \text { (est.) } \\ \pm 450 & 1990 \text { (est.) }\end{array}$

Mexico, Yukatan - Mexico City

Phoenix - Mead

U.S.S.R., Ekibastuz - Center

China, Gezhouba - Nan Qiao

India, Rihaud - Delhi

Finland/Sweden Feno-Skan

U.S./Canada Des Cantons - Comerford Phase II 
Thus, the electrical environment of a $d$-c line is more complex and variable than that of an the a-c line. Likewise, techniques for measuring and calculating HVDC transmission electrical parameters are complex because of effects of air ions. Ion concentrations constitute a "space charge" that contributes to the electric field from a d-c line. Therefore, three measures are used to describe the $d$-c electrical environment: 1) ion current density; 2) ion concentration (space charge density); and 3) electric fields produced by the charge on the conductors and the space charge (Figure 44). In addition, current in the conductors produces a static magnetic field. The magnetic field beneath the $\pm 500 \mathrm{kV}$ Pacific Intertie is about $0.022 \mathrm{mT}(0.22$ G), which is less than half the $0.05 \mathrm{mT}(0.5 \mathrm{G}) \mathrm{d}$-c field of the earth. Conversion from a.c. to d.c. produces harmonics of $60 \mathrm{~Hz}$, causing small a-c fields near a d-c line (Bracken 1979).

Negative do recombine with positive ions but, overall, $d-c$ conductors in corona create ion currents and space charge of like polarity near each conductor. At ground level, space charge increases the electric field above the nominal electric field due to voltage on the conductors.
Space charge contributes significantly to the total electric field near a $d$-c line. This enhancement represents a near maximum value which occurs only under relatively calm conditions. This total electric field due to space charge is highly variable because wind disperses the ions and the total field fluctuates between the maximum and the nominal value. Momentary readings above the calculated maximum are, therefore, not surprising, in view of the significant dependence of ion movement on wind. An electric field profile for a d-c transmission line is shown in Figure 45.

Earlier research with d-c lines involved electrical measurements on and near the right-of-way where small air ions are thought to predominate. Ions can also attach to water and dust particles to form charged aerosols. The aerosols can be carried away from a d-c line by wind for considerable distances. A study in Minnesota found that charged aerosols (and small air ions) were still measurable above ambient at distances of at least $1.6 \mathrm{~km}$ (1 mi) downwind from $a \pm 400-k V d-c$ line (Hendrickson 1985). Measurements of off-right-of-way aerosol concentrations have also

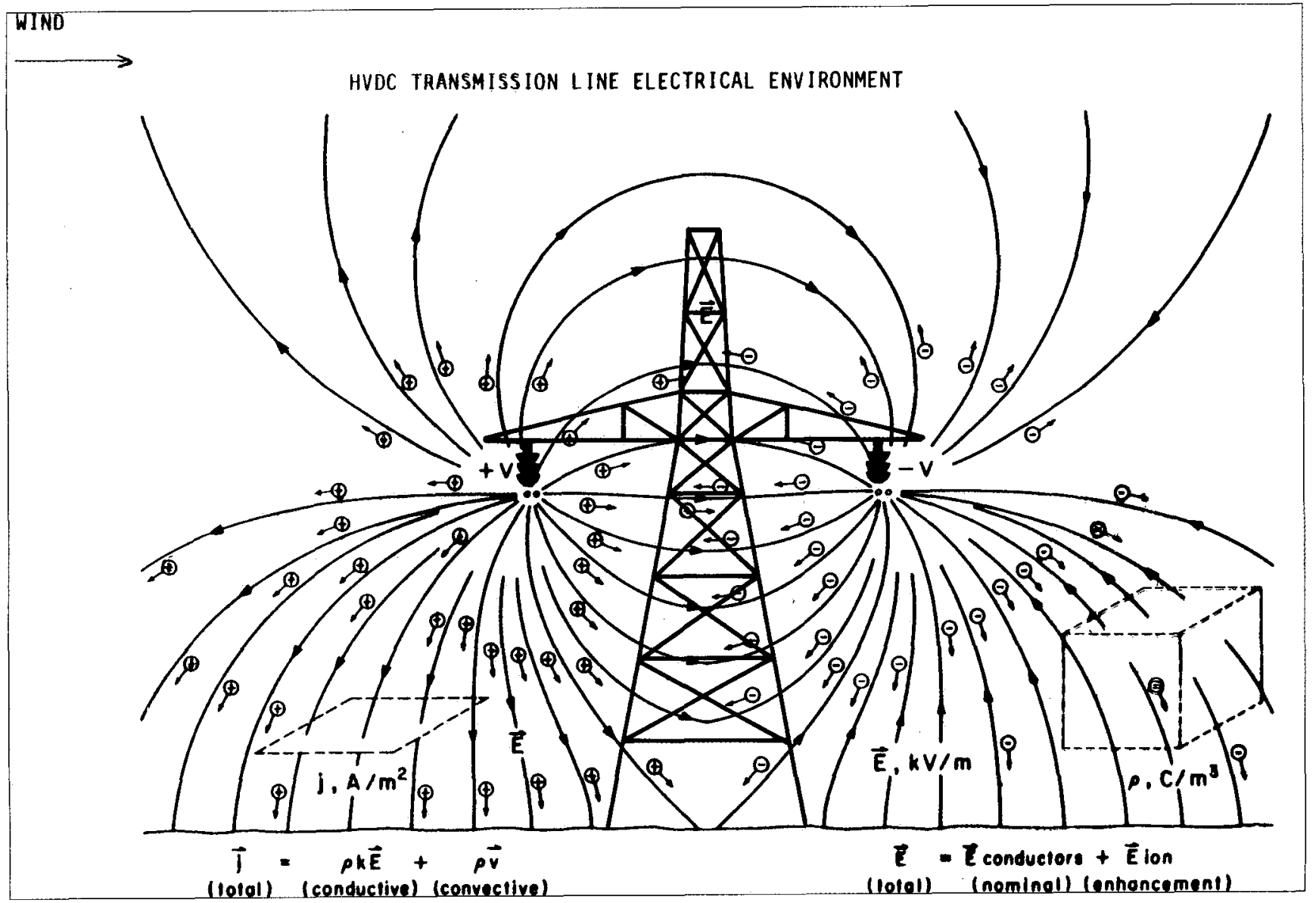

Figure 44. Diagrammatic depiction of the HVDC electrical environment. 
been made at the High Voltage Transmission Research Facility in Massachusetts (Johnson 1984).

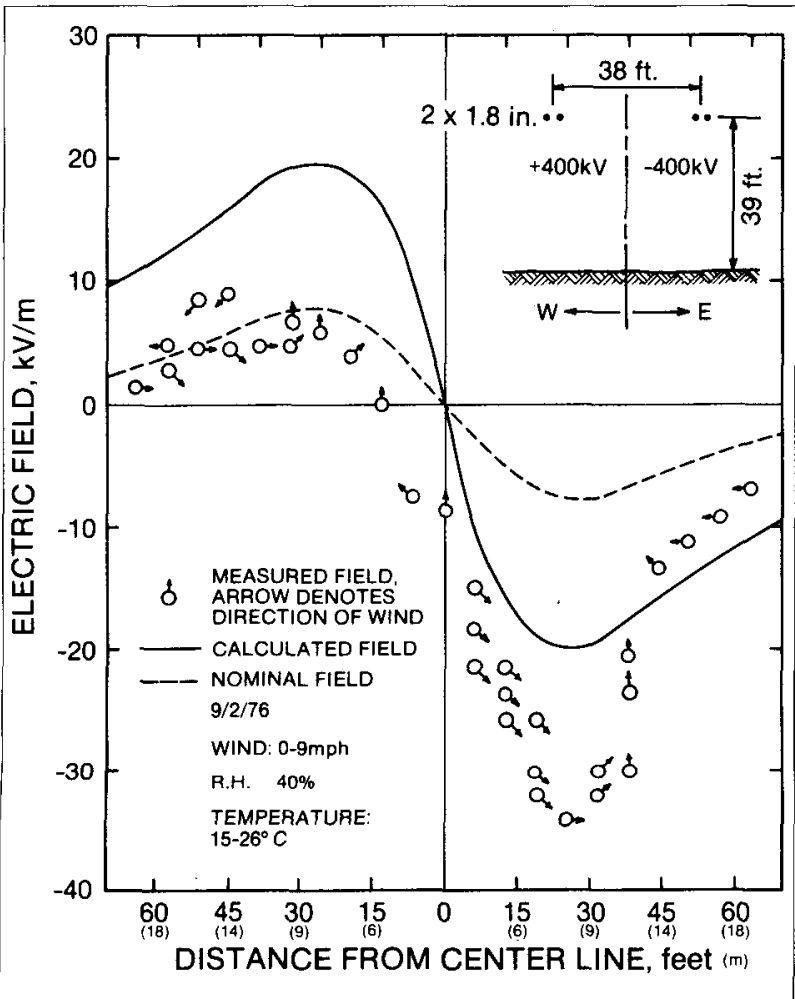

FIGURE 45. Calculated total electric field (due to voltage on conductors and ion space charge) and nominal field (due to voltage only) near ground for $a \pm 400 \mathrm{kV}$ d.c. transmission line. Field measurements on one day show how movement of ions by wind greatly influences the electric field. (Source: Bracken et al. 1978).

In 1984, BPA initiated a project to obtain more information about the electrical environment on and off the right-of-way of the D-C Intertie (Lee and Burns 1987). The study, in central Oregon, included long-term monitoring of electric field and ion levels out to $610 \mathrm{~m}(2000 \mathrm{ft})$ from the line (Figure 46).

Some results of the BPA study of the $\pm 500 \mathrm{kV} \mathrm{d}$-c line in Central Oregon are given in Table 13. For instance, field and ion levels were found to be 2-3 times higher on the negative side of the line than on the positive side. Previous studies of $d-c$ test lines (which carried no current) did not show this imbalance. As expected, average levels were higher during foul weather than during fair weather. D-c electric fields and air ions from the line were detected at 610 $\mathrm{m}(2000 \mathrm{ft})$ from the line a small percentage of time. (This is the farthest distance that measurements were made.)

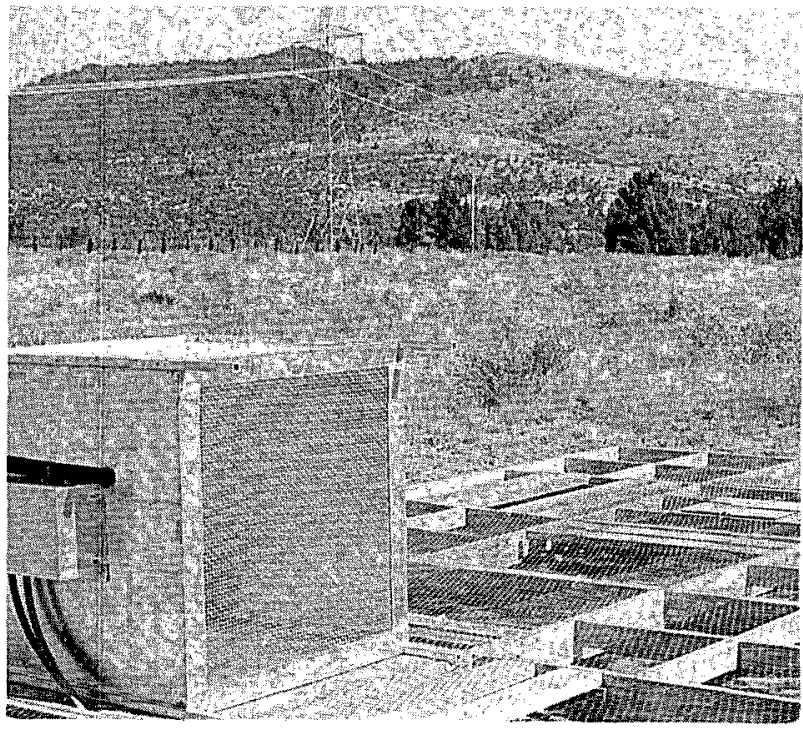

FIGURE 46. BPA made long-term measurements of the electric field and air ions produced by the Pacific D-C Intertie line in Oregon.

Equal $d-c$ and a-c field strengths do not produce the same electrical or biological effects. The field coupling to organisms or objects for the two cases are entirely different. In the $d-c$ case, the electric field coupling is resistive, with charge carried by natural and corona-generated ions. For a.c., the coupling is capacitive and induced currents are the result of the changing electric field. Typically, the d-c current coupled to an object is several orders of magnitude smaller than the induced current in an a-c field of comparable amplitude. Electromagnetic induction does not occur from d.c., because the current which causes the magnetic field moves in one direction.

\section{CORONA EFFECTS}

Corona activity and effects (noise, ozone, light) occur whenever the electric field strength on the conductor surface exceeds the breakdown strength of air. For a-c lines, corona activity is greatest during heavy precipitation because the water droplets concentrate the electric field strength. With d-c lines, however, radio and audible noise generally decrease during foul weather, when ions formed near $\mathrm{d}-\mathrm{c}$ conductors tend to suppress the formation of positive corona streamers. Studies of a d-c test line in Massachusetts indicated that insects deposited primarily on the positive conductor, and that this was a primary and significant corona source in summer during fair weather (Johnson 1984).

Audible noise produced by a $d$-c line is generated primarily by corona streamers on the positive conductor. This results 
Table 13. Some summary resuits from the BP A electrical monitoring study of the $1500-k V$ d c Pacific intertle

Line in Oregon. (Source: Chartier et al. 1988).

Parameter/

Weather Conditions

Location

Fair

Rain

Freezing Fog

Ave. Electric Fields $( \pm \mathrm{kV} / \mathrm{m})$

Max. on Right-of-way

Edge of Right-of-way

$+9.3,-17.9$

$+6.0,-10.6$

Ave. Air lon Concentration

$\left( \pm 1000\right.$ ions $\left./ \mathrm{cm}^{3}\right)$

Max. on Right-of-way

Edge of Right-of-way
$+31.0,-34.3$

$+14.9,-4.9$
$+12.7,-23.9$

$+8.0,-13.4$

$+12.9,-34.6$

$+7.4,-25.5$ in an impulsive "popping" noise. The $d-c$ line noise levels are generally lower than those for comparable a-c lines. The $L_{50}$ fair weather noise level (edge of right-of-way) calculated for the $\pm^{500-k V ~ d-c ~ I n t e r t i e ~ i s ~} 40 \mathrm{~dB}(\mathrm{~A})$. However, Hill et al. (1977) pointed out that, while a-c line noise is generally of short duration (foul weather), the noise from a d-c line is essentially continuous.

Radio-frequency noise from a $d-c$ line is also greatest during fair weather; the positive conductor is the primary source. During rain, $d-c$ radio noise decreases by 2 to $9 d B$ when the conductors become thoroughly wet. Although d$c$ lines can occasionally cause interference with radio reception, television reception interference has generally not been reported. As with a-c lines, BPA's policy is to correct radio or television reception problems if a BPA line is involved.

Studies of the BPA HVDC Test Line by Battelle Northwest Laboratories showed that ozone production from the line was not measurable during fair weather (Droppo 1979). With a slight wind parallel to the conductors and during precipitation, small amounts of ozone from the line could be detected at conductor height on some occasions at \pm 500 kV. Studies of $a \pm 400-k V d-c$ line in Minnesota and North Dakota also showed that ozone production was insignificant (Krupa and Pratt 1982).

\section{FIELD EFFECTS}

It must be emphasized that, for $d-c$ lines, the electric field strength alone does not characterize the electrical effects. The direct current which is intercepted by a person or object is of more significant because it can readily be compared with the d-c threshold of perception and let-go levels.

Shock tolerance levels for d.c. are much higher than for a.c.
(IEEE W.G. 1972, Hill et al. 1977). The mean threshold for perception of d.c. by men is $5.2 \mathrm{~mA}$; for women, the value is $3.5 \mathrm{~mA}$. In comparison, a-c perception levels for men and women are around $1.0 \mathrm{~mA}$ and $0.7 \mathrm{~mA}$ respectively. Direct currents of $62 \mathrm{~mA}$ and $41 \mathrm{~mA}$ represent the release current for 99.5 percent of men and women, respectively. These are analogous to the 9-mA and 6-mA values for a-c let-go current. The let-go or involuntary muscle contraction reaction does not occur with d.c., but with high currents it becomes very painful to release a current-carrying conductor. Hence the term "release current" refers to a psychological rather than a physiological limit.

The ion current intercepted by persons or objects beneath $\mathrm{d}-\mathrm{c}$ lines is many times below the human perception level. Measurements made at The Dalles Test Site in total electric fields of $40 \mathrm{kV} / \mathrm{m}$ showed only $0.003-0.004-\mathrm{mA}$ current interception by a person with arms raised directly beneath the $\pm 600-k V ~ d-c$ line (Hill et al. 1977). The maximum measured current from a $13.7-\mathrm{m}(45-\mathrm{ft})$ tractor trailer under a similar test line in Canada was about $0.05 \mathrm{~mA}$ with a 12$\mathrm{m}(40-\mathrm{ft})$ conductor-to-ground clearance and $0.15 \mathrm{~mA}$ with

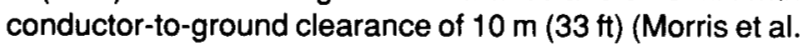
1967).

Near a d-c line, charge will accumulate on an insulated object, causing a voltage difference with respect to ground. $D$-c voltage is a function of the charge buildup, but cannot exceed the corona limiting voltage of the object. For example, barbed wire fences will not assume a higher voltage than $25 \mathrm{kV}$, because at that voltage corona occurs at the tips of the barbs and the voltage stabilizes. Even this voltage level is very rare, because it requires extreme conditions of dryness. 
Table 14 shows data from The Dalles Test Site on fences and a metal roof. Typical levels of current and stored energy are given, along with the associated shock sensation for spark discharges. These stored energies can be compared with the d-c shock experienced when touching a door knob after walking across a nylon carpet. For a carpet shock, the energy level is typically around 3 to 4.5 millijoules (mJ). Thus, a fence 40-m (130-ft) long on the right-of-way could reach this level of stored energy in very dry weather. The 50-mJ shock from an $240-\mathrm{m}$ (787-ft) fence on the rightof-way parallel to the line and $4.6 \mathrm{~m}$ (15 ft) outside the conductor could be classed as a definite annoyance. A $250-\mathrm{mJ}$ shock is very uncomfortable. However, the $1500 \mathrm{~m}$ (5000-ft) of parallel fence on a transmission line right-ofway which would be required for this level is a rare occurrence. In any event, one metal post attached to the fence is sufficient to drain the energy below perceptible levels.

It is BPA practice to ground fences on and adjacent to certain transmission line rights-of-way (Appendix A). Several metal grounding posts are usually used. A 186- $\mathrm{m}^{2}$ (2000$\mathrm{ft}^{2}$ ) building, $30 \mathrm{~m}$ ( $100 \mathrm{ft}$ ) from the line (simulated by a metal roof) poses no problems as far as stored energy or shortcircuit current magnitudes are concerned.
Tests made by BPA with vehicles on soil, asphalt, and concrete surfaces show that present-day tires are semiconducting and have a sufficiently low resistance to ground to limit the potential on vehicles to several hundred volts. Thus, the vehicle will not store enough energy to ignite gasoline or deliver a shock.

All these examples point out why there is such a low probability of receiving shocks near a d-c transmission line. As of this writing, BPA has not received any complaints from the public about electrostatic shocks due to the CeliloSylmar d-c line.

Subjective tests with nine men in conditions of 60 percent relative humidity at The Dalles Test Site indicate that, when an individual is well insulated from ground, a d-c field of 22 $\mathrm{kV} / \mathrm{m}$ can be perceived as a slight tingling of the scalp (Hill et al. 1977). Test site personnel indicated that perception levels and field strengths are both affected by humidity. With normal footwear, BPA personnel have reported that, on rare occasions, with the line at $\pm 500 \mathrm{kV}$, significant stimulation of head hair occurred in fields greater than 30 $\mathrm{kV} / \mathrm{m}$.

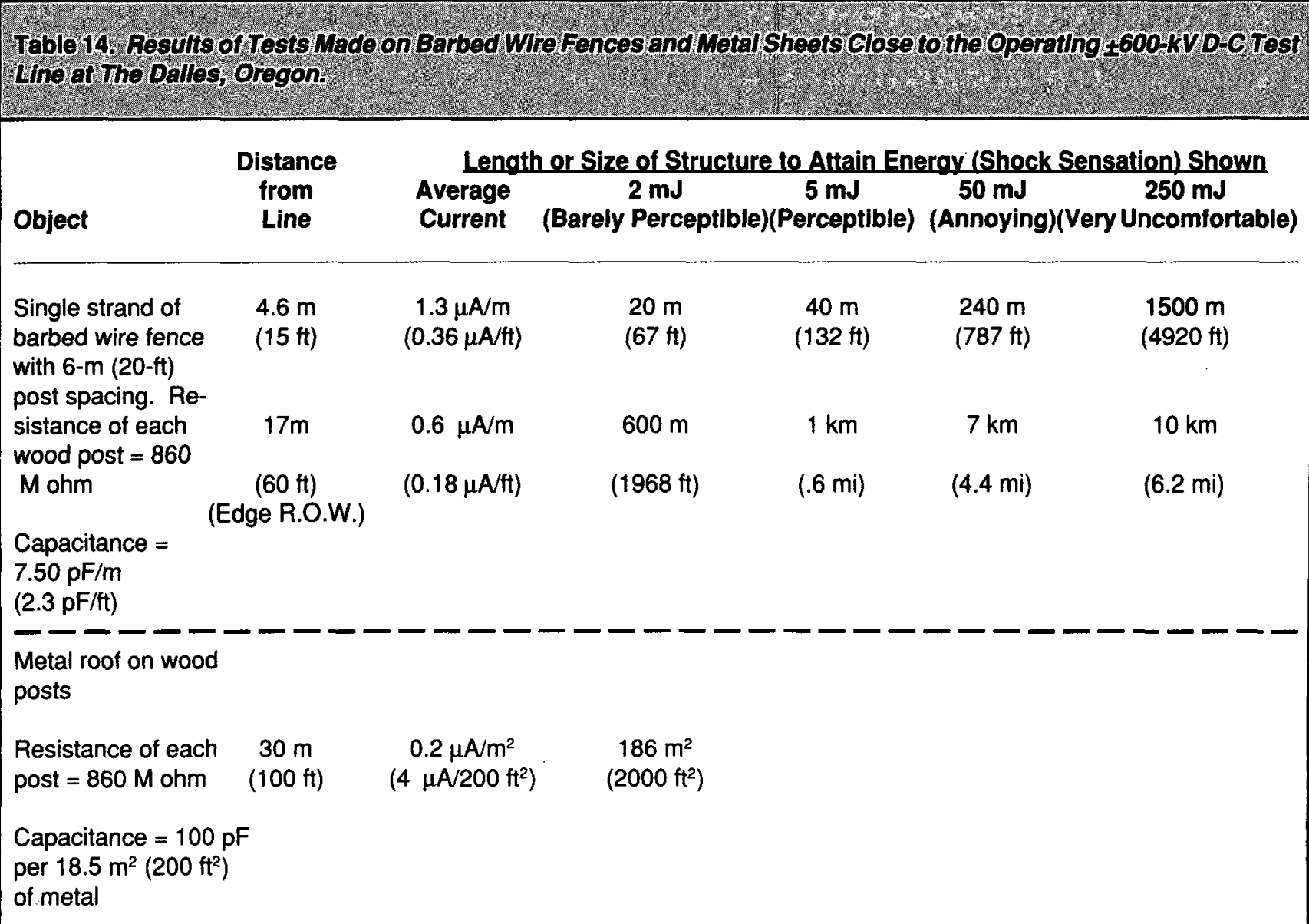




\section{Background and Issues}

As discussed above, the small currents intercepted by people or animals near an HVDC line appear insignificant. Also, compared to a-c lines, it is less likely that the electric field from d-c lines can be perceived by people or that nuisance shocks will occur. Operational experience with HVDC lines in general has been very good. Personnel who have worked near the $B P A \pm 600-k V d-c$ test line report no harmful effects.

Public awareness of $d-c$ transmission lines developed largely as a result of controversy surrounding a $\pm 400-\mathrm{kV} \mathrm{d}$ c line in Minnesota (Ames 1978, Casper and Wellstone 1981). That line extends $708 \mathrm{~km}$ (440 mi) from a power plant in western North Dakota to a point near the Twin Cities in Minnesota (Figure 47). Strong and sometimes violent public opposition to the line occurred in parts of Minnesota during the planning and construction processes. Persons opposing the project believed the line was not needed, and they did not like the way land was acquired for the right-of-

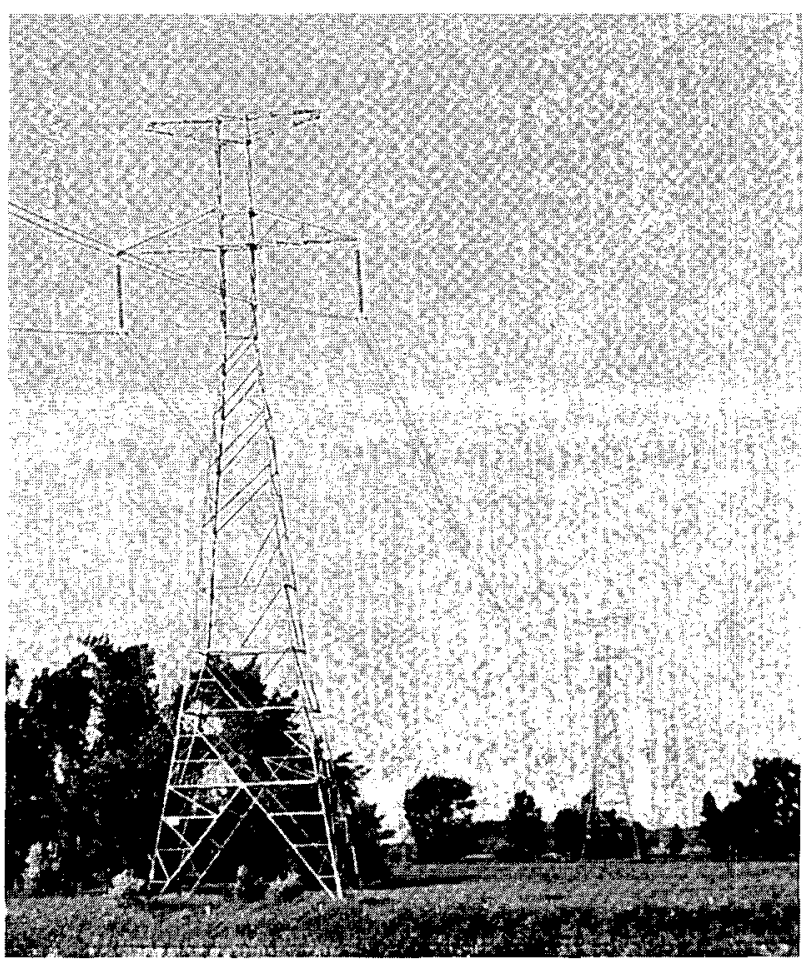

FIGURE 47. Public awareness of $d-c$ transmission lines developed largely as a result of controversy over this \pm 400 $k V$ d-c line constructed from North Dakota to Minnesota. way (McConnon 1984). By the time the line was constructed, the only remaining issues were health and safety related to $d-c$ fields, air ions, and ozone (Casper and Wellstone 1981).

Studies by the Minnesota Environmental Quality Board (Banks et al. 1977) and the Comptroller General of the United States (1979) found no evidence to indicate that a d$c$ line poses a threat to human health. However, after the $\pm 400-k V$ d-c line was first energized, some people surveyed in Minnesota reported that the line caused adverse effects on themselves and their livestock (Genereux and Genereux 1980). Other persons surveyed experienced no effects.

A Science Advisory Committee formed by the State of Minnesota found that the survey was flawed. A majority of the Committee also concluded that there was no indication that the $\pm 400-k V ~ d-c$ line presented a risk to human health from short-term exposure (Bailey et al. 1982, 1986). (See Brambl 1982 in Table 15 for a minority viewpoint.) The advisors also recommended studies of livestock and crops raised near the $d-c$ line.

The Minnesota Environmental Quality Board subsequently sponsored a statistical study to determine whether dairy cattle were affected by the $\pm 400-k V d-c$ line. Data were obtained by examining records from a Dairy Herd Improvement Association from before and after the line was energized. In comparing farms near to and away from the line, no differences were found on milk production, calving intervals, rate of culling for reproductive problems, and incidence of abortions (Martin et al. 1986).

By contrast, little controversy over the d-c line developed in North Dakota, where two-thirds of the line is located (McConnon 1984). Although in North Dakota the conductors are actually closer to ground and the electric field is therefore stronger, health effects from the line have generally not been reported in that state.

The Minnesota Science Advisors were reconvened in 1986 to consider results of electrical monitoring studies of the d$c$ line, and to review results of recent biological research. The Advisors concluded that the newer information still indicated that there was little likelihood for either acute or chronic health effects of air ions or d-c electric fields (Bailey et al. 1986). The Advisors acknowledged, however, that long-term research on possible d-c effects was still limited.

We are not aware of any reports of health effects from persons living or working near the Celilo-Sylmar d-c line. A health survey of residents near the Celilo-Sylmar line in California did not reveal any perceived effects attributable to the line (Nolfi and Haupt 1982). The survey compared persons living near the $\pm 400-k V d-c$ line with persons farther away. Residents were questioned about perceived overall health and about health problems experienced during time periods of 2 weeks, 1 month and 12 months 
preceding the survey. The $d-c$ line was undergoing routine maintenance at times during the survey, which complicated interpretation of the results. The survey was sponsored by the state of Vermont, where interest developed in d.c. because of a proposed d-c line between Canada and New England.

Overall, there appears to be no evidence that the electric fields and ions of d-c lines pose any hazards to public health (Banks and McConnon 1987). A monitoring study in Minnesota and North Dakota found that ozone production from the $\pm 400-k V d-c$ line was insignificant (Krupa and Pratt 1982). Gatchel et al. (1981) suggested that the health effects reported from some people in Minnesota (described above) may be related to stress, apparently associated with controversy over the line, or perceived hazards.

\section{Air lons and D-C Fields}

\section{Laboratory Animals}

Although there is a large body of laboratory research on air ions and d-c fields (e.g., Krueger and Sigel 1978, Kotaka 1978, Sulman 1980, Charry and Kavet 1987), few studies have been done specifically for HVDC transmission. The Electric Power Research Institute sponsored some laboratory research relevant to HVDC transmission lines.

One EPRI-sponsored study was done in the laboratory where Dr. A.P. Krueger conducted many well-known studies of air ions. In the study, no effects of air ions were found on growth of male mice or on their resistance to influenza virus (Kellogg 1982). After 2 years, serum glucose levels were slightly lower in female mice exposed to $2 \times 10^{3}$ ions/ $\mathrm{cm}^{3}$ (monopolar) than in mice in grounded cages (no ions or field) (Kellogg et al. 1985). The levels were highest in mice exposed to $a+2-k V / m$ field. The \pm electric field groups had the longest median survival time (MST). MST was lowest in mice exposed to negative ions $\left(2 \times 10^{3}-2 \times 10^{5}\right.$ ions $/ \mathrm{cm}^{3}$ ); however, the group exposed to high positive ions $\left(2 \times 10^{5}\right.$ ions $\left./ \mathrm{cm}^{3}\right)$ had an MST longer than the grounded cage group. (See reviews of this study in Bailey et al. 1986.)

A second study was conducted at the institute for Basic Research in New York. Researchers there reported no effects of air ions at $5 \times 10^{5}$ ions $/ \mathrm{cm}^{3}$ on levels of the neurotransmitters, serotonin, norepinephrine, and dopamine in rats (Bailey and Charry 1987, Charry and Bailey 1985). Exposures ranged from 2 to 66 hours. The New York studies also found no effects of air ions $\left(5 \times 10^{5}\right.$ ions/ $\mathrm{cm}^{3}$ ) or $12 \mathrm{kV} / \mathrm{m}$ d-c electric fields on the behavior of rats (Bailey and Charry 1986).

Researchers at the Battelle Pacific Northwest Laboratories also studied behavior of rats exposed to d-c electric fields and air ions (Figure 48). A shuttlebox experiment was used to determine whether rats would avoid strong positive field and/or ion concentrations. The studies showed that rats spent less time in the exposed side of the box at field strengths of 55 and $80 \mathrm{kV} / \mathrm{m}$ but not at 30 or $46.5 \mathrm{kV} / \mathrm{m}$ (air ion concentration was held constant at $1.4 \times 10^{5} \mathrm{ions} / \mathrm{cm}^{3}$ )

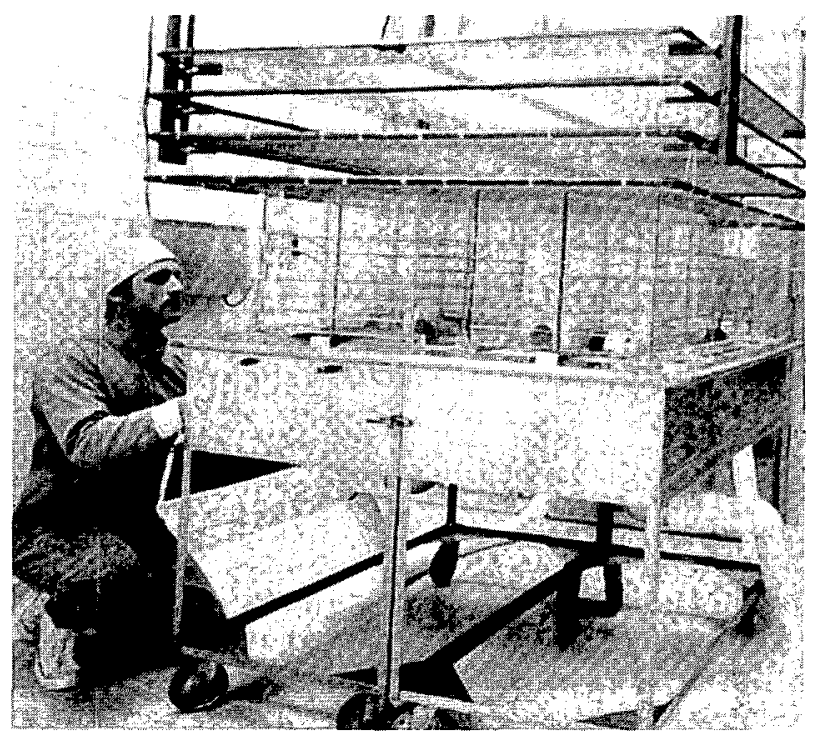

FIGURE 48. System developed by Battelle Pacific Northwest Laboratories for exposing rodents to $d$-c electric fields and air ions.

(Creim et al. 1986a). This behavior was not altered by exposing the animals to the electric field and to different positive air ion concentrations of $1.4 \times 10^{6}, 2.5 \times 10^{5}$, or 1.0 $\times 10^{4}$ ions $/ \mathrm{cm}^{3}$ (Creim et al. 1986b).

There has been some recent interest in the possible biological interactions with weak, combined $a-c$ and d-c magnetic fields. This is in part related to studies described earlier involving chicken eggs and pulsed a-c magnetic fields (Delgado et al. 1982). Attempts by other researchers to replicate the findings raised the possibility that effects depended on how the egg is oriented with respect to the earth's d-c magnetic field (Microwave News 1984). Another study reported that when rats were exposed to $50 \mu \mathrm{T}$ (500 $\mathrm{mG}$ ) $60-\mathrm{Hz}$ magnetic fields while in a d-c field of $26 \mu \mathrm{T}$ (260 $\mathrm{mG}$ ), the animal's ability to judge time intervals was affected (Thomas et al. 1986). The effect was reversible about 1 hour after exposure ended.

\section{Environmental Studies}

BPA sponsored a study in Oregon that involved natural vegetation, crops, and wildlife living near the $\pm 400-k V$ Celilo-Sylmar line (Griffith 1977, Lee and Griffith 1978). Some slight differences were found in the abundance and 
diversity of wildlife on and off the right-of-way. These differences were attributed to effects of construction that changed vegetation composition and patterns on the rightof-way. No effects of the d-c line were found on wheat growing on the right-of-way. Cattle were also frequently observed feeding or resting near the line. The principal researcher conducting the study spent hundreds of hours on the $d$-c line right-of-way and never perceived the electric field and never experienced any shocks.

Japanese researchers studied wheat growing under a d-c test line (Endo et al. 1979). A d-c field of up to $19.5 \mathrm{kV} / \mathrm{m}$ was reported to have had no effect on growth or yield of the wheat. However, in reviewing this study, the Minnesota
Science Advisors (Bailey et al. 1982:IV-9) suggested that the data indicated that the $d$-c field did appear to affect plant growth and yield.

An extensive, long-term environmental study of the D-C Intertie in central Oregon was conducted by Oregon State University from 1985 to 1988 (Raleigh 1988). BPA and a group of nine other utility organizations sponsored the experimental study, which involved beef cattle and crops raised on the right-of-way of the $\pm 500-k V ~ d-c$ line (Figure 49). The study was designed to simulate ranching and farming conditions. The growth and reproduction of 100 beef cows and two crop species raised under the line were compared to those of control groups raised in an area away from the line.

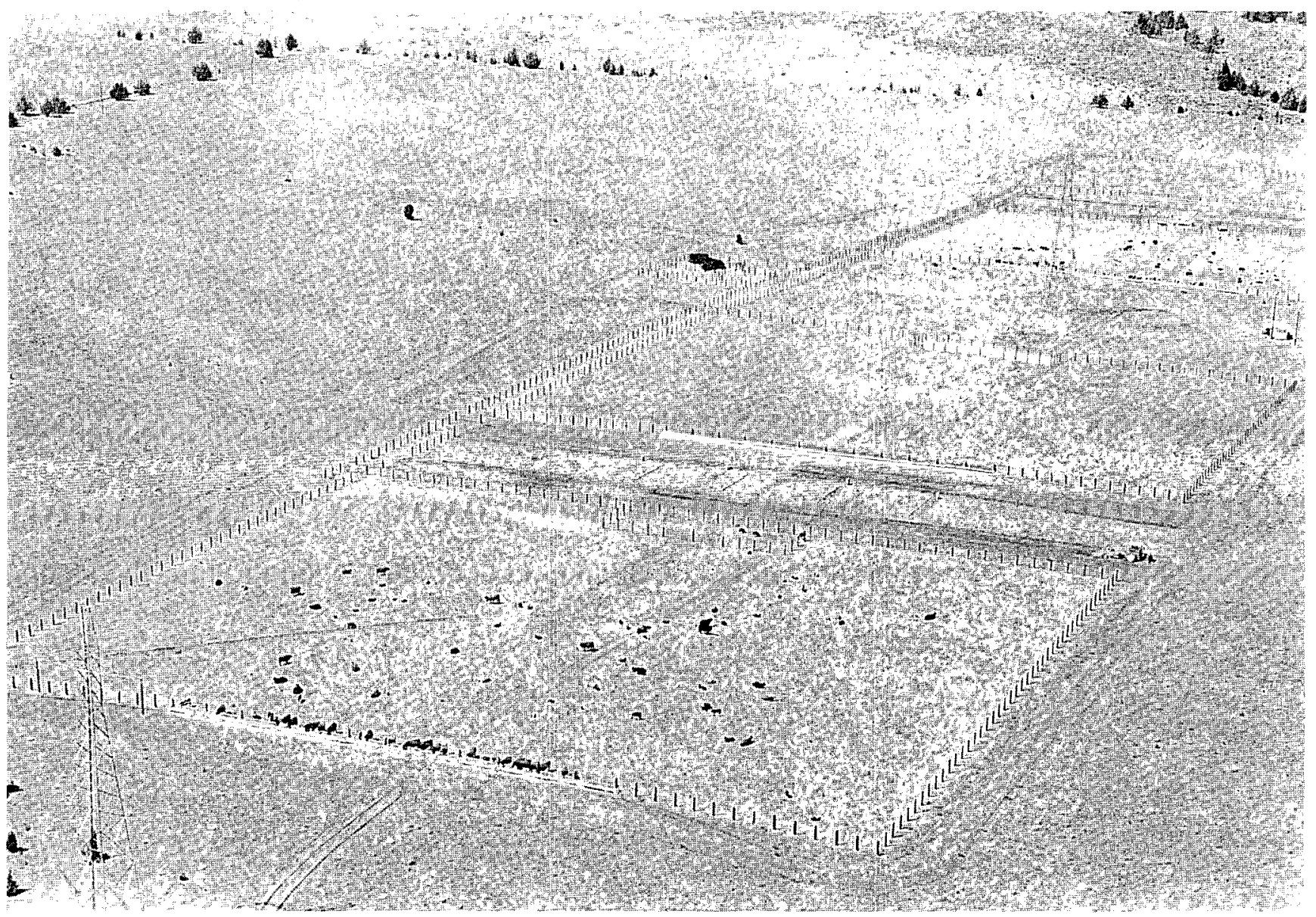

FIGURE 49. Oregon State University conducted a 3-year study of beef cattle raised on the right-of-way of the $\pm 500-k V D-C$ Intertie. 
Results of the study showed no statistically significant differences in growth or reproduction between the cattle raised under the line and the control animals. Behavioral studies indicated that from 1 to 4 percent fewer cattle occupied areas directly under the $d$-c line conductors. Such a small effect would not be noticeable in a normal ranching operation. This finding could not be correlated with either the electric field or the audible noise produced by the line. There were also no differences in yield of alfalfa or wheat between the line and control areas (Figure 50). A few small and inconsistent differences in crop growth were found, but the causes could not be determined.

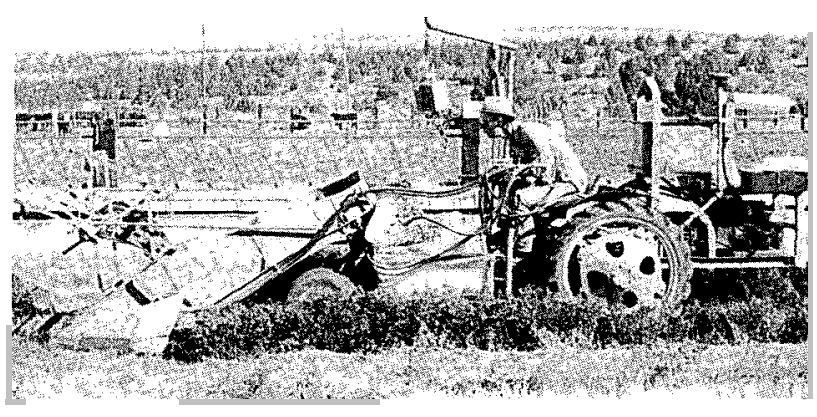

FIGURE 50. The growth of wheat and alfalfa planted beneath the $\pm 500-k V D-C$ Intertie was studied by Oregon State University. Here, alfalfa is being harvested.

\section{Orientation/Navigation}

A large body of evidence suggests that several species, ranging from bacteria to fish and possibly humans may have some ability to detect and make use of the earth's dc magnetic field (Blakemore et al. 1988, Kalmijn 1988).

Birds may to be able to use information from the earth's dc magnetic field as one aid to navigation (Gould 1980, Southern 1988). This ability may be related to the presence of magnetic material (magnetite) known to exist in the tissues of birds, bees, and other animals. When homing pigeons were exposed to slowly alternating magnetic fields of up to $0.06 \mathrm{mT}(0.6 \mathrm{G})$ for a few hours before release, their initial orientation was disturbed (Papi et al. 1983). However, the birds seemed to compensate quickly for the disturbance, and their homing performance was not affected.

Recent studies raise some doubts about the ability of birds to detect weak magnetic fields. Moore et al. (1987) tested the ability of four pigeons to detect changes in an earthstrength magnetic field varying between 0.01 and $10 \mathrm{~Hz}$. The birds were trained to contact a response key to obtain a water reward. Even with extensive training, none of the birds was able to distinguish between the constant and changing field.

Another similar study tested the ability of six pigeons to detect changes in a d-c magnetic field of up to 3 times the normal strength of the earth field (Alsop 1987). Results indicated that the birds could not distinguish between the static or fluctuating applied fields and the ambient earth field. The researchers suggested that if birds can actually detect weak magnetic fields, far more elaborate study designs may be needed to measure this phenomenon.

\section{Human Health}

There are some claims that negative air ions can have a therapeutic effect, at least for some sensitive people. Commercial negative ion generators are sold that supposedly produce a more healthful home or office environment (Field 1976, Sulman 1980). Negative ions have also been used in the treatment of burns, allergies, and other medical problems (Charry 1984, Sulman 1980).

The "sick building syndrome," referring to worker discomfort in office buildings, has been suggested to be, in part, caused by a deficiency of negative ions. A study by Finnegan et al. (1987), however, found no evidence that the use of negative ion generators had any effect on the comfort or well-being of the 26 people in the study.

The serotonin hypothesis has been advanced to explain certain reported effects of air ions. Krueger and Sigel (1978) believed that small positive ions, when inhaled, cause release of the brain hormone serotonin. In contrast, negative ions speed the removal of this hormone from the blood. The presence of serotonin is associated with a variety of minor ill effects. The unpleasant effects of desert winds on weather-sensitive people have also been attributed to ions and/or charged particulates and release of serotonin (Sulman 1980).

Bailey (1982) challenged the factual basis of the assumption that air ion effects are due to alterations in serotonin metabolism. He believed that the serotonin hypothesis has not been rigorously tested. A study by Beardwood et al. (1987), however, on research with rats exposed to positive ions did not refute the hypothesis.

Kavet et al. (1985) advanced another hypothesis for explaining effects attributed to air ions. They proposed that such effects are mediated by certain neuroendocrine cells which are found in the respiratory epithelium. They indicated that studies are needed to test the hypothesis. 
Charry (1987) reviewed 33 air ion studies involving human physiology and behavior, and 18 studies on human biomedical responses. He found that, while a large variety of effects have been reported, there is no overall agreement among the findings. Many of the studies were flawed by design and methodology problems. Many studies reported no effects of exposures to air ions. Charry concluded that it appears that air ions can affect human biological responses, but the effects are small and usually disappear after exposure ends.

It must be emphasized that there is continued controversy among scientists about the various effects reported from studies of air ions and d-c fields. In general, much of this research cannot be directly applied to an HVDC transmission line. In most studies, ion and/or field levels are relatively constant for long periods. In contrast, ion concentrations, distributions, and fields are constantly changing near a d-c line. Likewise, people and animals typically are not stationary. In many air ion papers, it is also difficult or impossible to determine exactly what type and concentration of ions were present and the actual exposure experienced by the test subjects. Other than the questionable reports from Minnesota, persons living or working near HVDC commercial and test lines have generally not reported either adverse or beneficial effects from air ions or d-c fields. More recent research with animals and humans indicates no evidence that exposure to either $d-c$ electric and magnetic fields or air ions causes any hazardous effects.

Table 15 is a summary of conclusions from several reviews of the literature involving the biological effects of air ions.

\section{Table 15. Conclusions of Reviews (since 1980) of the Literature Involving the Biological Effects of Air lons.}

\section{Reference}

Bailey et al. (1982:8)

Bailey et al. (1986)

Banks et al. (1983:66)

Brambl (1982:MR-6)

\section{Conclusions}

"In summary, while air ions appear to affect some biological processes in animals, plants, and microorganisms, there is insufficient reason to believe that acute exposures to air ions are harmful or injurious. As far as is known, all effects that have been described in animals and humans are quite mild and fully reversible, usually within a few hours. However, there are insufficient data to determine what effects, if any, might be observed with exposures to high ion concentrations over extended periods of time."

"There still appears to be little likelihood that either chronic or acute exposure to small air ions and static electric fields at levels measured either on or downwind of the right-of-way of the dc line cause adverse health effects. The scientific literature since 1982 is similar to the earlier literature in that the evidence for biological effects of air ions is still inconsistent. Certain authors have begun to address the question of chronic exposure. However, these studies are not conclusive and would need to be replicated before their results could be accepted."

"In summary, it can be concluded, based on a more detailed examination of those studies meeting reasonable criteria for acceptable scientific quality, that the effects on biological and behavioral responses in both animals and humans are for the most part small in absolute magnitude and are transient (i.e., the effects disappear after subjects are removed from the ion conditions). The exception to the above are the series on the course of respiratory infection in mice ... These findings taken as a whole indicate that there is no scientific basis at present for asserting that small air ions are a threat to human or animal health."

"The conclusion of this minority report is that it is more likely than not that the CPA UPA HVDC transmission line represents a potentially significant hazard to human health and welfare. Since the air ions produced by this line (or their products) are the most probable agent of this hazard, the concentration of air ions in the vicinity of this line (beyond the right-of-way) should be reduced to ambient levels by any of several technical modifications of the transmission line that are now available." 
Charry (1987:146)

Dow Associates (1980:3-54)

Frazier and Preache (1980:113)

Kellogg (1984:132)

Sheppard (1983b:III-22)
"Based on a detailed examination of those studies meeting such minimum standards [of scientific quality], the following conclusions seem reasonable: (1) there appear to be effects of ions on biological and behavioral responses in both animals and humans; (2) when these effects occur, they are for the most part small in absolute magnitude; and (3) the effects that have been observed are for the most part transient (the effects disappeared after subjects were removed from the ion exposure condition)."

"For air ions, the strongest statement that can be made is that they do have biological effects. Extrapolations to the powerline environment are extremely difficult to make. . . there are no substantive laboratory or 'real life' studies describing what the role of intervening variables, such as fluctuations in ambient air conditions, might be."

"In summary, the questions of bioactivity of small air ions and the role of 5-HT [serotonin] metabolism in such effects are still controversial issues. ... In any event, the reports of adverse effects of sometimes relatively short exposures to environments containing excess positive ions (some of which are based on ion densities that occur in nature in unusual weather conditions and will almost certainly occur in the vicinity of HVDC transmission lines), it is important for the objectives of the proposed experimental design that some of the lines of investigation suggested by the air ion literature be pursued [sic]."

"Certainly the scientific literature contains a core of well-controlled studies which have clearly demonstrated air ion effects of physiological relevance to conditions found in both natural and man-made environments. Nevertheless, because many early workers neglected to pay strict attention to the experimental details required in this type of research, much uncertainty still exists about many reported air ion effects."

"The evidence from either laboratory or human studies is so deeply flawed by methodological or experimental problems that one can conclude there is no sound body of literature on the biological effects of air ions. Nevertheless, a few isolated research reports, primarily in the area of animal physiology, suggest possible air ion effects using ion concentration greater than would be found beneath the HVDC transmission line." 


\section{UNDERGROUND POWER TRANSMISSION}

The question is often asked, "Why can't transmission lines be placed underground so actual and potential effects could be eliminated?" Although underground power cables have been used in urban areas for many years, the amount of underground EHV transmission is very small compared to overhead lines: There are less than $16 \mathrm{~km}(10 \mathrm{mi})$ of underground $500 \mathrm{kV}$ world-wide. Because of the public interest in underground transmission, BPA sponsored a study of the generic environmental effects of underground cable systems. The report on this study was prepared by the firm of Dames \& Moore (1981) and is titled, Underground Cable Systems: Potential Environmental Impacts. It is available from the BPA Environmental Section (EFBG), P.O. Box 3621, Portland, OR 97208. Some of the information in the report is summarized below.

There are three basic commercially proven underground cable types: 1) gas-insulated pipe, 2) oil-insulated pressurized pipe, and 3) self-contained oil-insulated cables. BPA has operated a $192-\mathrm{m}(630-\mathrm{ft})$ section of $500-$ $\mathrm{kV}$ compressed gas-insulated underground cable since 1975 near Ellensburg, Washington (Figure 51).

Rights-of-way for underground systems may range from 7.5- to 30-m (25- to 100-ft) wide. Although such land uses as grazing and agriculture are allowed on these rights-ofway, buildings and trees are not permitted. Many of the impacts associated with cable systems are due to the actual trenching operation. Electric fields from cables are essentially zero, and magnetic fields are small. Most cable systems require above-ground equipment for cooling. In addition to visual impacts from this equipment, noise is also produced by fans and motors.

Although underground systems are not affected by weather conditions, failures can occur from internal and external causes. Some failures are difficult to locate and repair, and may require time-consuming excavation and re-installation of cable sections. If cables are damaged, gas or oil leaks can develop.

Overall, EHV cable systems are very expensive to manufacture, install, operate, and maintain. Costs for underground systems are at least $8-10$ times those of comparable overhead lines. Considering that costs for BPA 500-kV overhead lines can average between $\$ 500,000$ and $\$ 900,000$ per mile, costs for undergrounding become enormous, except for very short distances. The high cost and the problems associated with outages are the primary reasons that EHV lines are seldom placed underground.

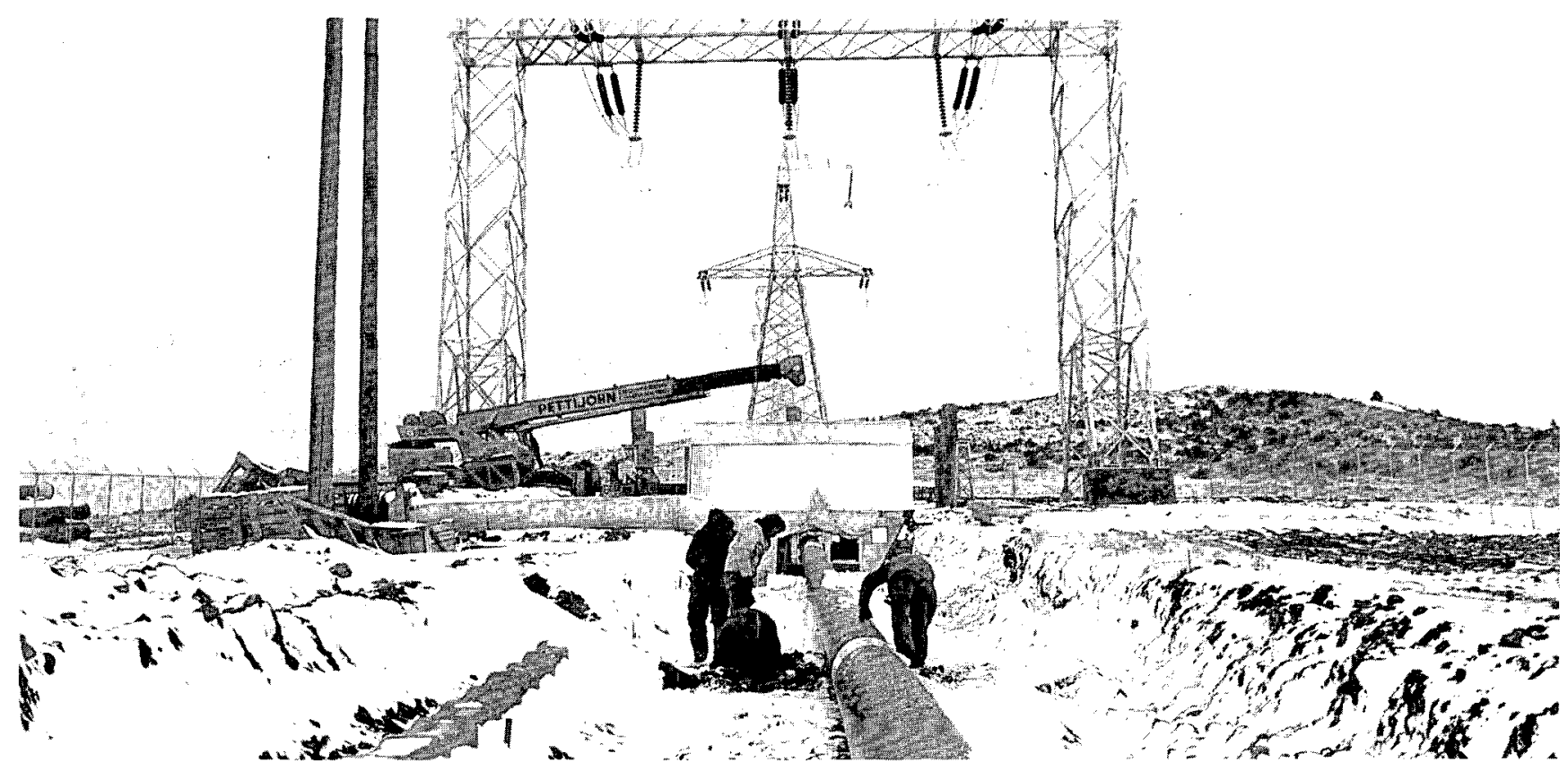

FIGURE 51. The BPA 500-kV compressed gas insulated cable near Ellensburg, Washington. 







\section{Grounding Criteria for Objects Subject to Induced Voltage}

If a fence, insulated from ground, closely parallels an energized transmission line, a voltage will be induced on the metal strands of the fence by the electric field. The voltage will be at the same potential as the electric field at that point and will not depend on the length of the parallel. The current-to-ground is directly proportional to the length of the parallel fencing. It is possible, depending upon the quality of the insulation and the proximity of the energized conductors, to induce a high voltage on an insulated strand of fencing. Voltages and currents can also be induced by the magnetic field.

\section{Grounding Policy}

It is BPA's policy to ground all wire fences, metal buildings, and other metal objects that are within specified distances of 500-kV lines. Where the lines are less than $500 \mathrm{kV}$, conducting objects are grounded only after a complaint has been received and a proper investigation indicates the need.

The policy is applied as follows.

\section{A. Fences}

\section{Nonelectric Fences}

a. Ground those fences that cross at right angles or obliquely at points of entry every $60 \mathrm{~m}$ (200 $\mathrm{ft}$ ) and each side of a break, if necessary.

b. Ground at each end, at every $60 \mathrm{~m}(200 \mathrm{ft})$, and at each side of a random break, those parallel fences that are:

(I) Forty-six meters (150 ft) or more in length

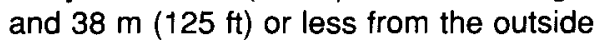
conductor.

(2) Eight hundred meters (2624 ft) in length and 38 to $76 \mathrm{~m}(125$ to $250 \mathrm{ft})$ from the outside conductor.

\section{Electric Fences}

a. Install filters in all electric fences near a-c lines that cross the right-of-way and at intervals not to exceed $762 \mathrm{~m}(2500 \mathrm{ft})$ in those lines that are parallel, less than $18 \mathrm{~m}(60 \mathrm{ft})$ from the outside conductor, and more than $305 \mathrm{~m}$ (1000 ft) long.
For those fences 18 to $38 \mathrm{~m}$ ( 60 to $125 \mathrm{ft}$ ) from the outside conductor and at least $610 \mathrm{~m}(2000$ ft) long, install filters at intervals of not more than $1524 \mathrm{~m}(5000 \mathrm{ft})$.

b. Replace with an Underwriters Laboratory (UL) approved charger all those that do not have a UL approval.

\section{B. Buildings}

Ground all buildings that have a metal roof or metal sides or both when they are:

1. Within $30 \mathrm{~m}(100 \mathrm{ft})$ of the outside conductor; or

2. Thirty to forty-six meters ( 100 to $150 \mathrm{ft}$ ) from the outside conductor when the building has $186 \mathrm{~m}^{2}$ $\left(2000 \mathrm{ft}^{2}\right)$ or more of metallic surface; or

3. Within $76 \mathrm{~m}(250 \mathrm{ft})$ of the outside conductor and are used to store flammable or explosive items.

\section{Wheel-Type Irrigation System}

The following safety practices should be observed when working with long, wheel-type irrigation sys-

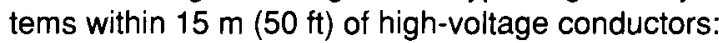

1. Ground the irrigation system before touching it. This can be done by connecting the movable section of pipe to a solid ground, such as a header pipe valve or driven ground rod with a length of No. 8 wire fitted with battery clips.

2. Where possible, especially with circular systems, park the irrigation line at right angles to the transmission line before performing maintenance. If the main section has to be disconnected from the pivot point and the pipe is parallel to and within 15 $\mathrm{m}(50 \mathrm{ft})$ of a high-voltage line, the disconnected pipe sections should be connected to a driven ground rod.

\section{Other Objects (Gutters, downspouts, etc.)}

Ground all such objects when they are:

1. Within $30 \mathrm{~m} \mathrm{(100} \mathrm{ft)} \mathrm{of} \mathrm{the} \mathrm{outside} \mathrm{conductor;} \mathrm{or}$

2. Are $46 \mathrm{~m}(150 \mathrm{ft})$ or longer and within 30 to $46 \mathrm{~m}$ (100 to $150 \mathrm{ft}$ ) from the outside conductor. 


\section{Summary of Recent Literature Reviews Published Since 1985 Involving Biological Effects of Electric and Magnetic Fields}

\author{
Study' \\ Country/Author \\ Affiliation
}

Findings 1
AIBS Committee 1985:22-23

U.S., American Institute of Biological Sciences.

Ahlbom et al. 1987:10 Scientific Advisory Panel NY Power Lines Project

Ahlbom 1988: 342 Institute of Environmental Medicine, Stockholm Sweden

Aldrich and Easterly 1987:159

Oak Ridge National Laboratory

Becker and Selden 1985:327 U.S., Orthopedic surgeon, Technical writer (respectively)
"ELF electric and magnetic fields can, at least in some frequency and intensity combinations and under certain circumstances, cause a variety of effects at any of several levels of biological organization of plants and animals or in vitro preparations. Additional research on coupling of living systems to ELF electric and magnetic fields, on mechanisms of interaction, and on responses of biological materials to such fields will be necessary to gain a more nearly complete understanding of the biological significance, if any, of interactions of these fields with living systems."

"In conclusion, results of the New York funded projects document biologic effects of electric and magnetic fields in several systems. The variety of effects of magnetic fields have not been previously appreciated. Several areas of potential concern for public health have been identified, but more research must be done before final conclusions can be drawn. Of particular concern is the demonstration of a possible association of residential magnetic fields with incidence of certain childhood cancers. Further study of this possible association and mechanisms to explain it are important. The variety of behavioral and nervous system effects may not constitute a major hazard because most appear to be reversible, but they may impact temporarily on human function. Further research should also be done in this area."

"Despite the obvius limitations of these [occupational] studies and the somewhat erratic findings, it is difficult to avoid the conclusions that there is a certain consistency between the results and that it seems likely that these occupations are in fact at an increased risk of leukemia. ... exposure to magnetic fields remains one of the candidates to explain the elevations in cancer risk. . . . studies on residential exposure should be considered in tandem with studies on occupational exposure, and when their results are combined, indeed, an association cannot be disproved."

"General observation would accord with the implication that there is no single and manifest healtheffect as the result of exposure to these fields. There are persistent indications, however, that these fields have biologic activity, and consequently, there may be a deleterious component to their action, possibly in the presence of other factors. Power frequency electromagnetic field exposures are essentially ubiquitous in modern society, and their implications in the larger perspective of public health are unclear at this time."

“... ELF electromagnetic fields vibrating at about 30 to 100 hertz, even if they're weaker than the earth's field, interfere with the cues that keep our biological cycles properly tuned; chronic stress and impaired disease resistance result. Second, the available evidence strongly suggests that regulation of cellular growth processes is impaired by electropollution, increasing cancer rates and producing serious reproductive problems."

1 The statements quoted may not necessarily be specifically identified as findings or conclusions by authors of the reports cited. However, we believe the statements do characterize the overall results of the reviews. 
Carstensen 1987:182 U.S.

Coleman and Beral 1988:1 International Agency for Research on Cancer, London School of Hygiene and Tropical Medicine

Committee for Biological Effects of Power Frequency EMF 1987

Royal Swedish Academy of Engineering Sciences

Czerski 1988a:266

U.S., Food and Drug Administration

Czerski 1988b:298-299

U.S., Food and Drug

Administration

FEMFSAC 1985:194 U.S., Florida Advisory Commission

Graves 1986:8

Consultant to the State Electricity Commission of Victoria (Australia)

Justesen et al. 1986:6 WEST Associates - Energy Task Force, U.S.
"After study and deliberation by scientific and governmental bodies throughiout the world, only three potentially adverse effects from exposure to transmission lines hiave been specifically identified-shock from contact with conducting objects, inhibition in a subset of cardiac pacemakers, and lowered productivity in honeybees. . . . None of the bodies has identified specific hazards that will result from long-term exposure to trarısmission line fields."

"The most consistent finding is that electrical workers appear to be at increased risk of leukaemia, especially acute myeloid leukaemia. The effect is small. ... There is no clear association between cancer risk and residences near sources transmitting electricity, although some data suggest that there may be small increases in leukaemia in those living very close to the source. The relationship between adverse outcome of pregnancy and exposure to sources of ELF electromagnetic fields needs further invisstigation."

"In the 1983 report (IVA-Rapport 240) it was stated that there is a range of will established effects of power-frequency electric and magnetic fields, but that none of these effects were judged to constitute a health hazard. Since then, international resea.'ch in the area has been intense and a great number of investigations have been published. We find that the above judgment may still be valid even today. However, there are more studies than before showing effects, such as if [sic] they can be confirmed they must be judged as being hazardous to health. Primarily, it is the magnetic field which allegedly can cause these effects."

"Studies of occupationally exposed populations and volunteers did not reveal any specific symptoms or syndromes associated with 50 and $60 \mathrm{~Hz} E$ [electric] field exposures. However, the limited size of the populations examined does not allow any sonclusions to be drawn on the effects of exposure on incidence of rare diseases. ... Animal studies have not revealed any specific symptoms or syndromes from ELF [electric] field exposure."

"In summary, the causal relationship between ELF [magnetic] field exposure and incidence of cancer is a hypothesis, and not a proven fact. The hypothesis has to be taken seriously, if only because of its possible implications for public health. . . It is difficult at present to make a definitive statement on health risk evaluation relevant to public exposure."

"The Commission unanimously believes that the scientific information now available supports the conclusion that it is unlikely that $60-\mathrm{Hz}$ electric and magnetic fields associated with high voltage transmission lines has led, or can lead, to public health problems. However, some ambiguities in the currently available science precludes our [sic] categorically concluding that absolutely no public health problem exists."

"It is not possible to make unequivocal statements about the potential health hazards of any agent. However, a careful review of the literature on biological, including human health, effects of extremely low frequency electric and magnetic fields leads to the firm conclusion that no adverse health effects of exposure to fields in the range of those associated with SECV [State Electricity Commission of Victoria] transmission lines or stations have yet been established and to the further conclusion that such adverse health effects are very unlikely."

"On the basis of all study areas, the risk of adverse effects on human health from exposure to power frequency environmental fields appears to be low. Of paramount concern are the unresolved questions of cancer, reproductive defects, and pathophysiological changes which might result from disruption of body rhythms during long-term exposures. Data from human epidemiologic studies may implicate an association with cancer, and the data on animal models and cell- and tissue-cultures may indicate disruption of normal physiological or biochemical processes. Where physiological changes have been seen, such as the disruption of biologic rhythms, there has been no direct evidence of disease. However, the unresolved questions are important because even a very small risk could 
Marino, A. A. 1988:1019 U.S., Louisiana State University

Ontario Ministry of Health. 1987:i

Parker, J.H. et al. 1987:v Florida EMF Science Advisory Panel

Shandala, M.G., et al. 1988:943 U.S.S.R., Kiev

Sheppard 1988:3, U.S.

Tenforde, T.S. 1986:34 U.S., Lawrence Berkeley Laboratory

EPA 1987:2-167

U.S. Environmental

Protection Agency have a substantial public health impact since virtually everybody is exposed to lowintensity fields, but only a few percent are exposed at higher field strengths."

"Controversy, or at least the appearance of controversy, regarding the health risks associated with environmental electromagnetic fields has developed because the emerging scientific picture runs markedly counter to the long-standing interests of some industries and government agencies in unbridled use of the electromagnetic spectrum. The existence of a link between electromagnetic fields in the environment and disease has been established despite the fact that many important details regarding it remain undiscovered."

"There is general agreement among scientific researchers that there are many ambiguities present in the current literature. Despite the amount of effort and the diversity of the questions examined in the literature, the results have failed to support a causal relationship between ELF field exposure and a variety of adverse health effects. This literature fails to provide conclusive or convincing evidence that there is a public health risk associated with ELF fields."

"Although a large number of studies indicate no health effects on people, some studies indicate potential health risks. There appears to be some evidence of biological effects due to exposure to EMF. The exposure levels that appear to cause effects in laboratories occur at field strengths higher than people normally experience. Not enough is known about the mechanisms that might cause adverse effects due to exposure to EMF. It is not possible from current knowledge to say with any confidence how safe or dangerous long term exposure to EMF might be."

"Most investigators have concluded that powerline electric fields elicit a measurable reaction in a number of organ systems including the CNS [Central Nervous System], cardiovascular, blood, and reproductive systems. Some investigators propose that the field elicits regulatory-system reactions based on recorded functional effects. Other investigators consider that a powerline electric field elicits only non-specific or normal physiological reactions that do not pose a threat to human health. There are also reports of no effects of powerline electric fields on biological systems."

"In general, the present situation with laboratory studies permits greater confidence in the validity of the various laboratory phenomena. ... Despite this positive note, the present data are still insufficient for a desirable degree of scientific proof and understanding. . . - I recommend that it is now reasonable to consider the epidemiological evidence in making public policy, although it would still be wrong to treat the evidence as if a causeand-effect relation had been proven."

"Although a wide variety of biological effects resulting from exposure to ELF magnetic fields have been reported in studies on cellular, tissue, and animal systems, the only phenomenon consistently replicated is the induction of magnetophosphenes. . . . Numerous deficiencies have been noted in the dosimetric and epidemiological procedures that were used in these [epidemiological] studies, and no definitive conclusion concerning the possible relationship between ELF magnetic field exposure and cancer risk can be drawn from the evidence that is currently available."

"Thus the specter of potential cancer induction/promotion and of aberrant behavioral changes have been associated with exposure to fields in homes caused by the electric power system and the use of home appliances. These reports do not unequivocally demonstrate that power-line frequency fields are a human health hazard separate and apart from the known hazard due to electric shock and burns; however, the combined reports do indicate that a great deal of caution must be exercised before allowing any increase in exposure of the general population until a better understanding is obtained of the underlying mechanism of action and possible synergism with other potentially hazardous agents and stressors in the environment." 
WHO/IRPA 1987:126

World Health Organization
"For human exposure to time-varying [magnetic] fields, it seems reasonable to assume that a health risk assessment can be made on the basis of significant perturbations of biological functions caused by electric currents induced by the fields. Available data suggest that, when current densities less than $10 \mathrm{~mA} / \mathrm{m}^{2}$ are induced in tissues and extracellular fluids, the induction of adverse health effects is unlikely. However, the possibility of some perturbing effects occurring following long-term exposure cannot be excluded." 


\section{BPA Interim Guidance on Electric and Magnetic Fields}

(Office of Engineering 12/6/88)

- Because it appears that it will take several more years before sufficient scientific data is available to finally establish whether or not E/MF are a threat to public or worker health, it does not appear prudent for BPA to change its present standards for E/MF.

As States in the Region review the issue of E/MF and consider limits on these fields, BPA will participate in the process and adopt the resulting standards.

- BPA employees will be kept informed on current research and information through the Central Safety and Health Committee and informational releases.

- BPA will continue to support agency and industry R\&D efforts dealing with E/MF issues.

- E/MF exposure should be one of the considerations in the design and location of new transmission facilities. Methods for dealing with this can be developed through existing BPA engineering and environmental processes.

- Public and employee exposure to E/MF should not be increased where practical alternatives exist.

- BPA should continue to develop appropriate educational materials and respond to requests from the public for information or measurements of E/MF associated with the transmission system. 


\section{DO NOT MICROFILM \\ THIS PAGE}


Adey, W. R. 1988. The Cellular Microenvironment and Signaling Through Cell Membranes. Pages 81-106, in, M.E. O'Connor, and R.H. Lovely (editors). Electromagnetic Fields and Neurobehavioral Function. Alan R. Liss, Inc. New York.

Adey, W.R. 1981. Tissue Interaction with Nonionizing Electromagnetic Fields. Physiological Reviews 61(2):435-514.

Adey, W.R. et al. 1981. Tissue Interaction with Nonionizing Electromagnetic Fields. DOE/ET/29078-T1(DE81027654). National Technical Information Service. Springfield, Virginia.

Adey, W.R., S.M. Bawin, and A.F. Lawrence. 1982. Effects of Weak Amplitude-Modulated Microwave Fields on Calcium Efflux From Awake Cat Cerebral Cortex. Bioelectromagnetics 3(3):295-307.

Adey, W.R., and S.M. Bawin. 1977. Brain Interactions With Weak Electric and Magnetic Fields. Neurosciences Research Progress Bulletin 15(1). MIT Press. Cambridge, Massachusetts.

Ahlbom, A. 1988. A Review of the Epidemiologic Literature on Magnetic Fields and Cancer. Scand. J. Work Environ. Health 14:337-343.

Ahlbom, A. et al. 1987. Biological Effects of Power Line Fields. New York State Powerlines Project Scientific Advisory Panel Final Report. New York State Department of Health, Power Lines Project. Albany, New York.

AlBS Committee. 1985. Biological and Human Health Effects of Extremely Low Frequency Electromagnetic Fields. Post 1977 Literature Review. American Institute of Biological Sciences. Arlington, Virginia.

Albert, E., G. Cohen, L. Avellino, G. Kornhouser, and A. Yoshioka. 1984. Electron Microscopic Observations on Rat Cerebellum and Hippocampus After Exposure to 60-Hz Electric Fields. Abstracts, Sixth Annual Meeting, Bioelectromagnetics Society. p. 4.

Aldrich, T.E., A. Glorieux, and S. Castro. 1984. Florida Cluster of Five Children with Endodermal Sinus Tumors. Oncology 41:233-23.

Aldrich, T. E., and C.E. Easterly. 1985. Handbook of Epidemiological Methods with Special Emphasis on Extremely Low-Frequency Electromagnetic Fields. ORNL-6237. National Technical Information Service. Springfield, Virginia.

Aldrich, T.E., and C.E. Easterly. 1987. Electromagnetic Fields and Public Health. Environmental Health Perspectives 75:159-171.

Algers, B., I. Ekesbo, and K. Hennichs. 1981. The Effects of Ultra High-Voltage Transmission Lines on the Fertility of Dairy Cows. A Preliminary Study. Swedish University of Agricultural Sciences, Department of Animal Hygiene with Farrier's School. Report No. 5. Skara, Sweden.

Algers, B., and J. Hultgren. 1987. Effects of Long-Term Exposure to a 400-kV, 50-Hz Transmission Line on Estrous and Fertility in Cows. Preventive Veterinary Medicine 5:21-36.

Alsop, B. 1987. A Failure to Obtain Magnetic Discrimination in the Pigeon. Animal Learning Behavior 15(2):110-114.

American National Standards Institute (ANSI). 1973. American National Standard for Leakage Current for Appliances. ANSI C101.1-1973. New York.

Ames, S. 1978. Tail of the Dragon. Rain. August/September. pp. 8-11.

Amstutz, H.E., and D.B. Miller. 1980. A Study of Farm Animals Near 765 kV Transmission Lines. Bovine Practitioner 15:51-62.

Anderson, L.E., R.J. Reiter, and B.W. Wilson. 1988. Influence of $60-\mathrm{Hz}$ Electric Fields on the Nocturnal Rise in Pineal Melatonin Levels in the Developing Rat. Abstracts, Tenth Annual Meeting, Bioelectromagnetics Society. p. 35.

Anderson, S.H., K. Mann, and H.M. Shugart, Jr. 1977. The Effect of Transmission Line Corridors on Bird Populations. American Midlands Naturalist 97:216-221.

Arner, D., and R.E. Tillman (editors). 1981. Environmental Concerns in Rights-of-Way Management. Symposium Proceedings. Electric Power Research Institute. Palo Alto, California.

Asanova, T.P., and A.I. Rakov. 1966. The State of Health of Persons Working in Electric Field of Outdoor 400-kV and 500-kV Switchyards. Hygiene of Labor and Professional Diseases, 5.

Bailey, W.H. 1982. Biological Effects of Air lons: Fact and Fancy Concerning Serotonin. Pages 91-120, in, J.M. Charry (editor). Conference on Environmental lons and Related Biological Effects. American Institute of Medical Climatology. Philadelphia, Pennsylvania.

Bailey, W.H. et al. 1982. A Health and Safety Evaluation of the $\pm 400-\mathrm{kV}$ DC Powerline. A Report to the Minnesota Environmental Quality Board. St. Paul, Minnesota.

Bailey, W.H. et al. 1986. Comments of the MEQB Science Advisors on Electrical Environment Outside the Right-of-Way of CU-TR-1, Report 5. Minnesota Environmental Quality Board. St. Paul, Minnesota.

Bailey, W.H., and J.M. Charry. 1986. Behavioral Monitoring of Rats During Exposure to Air lons and DC Electric Fields. Bioelectromagnetics 7:329-339.

Bailey, W.H., and J.M. Charry. 1987. Acute Exposure of Rats to Air lons: Effects on the Regional Concentration and Utilization of Serotonin in Brain. Bioelectromagnetics 8:173-181.

Bankoske, J.W., H.B. Graves, and G.W. McKee, 1976. The Effects of High Voltage Electric Fields on the Growth and Development of Plants and Animals. Pages 112-123, in, R. Tillman (editor). Proceedings of the First National Symposium on Environmental Concerns in Rightsof-Way Management. Mississippi State University. Mississippi State, Mississippi.

Banks, R.S. et al. 1983. The Public Health Implications of HVDC Transmission Facilities: An Assessment of the Available Evidence. Report Prepared for New England Electric Transmission Corporation and Vermont Electric Power Company.

Banks, R.S., C.M. Kanniainen, and R.D. Clark. 1977. Public Health and Safety Effects of High-Voltage Overhead Transmission Lines: An Analysis for the Minnesota Environmental Quality Board. Minnesota Department of Health. Minneapolis, Minnesota.

Banks, R.S., and D. McConnon. 1987. High Voltage Direct-Current Transmission Lines: A Public Health Hazard? Pages 67-87, in, L.E Anderson et al. (editors). Interaction of Biological Systems with Static and ELF Electric and Magnetic Fields. CONF-841041 National Technical Information Service. Springfield, Virginia. 
Banks, R.S., and T. Vinh. 1984. An Assessment of the 5-mA 60-Hz Contact Current Safety Level. IEEE Transactions on Power Apparatus and Systems. PAS-103(12):3608-3614.

Barker, A.T. 1985. Nonionizing Electromagnetic Therapy: Fact or Fantasy? Physics Bulletin 36(6):251-253.

Barker, A.T., and I.L. Freeston. 1985. Medical Applications of Electric and Magnetic Fields. Electronics and Power 31(10): 757-760.

Barnes, H.C., A.J. McElroy, and J.H. Charkow. 1967. Rational Analysis of Electric Fields in Live Line Working. IEEE Transactions on Power Apparatus and Systems PAS-86(4):482-492.

Bassett, C.A.L. 1988. Historical Overview of Pemf-Assisted Bone and Tissue Healing. Abstracts, Tenth Annual Meeting, Bioelectromagnetics Society. p. 19.

Bauchinger, M., R. Hauf, E. Schmid, and J. Dresp. 1981. Analysis of Structural Chromosome Changes and SCE After Occupational LongTerm Exposure to Electric and Magnetic Fields from $380 \mathrm{kV}$ Systems. Radiation and Environmental Biophysics 19:235-238.

Bayer, A., J. Brinkmann, and G. Whittke. 1977. Experimental Research on Rats for Determining the Effect of Electrical A.C. Fields on Living Systems. (English Translation) Elektrizitaetswirtschaft. 4:77-81.

Beardwood, C.J., P. Jordi, and A. Abrahams. 1987. Alterations in Rat Flexor Withdrawal Reflex Response to a Noxious Stimulus After Exposure to Gaseous Air lons. Pages 29-38, in, L.E. Anderson et al. (editors). Interaction of Biological Systems with Static and ELF Electric and Magnetic Fields. CONF-841041. National Technical Information Service. Springfield, Virginia.

Beaulaurier, D.L., B.W. James, P.A. Jackson, J.R. Meyer, and J.M. Lee Jr. 1984. Mitigating the Incidence of Bird Collisions With Transmission Lines. Pages 539-550, in, A.F Crabtree (editor). Proceeding of the Third Symposium on Environmental Concerns in Rightsof-way Management. Mississippi State University. Mississippi State, Mississippi.

Becker, R.O., and G. Selden. 1985. The Body Electric; Electromagnetism and the Foundation of Life. William Morrow and Company, Inc. New York.

Beischer, D.E., J.D. Grissett, and R.E. Mitchell. 1973. Exposure of Man to Magnetic Fields Alternating at Extremely Low Frequency. Naval Aerospace Medical Research Laboratory. Pensacola, Florida.

Berman, E. et al. 1988. The Henhouse Project: Effect of Pulsed Magnetic Fields on Early Chick Embryos. Abstracts, Tenth Annual Meeting, Bioelectromagnetics Society. p. 14.

Berry, L. 1984. Minutes of the Board of Natural Resources and Conservation Meeting. December 10, 1984. Helena, Montana.

Bindokas, V.P., J.R. Gauger, and B. Greenberg. 1988. Mechanisms of Biological Effects Observed in Honey Bees (Apis mellifera, L.) Hived Under Extra-High-Voltage Transmission Lines: Implications Derived From Bee Exposure to Simulated Intense Electric Fields and Shocks. Bioelectromagnetics 9(3):285-301.

Blackman, C.F. et al. 1988. Effect of Ambient Levels of Power-Line Frequency Electric Fieids on a Developing Vertebrate. Bioelectromagnetics 9:129-140.

Blackman, C.F., S.G. Benane, D. E. House, and W.T. Joines. 1985. Effects of ELF $(1-120 \mathrm{~Hz})$ and Modulated $(50 \mathrm{~Hz}) \mathrm{RF}$ Fields on the Efflux of Calcium lons From Brain Tissue in Vitro. Bioelectromagnetics 6(1):1-11.

Blakemore, R.P., N.A. Blakemore, and R.B. Frankel. 1988. Bacterial Biomagnetism and Geomagnetic Field Detection by Organisms. Pages 19-34, in, A.A. Marino (editor). Modern Bioelectricity. Marcel Dekker, Inc. New York.

Blank, M., and B.F. Sisken. 1988. Effects of Pulsed EM Fields on Protein Synthesis in Normal and Cut Nerves. Project Resume. Contractor's Review. U.S. Department of Energy/Electric Power Research Institute.

Bonnell, J.A. et al. 1985. Can Induced 50-Hz Body Currents Affect Mental Functions? Pages 117-121, in, International Conference on Electric and Magnetic Fields in Medicine and Biology. London. IEE Conference Publication No. 257.

Bowman, J.D. et al. 1988. Exposures to Extremely Low Frequency (ELF) Electromagnetic Fields in Occupations with Elevated Leukemia Rates. Applied Industrial Hygiene 3(6):189-193.

Bracken, T.D. 1985. Blasting Near High Voltage Transmission Lines. (Draft Report). Prepared for Bonneville Power Administration. Portland, Oregon.

Bracken, T.D. 1988. Measurement of Occupational Exposure of Substation Workers to $60-\mathrm{Hz}$ Magnetic Fields. Report for Bonneville Power Administration. Vancouver, Washington.

Bracken, T.D. 1979. The HVDC Transmission Line Environment. Pages 1.1- 1.28, in, T.D. Bracken (editor). Proceedings of the Workshop on Electrical and Biological Effects Related to HVDC Transmission. PNL-3121 UC-97a. National Technical Information Service. Springfield, Virginia.

Bracken, T.D., A.S. Capon, and D.V. Montgomery. 1978. Ground Level Electric Fields and lon Currents on the Celilo-Sylmar $\pm 400-k V$ D.c. Intertie During Fair Weather. IEEE Transactions on Power Apparatus and Systems PAS 97:370-378.

Bracken, T.D., and A.L. Gabriel. 1981. Lyons Ozone Instrumentation Program and Data Analysis. Laboratory Report No. EL-81-3. Bonneville Power Administration. Portland, Oregon.

Bracken, T.D., and J.J. Ray. 1980. Survey of Maximum Electric Field Under BPA 500 kV Transmission Lines. Laboratory Report No. ERJ80-44. Bonneville Power Administration. Portland, Oregon.

Bracken, T.D., and V. Chartier. 1987. Occupational Exposure of High Voltage Workers to $60-\mathrm{Hz}$ Electric Fields. Part 2 - Analysis and Results. Pages 395-405, in, L.E. Anderson et al. (editors). Interaction of Biological Systems with Static and ELF Electric and Magnetic Fields. CONF-841041. National Technical Information Service. Springfield, Virginia.

Brambl, R. 1982. Evaluation of the Health and Welfare Hazards of the CPA/UPA High Voltage DC Transmission Line (Cu-TR-1). Minority Report. Pages MR-1 to MR-6, in, W.H. Bailey et al. A Health and Safety Evaluation of the $\pm 400 \mathrm{kV}$ DC Powerline. Prepared for the Minnesota Environmental Quality Board. St. Paul, Minnesota.

Breysse, P.N. et al. 1988. Magnetic Field Exposure Assessment for Telephone Company Employees. Project Resume. Contractor's Review. U.S. Department of Energy/Electric Power Research Institute. 
Bridges, J.E., and M.J. Frazier. 1979. The Effects of 60-Hertz Electric and Magnetic Fields on Implanted Cardiac Pacemakers. Final Report of Research Project 679-1 by IIT Research Institute for Electric Power Research Institute. Palo Alto, California.

Broadbent, D.E. et al. 1985. Health of Workers Exposed to Electric Fields.British Journal of Industrial Medicine 42:75-84.

Brown, H.D. and S.K. Chattopadhyay. 1988. Electromagnetic-field Exposure and Cancer. Cancer Biochemistry Biophysics 9:295-342.

Brulfert, A. et al. 1985. A Cytohistological Analysis of Roots Whose Growth is Affected by a $60-\mathrm{Hz}$ Electric Field. Bioelectromagnetics 6(3):283-291.

Bulawka, A.O., W.G. Wisecup, and W.E. Feero. 1982. The U.S. Department of Energy 60-Hz Electric Fields Bioeffects Research. 82 WM 220-2. Paper Presented at the IEEE PES Winter Power Meeting, Jan. 31-Feb. 5. New York.

Burack, G.D., U.J. Seto, S.T. Hsieh, and J.J. Seto. 1984. The Effects of Prenatal Exposure to a 60-Hz High-Intensity Electric Field on Postnatal Development and Sexual Differentiation. Journal of Bioelectricity 3(3): 451-467.

Busby, K., D. Driscoll, and W.E. Washbon. 1974. A Field Survey of Farmer Experience with $765 \mathrm{kV}$ Transmission Lines. Agricultural Resources Commission. State Campus Albany, New York.

Butrous, G.S. et al. 1982. Effects of High Intensity Power-Frequency Electric Fields on Implanted Modern Multiprogrammable Cardiac Pacemakers. Journal of the Royal Society of Medicine 75:327-331.

Butrous, G.S. et al. 1983a. The Effect of Power Frequency High Intensity Electric Fields on Implanted Cardiac Pacemakers. PACE 6:1282.

Butrous, G.S. et al. 1983b. Interference with the Pacemakers of Two Workers at Electricity Substations. British Journal of Industrial Medicine. 40:462-465.

Byus, G.V., S.E. Peiper, and W.R. Adey. 1987. The Effects of Low-Energy 60-Hz Environmental Electromagnetic Fields Upon the GrowthRelated Enzyme Ornithine Decarboxylase. Carcinogenesis 8:1385-1389.

Cabanes, J., and C. Gary. 1981. Direct Perception of the Electric Field. Paper 233-08 (English Translation from French). Paper presented at CIGRE Symposium on Transmission Lines and the Environment, June 23-25. Stockholm, Sweden.

Calle, E.E., and D.A. Savitz. 1985. Leukemia in Occupational Groups with Presumed Exposure to Electrical and Magnetic Fields. New England Journal of Medicine 313(23):1476-77

Cantor, K.P. et al. 1988. Hair Dye Use and Risk of Leukemia and Lymphoma. American Journal of Public Health 78(5):570-571

Caola, R.J., D.W. Deno, and V.S.W. Dymek. 1983. Measurements of Electric and Magnetic Fields in and Around Homes Near a 500-kV Transmission Line. IEEE Transactions on Power Apparatus and Systems PAS-102 (10): 3338-3347.

Carpenter, D.O. 1988. Electromagnetic Fields: Do we Know Enough to Act? Health and Environment Digest 2(2):3-4.

Carstensen, E.L. 1987. Biological Effects of Transmission Line Fields. Elsevier. New York.

Casper, B.M., and P.D. Wellstone. 1981. Powerline; the First Battle of America's Energy War. The University of Massachusetts Press. Amherst, Massachusetts.

Cerretelli, P., A. Veicsteinas, V. Margonato, A. Cantone, D. Vida, C. Malaguti, and A. Previ. 1979. 1000-kV Project: Research on the Biological Effects of 50-Hz Electric Fields in Italy. Pages 241-257, in, R.D. Phillips et al. (editors). Biological Effects of Extremely LowFrequency Electro- magnetic Fields. Technical Information Center, USDOE. Available as CONF-78 1016 from NTIS. Springfield, Virginia.

Charry, J.M. 1984. Biological Effects of Small Air lons: A Review of Findings and Methods. Environmental Research 34:351-389.

Charry, J.M. 1987. Biological Effects of Air lons: A Comprehensive Review of Laboratory and Clinical Data. Pages 91-150, in, J.M. Charry, and R. Kavet (editors). Air lons: Physical and Biological Aspects. CRC Press, Inc. Boca Raton, Florida.

Charry, J.M., and W.H. Bailey. 1985. Regional Turnover of Norepinephrine and Dopamine in Rat Brains Following Acute Exposure to Air lons. Bioelectromagnetics 6:415-425.

Charry, J.M., and R. Kavet. 1987. Air lons: Physical and Biological Aspects. CRC Press, Inc. Boca Raton, Florida.

Chartier, V.L., L.Y. Lee, L.D. Dickson, and K.E. Martin. 1987. Effect of High Altitude on High Voltage AC Transmission Line Corona Phenomena. IEEE Transactions on Power Delivery PWRD-2:225-237.

Chartier, V.L., R.D. Stearns, and A.L. Burns. 1988. Electrical Environment of the Uprated Pacific NW/SW HVDC Intertie. Paper 88 SM 561-3. Presented at IEEE/PES Summer Meeting. Portland, Oregon.

Chartier, V.L., S.H. Sarkinen, R.D. Stearns, and A.L. Burns. 1981. Investigation of Corona and Field Effects of AC/DC Hybrid Transmission Lines. IEEE Transactions Power Apparatus and Systems. PAS-100:72-80.

Chartier, V.L., T.D. Bracken, and A.S. Capon. 1985. BPA Study of Occupational Exposure to 60-Hz Electric Fields. IEEE Transactions on Power Apparatus and Systems PAS-104(3):733-744.

Chartier, V.L., and T.D. Bracken. 1987. Occupational Exposure of High Voltage Workers to 60-Hz Electric Fields: Part 1 - Exposure Instrumentation for Electric Field Exposure. Pages 125-134, in, L.E. Anderson et al. (editors). Interaction of Biological Systems with Static and ELF Electric and Magnetic Fields. CONF-841041. National Technical Information Service. Springfield, Virginia.

Clayden, A.D., and A. Myers. 1988. Childhood Cancer and Overhead Power Lines: A Case/Control Study in the U.K. Project Resume. Contractor's Review. U.S. Department of Energy/Electric Power Research Institute.

Coate, W.B., et al. 1970. Project Sanguine Biological Effects Test Program Pilot Studies Final Report. Prepared for Naval Electronics Systems Command Headquarters. Washington, D.C.

Cotfey, P.E., and W.N. Stasiuk. 1975. Evidence of Atmospheric Transport of Ozone into Urban Areas. Environmental Science and Technology 9(1):59-62.

Cole, P. 1988. An Epidemiologic Perspective on Electromagnetic Fields and Cancer; Testimony by Philip Cole, MD, DrPH. Pages 122-123, in Subcommittee on Water and Power Resources. Health Effects of Transmission Lines. Oversight Hearing. Serial No. 100-22. Superintendent of Documents, U.S. Government Printing Office. Washington, D.C.

Coleman, M. et al. 1989. Extremely Low Frequency Electric and Magnetic Fields and Human Cancer Risk. Bioelectromagnetics (In Press). 
Coleman, M. et al. 1985. Leukaemia and Electromagnetic Fields: A Case-Control Study. Pages 122-125, in, International Conference on Electric and Magnetic Fields in Medicine and Biology. Institution of Electrical Engineers. London and New York.

Coleman, M., J. Bell, and R. Skeet. 1983. Leukemia Incidence in Electrical Workers. Lancet 1:982-983.

Coleman, M., and V. Beral. 1988. A Review of Epidemiological Studies of the Health Effects of Living Near or Working with Electricity Generation and Transmission Equipment. International Journal of Epidemiology 17(1):1-13.

Committee on Biological Effects of Electromagnetic Fields. 1987. Biological Effects of Power-Frequency Electric and Magnetic Fields. (English Translation.) The Royal Swedish Academy of Engineering Sciences. Stockholm, Sweden.

Committee on Biosphere Effects of Extremely Low-Frequency Radiation (CBEELFR). 1977. Biologic Effects of Electric and Magnetic Fields Associated with Proposed Project Seafarer. National Academy of Sciences. Washington, D.C.

Comptroller General of the United States. 1979. Coal Creek: A Power Project with Continuing Controversies Over Costs, Siting and Potential Health Hazards. U.S. General Accounting Office. Washington, D.C.

Conti, R. et al. 1985. Possible Biological Effects of 50-Hz Electric Fields: A Progress Report. Journal of Bioelectricity 4(1):177-193.

Conti, R. et al. 1988. Research Carried out in Italy on the Possible Effects of 50-Hz Electric Fields. Pages 2-1 to 2-12, in, Second Workshop on the Italy/USA Cooperation in Electric Power Transmission. Proceedings. EL-6018-SR. Electric Power Research Institute. Palo Alto, California.

Cooper, L.J., and H.B. Graves. 1981. Behavioral Responses of Pigeons to High Strength Intensity Electric Fields. Behav. Neural. Biol. 32(2):214-228.

Cory, W., H. Barsun, J. Lucas, J. Polonis, and W. Rogers. 1987. High Voltage 60-Hz Electric Field Exposure Facility for Nonhuman Primates. Pages 101-110, in, L.E. Anderson et al. (editors). Interaction of Biological Systems with Static and ELF Electric and Magnetic Fields. CONF-841041. National Technical Information Service. Springfield, Virginia.

Crabtree, A.F. (editor). 1984. Proceedings of the Third International Symposium on Environmental Concerns in Rights-of-Way Management. Mississippi State University. Mississippi State, Mississippi.

Creim, J.A. et al. 1986a. Avoidance of Exposure to HVDC Electric Fields by Rats. Abstracts. Eighth Annual Meeting, Bioelectromagnetics Society. p. 26.

Creim, J.A. et al. 1986b. The Role of Positive Air lons in HVDC Field Avoidance by Rats. Abstracts. Eighth Annual Meeting, Bioelectromagnetics Society. p. 27.

Czerski, P. 1988a. Extremely Low Frequency (ELF) Electric Fields; Biological Effects and Health Risk Assessment. Pages 255-271, in, M.H. Repacholi (editor). Non-lonizing Radiations: Physical Characteristics, Biological Effects and Health Hazard Assessment. International Radiation Protection Association. Australian Radiation Laboratory. Yallambie, Victoria, Australia.

Czerski, P. 1988b. Extremely Low Frequency Magnetic Fields; Biological Effects of Health Risk Assessment. Pages 291-301, in, M.H. Repacholi (editor). Non-lonizing Radiations: Physical Characteristics, Biological Effects and Health Hazard Assessment. International Radiation Protection Association. Australian Radiation Laboratory. Yallambie, Victoria, Australia.

Dalziel, C.F. 1943. Effect of Wave Form on Let-Go Currents. Electrical Engin. 62:739-744.

Dames \& Moore. 1981. Underground Cable Systems: Potential Environmental Impacts. Prepared for Bonneville Power Administration by Dames \& Moore. Washington, D.C.

Deadman, J.E. et al. 1988. Occupational and Residential 60-Hz Electromagnetic Fields and High Frequency Electric Transients: Exposure Assessment Using a New Dosimeter. American Industrial Hygiene Association Journal 49(8):409-419.

Delgado, J.M.R. et al. 1982. Embryological Changes Induced by Weak, Extremely Low Frequency Electromagnetic Fields. Journal of Anatomy 134(3):533-551.

Deno, D.W., and L.E. Zaffanella. 1975. Electrostatic Effects of Overhead Transmission Lines and Stations. Pages 248-280, in, General Electric Co., Transmission Line Reference Book $345 \mathrm{kV}$ and Above. Electric Power Research Institute. Palo Alto, California.

Diprose, M.F., F.A. Benson, A.J. Willis. 1984. The Effect of Externally Applied Electrostatic Fields, Microwave Radiation and Electric Currents on Plants and Other Organisms, with Special Reference to Weed Control. The Botanical Review 50(2):171-223.

Dlugosz, L. 1987. Electrically Heated Beds and Congenital Defects. Project Resume. Contractor's Review. U.S. Department of Energy/ Electric Power Research Institute.

Douglas, J. 1984. Electromagnetic Fields and Human Health. EPRI Journal 9(6):14-21.

Dow Associates. 1980. Biological Effects and Physical Characteristics of Fields, Ions, and Shock. Dow Associates, Inc. Berkeley, California.

Droppo, J.G. 1979. Ozone Field Studies Adjacent to a High-Voltage Direct-Current Test Line. Pages 501-529, in, R.D. Phillips et al. (editors). Biological Effects of Extremely Low-Frequency Electromagnetic Fields. CONF-78 10 16. National Technical Information Service. Springfield, Virginia.

Duffy, P.H., and C.F. Ehret. 1982. Effects of Intermittent 60-Hz Electric Field Exposure: Circadian Phase Shifts, Splitting, Torpor, and Arousal Responses in Mice. Abstracts. 4th Annual Scientific Session. Bioelectromagnetics Society. p. 61.

Dufour, P.A. 1980. Effects of Noise on Wildlife and Other Animals. Review of Research Since 1971. U.S. Environmental Protection Agency EPA 550/9-90-100. Office of Noise Abatement and Control. Washington, D.C.

Dumansky, Y.D., V.M. Popovich, and E.V. Rokhvatilo. 1976. Hygiene Assessment of an Electromagnetic Field Created by High-Voltage Lines of Electro-Transmission. (English Translation). Gigiyena i Sanitarniya No. 8, pp. 19-23.

Durfee, W.K. et al. 1976. Extremely Low Frequency Electric and Magnetic Fields in Domestic Birds. Contribution number 1729 . Rhode Island Agricultural Experiment Station. Kingston, Rhode Island.

Dyshlovoi, V.D., and V.S. Kachura. 1977. The Effect of Electromagnetic Field of Industrial Frequency on the Human Organism and Other Biological Objects. Kiev, USSR. (Cited in Savin et al. 1978).

Eabry, S. 1987. The Body Electric, Electromagnetism: Therapeutic, Harmful, or a Little of Each? Healing and Harmony 2(2): 12-14. 
Ehret, C.F., R.S. Rosenberg, G.A. Sacher, P.H. Duffy, K.R. Groh, and J.J. Russell. 1980. Biomedical Effects Associated with Energy Transmission Systems: Effects of $60 \mathrm{~Hz}$ Electric Fields on Circadian and Uitradian Physiological and Behavioral Functions in Small Rodents. Report for the Period Jan. 1-Dec. 31, 1980. USDOE. Argonne National Laboratory. Argonne, Illinois.

Endo, O., M. Nakayama, Y. Itaku, and F. Nishiyama. 1979. Biological Effects of Ultra High Voltage Transmission Lines-A Preliminary Investigation On Wheat. Bio-Environment Laboratory. Central Research Institute of Electric Power Industry. Abiko City, Chiba, Japan.

Engle, J.F. 1982. Spark Ignition of Fuel-Air Mixtures. Final Project Report to BPA. Department of Electrical and Computer Engineering, Oregon State University. Corvallis, Oregon.

Environmental Protection Agency (EPA). 1987. EPA Indoor Air Quality Implementation Plan Appendix A: Preliminary Indoor Air Pollution Information Assessment. U.S. EPA. Washington, DC.

Environmental Protection Agency (EPA). 1974. Information on Levels of Environmental Noise Requisite to Protect Public Health and Welfare with an Adequate Margin of Safety. U.S. EPA. Washington, D.C.

Environmental Protection Agency (EPA). 1979. Revisions to the National Ambient Air Quality Standards for Photochemical Oxidants. Federal Register 44(28):8202-8237.

Feinstein, A.R. 1988. Scientific Standards in Epidemiologic Studies of the Menace of Daily Life. Science 242:1257-1263.

Fidell, S.A., S.R. Teffeteller, and K.S. Pearsons. 1979. Initial Study on the Effects of Transformer and Transmission Lines Noise on People; Vol. 3 Community Reaction. EA-1240. Electric Power Research Institute. Palo Alto, California.

Field, A.A. 1976. The Electroclimate. Heating/Piping/Air Conditioning. December:66-68.

Fielding, J.E., and K.J. Phenow. 1988. Health Effects of Involuntary Smoking. New England Journal of Medicine 319(22):1452-1460.

Finnegan, M.J. et al. 1987. Effect of Negative lon Generators in a Sick Building. British Medical Journal 294:1195-1196.

Flodin, U. et al. 1986. Background Radiation, Electrical Work, and Some Other Exposures Associated with Acute Myeloid Leukemia in a Case-Referent Study. Archives of Environmental Health 41:77- ¿4.

Florida Electric and Magnetic Fields Science Advisory Commission (FEMFSAC). 1985. Biological Effects of 60-Hz Power Transmission Lines. Report submitted to the Department of Environmental Regulation. Tallahassee, Florida.

Florig, H.K., J.F. Hoburg, and M.G. Morgan. 1987. Electric Field Exposure From Electric Blankets. IEEE Transactions on Power Delivery PWRD-2(2):527-536.

Florig, K.H., and J.F. Hoburg. 1988. Electric and Magnetic Field Exposure Associated with Electric Blankets. Project Resume. Contractor's Review. U.S. Department of Energy/Electric Power Research Institute.

Fole, F.F. 1972. Effet Pas Dams Les Sous-Stations Electriques (French). 2nd International Colloquium on the Prevention of Occupational Risks due to Electricity. Kohn.

Fole, F.F., F.G. Martinez, and E. Dutrus. 1974. New Contribution to the Study of Electromagnetic Fields Generated by High Voltages. Paper presented at the AISS Symposium, Paris, March 1974. English translation in Technical Memorandum E8180-1 by IIT Research Institute for Electric Power Research Institute. Chicago, Illinois.

Fraumeni, J.F., and W.J. Blot. 1982. Lung and Pleura. Pages $564-582$, in, D. Schottenfeld and J.F. Fraumeni, Jr. (editors) Cancer Epidemiology and Prevention. W.B. Saunders, Co. Philadelphia, Pennsylvania.

Frazier, M.J., and M.M. Preache. 1980. Design, Construction and Testing of a DC Bioeffects Test Enclosure for Small Animals. DOE/RA/ 10157-1 US Department of Energy, Power Delivery Division. Washington, D.C.

Free, M.J., W.T. Kaune, R.D. Phillips, and H.C. Cheng. 1981. Endocrinological Effects of Strong 60-Hz Electric Fields on Rats. Bioelectromagnetics 2(2):105-122

Fulton, J.P., S. Cobb, L. Preble, L. Leone, and E. Forman. 1980. Electrical Wiring Configuration and Childhood Leukemia in Rhode Island. American Journal of Epidemiology 111:292-296.

Gallagher, R.P. et al. 1985. Risk Factors for Ocular Melanoma; Western Canada Melanoma Study. Journal National Cancer Institute 74(4):775-778.

Gatchel, R.J., A. Baum, and C.S. Baum. 1981. Stress and Symptom Reporting as Related to the CU Line. Report by Human Design Group for Cooperative Power Association and United Power Association. Elk River, Minnesota.

Gauger, J.R. 1985. Household Appliance Magnetic Field Survey. IEEE Transactions on Power Apparatus and Systems PAS 104(9):24362444.

Genereux, J.P., and M.M. Genereux. 1980. Perceptions of Landowners About the Effects of the UPACPA Powerline on Human and Animal Health in West Central Minnesota. For the Minnesota Environmental Quality Board. Consulting and Research in the Social Sciences. St. Paul, Minnesota.

Gilman, P.A., R.G. Ames, and M.A. McCawley. 1985. Leukemia Risk Among U.S. White Male Coal Miners. Journal of Occupational Medicine 27(9):669-671.

Gona, A.G., and M.C. Yu. 1987. Effects of $60 \mathrm{~Hz}$ Electric and Magnetic Fields on the Developing Rat Brain. Contractor's Final Report. New York State Power Lines Project. Albany, New York.

Goodman, R., and A.S. Henderson. 1988. Exposure of Salivary Gland Cells to Low-Frequency Electromagnetic Fields Alters Polypeptide Synthesis. Proceedings National Academy of Science 85:3928-3932.

Goodwin, J.G., Jr. 1975. Big Game Movement Near a $500 \mathrm{kV}$ Transmission Line in Northern Idaho. A study by the Western Interstate Commission for Higher Education for the Engineering and Construction Division, Bonneville Power Administration. Portland, Oregon.

Gould, J.L. 1980. The Case for Magnetic Sensitivity in Birds and Bees (Such as It Is). American Scientist 68:256-267.

Graham, C. et al. 1988. Effects of Intermittent Exposure to 60-Hz Fields on Human Cardiac Activity. Abstracts. Tenth Annual Meeting, Bioelectromagnetics Society. p. 40: 
Graham, C., H.D. Cohen, M.R. Cook, J. Phelps, M. Gerkovich, and J. Phelps. 1987. A Double-Blind Evaluation of 60-Hz Field Effects on Human Performance, Physiology, and Subjective State. Pages 471-485, in, L.E. Anderson et al. (editors). Interaction of Biological Systems with Static and ELF Electric and Magnetic Fields. CONF-841041. National Technical Information Service. Springfield, Virginia.

Grattarola, M., F. Caratozzolo, and A. Chiabrera. 1985. Interaction of ELF Electromagnetic Fields with Cell Membrane Receptors. Pages 273-294, in, M. Grandolfo et al. (editors). Biological Effects and Dosimetry of Static and ELF Electromagnetic Fields. Plenum Press. New York.

Graves, H.B. 1985. Effects of 60-Hz Electric Fields on Chick Embryo and Chick Development, Growth, and Behavior (RP-1064). Westinghouse Electric Corporation, for Electric Power Research Institute. Palo Alto, California.

Graves, H.B. 1986. A Review of the State Electricity Commission of Victoria (SECV) Transmission Line and Station Design Practices in Relationship to the Health and Safety Effects on People. Report Prepared for Minister of Health, Victorian Government. Australia.

Graves, H.B., P.D. Long, and D. Poznaniak. 1979. Biological Effects of $60 \mathrm{~Hz}$ Alternating Current Fields: A Cheshire Cat Phenomenon. Pages 184-197, in, R.D. Phillips et al. (editors). Biological Effects of Extremely Low Frequency Electromagnetic Fields. CONF-78 1016. National Technical Information Service. Springfield, Virginia.

Greenberg, B., V.P. Bindokas, and J.R. Gauger. 1981. Biological Effects of a 765-kV Transmission Line: Exposures and Thresholds in Honeybee Colonies. Bioelectromagnetics 2(4):315-328.

Greenberg, B., V.P. Bindokas, and J.R. Gauger. 1985. Extra-High Voltage Transmission Lines: Mechanisms of Biological Effects on Honeybees. EA-4218. Prepared for Electric Power Research Institute. Palo Alto, California.

Greene, R.W. 1979. Study of Biological Effects of UHV Transmission Line Electric Fields. A Report to American Electric Power Service Corporation by the Department of Biology, University of Notre Dame. South Bend, Indiana.

Greene, R.W. 1983. 60-Hz Ultra-High Voltage Electric Field Effect on Onion Root Mitotic Index: A Lack of Impact. Environmental and Experimental Botany 23(4):355-360.

Griffith, D.B. 1977. Selected Biological Parameters Associated with a $\pm 400 \mathrm{kV} \mathrm{d}$-c Transmission Line in Oregon. A Report by the Western Interstate Commission for Higher Education for the Bonneville Power Administration. Portland, Oregon.

Grissett, J.D., J.L. Kupper, M.J. Kessler, R.J. Brown, G.D. Prettyman, L.L. Cook, and T.A. Griner. 1977. Exposure of Primates for One Year to Electric and Magnetic Fields Associated with ELF Communications Systems. Naval Aerospace Medical Research Laboratory. Pensacola, Florida.

Gustafson, R.J., and V.D. Albertson. 1982. Neutral-to-Earth Voltage and Ground Current Effects in Livestock Facilities. IEEE Transactions on Power Apparatus and Systems PAS-101(7):2090-2095.

Halle, B. 1988. On the Cyclotron Resonance Mechanism for Magnetic Field Effects on Transmembrane lon Conductivity. Bioelectromagnetics 9:381-385.

Hansson, H.A. 1981. Purkinje Nerve Cell Changes Caused by Electric Fields-Ultrastructural Studies on Long-Term Effects on Rabbits. Medical Biology 59:103-110.

Harvey, E.B. et al. 1985. Prenatal X-Ray Exposure and Childhood Cancer in Twins. New England Journal of Medicine 312(9):541-545.

Hauf, R. (editor). 1981. First Aid and Treatment of Accidents Due to Electric Shock. Investigations of Effect of the Energy Fields on Man. (English Translation). The Research Center for Electropathology. Freiburg, West Germany.

Hauf, R. 1982. Electric and Magnetic Fields at Power Frequencies, With Particular Reference to 50 and 60-Hz. Pages 175-197, in, M.J. Suess (editor). Nonionizing Radiation Protection. World Health Organization. Copenhagen.

Hendrickson, R.C. 1985. Electrical Environment Outside the Right-of-Way of Cu-TR-1, Report 5. Power Plant Siting Program. Minnesota Environmental Quality Board. St. Paul, Minnesota.

Hennichs, K. 1982. Cows Exposed to 400-kV Lines. Inventory and Fertility Study. Swedish University of Agricultural Sciences, Dept. of Animal Hygiene with Farrier's School. Report No. 7. Skara, Sweden.

Hill, H.L., A.S. Capon, O. Ratz, P.E. Renner, and W.D. Schmidt. 1977. Transmission Line Reference Book HVDC to \pm 600 kV. Prepared by the Bonneville Power Administration and published by Electric Power Research Institute. Palo Alto, California.

Hilson, D.W., J.C. Noggle, and E.R. Burns. 1983. Effects of Electric Field on Plants Growing Under High Voltage Transmission Lines. Office of Natural Resources, Air Quality Branch, Tennessee Valley Authority. Chattanooga, Tennessee.

Hingorani, N. 1978. The Reemergence of DC in Modern Power Systems. EPRI Journal 3(5):6-13.

Hjeresen, D.L., W.T. Kaune, J.R. Decker, and R.D. Phillips. 1980. Effects of 60-Hz Electric Fields on Avoidance Behavior and Activity of Rats. Bioelectromagnetics 1:299-312.

Hodges, T.K., C.A. Mitchell, and G. Heydt. 1975. Effect of Electric Fields from 765-kV Transmission Lines on Plant Growth. A Report by Purdue University for Indiana and Michigan Electric Company, a Subsidiany of American Electric Power. New York.

Hodges, T.K., and C.A. Mitchell. 1979. Growth and Yield of Field Crops in the Proximity of an Ultra-High Voltage Electric Test Line. American Electric Power System. North Liberty, Indiana.

Hodges, T.K., and C.A. Mitchell. 1984. Influence of High Intensity Electric Fields on Yield of Sweet Corn and Dent Corn - 1982. A Report for the American Electric Power Service Corporation. North Liberty, Indiana.

Hohenemser, C., R.W. Kates, and P. Slovic. 1983. The Nature of Technological Hazard. Science 220(4595):378-384.

Howard, R.P., and J.F. Gore (editors). 1980. Workshop on Raptors and Energy Developments: Proceedings. Fish and Wildlife Service, Boise, Idaho.

IARC. 1987. Monograph on the Evaluation of Carcinogenic Risks to Humans. Supplement 7. International Agency on Research on Cancer (IARC). World Health Organization.

IEEE (Institute of Electrical and Electronics Engineers) Working Group on Electrostatic and Electromagnetic Effects of Overhead Transmission Lines. 1972. Part I Hazards and Effects. IEEE Transactions Power Apparatus and Systems PAS 91:422-444. 
IEEE Committee. 1983. Electrical Effects of AC Power Transmission Lines. An Introduction for the Public. IEEE Power Engineering Society. IEEE Service Center. Piscataway, New Jersey.

IEEE Subcommittee. 1985. Corona and Field Effects of AC Overhead Transmission Lines. Information for Decision Makers. IEEE Corona and Field Effects Subcommittee. Power Engineering Society. IEEE Service Center. Piscataway, New Jersey.

IEEE Working Group on Electromagnetic and Electrostatic Effects of Overhead Transmission Lines. 1973. Electromagnetic Effects of Overhead Transmission Lines: Practical Problems, Safeguards, and Methods of Calculation. IEEE Transactions on Power Apparatus and Systems PAS-93:892.

IERE (International Electricity Research Exchange Working Group. 1988. Epidemiological Studies Relating Human Health to Electric and Magnetic Fields: Criteria for Evaluation. (IERE). Electric Power Research Institute. Palo Alto, CA.

IIT Research Institute (IITRI). 1979. Biological Effects of High Voltage Electric Fields: An Update. Vol. 1. Electric Power Research Institute Palo Alto, California.

Jaffa, K.C. 1981. Magnetic Field Induction from Overhead Transmission and Distribution Power Lines on Parallel Fences. IEEE Transactions on Power Apparatus and Systems PAS-100:1624-1636.

Jaffa, K.C., and J.B. Stewart. 1981. Magnetic Field Induction from Overhead Transmission and Distribution Power Lines on Buried Irrigation Pipelines. IEEE Transactions on Power Apparatus and Systems PAS-100:990-1000.

Jaffe, L.S. 1967. The Biological Effects of Ozone on Man and Animals. American Industrial Hygiene Association Journal. May-June pp. 267-277.

Jaffe, R.A., B.L. Laszewski, D.B. Carr, and R.D. Phillips. 1980. Chronic Exposure to a 60-Hz Electric Field: Effects on Synaptic Transmission and Peripheral Nerve Function in the Rat. Bioelectromagnetics 1:131-147.

Jaffe, R.A., C.A. Lopresti, D.B. Carr, and R.D. Phillips. 1983. Prenatal Exposure to $60-\mathrm{Hz}$ Electric Fields: Effects on the Development of the Visual-Evoked Response in Rats. Bioelectromagnetics 4(4):327-339.

Janes, D.E. 1980. Evaluation of Health and Environmental Effects of Extra High Voltage (EHV) Transmission. U.S. Environmental Protection Agency, Office of Radiation Programs. Washington, D.C.

Jingyi, E. and, W. Fanghua. 1980. Research Report on the Effect of High Voltage Field Intensity on the Human Body (Stages I and II). (English Translation from Chinese). Sheyang Municipality Vocational Disease Prevention and Treatment Hospital, and the Technology Innovation Bureau of Northwest Power Administration.

Johansson, R., A.G. Lundquist, S. Lundquist, and V. Scuka. 1973. Is There a Connection Between the Electricity in the Atmosphere and the Function of Man? Part 3, $50 \mathrm{~Hz}$ Field Variations. Translation of FOA Report dated September 1973.

Johnson, G.B. 1982. The Electrical Environment and HVDC Transmission Lines. Pages 66-82, in, J.M. Charry (editor). Conference on Environmental lons and Related Biological Effects. American Institute of Medical Climatology. Philadelphia, Pennsylvania.

Johnson, G.B. 1984. Study of Electric Field and Ion Effects on HVDC Lines. Technical Progress Report No. 7. General Electric Company for U.S. Department of Energy. Technical Information Center. Office of Scientific and Technical Information. Washington, D.C.

Justesen, D.R. et al. 1986. A Critical Review of the Scientific Literature on Low-Frequency Electric and Magnetic Fields: Assessment of Possible Effects on Human Health and Recommendations for Research. Southern California Edison Company. Rosemead, California.

Juutilainen, J. et al. 1988. Results of Epidemiological Cancer Study Among Electrical Workers in Finland. Journal of Bioelectricity 7(1);119121.

Juutilainen, J., E. Laara, and K. Saali. 1987. Relationship Between Field Strength and Abnormal Development in Chick Embryos Exposed to $50 \mathrm{~Hz}$ Magnetic Fields. International Journal of Radiation Biology 52(5):787-793.

Juutilainen, J., and K. Saali. 1986. Development of Chick Embryos in $1 \mathrm{~Hz}$ to $100 \mathrm{~Hz}$ Magnetic Fields. Radiation and Environmental Biophysics 25:135-140.

Kalmijn, A.J. 1982. Electric and Magnetic Field Detection in Elasmobranch Fishes. Science 218:916-918.

Kalmijn, A.J. 1988. Electromagnetic Orientation: A Relativistic Approach. Pages 23-45, in, M.E. O'Connor, and R.H. Lovely (editors). Electro- magnetic Fields and Neurobehavioral Function. Alan R. Liss, Inc. New York.

Kalmijn, A.J., 1966. Electro-Perception in Sharks and Rays. Nature (London),212:1232-1233.

Kalyada, T.V. et al. 1985. Biological Action of a 50-Hz Electric Field on the Human Body. Pages 317-332, in, Proceedings of the US-USSR Workshop on Physical Factors-Microwaves and Low Frequency Fieids. Report by the National Institute of Environmental Health Sciences.

Kaune, W.T. 1986. Physical Interaction of Humans and Animals with Power-Frequency Electric and Magnetic Fields. Pages 11-20, in, Panel Session on Biological Effects of Power Frequency Electric and Magnetic Fields. IEEE Service Center. Piscataway, New Jersey.

Kaune, W.T. et al. 1986. Residential Magnetic and Electric Fields Measured Over 24-H Periods. Report for Health Research, Inc. Albany, New York.

Kaune, W.T., and R.D. Phillips. 1980. Comparison of the Coupling of Grounded Humans, Swine, and Rats to Vertical, 60-Hz Electric Fields. Bioelectromagnetics 1(2):117-129.

Kavet, R. 1982. Biological Effects of Electric Fields: EPRI's Role. IEEE Transactions on Power Apparatus and Systems PAS-101(7):21152121.

Kavet, R., W.H. Bailey, and J.M. Charry. 1985. Respiratory Neuroendocrine Cells: A Plausible Site for Air lon Effects. Abstracts, Seventh Annual Meeting, Bioelectromagnetics Society. p. 39.

Keesey, J.C., and F.S. Letcher. 1970. Human Thresholds of Electric Shock at Power Transmission Frequencies. Archives of Environmental Health 21:547-552.

Kellogg, E.W. 1982. RP1640 Biological Effects of Air lons. Synopsis for EPRI Contractor Workshop. Electric Power Research Institute. Palo Alto, California.

Kellogg, E.W. 1984. Air lons: Their Possible Biological Significance and Effects. Journal of Bioelectricity 3(1\&2):119-136. 
Kellogg, E.W. et al. 1985. Long-term Biological Effects of Air lons and D.C. Electric Fields on Namru Mice: Second Year Report. International Journal of Biometeorology 29(3):269-283.

Klein, D.R. 1971. Reaction of Reindeer to Obstructions and Disturbances. Science 172(3995):393-397.

Klinger, M., S.A. Annestrand, G.A. Parks, and J.M. Lee, Jr. 1984. Experience of a 6-year 1200-kV Transmission Line Test and Development Program at the Bonneville Power Administration. CIGRE paper 38-08.

Knave, B. 1981. A Prospective Investigation Into the Health Risks Associated with Work on the Generation and Distribution of Electric Power. Paper 233-09, in, CIGRE Symposium on Transmission Lines and the Environment. June 23-25. Stockholm, Sweden.

Knave, B., F. Gamberale, S. Bergstrom, E. Birke, A. Iregren, B. Kolmodin-Hedman, and A. Wennberg. 1979. Long-Term Exposure to Electric Fields: A Cross-Sectional Epidemiologic Investigation on Occupationally Exposed High Voltage Substation Workers. Scandinavian Journal of Work Environment and Health 5:115-125.

Knickerbocker, G.G. 1975. Study in the USSR of Medical Effects of Electric Fields on Electric Power Systems. (Translations from Russian.) Special Publication No. 10 of The Power Engineering Society. The Institute of Electrical and Electronics Engineers, Inc. New York.

Knickerbocker, G.G., W.B. Kouwenhoven, and H.C. Barnes. 1967. Exposure of Mice to a Strong AC Electric Field-An Experimental Study. IEEE Transactions on Power Apparatus and Systems PAS-86:498-505.

Korobkova, V.P., Uy. A. Morozov, M.D. Stolyarov, and Uy. A. Yakub. 1972. Influence of the Electric Field in 500 and $750 \mathrm{kV}$ Switchyards on Maintenance Staff and Means for its Protection. International Conference on Large High Tension Electric Systems. CIGRE Paper 23-06.

Kotaka, S. 1978. Effects of Air lons on Microorganisms and Other Biological Materials. CRC Critical Reviews in Microbiology 6(2):109-149.

Kouwenhoven, W.B., O.R. Langworthy, M.L. Singewald, and G.G. Knickerbocker. 1967. Medical Evaluation of Man Working in A.C Electric Fields. IEEE Transactions on Power Apparatus and Systems PAS-86:506-511.

Kroodsma, R.L. 1984. Effects of Power-line Corridors on the Density and Diversity of Bird Communities in Forested Areas. Pages 551-561, in, A.F. Crabtree (editor). Proceedings of the Third International Symposium on Environmental Concerns in Rights-of-Way Management. Mississippi State University.

Kroodsma, R.L., and J.W. Van Dyke. 1985. Technical and Environmental Aspects of Electric Power Transmission. ORNL-6165. Oak Ridge National Laboratory. Environmental Sciences Division. Oak Ridge, Tennessee.

Krueger, A.P. 1980. On Air lons - And Your Health, Moods, and Efficiency. Executive Health 17(2):1-6.

Krueger, A.P., and S. Sigel. 1978. Ions in the Air. Human Nature. July. pp. 46-52.

Krupa, S., and G.C. Pratt. 1982. UPA/CPA High Voltage Transmission Line Potential Generation of Air Pollutants and Their Impact on Vegetation. Final Report by Department of Plant Pathology, University of Minnesota. St. Paul, Minnesota.

Larkin, R.P., and P.,J. Sutherland. 1977. Migratory Birds Respond to Project Seafarer's Electromagnetic Field. Science 195:777-778.

LeBars, H. et al. 1983. The Biological Effects of Electrical Field Effects on Rats, Mice, and Guinea Pigs. Recueil de Medicine Veterinaire 159:823-837.

Le Bars, H. and G. Andre. 1976. Biological Effects of an Electric Field on Rats and Rabbits. Pages 91-97, in, RGE (Revue Generale De L'electricite). Special Issue. ISSN 0035-3116.

Lee, J.M. Jr., and A.L. Burns. 1987. Introduction of Commercial $\pm 500 \mathrm{kV} \mathrm{DC} \mathrm{Transmission} \mathrm{Lines:} \mathrm{Operating} \mathrm{Characteristics,} \mathrm{Environmental}$ Effects, and Status of BPA Research. Pages 51-65, in, L.E. Anderson et al. (editors). Interaction of Biological Systems with Static and ELF Electric and Magnetic Fields. CONF-841041. National Technical Information Service. Springfield, Virginia.

Lee, J.M. Jr., and C.F. Clark. 1981. Ecological Effects of EHV and UHV Transmission Lines Current Issues. Paper 233-07 in ClGRE Symposium on Transmission Lines and the Environment. June 23-25. Stockhoim, Sweden.

Lee, J.M., Jr. 1978. Effects of Transmission Lines on Bird Flights: Studies of Bonneville Power Administration Lines. Pages 53-68, in, M.L. Avery (editor). Impacts of Transmission Lines on Birds in Flight. Proceedings of the Workshop on Impact of Transmission Lines on Migratory Birds. Jan. 31-Feb. 2, 1978, Oak Ridge, Tennessee. Superintendent of Documents, U.S. Govt. Printing Office. Washington, D.C. Stock Number 024-010-00481-9.

Lee, J.M., Jr. 1980. Raptors and the BPA Transmission System. Pages 41-55, in, R.P. Howard and J.F. Gore (editors). A Workshop on Raptors and Energy Developments. Jan. 25-26. U.S. Fish and Wildlife Service. Boise, Idaho.

Lee, J.M., Jr., L.E. Rogers, and T.D. Bracken. 1979. Electric and Magnetic Fields as Considerations in Environmental Studies of Transmission Lines. Pages 55-73, in, R.D. Phillips et al (editors). Biological Effects of Extremely Low Frequency Electromagnetic Radiation. CONF 781016 National Technical Information Service. Springfield, Virginia.

Lee, J.M., Jr., and D.B. Griffith. 1978. Transmission Line Audible Noise and Wildife. Pages 105-168, in, J.L. Fletcher, and R.G. Busnel (editors). Effects of Noise on Wildlife. Academic Press, New York.

Lee, J.M., Jr., and G.L. Reiner. 1983. Transmission Line Electric Fields and the Possible Effects on Livestock and Honeybees. Transactions of the American Society of Agricultural Engineers 26(1):279-286

Leung, F.C. et al. 1988. Evidence of Stress in Rats Exposed to 60-Hz Electric Fields. Project Resume. Contractor's Review. U.S. Department of Energy/Electric Power Research institute.

Liboff, A.R. 1988. Ion Cyclotron Resonance Study in Turtle Colon. Abstracts, Tenth Annual Meeting, Bioelectromagnetics Society. p. 32.

Libotf, A.R., and B.R. McLeod. 1988. Kinetics of Channelized Membrane lons in Magnetic Fields. Bioelectromagnetics 9:39-51.

Lilienfeld, A.M., and D.E. Lilienfeld. 1980. Foundations of Epidemiology. Second Edition. Oxford University Press. New York.

Lin, R.S. et al. 1985. Occupational Exposure of Electromagnetic Fields and Occurrence of Brain Tumors. Journal of Occupational Medicine 27(6):413-419.

Lindh, T., L.I. Andersson, and S. Tornqvist. 1987. Low-Frequency Electromagnetic Fields-Dosimetry in Field Measurements. Project Resume. Contractor's Review. U.S. Department of Energy/Electric Power Research Institute. 
Lindsay, J.P. and G.R. Howe. 1986. A System for Monitoring Cancer Mortality in a Ten Percent Sample of the Canadian Labour Force. Pages 37-45, in, Proceedings, A Workshop on Computerized Record Linkage in Health Research. University of Toronto Press. Toronto, Ontario, Canada.

Linet, M.S. et al. 1988. Leukemias and Occupation in Sweden: A Registry Based Analysis. American Journal of Industrial Medicine 14:319-330.

Loftness, M.O. 1977. A Practical Handbook for the Location, Prevention, and Correction of Television Interference from Overhead Power Lines. Prepared for Bonneville Power Administration. Portland, Oregon.

Loftness, M.O. 1980. A Practical Handbook for Correction of Radio Interference from Overhead Power Lines and Facilities. Prepared for Bonneville Power Administration. Portland, Oregon.

Loftness, M.O., V.L. Chartier, and G.L. Reiner. 1981. EMI Correction Techniques for Transmission Line Corona. IEEE International Electromagnetic Compatibility Conference Symposium Record. Boulder, Col. Aug. 18-20.

Lotz, W.G., and J.L. Saxton. 1987. Growth and Sexual Maturation of Rhesus Monkeys Chronically Exposed to ELF Electric and Magnetic Fields. Pages 347-364, in, L.E. Anderson et al. (editors). Interaction of Biological Systems with Static and ELF Electric and Magnetic Fields. CONF-841041. National Technical Information Service. Springfield, Virginia.

Lyle, D.B. et al. 1988. Suppression of T-Lymphocyte Cytotoxicity Following Exposure to $60-\mathrm{Hz}$ Sinusoidal Electric Fields. Bioelectromagnetics 9:303-313.

Lymangrover, J.R., E. Keku, and Y.J. Seto. 1983. 60-Hz Electric Field Alters the Steroidogenic Response of Rat Adrenal Tissue, In Vitro Life Sciences 32:691-696.

Lyskov, Yu. I., Uy. S. Emma, and M.D. Stolyarov. 1975. Electrical Field as a Parameter Considered in Designing Electric Power Transmission of 750-1150 kV; The Measuring Methods, The Design Practices, and Direction of Further Research. Pages 54-76, in, Proceedings of the Symposium on EHV AC Power Transmission. Washington, D.C. Feb. 17-27, 1975. Bonneville Power Administration. Portland, Oregon.

Magnetic Fields Task Force (MFTF). 1988. Magnetic Fields From Electric Power Lines Theory and Comparison to Measurements. IEEE Paper 88 WM 078-8.

Mahmoud, A.A., and D.R. Zimmerman. 1983. High Voltage Transmission and Environmental Effects. Right-of-Way. December. pp. 15-19.

Mahmoud, A.A., and D.R. Zimmerman. 1984. Reproductive Performance in Pigs Exposed to High Voltage Electric Field: Second Generation. Paper $\mathbf{8 4 0 3 0 3 4}$ presented at the Summer Meeting of American Society of Agricultural Engineers; June 24-27. Knoxville, Tennessee.

Malboysson., E. 1976. Medical Control of Men Working Within Electromagnetic Fields. In Recherches Sur Les Effects Biologiques Des Champs Electrique et Magnetique. Revue Generale de L'Electricite Numero Special (July) pp. 75-80.

Maresh, C.M. et al. 1988. Exercise Testing in the Evaluation of Human Responses to Powerline Frequency Fields. Aviation, Space, and Environmental Medicine. December:1139-1145.

Marino, A.A. 1988. Environmental Electromagnetic Energy and Public Health. Pages 965-1044, in, A.A. Marino (editor). Modern Bioelectricity. Marcel Dekker, Inc. New York.

Marino, A.A., F.X. Hart, and M. Reichmanis. 1983. Weak Electric Fields Affect Plant Development. IEEE Transactions on Biomedical Engineering BME-30(12):833-834.

Marino, A.A., J.M. Cullen, M. Reichmanis, and R.O. Becker. 1979. Power Frequency Electric Fields and Biological Stress: A Cause-andEffect Relationship. Pages 258-276, in, R. D. Philips, et al. (editor). Biological Effects of Extremely Low Frequency Electromagnetic Fields. Technical Information Center, U.S. Department of Energy. Available as CONF-781016 from NTIS. Springfield, Virginia.

Marino, A.A., R.O. Becker, and B. Ullrich. 1976. The Effect of Continuous Exposure to Low-Frequency Electric Fields on Three Generations of Mice; A Pilot Study. Separatum Experientia 32:565-566.

Marino, A.A., T.J. Berger, B.P. Austin, R.O. Becker, and F.X. Hart. 1977. In Vivo Bioelectrochemical Changes Associated With Exposure to Extremely Low Frequency Electric Fields. Physiological Chemistry and Physics Journal 9(4):433-441.

Marron, M.T. et al. 1983. Cell Surface Effects of 60-Hz Electromagnetic Fields. Radiation Research 94:217-220.

Martin, F.B. et al. 1986. Epidemiology Study of Holstein Dairy Cow Performance and Reproduction Near a High-Voltage Direct-Current Powerline. Journal of Toxicology and Environmental Health 19:325-336.

Maruvada, P.S. et al. 1981. Corona and Electric Field Effects of HVDC Transmission Lines in the Range of $\pm 600 \mathrm{kV}$ to $\pm 1200 \mathrm{kV}$. Paper 232-02 in CIGRE Symposium on Transmission Lines and the Environment, June 23-25. Stockholm, Sweden.

Matanoski, G. et al. 1988. Leukemia in Telephone Company Employees. Project Resume. Contractor's Review. U.S. Department of Energy/ Electric Power Research Institute.

McClanahan, B.J., and R.D. Phillips. 1983. The Influence of Electric Field Exposure on Bone Growth and Fracture Repair in Rats. Bioelectromagnetics 4(1):11-19.

McCleave, J.D., E.H. Albert, and N.E. Richardson. 1974. Perception and Effects on Locomotor Activity in American Eels and Atlantic Salmon of Extremely Low Frequency Electric and Magnetic Fields. Final Report No. N000014-72-C-0130, Naval Electronics System Command, Department of Zoology, University of Maine. Orono, Maine.

McConnon, D. 1984. The Minnesota DC Transmission Line: What Went Wrong and Why? Pages 110-122, in, A.F. Crabtree (editor). Proceedings of the Third Symposium on Environmental Concerns in Rights-of-Way Management. Feb. 15-18. San Diego, California. Mississippi State University. Mississippi State, Mississippi.

McDowall, M.E. 1983. Leukaemia Mortality in Electrical Workers in England and Wales. Lancet:246.

McDowall, M.E. 1986. Mortality of Persons Resident in the Vicinity of Electricity Transmission Facilities. British Journal of Cancer 53:271-279. 
McKee, G.W. (Principal Investigator). 1985. Effects of $60-\mathrm{Hz}$ Electric Fields on Living Plants Exposed for Extended Periods. EA-4159 Research Project 1064. Prepared by Westinghouse Electric Corporation and the Pennsylvania State University for Electric Power Research Institute. Palo Alto, California.

McKee, G.W., D.P. Knievel, D.T. Poznaniak, and J.W. Bankoske. 1978. Effects of $60 \mathrm{~Hz}$ High Intensity Electric Fields on Living Plants, IEEE Transactions on Power Apparatus Systems 97:1177-1181.

McLeod, B.R., and A.R. Liboff. 1986. Dynamic Characteristics of Membrane lons in Multifield Configurations of Low-Frequency Electromagnetic Radiation. Bioelectromagnetics 7:177-189.

Meyer, J.R., and J.M. Lee, Jr. 1981. Effects of Transmission Lines on Flight Behavior of Waterfowl and Other Birds. Pages 62-1 to 62-15, in, Arner and Tillman (editors). Environmental Concerns in Rights-of-way Management. WS-78-141. Electric Power Research Institute. Palo Alto, California.

Michaelson, S.M., and S.T. Lu. 1988. Electric Field and Physiologic Stress. Project Resume. Contractor's Review. U.S. Department of Energy/Electric Power Research Institute.

Microwave News. 1984. Pulsed Magnetic Fields: Conflicting Results. Microwave News IV(5):1-3.

Mild, K.H., L. Lovdahl, K.G. Lovstrand, and S. Lovtrup. 1982. Effect of High Voltage Pulses on the Viability of Human Leucocytes in Vitro. Bioelectromagnetics 3:213-218.

Milham, S. 1982. Mortality From Leukemia in Workers Exposed to Electrical and Magnetic Fields. (Letter to the editor). New England Journal of Medicine 307(4):249.

Milham, S. 1983. Occupational Mortality in Washington State 1950-1979. U.S. Department of Health and Human Services. DHHS (NIOSH) Publication No. 83-116.

Milham, S. Jr. 1985a. Mortality in Workers Exposed to Electromagnetic Fields. Environmental Health Perspectives 62:297-300.

Milham, S. 1985b. Silent Keys: Leukaemia Mortality in Amateur Radio Operators. Lancet 1:811

Milham, S. Jr. 1988. Increased Mortality in Amateur Radio Operators Due to Lymphatic and Hematopoietic Malignancies. American Journal of Epidemiology 127(1):50-54.

Miller, D.A. 1974. Electrical and Magnetic Fields Produced by Commercial Power Systems. Pages 62-70, in, J.G. Llaurado. et. al. (editors). Biological and Clinical Effects of Low-Frequency Magnetic and Electric Fields. Charles C. Thomas. Springfield, Illinois.

Miller, L.N. 1978. Sound Levels of Rain and Wind in the Trees. Pages 101-108, in, Noise Control Engineering. Nov./Dec

Miller, M.W., E.L. Carstensen, G.E. Kaufman, and D. Robertson. 1979. $60 \mathrm{~Hz}$ Electric Field Parameters Associated with the Peturbation of a Eukaryotic System. Pages 109-116, in, R.D. Phillips et al. (editors). Biological Effects of Extremely Low Frequency Electromagnetic Fields. CONF 781016. National Technical Information Service. Springfield, Virginia.

Miller, M.W., and G.E. Kaufman. 1978. High-Voltage Overhead. Environment 20(1):6-36.

Misakian, M. 1984. Electrical Parameters in 60-Hz Biological Exposure Systems and Their Measurement: A Primer. Tech. Note 1191, National Bureau of Standards, U.S. Department of Commerce. Washington, D.C.

Modan, B. 1988. Exposure to Electromagnetic Fields and Brain Malignancy: A Newly Discovered Menace? American Journal of Industrial Medicine 13:625-627.

Molino, J.A., G.A. Zerdy, N.D. Lerner, and D.L. Harwood. 1979. Use of the Acoustic Menu in Assessing Human Response to Audible (Corona) Noise From Electric Transmission Lines. Journal of the Acoustical Society of America 66(5):1435-1445.

Monson, R.R. 1980. The Analysis of Epidemiologic Data. Pages 67-91, in, Occupational Epidemiology. CRC Press. Boca Raton, Florida.

Moore, B.R., K.J. Stanhope, and D. Wilcox. 1987. Pigeons Fail to Detect Low-Frequency Magnetic Fields. Animal Learning and Behavior 15(2):115-117.

Morgan, M.G. et al. 1987. Power-Frequency Fields: The Regulatory Dilemma. Issues in Science and Technology. Summer 1987. pp. $81-91$.

Morgan, M.G., et al. 1985a. Power-line Fields and Human Health. IEEE Spectrum 22(2):62-68

Morgan, M.G., et al. 1985b. Powerline Frequency Electric and Magnetic Fields: A Pilot Study of Risk Perception. Risk Analysis 5(2):139-149.

Morris, R.M., A.R. Morse, R.E. Treen, and P. Buchanan. 1967. Test Relating to the Safe Clearance to Ground of High Voltage DC Transmission. Bulletin of the Radio and Electrical Engineering Division. National Research Council 17(3).

Morrison, A.S., and P. Cole. 1982. Urinary Tract. Pages 925 - 937, in, D. Schottenfeld and J.F. Fraumeni, Jr. (editors). Cancer Epidemiology and Prevention. W.B. Saunders, Co. Philadelphia, Pennsylvania.

Moss, A.M., and E. Carstensen. 1985. Evaluation of the Effects of Electric Fields on Implanted Cardiac Pacemakers. EA-3917. University of Rochester for the Electric Power Research Institute. Palo Alto, California.

Myers, A., et al. 1985. Overhead Power Lines and Childhood Cancer. Pages 126-130, in, International Conference on Electric and Magnetic Fields in Medicine and Biology. The Institution of Electrical Engineers. London and New York.

Nasca, P.C. et al. 1988. An Epidemiologic Case-Control Study of Central Nervous System Tumors in Children and Parental Occupational Exposures. American Journal of Epidemiology 128(6):1256-1265.

Nero, A.V. Jr. 1988. Controlling Indoor Air Pollution. Scientific American 258(5):42-48.

New Jersey Commission on Radiation Protection. 1981. News Release: Guidelines for High Voltage Transmission Lines Adopted. New Jersey State Department of Environmental Protection. Trenton, New Jersey.

Nichols, D.J. 1978. Guidelines for the Installation and Operation of Irrigation Systems Near High Voltage Transmission Lines. Bonneville Power Administration. Portland, Oregon.

Nolfi, J.R., and R.C. Haupt. 1982. Effects of High Voltage Power Lines on Health: Results From a Systematic Survey of a Population Sample Along the \pm 400 kV DC Pacific Intertie. A Report by Associates in Rural Development, Inc. For Public Service Dept., State of Vermont. Montpelier, Vermont. 
Nordenson, I. et al. 1984. Clastogenic Effects in Human Lymphocytes of Power Frequency Electric Fields: In Vivo and In Vitro Studies. Radiation and Environmental Biophysics 23:191-201

Nordenson, I., and K.H. Mild. 1985. Chromosomal Aberrations in 400-kV Substation Workers. Abstracts. Seventh Annual Meeting. Bioelectromagnetics Society. p. 18.

Nordstrom, S. 1981. Reproductive Hazards and Chromosomal Aberrations Among Workers at High Voltage Substations. Paper Presented at an International Seminar on Biological Effects of Electromagnetic Fields in Relation to the Evaluation of Health Hazards from Power Transmission Lines. March 12, 13. NTNT Conf. Center, Oslo, Norway.

Nordstrom, S., E. Birke, and L. Gustavsson. 1983. Reproductive Hazards Among Workers at High Voltage Substations. Bioelectromagnetics 4:91-101.

Norris, D.O. 1985. Vertebrate Endocrinology. Lea \& Febiger. Philadelphia, Pennsylvania.

Olcese, J., and S. Reuss. 1986. Magnetic Field Effects on Pineal Gland Melatonin Synthesis: Comparative Studies on Albino and Pigmented Rodents. Brain Research 369:365-368.

Olendorff, R.R., A.D. Miller, and R.N. Lehman. 1981. Suggested Practices for Raptor Protection on Power Lines. Raptor Research Report No. 4. Raptor Research Foundation, Inc., University of Minnesota, Department of Veterinary Biology. St. Paul, Minnesota.

Olin, R., D. Vagero, and A. Ahlbom. 1985. Mortality Experience of Electrical Engineers. British Journal of Industrial Medicine 42:211-212.

Ontario Ministry of Health. 1987. Health Effects of Extremely Low Frequency Electromagnetic Fields. A Review of Clinical and Epidemiological Studies. Ontario Ministry of Health. Toronto, Ontario.

Orr, J.L. et al. 1987. Effects of Electric Fields on Operant Behavior. Project Resume. Contractor's Review. U.S. Department of Energy/ Electric Power Research Institute.

Ossenkopp, K.P., and D.P. Cain. 1987. ELF Low-Intensity Magnetic Fields and Epilepsy. Contractor's Final Report. New York State Power Lines Project. Albany, New York.

Ossenkopp, K.P., and M. Kavaliers. 1987a. Morphine-Induced Analgesia and Exposure to Low-Intensity $60-\mathrm{Hz}$ Magnetic Fields: Inhibition of Nocturnal Analgesia in Mice is a Function of Magnetic Field Intensity. Brain Research 418:356-360.

Ossenkopp, K.P., and M. Kavaliers. 1987b. ELF Low-Intensity Magnetic Fields and Morphine-Induced Analgesia. Contractor's Final Report. New York State Power Lines Project. Albany, New York.

Papi, F., E. Meschini, and N.E. Baldaccini. 1983. Homing Behavior of Pigeons Released After Having Been Placed in an Alternating Magnetic Field. Comparative Biochemical Physiology 76A(4):673-682.

Parker, J.H. et al. 1987. Report of the Florida Electric and Magnetic Fields Science Advisory Panel. Report for the Florida Department of Environmental Regulation. Tallahassee, Florida.

Parola, A.H., N. Porat, and L.A. Kiesow. 1988. Time-Varying Magnetic Fields Causes Cell Transformation. Biophysical Journal 53: W-Pos26.

Parsch, L.D., and M.D. Norman. 1986. Impact of Powerlines on Crop Yields in Eastern Arkansas. Arkansas Farm Research Sept.-Oct. p. 4.

Pearce, N.E. 1988. Leukemia in Electrical Workers in New Zealand: A Correction. Lancet II(8601):48.

Pearce, N.E., R.A. Sheppard, J.K. Howard, J. Fraser, and B.M. Lilley. 1985. Leukemia in Electrical Workers in New Zealand. Lancet $1: 811-12$.

Pearsons, K.S. 1975. Direct Testimony Before The New York Public Service Commission, PSC Case 26529, 765-kV Transmission Line. Power Authority of the State of New York. Albany, New York.

Pearsons, K.S., R.L. Bennett, and S.A. Fidell. 1979. Initial Study on the Effects of Transformers and Transmission Line Noise on People, Vol. 1: Annoyance. Prepared by Bolt, Beranek, and Newman, Inc., for Electric Power Research Institute. Palo Alto, California.

Peceny, J. et al. 1983. Effect of Chronic Exposure to Industrial-Frequency Electric Field in Very High Voltage Switch Rooms on Humoral Regulation (English Translation). Pracov. Lek. 35(2):58-61.

Perry, D.E. 1972. An Analysis of Transmission Line Noise Levels Based Upon Field and Three-Phase Test Line Measurements. IEEE Transactions on Power Apparatus and Systems. PAS-91:857.

Perry, F.S., M. Reichmanis, A.A. Marino, and R.O. Becker. 1981. Environmental Power-Frequency Magnetic Fields and Suicide. Health Physics 41:267-277.

Perry, S., and L. Pearl. 1988. Power Frequency Magnetic Field and Illness in Multistorey Blocks. Public Health 102:11-18.

Phillips, J.L., and W.D. Winters. 1987. Electromagnetic-Field Induced Bioeffects in Human Cells in Vitro. Pages 279-295, in, L.E. Anderson et al. (editors). Interaction of Biological Systems with Static and ELF Electric and Magnetic Fields. CONF-841041. National Technical Information Service. Springfield, Virginia.

Phillips, R.D., L.E. Anderson, and W.T. Kaune. 1981. Biological Effects of High Strength Electric Fields on Small Laboratory Animals. Interim Report October 1, 1979 - March 31, 1981. (DOE/RL 01830-77) Battelle Pacific Northwest Laboratory. Richland, Washington.

Picton, H.D., J. Canfield, and G. Nelson. 1985. Final Report North Boulder River Elk Study: 500-kV Powerline Impact. A Report by Montana State University for U.S. Forest Service. Butte, Montana.

Portet, R., J. Cabanes, J. Perre, and H. Delost. 1984. Development of a Young Rabbit Exposed to an Intense Electric Field. (English translation.) C.R. Soc. Biol. 178:142-152.

Portet, R., and J. Cabanes. 1988. Development of Young Rats and Rabbits Exposed to a Strong Electric Field. Bioelectromagnetics 9:95-104.

Power Lines Project Evaluation Task Force. 1988. Evaluation of the New York State Power Lines Project Scientific Advisory Panel's Final Report, and Recommendations for the NYS Public Service Commission. Report to Director, Office of Energy, Conservation, and Environment. State of New York Department of Public Service. Albany, New York. 
Preston-Martin, S. and J.M. Peters. 1988. Prior Employment as a Welder Associated with the Development of Chronic Myeloid Leukemia. British Journal of Cancer 58:105-108.

Quinlan, W.J., S.M. Michaelson, N.A. Lebda, S. Pettit, and M. Catallo. 1987. Central Neural Regulation in Rats Exposed to 60-Hz Electric Fields. Pages 287-295, in, L.E. Anderson et al. (editors). Interaction of Biological Systems with Static and ELF Electric and Magnetic Fields. CONF-841041. National Technical Information Service. Springfield, Virginia.

Raleigh, R.J. 1988. Joint HVDC Agricultural Study: Final Report. Oregon State University. Report for Bonneville Power Administration. Portland, Oregon.

Reese, J.A., R.F. Jostes, and M.E. Frazier. 1988. Exposure of Mammalian Cells to $60-\mathrm{Hz}$ Magnetic or Electric Fields: Analysis for DNA Single-Strand Breaks. Bioelectromagnetics 9:237-247.

Reichmanis, M., F.S. Perry, A.A. Marino, and R.O. Becker. 1979. Relationship Between Suicide and the Electromagnetic Field of Overhead Power Lines. Physiol. Chem. Phys. 11:395-404.

Reilly, J.P. 1979. Short-Term Effects on People. Pages 20-28, in, The Electrostatic and Electromagnetic Effects of AC Transmission Lines. IEEE Tutorial Course 79EH0145-3-PWR. IEEE Service Center, Piscataway, New Jersey.

Reiner, G.L. 1972. Electrostatic Effects Near HVAC Transmission Lines; Field Tests and Computer Results. IEEE Paper C $72-187-8$. Presented at IEEE Winter Power Meeting. New York, New York.

Reppert, S.M., D.R. Weaver, S.A. Rivkees, and E.G. Stopa. 1988. Putative Melatonin Receptors in a Human Biological Clock. Science 242:78-81.

Rivas, L., M.A. Oroza, and J.M.R. Delgado. 1987. Influence of Electromagnetic Fields on Body Weight and Serum Chemistry in Second Generation Mice. Medical Science Research 15:1041-1042.

Roach, J.F., V.L. Chartier, and F.M. Dietrich. 1974. Experimental Oxidant Production Rates for EHV Transmission Lines and Theoretical Estimates of Ozone Concentrations near Operating Lines. IEEE Transactions Power Apparatus and Systems PAS-93(2).

Roberge, P.F. 1976. Study of the State of Health of Electrical Workers on Hydro-Quebec's 735-kV Power Transmission System. HydroQuebec. Montreal, Quebec.

Rogers, L.E., J.L. Warren, N.R. Hinds, K.A. Gano, R.E. Fitzner, and G.F. Piepel. 1982. Environmental Studies of a 1100-kV Prototype Transmission Line: an Annual Report for the 1981 Study Period. Battelle Pacific Northwest Laboratories. Report Prepared for Bonneville Power Administration. Portland, Oregon.

Rogers, L.E., J.L. Warren, K.A. Gano, R.L. Hinds, R.E. Fitzner, and R.O. Gilbert. 1980. Environmental Studies of a 1100-kV Prototype Transmission Line. An Interim Report. Battelle Pacific Northwest Laboratories. Report Prepared for Bonneville Power Administration. Portland, Oregon.

Rogers, L.E., P.A. Beedlow, D.W. Carlile, and K.A. Gano. 1984a. Environmental Studies of a 1100-kV Prototype Transmission Line. An Annual Report for the 1984 Study Period. Battelle Northwest Laboratories. Report prepared for Bonneville Power Administration. Portland, Oregon.

Rogers, L.E., P.A. Beedlow, E.W. Carlile, and K.A. Gano. 1984b. Environmental Studies of a 1100-kV Prototype Transmission Line. An Annual Report for the 1983 Study Period. Battelle Northwest Laboratories. Report prepared for Bonneville Power Administration. Portland, Oregon.

Rogers, W.R. and H.D. Smith. 1987. Effects of Electric Fields on Posture and Position of Nonhuman Primates. Project Resume. Contractor's Review. U.S. Department of Energy/Electric Power Research Institute.

Rommereim, D.N., R.L. Rommereim, L.E. Anderson, and M.R. Sikov. 1988. Reproductive and Teratologic Evaluation in Rats Chronically Exposed at Multiple Strengths of $60-\mathrm{Hz}$ Electric Fields. Abstracts, Tenth Annual Meeting, Bioelectromagnetics Society. p. 37.

Roth, H.D. 1985. An Evaluation of Published Studies Analyzing the Association of Carcinogenesis with Exposure to Magnetic Fields (EA3904). Roth Associates for Electric Power Research Institute. Palo Alto, California.

Roy, W.R., and J.V. King. 1983. A Study of the Growth of Winter Wheat Near an Ultra-High Voltage Transmission Line. American Electric Power. North Liberty, Indiana.

Rural Electrification Administration (REA). 1976. Electrostatic and Electromagnetic Effects of Overhead Transmission Lines. REA Bulletin 62-4. U.S. Department of Agriculture, Rural Electrification Administration. Washington, D.C.

Sager, D.P. 1987. Current Facts on Pacemaker Electromagnetic Interference and Their Application to Clinical Care. Heart and Lung 16(2):211-221.

Salzinger, K. et al. 1987. Behavioral Effects of ELF. Contractor's Final Report. New York State Power Lines Project. Albany, New York.

Sander, R., J. Brinkmann, and B. Kuhne. 1982. Laboratory Studies on Animals and Human Beings Exposed to 50-Hz Electric and Magnetic Fields. CIGRE 36-01.

Sandler, D.P. and G.W. Collman. 1987. Cytogenetic and Environmental Factors in the Etiology of the Acute Leukemias in Adults. American Journal of Epidemiology 126:1017-1031.

Savin, B.M., M.G. Shandala, K.V. Nikonova, and Yu A. Morozov. 1978. Research Methods and Evaluation Criteria of the Biological Effects of Industrial Frequency Fields. Pages 433-456, in, Proceedings of the Symposium on EHV AC Power Transmission, US-USSR Joint Committee on Cooperation in the Field of Energy. May 15-25, Tashkent, USSR. Bonneville Power Administration. Portland, Oregon.

Savin, B.M., and I.P. Sokolova. 1985. Effect of 50-Hz Electric Fields on Embryogenesis and Postnatal Development of SHK White Mice in a System of Generations. Pages 295-315, in, Proceedings of the US-USSR Workshop on Physical Factors-Microwaves and Low Frequency Fields. Report by the National Institute of Environmental Health Sciences.

Savitz, D.A. 1987. Case-Control Study of Childhood Cancer and Residential Exposure to Electric and Magnetic Fields. Final Report to New York State Department of Health, Power Lines Project. Albany, New York.

Savitz, D.A. et al. 1988. Case-Control Study of Childhood Cancer and Exposure to 60-Hz Magnetic Fields. American Journal of Epidemiology 128(1):21-38. 
Savitz, D.A., and E.E. Calle. 1987. Leukemia and Occupational Exposure to Electromagnetic Fields: A Review of Epidemiologic Surveys. Journal of Occupational Medicine. 29:47-51.

Schreiber, R.K., W.C. Johnson, J.D. Story, C. Wenzel, and J.T. Kitchings. 1976. Effects of Powerline Rights-of-Way on Small Nongame Mammal Community Structure. Pages 264-273, in, R. Tillman (editor). Proceedings of the First National Symposium on Environmental Concerns in Rights-of-Way Management. Department of Wildlife and Fisheries. Mississippi State, Mississippi.

Scott-Walton, B. et al. 1979. Potential Environmental Effects of 765-kV Transmission Lines: Views Before the New York State Public Service Commission, cases 26529 and 26559, 1976-1978. U.S. Department of Energy. Washington, D.C.

Seto, Y.J., D.M. Chargois, J.R. Lymangrover, W.P. Dunlap, C.F. Walker, and S.T. Hsieh. 1984. Investigation of Fertility and In Utero Effects to Rats Chronically Exposed to a High Intensity 60- Hz Electric Field. IEEE Transactions on Biomedical Engineering BME31(11):693-702.

Seto, Y.J., S.T. Hsieh, D.M. Chargois, W.P. Dunlap, and J.R. Lymangrover. 1983. Food Consumption, Water Intake and Growth Data on Rats Chronically Exposed to a High-Intensity 60-Hz Field. Journal of Bioelectricity 2(243):197-205.

Seto, Y.J., W.P. Dunlap, D.M. Chargois, J.M. Seto, and S.T. Hsieh. 1982. Three Generation Chronic Exposure of Rats to 80-kV/m 60-Hz Electric Fields. Abstracts, 4th Annual Scientific Session. Bioelectromagnetics Society. p. 97.

Severson, R.K. et al. 1988. Acute Nonlymphocytic Leukemia and Residential Exposure to Power Frequency Magnetic Fields. American Journal of Epidemiology 128(1):10-20.

Shandala, M.G., Y.D. Dumansky, and I.S. Bezdol'naya. 1988. The Biological Effects of Power-Frequency Electric Fields in the Environment. Pages 927-964, in, A.A. Marino (editor). Modern Bioelectricity. Marcel Dekker, Inc. New York.

Shandala, M.G., Y.D. Dumansky, G.V. Prohvatilo, I.S. Bezdol'naya, and Y.I. Vasilenko. 1979. Biological Effects of the Low-Frequency Electromagnetic Field $(50 \mathrm{~Hz})$. Paper presented at Bioelectromagnetics Symposium. June 21, 1979; Seattle, Washington.

Sheppard, A.R. 1983a. Biological Effects of High Voltage AC Transmission Lines With Reference to the Colstrip Project: Garrison-Spokane HVTL. A Report to the Montana Department of Natural Resources and Conservation. Helena, Montana.

Sheppard, A.R. 1983b. Biological Effects of High Voltage Direct Current Transmission Lines. A Report to the DNRC with Reference to the Colstrip Project Garrison-Spokane HVTL. Montana DNRC. Helena, Montana.

Sheppard, A.R. 1985. Cellular Studies of Effects of ELF Electric and Magnetic Fields. Pages 124-184, in, AIBS Committee. Biological and Human Health Effects of Extremely Low Frequency Electromagnetic Fields. American Institute of Biological Sciences. Arlington, Virginia.

Sheppard, A.R. 1988. Update on the Scientific Literature Concerning Health Effects of $60-\mathrm{Hz}$ Electric and Magnetic Fields of Power Transmission and Distribution Facilities. Prepared for Seattle City Light Environmental Affairs Division. Seattle, Washington.

Sheppard, A.R., and M. Eisenbud. 1977. Biological Effects of Electric and Magnetic Fields of Extremely Low Frequency. New York University Press. New York.

Shupe, R.E., and N.B. Hornback. 1985. The Friendly Fields of RF. IEEE Spectrum 22(6):64-69.

Sikov, M.R., R.L. Buschbom, W.T. Kaune, D.N. Rommereim, and R.D. Phillips. 1987. Evaluation of Reproduction and Development in Hanford Miniature Swine Exposed to 60-Hz Electric Fields. Pages 379-393, in, L.E. Anderson et al. (editors). Interaction of Biological Systems with Static and ELF Electric and Magnetic Fields. CONF-841041. National Technical Information Service. Springfield, Virginia.

Silva, J.M. et al. 1988. AC Field Exposure Study. Project Resume. Contractor's Review. U.S. Department of Energy-Electric Power Research institute.

Silva, M. 1985. AC Field Exposure Study: Human Exposure to 60-Hz Electric Fields. RP79-16. Enertech Consultants for Electric Power Research Institute. Palo Alto, California.

Silva, M. et al. 1988. Power Frequency Magnetic Fields in the Home. IEEE No. 88 WM 101-8. Paper presented at the IEEE/PES Winter Meeting.

Singewald, M.L., O.R. Langworthy, and W.B. Kouwenhoven. 1973. Medical Follow-up Study of High Voltage Lineman Working in AC Electric Fields. IEEE Transactions Power Apparatus Systems 92-4:1307-1309.

Sliney, D. et al. 1987. Physical Agents TLV. Applied Industrial Hygiene 2(1): R-9 - R-10.

Slovic, P., B. Fischoff, and S. Lichtenstein. 1980. Perceived Risk. In R.C. Schwing and W.A. Albers (editors). Societal Risk Assessment: How Safe Is Safe Enough? Plenum, New York.

Smith, S.D. et al. 1987. Calcium Cyciotron Resonance and Diatom Mobility. Bioelectromagnetics 8:215-227.

Southern, W.E. 1988. The Earth's Magnetic Field as a Navigational Cue. Pages 35-74, in, A.A. Marino (editor). Modern Bioelectricity. Marcel Dekker, Inc., New York.

Sowton, E. 1982. Environmental Hazards for Pacemaker Patients. Journal of the Royal College of Physicians of London 16(3):159-169.

Spadaro, J.A. 1982. Bioelectric Stimulation of Bone Formation: Methods, Models, and Mechanisms. Journal of Bioelectricity 1(1):99-128.

Speers, M.A., J.G. Dobbins, and V.S. Miller. 1988. Occupational Exposures and Brain Cancer Mortality: A Preliminary Study of East Texas Residents. American Journal of Industrial Medicine 13:629-638.

Spitz, M.R., and C.C. Johnson. 1985. Neuroblastoma and Paternal Occupation A Case-Control Analysis. American Journal of Epidemiology 121(6):924-929.

State of New York Public Service Commission (SNYPSC). 1978. Opinion No. 78-13. Opinion and Order Determining Health and Safety Issues, Imposing Operating Conditions, and Authorizing, in Case 26529, Operation Pursuant to Those Conditions. Power Authority of the State of New York. Albany, New York.

Stern, F.B. et al. 1986. A Case-Control Study of Leukemia at a Naval Nuclear Shipyard. American Journal of Epidemiology 123(6):980-992.

Stern, S., V.G. Laties, C.V. Stancampiano, C. Cox, and J.O. deLorge. 1983. Behavioral Detection of 60-Hz Electric Fields by Rats. Bioelectromagnetics 4(3):215-247. 
Stern, S., and V.G. Laties. 1982. Behavioral Effects of $60-\mathrm{Hz}$ Electric Fields: I. Detection of $60 \mathrm{~Hz}$ Electric Field by Rats, in, Project Resumes: Biological Effects From Electric Fields Associated with High Voltage Transmission Lines. U.S. Department of Energy, Division of Electric Energy Systems. Washington, D.C.

Stern, S., and V.G. Laties. 1985. 60-Hz Electric Field Detection by Female Rats. Bioelectromagnetics 6(1):99-103.

Stevens, R.G. 1987. Electric Power Use and Breast Cancer: a Hypothesis. American Journal of Epidemiology 125:556-561.

Stevens, R.G. 1988. Observations on the Wertheimer-Leeper Post Hoc Analysis. (Letter) Transmission/Distribution Health \& Safety Report 6(6):3-4.

Stollery, B.T. 1987. Human Exposure to 50-Hz Electric Currents. Pages 445-454, in, L.E. Anderson et al. (editors). Interaction of Biological Systems with Static and ELF Electric and Magnetic Fields. CONF-841041. National Technical Information Service. Springfield, Virginia.

Stopps, G.J., and W. Janischewsky|. 1979. An Epidemiological Study of Personnel Working on A.C. Transmission Lines. Paper Presented Before the Canadian Electrical Association. March 1979; Vancouver, British Columbia.

Strumza, M.V. 1970. Influence on the Human Health of Close Electric Conductors at High Tension. Archives des Maladies Professionnelles de Medicine du Travail et de Securite Sociale (Paris) 31(6):269-276.

Subcommittee on Disinfectants and Disinfectant By-Products. 1987. Drinking Water and Health; Disinfectants and Disinfectant ByProducts Vol. 7 National Academy Press. Washington, D.C.

Subcommittee on Water and Power Resources. 1988. Health Effects of Transmission Lines. Oversight Hearing. Serial No. 100-22. Superintendent of Documents, U.S. Government Printing Office. Washington, DC.

Sulman, F.G. 1980. The Effect of Air lonization, Electric Fields, Atmospherics and Other Electric Phenomena on Man and Animal. Charles C. Thomas, Publisher. Springfield, Illinois.

Sulzman, F.M. and D.E. Murrish. 1986. Effects of Electromagnetic Fields on Primate Circadian Rhythms. Contractor's Final Report. New York State Power Lines Project. Albany, New York.

Surbrook, T.C., and N.D. Reese. 1981. Stray Voltage on Farms. ASAE Paper 81-3512. Michigan State University Cooperative Extension Service.

Swerdlow, A.J. 1983. Epidemiology of Eye Cancer in Adults in England and Wales, 1962-1977. American Journal of Epidemiology 118:294300

Tenforde, T.S. (editor). 1978. Proceedings of the Biomagnetics Workshop. Lawrence Berkeley Laboratory, University of California Berkeley, California.

Tenforde, T.S. 1985. Biological Effects of ELF Magnetic Fields. Pages 79-127 in, AIBS Committee. Biological and Human Health Effects of Extremely Low Frequency Electromagnetic Fields. American Institute of Biological Sciences. Arlington, Virginia.

Tenforde, T.S. 1986. Biological Effects of Extremely-Low-Frequency Magnetic Fields. Pages 21-40, in, Panel Session on Biological Effects of Power Frequency Electric and Magnetic Fields. IEEE Service Center. Piscataway, New Jersey.

Thomas, J.R., J. Schrot, and A. Liboff. 1986. Investigation of Potential Behavioral Effects of Exposure to $60 \mathrm{~Hz}$ Electromagnetic Fields. Contractor's Final Report. New York State Power Lines Project. Albany, New York.

Thomas, T.L. et al. 1987. Brain Tumor Mortality Risk Among Men with Electrical and Electronics Jobs: A Case-Control Study. Journal of the National Cancer Institute 79(2):233-238.

Thompson, R.A.E., S.M. Michaelson, and Q.A. Nguyen. 1988. Influence of 60-Hertz Magnetic Fields on Leukemia. Bioelectromagnetics 9:149-158.

Tomenius, L. 1986. 50- $\mathrm{Hz}$ Electromagnetic Environment and the Incidence of Childhood Tumors in Stockholm County. Bioelectromagnetics 7:191-207.

Tornqvist, S., S. Norell, A. Ahlbom, and B. Knave. 1986. Cancer in the Electric Power Industry. British Journal of Industrial Medicine 43:212213.

Tucker, R.D. and O.H. Schmitt. 1978. Tests for Human Perception of 60-Hz Moderate Strength Magnetic Fields. IEEE Transactions on Biomedical Engineering BME-25(6):509-518.

Tuyns, A.J. 1982. Alcohol. Pages 293 - 303, in, D. Schottenfeld and J.F. Fraumeni, Jr., Cancer Epidemiology and Prevention. W.B. Saunders, Co. Philadelphia, Pennsylvania.

U.S. Department of Energy, Electric Power Research Institute. 1988. Project Resumes: Biological Effects from Electric and Magnetic Fields, Air lons and lon Currents Associated with High Voltage Transmission Lines. W/L Associates. 120 W. Church St., Frederick, Maryland.

Valentino, A.R. 1972. A Small ELF Electric Field Probe. IEEE Int. Electromagnetic Compatibility Symposium Rec. p. 265.

Vasquez, B.J., L.E. Anderson, C.I. Lowery, and W.R. Adey. 1988. Diurnal Patterns in Brain Biogenic Amines of Rats Exposed to 60-Hz Electric Fields. Bioelectromagnetics 9:229-236.

Veicsteinas, A., V. Margonato, R. Conti, and P. Cerretelli. 1987. Effects of 50-Hz Electric Field Exposure on the Growth Rate of Chicks. Pages 341-346, in, L.E. Anderson et al. (editors). Interaction of Biological Systems with Static and ELF Electric and Magnetic Fields. CONF-841041. National Technical Information Service. Springfield, Virginia.

Villmo, L. 1972. The Scandinavia Viewpoint. Pages 4-9, in, J.R. Luick et al. (editors). Proceedings of the First International Reindeer and Caribou Symposium. Biological Papers of The University of Alaska Special Report No. 1. Fairbanks, Alaska.

WHO/IRPA Task Group on Magnetic Fields. 1987. Environmental Health Criteria 69. Magnetic Fields. World Health Organization. Geneva.

Ware, B. J. 1974. Effect of 765-kV Transmission Lines on Animal Grazing Habits. American Electric Power Service Corp. New York.

Warren, J.L., N.R. Hinds, K.A. Gano, R.E. Fitzner, and G.F. Piepel. 1981. Environmental Studies of a 1100 kV Prototype Transmission Line. An Annual Report for the 1980 Study Period. Battelle Pacific Northwest Laboratories. Richland, Washington.

Welker, H.A. et al. 1983. Effects of an Artificial Magnetic Field on Serotonin N-Acetyltransferase Activity and Melatonin Content of the Rat Pineal Gland. Experimental Brain Research 50:426-432. 
Wellenstein, G. 1973. The Influence of High-Tension Lines on Honeybee Colonies (Apis mellifical L.). Zeitschrift Fur Angewandte Entomologie, pp. 86-94. Translated from German for Battelle-Northwest by Addis Translations International.

Wertheimer, N. and E. Leeper. 1989. Fetal Loss Associated with Two Seasonal Sources of Electromagnetic Field Exposure. American Journal of Epidemiology 129(1):220-224.

Wertheimer, N., and E. Leeper. 1988. Some Supplementary Analyses of Data from the Two Epidemiological Studies in the New York Power Lines Project. Unpublished Report. Summary, in, Transmission/Distribution Health and Safety Report, 1988, 6(6).

Wertheimer, N., and E. Leeper. 1986. Possible Effects of Electric Blankets and Heated Waterbeds on Fetal Development. Bioelectromagnetics 7:13-22.

Wertheimer, N., and E. Leeper. 1979. Electrical Wiring Configurations and Childhood Cancer. American Journal of Epidemiology 109:273:284

Wertheimer, N., and E. Leeper. 1982. Adult Cancer Related to Electrical Wires Near the Home. International Journal of Epidemiology 11(4):345-355.

Wheaton, F.W. 1970. Influence of Electrical Energy on Plants: A Review. Agricultural Experiment Station, University of Maryland, College Park, Maryland.

Williams, J.H., and E.J. Beiler. 1979. An Investigation of Dairy Farm Operations in Association with 765-kV Transmission in Ohio. Ohio Power Siting Commission and Cleveland Electric Illuminating Company. Cleveland, Ohio.

Wilson, B.W. et al. 1981. Chronic Exposure to 60- $\mathrm{Hz}$ Electric Fields: Effects on Pineal Function in the Rat. Bioelectromagnetics 2:371-380.

Wilson, B.W. et al. 1983. Chronic Exposure to 60- $\mathrm{Hz}$ Electric Field: Effects on Pineal Function in the Rat. Bioelectromagnetics 4:293.

Wilson, B.W. et al. 1988. Effects of Electric Blanket Use on Human Pineal Gland Function. Project Resume. Contractor's Review. U.S. Department of Energy/Electric Power Research Institute.

Wilson, B.W., E.K. Chess, and L.E. Anderson. 1986. 60- Hz Electric-Field Effects on Pineal Melatonin Rhythms: Time Course for Onset and Recovery. Bioelectromagnetics 7:239-242.

Wilson, R., and E.A.C. Crouch. 1987. Risk Assessment and Comparisons: An Introduction. Science 236:267-270.

Wolpaw, J.R. et al. 1987. Chronic Effects of $60 \mathrm{~Hz}$ Electric and Magnetic Fields on Primate Central Nervous System Function. Contractor's Final Report. New York State Power Lines Project. Albany, New York.

World Health Organization, International Radiation Protection Association (WHO/IRPA). 1984. Environmental Health Criteria 35. Extremely Low Frequency (ELF) Fields. World Health Organization, Geneva.

World Health Organization, International Radiation Protection Association (WHO/IRPA). 1987. Environmental Health Criteria 69 Magnetic Fields. World Health Organization, Geneva.

Wright, W.E., J.M. Peters, and T.M. Mack. 1982. Leukaemia in Workers Exposed to Electrical and Magnetic Fields. Lancet 2:1160-1.

Wynder, E.L., and D. Hoffman. 1982. Tobacco. Pages 277-292, in D. Schottenfeld and J.F. Fraumeni, Jr. (editors). Cancer Epidemiology and Prevention. W.B. Saunders, Co. Philadelphia, Pennsylvania.

Yasuda, E.D., and F.B. Dewey. 1980. BPA's New Generation of 500-kV Lines. IEEE Transactions on Power Apparatus and Systems PAS99(2):616-624.

Young, L.B. 1974. Power Over People. Oxford University Press, Inc. New York.

Zaffanella, L.E., and D.W. Deno. 1978. Electrostatic and Electromagnetic Effects of Ultrahigh-Voltage Transmission Lines. DOE Report EPRI-EL-802. National Technical Information Service. Springfield, Virginia. 


\section{DO NOT MILCROFHLM THIS PAGE}

